University of San Diego

Digital USD

1990

\title{
A Study of the Differences between Classrooms Using a Meaning- Centered Approach and a Code-Centered Approach in the First Year Implementation of the California English-Language Arts Framework
}

Carolyn F. Salerno EdD

University of San Diego

Follow this and additional works at: https://digital.sandiego.edu/dissertations

Part of the Leadership Studies Commons

\section{Digital USD Citation}

Salerno, Carolyn F. EdD, "A Study of the Differences between Classrooms Using a Meaning-Centered Approach and a Code-Centered Approach in the First Year Implementation of the California EnglishLanguage Arts Framework" (1990). Dissertations. 552.

https://digital.sandiego.edu/dissertations/552

This Dissertation: Open Access is brought to you for free and open access by the Theses and Dissertations at Digital USD. It has been accepted for inclusion in Dissertations by an authorized administrator of Digital USD. For more information, please contact digital@sandiego.edu. 
A STUDY OF THE DIFFERENCES BETWEEN CLASSROOMS USING

A MEANING-CENTERED APPROACH AND A CODE-CENTERED APPROACH

IN THE FIRST YEAR IMPIEMENTATION OF THE

CAIIFORNIA ENGIISH-LANGUAGE ARTS FRAMEWORK

by

Carolyn F. Salerno

A dissertation submitted in partial fulfillment

of the requirements for the degree of

Doctor of Education

University of San Diego
1990

Dissertation Committee

Robert I. Infantino, Ed D., Director

Jerome J. Ammer, Ph.D.

Edward Kujawa, Ph.D. 


\section{ABSTRACT}

A Study of the Differences Between Classrooms Using

a Meaning-Centered Approach and a Code-Centered Approach

in the First Year Implementation of the

California English-Language Arts Framework

SALERNo, Carolyn F., Ed.D. University of San Diego, 1990
Director: Robert L. Infantino, Ed.D.

The purpose of this descriptive study was to determine how a meaning-centered approach versus a code-centered approach affects student performance: (a) in the teaching of language arts; (b) in regular education classrooms containing low achieving, low socio-economic, multi-ethnic, and learning handicapped students; (c) in grades one, three and six; and (d) in the first year implementation of the California English-Language Arts Framework.

This study focused on three interrelated dimensions of organizational change which are linked to student performance: curriculum materials, teacher behaviors, and organizational change processes. Eight research questions guided the examination of qualitative and quantitative data originating from teacher and principal interviews, teacher questionnaires, teacher meeting observations, classroom observations, and standardized test scores in language arts and reading of the student sample population, the school and the district. 
Some of the findings indicated that:

1. New language arts curriculum materials generated motivation and excitement.

2. Teachers continued to supplement the prescribed curriculum with materials they had previously found to be effective.

3. Students who received opportunities to use both a systematic skill program and inventive spelling appeared to reflect the greatest improvement in the subject of spelling on standardized tests.

4. Of the 11 instructional practices identified for examination, three practices consistently appeared to influence student performance: (a) instruction in both a systematic skill program and in an integrated literature program; (b) hearing literature read daily; (c) and daily writing activities.

5. Observations indicated that teachers' instructional behaviors did not focus on transference of learning through the use of guided practice, generalization, or independent practice.

6. Teachers' estimations of students' progress seemed to correlate with achievement test results.

7. The percentage of multi-ethnic, low socio-economic, low achievement, and learning handicapped students in classrooms did not appear to make a difference in student performance. 
8. There appeared to be a limited focus on minority languages and cultures in the curriculum materials and in classroom cooperative discussions.

9. The types of openness and bonding behaviors observed among organizational members did not appear to be effective in bringing about changes in teacher behaviors which would lead to better student performance.

10. Teachers' degree of commitment to the language arts philosophy seemed to depend upon the level of achievement of their students on end of year standardized tests.

11. Reform implementation requires a revised focus on transformational leadership and organizational change processes.

One recommendation emerging from this study is that organizations seeking to change must provide training and development which support the change process through demonstration, modeling, practice, correction, teaching, feedback, sharing and coaching in a collegial fashion.

This study concludes with a series of implications, recommendations, and suggestions for further research whis:. are needed to create change in literacy instructional practices. 


\section{Copyright (C) 1990 \\ by \\ Carolyn E. Salezno \\ All Rights Reserved}


To my God, my spiritual guide,

my parents, whose love and support make goals possible, my son, Iuke, whose love directs and nourishes my life, my daughter, Rachelle, whose iife creates areams for a new future, and my teachers, who offer opportunities to explore understandings, knowledge and visions, and to

all teachers, parents and children whose explorations will pass on a greater future to our new generations. 


\section{ACKNOWLEDGEMENTS}

The motivarion required for me to remain with this research study process and realize this goal was generated from the collaborative efforts of many admired scholars, educators, professionals and students.

My most grateful tribute and appreciation is to Dr.Bob Infantino, my advisor throughout the doctoral program and my dissertation chairman. His consistent help in guiding my efforts, in helping me clarify my thoughts and his patience with my protests and frustrations through this very lengthy process provided the foundation I needed to continue the pursuit of the realization of this goal. His insights, knowledge and expertises were invaluable in this dissertation process. My admiration of his dedication to the teaching profession and his participation in the San Diego Area Writing Project was an inspiration for me. I also want to thank him for his support and belief in me throughout the years $I$ have worked under his guidance.

I would like to graciously thank Dr. Ed Kujawa whose reasoning and precision inspired a constant voice for me to consider when designing, witing and preparing my analysis for his valued approval. My admiration of his ability to make each individual feel as if her/his contribution is most important to the group fueled my efforts in focusing on collaborative activities among teachers and students. I have always been so appreciative to have him as a member of my committee. 
I would like to thank a most valued member of my committee, Dr. Jerry Ammer, whose understandings and rationale guided my efforts in several significant directions. I especially admire his dedication to the teachers and children designated for special education instruction. He has always exhibited support and interest in my efforts and concerns. Thank you.

An unforgettable scholar that spent unending hours with me pouring over numbers and punching computer keys was Dr. Pat Anderson. I constantly admired her knowledge, dedication and commitment in helping, teaching, guiding and directing me in my efforts. Amidst my hidden tears of frustrations, she patiently encouraged me and enthusiastically acknowledged my small and gradual successes. I am immensely grateful.

For me, Dr. Joe Rost was the spirit of this leadership program that guided me to focus on human connectedness and the generative nature in the leadership process. I am honored to have been a member of Dr. Joe Rost's leadership program. I thank him for my new visions and inspirations.

I would like to thank the most admired and unforgettable Dr. Bill Foster, who encouraged me to explore and create new beginnings and new interpretations. His thoughts and ideas inspired the framework for this study.

This study would not have been possible and this goal would not have been realized if members of two school districts had not volunteered to participate in my study. Their encouragement, enthusiasm and leadership in education 
made this research possible. I am especially grateful and thankful to Mrs. Cheryl Ernst, Dr. Judith Trinkle, Dr. Gary Smith and Dr. George Cameron.

I will always be grateful and thankful to the principals and teachers who agreed to participate in this study. They volunteered precious time and provided the heart and soul of this study.

A special appreciation and love is reserved for my family and friends in my life both at home and at school during these years of my doctoral study. My motivation, and dedication was inspired through their continued love, support and friendship. 
DEDICATION

ACKNOWLEDGEMENTS

IIST OF TABLES

IIST OF FIGURES

IIST OF APPENDIXES

xiv

CHAPTER I: STATEMENT OF THE ISSUE.................

Int roduction $\ldots \ldots \ldots \ldots \ldots \ldots \ldots \ldots \ldots \ldots \ldots \ldots \ldots \ldots \ldots$

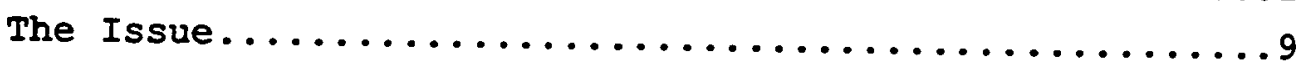

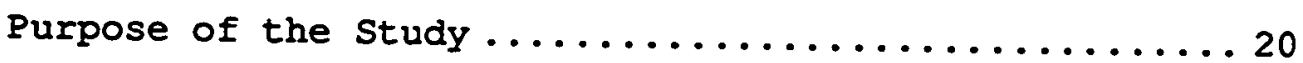

Relevance of the Issue to Leadership ........... 23

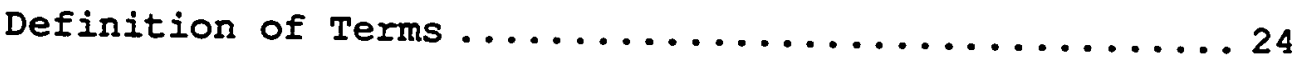

Limitations of This study ................. 28

CHAPTER II: REVIEW OF THE IITERATURE ............. 30

Introduction . ............................ 30

Language Arts Curriculum Materials ............. 33

Teacher Centered Behaviors .................. 35

Instructional Management Behaviors ........... 39

Instructional Techniques ...............44

Instructional Behaviors Specific to Learning

Strategies.......................45

Individual Behaviors................46

Interpersonal Behaviors ............... 51

Organizational Change Processes................ 54

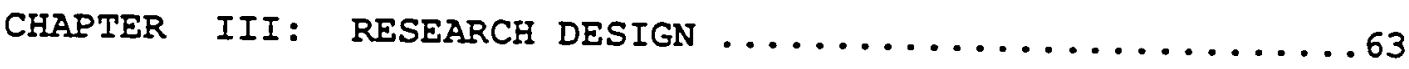

Introduction. .......................63

Researcin Design........................64

Research Questions...................65

Chronological Summary of Research Procedures....72

Data Gathering Techniques.....................

Data Analysis...........................

vi 
ChAPTER IV: ANALYSIS Of DATA.................. 92

Introduction .......................... 92

Overview of Analysis ..................... 96

Research Question One ........................ 104

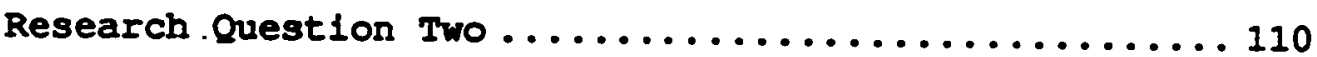

Research Question Three ..................... 142

Research Question Four ....................... 162

Research Question Five ...................... 180

Research question six........................ 207

Research Question Seven ..................... 218

Research Question Eight .................... 247

CHAPTER V: SUMMARY, INTEGRATION AND SYNTHESIS,

IMPLICATIONS, RECOMMENDATIONS, AND SUGGESTIONS FOR

FURTHER RESEARCH $\ldots \ldots \ldots \ldots \ldots \ldots \ldots \ldots \ldots \ldots \ldots \ldots \ldots \ldots$

Introduction ................................ 316

Summary of the Research .................... 320

Differences Between Code-Centered and Meaning-

Centered Classrooms In the First Year

Implementation of the English-Ianguage Arts

Framework: Integration and Synthesis ............353

Implications for the Implementation of English-

Language Arts Framework in Code-Centered and

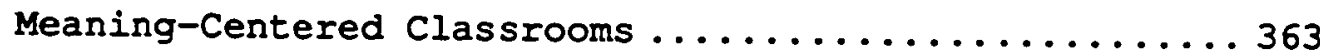

Recommendations Aimed at Strengthening the

Implementation Process of the English-Ianguage Arts

Framework in Code-Centered and Meaning-Centered

Classrooms .......................... 376

Suggestions for Further Research .............. 381

Concluding Remarks ...................... 385

REFERENCES .......................... 388

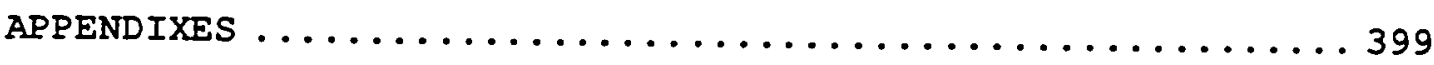

vii 


\section{IIST OF TABLES}

Table

Page

1 Population Characteristics of Representative

Students by Grade Level (Feb.1990) .............. 98

2 Years of Teaching Experience of Teacher

Population by Grade Level.................... 101

3 Years of Principalship Experience by District...... 102

4 Adherence to Prescribed Language Arts Curriculum

Recommendations by Grade Level.............. 106

5 Teachers' Comments About Prescribed Language

Arts Curriculum....................... 108

6 Teacher Behaviors That Reflect Instructional

Management by Levels of Performance............ 114

7 Student Time on Task Behaviors by Levels of

Performance and Observed Student Behaviors....... 120

8 Positive to Negative Interactions Between Students

and Teachers by Reinforcement and Grade Level..... 122

9 Assessment Strategies Used by Teachers Each Week

in Grade One........................ 126

10 Assessment Strategies Used by Teachers Each Week

in Grade Three....................... 128

11 Assessment Strategies Used by Teachers Each Week

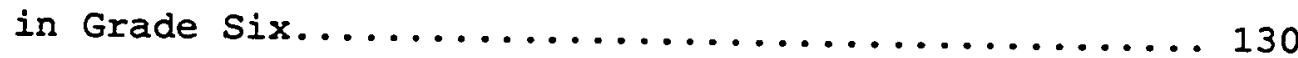

12 Instructional Management Approaches and

Instructional Effectiveness Determined by

Teacher.......................... 132

viii 
13 Performance Expectations for Students by Grade and Level of Expectations as Reported by Teachers... 135

14 Language Arts Instruction by Techniques and Observed Levels of Performance............... 145

15 Degree of Effectiveness of Instructional Techniques Used in the Classroom.............. 149

16 Stage of Mastery of Writing Performance Exhibited by First Grade High and Low Performing Students... . 165

17 Stage of Mastery of Writing Performance Exhibited by Third Grade High and Low Performing Students.... 167

18 Stage of Mastery of Writing Performance Exhibited by Sixth Grade High and Iow Performing Students.... 168

19 Estimated First Grade Reading Performance Exhibited by High and Low Performing Students...... 170

20 Estimated Third Grade Reading Performance Exhibited by High and Low Performing Students...... 171

21 Estimated Sixth Grade Reading Performance Exhibited by High and Low Performing Students...... 172

22 Parents Who Model Effective Iistening, Reading, Speaking, and writing for Students as Estimated by Teachers................... 183

23 Teachers, Adults and Administrators Who Model Effective Listening, Speaking, Reading and Writing for Students as Estimated by Teachers........... 184

24 Teachers who Teach Reading, witing, Speaking, and Listening Throughout All Subjects.......... 185

$$
\text { viv }
$$


25 Amount of Administrative Support for Language Arts Program as Estimated by Teachers........... 186

26 Teacher Education in Integrated Language Arts Instruction. ........................ 189

27 Perceptions Developed by Teacher Population and Instructional Observation and Feedback.......... 190

28 Teacher Estimation of Percentage of Students who Fall Below Grade Level Ability in Language Arts... 193

29 Scheduled Minutes for First Grade Language Arts Instruction as Reported by Teachers............ 195

30 Scheduled Minutes for Third Grade Language Arts Instruction as Reported by Teachers........... 196

31 Scheduled Minutes for Sixth Grade Language Arts Instruction as Reported by Teachers........... 197

32 Number of Minutes Committed to Participating in Collegial Activities by First Grade Teachers...... 210

33 Number of Minutes Committed to Participating in Collegial Activities by Third Grade Teachers...... 211

34 Number of Minutes Committed to Participating in Collegial Activities by Sixth Grade Teachers...... 213

35 Administrative Competence in Guiding Staff in the Implementation of English-Language Arts Framework ........................ 228

36 Administrative Perceptions of the Effectiveness of the Language Arts Philosophy on Student Performance........................ 229 
37 Power Approach Used When Changes Are Expected in the Curriculum..................... 231

38 Principal Perceptions of Staff Relationships...... 235

39 Observed Relationship-Building Behaviors......... 237

40 Observed Bonding and Openness of Behaviors........ 239

41 Writing Ability by Grade Level and Estimated Percentage of Students Passing District Proficiency Examination.................. 25i

42 Estimated Number of Recreational Books Selected and Read by Students..................... 254

43 Estimated Numbsr of Students who Complete Homework Assignments on Time............... 256

44 Estimated Percentage of Students Who Achieve Average or Better the First Time on Criterion Tests.............................. 259

45 Selected Random Sample of the Population of Students by Ethnicity, Grade Level, and Sex...... 266

46 First Grade Standardized Test Scores in Language Arts and Reading for Sample Population......... 268

47 District Standardized Test Scores for First Grade in Language Arts and Reading............ 271

48 School Language Arts Standardized Test Scores for First Grade..................... 273

49 Third Grade Standardized Test Scores in Language Arts and Reading for Sample Population......... 276

50 District Standardized Test Scores for Third Grade in Language Arts and Reading.......... 278 
51 School Language Arts Standardized Test Scores for Third Grade....................... 281

52 Sixth Grade Standardized Test Scores in Language Arts and Reading for Sample Population.......... 283

53 District Language Arts Standardized Test Scores for $\operatorname{sixth}$ Grade........................ 285

54 School Language Arts Standardized Test Scores for $\operatorname{sixth}$ Grade...................... 287

55 Checklist of Teacher Centered Behaviors Performed More Frequently in Either Code-Centered Classrooms or Meaning-Centered Classrooms........ 293 


\section{LIST OF FIGURES}

Figure

Page

1. An Overview of Three Reform Dimensions........... 60

2. An Overview of the Data Sources............... 85

xiii 


\section{IIST OF APPENDIXES}

Page

Appendix A: Observation Instrument of Teacher Meetings.. 400 Appendix B: Principal Interview.................4402

Appendix C: Teacher Interview...................404

Appendix D: Teacher Questionnaires................407

Appendix E: Teacher Observation.................412

Appendix F: Principal Surveys..................425

Appendix G: Confidentiality Agreements..............4430

Appendix H: Research Question Overview..............435

Appendix I: Protection of Human Subjects Form..........438

xiv 


\section{CHAPTER I \\ STATEMENT OF THE ISSUE}

Int roduction

The fundamental purpose of public education is to provide all students with the competencies, knowledge and orientations that will enable them to lead successful lives in a contemporary and future economic, social, cultural, and political environment. Our failure to meet the educational needs of all students is reflected in the claim made from Secretary of Education Terrel Bell, "The school reform movement has benefitted about 70 percent of our students, but has had no significant impact on the other 30 percent" (Salvin et al., 1988, p.28). Our literacy problems are confirmed by reports that indicate that 90 percent of remedial reading students today are not able to decode fluently, accurately, and at an automatic level of response (Chall, 1983; Groff, 1987). California schools continue to enroll a growing number of low socio-economic, and multiethnic students. Our educational organizations enthusiastically embrace and implement interventions, generated by more than 8,000 studies and 112 reviews (Salvin et al., 1988). "It is one thing to legislate integration of 
disabled, minority, or even disabled minority children into the mainstream; it is quite another to make their stay educationally worthwhile" (Gerber, 1988, p. 311).

Cultural and political explanations have been offered as reasons for the literacy problems. However, these explanations have to be translated in practical terms for schools and parents. Such translations should include historical educational research (Chall, Jacobs \& Baldwin, 1990). The fact remains that we still have a commitment to educate all our children.

The commitment to educate all children has created instructional dilemmas for school districts in California. History has taught American educators that in times of desperation, educators have a tendency to look for global, charismatic, single solutions to very serious problems (Chall, 1989, p. 532). In the mid-1800s America was grappling with serious social growing pains. The purpose of education was to foster productive, creative, knowledgeable, independent, and responsible individuals. Jeffersonian ideals guided the goals of education to focus on meaning, ideas and the desire to learn. Horace Mann, a lawyer and Secretary of the Massachusetts, John Dewey, at the University of Chicago, and Arthur Gates, at Teachers College Columbia promoted the whole word "look and say" method to teaching reading (Armstrong, 1989). In the 1930s, Gray and Gates introduced the "basal reader" series which incorporated the whole word method. This "look and say" method became the 
1930 s description of meaning-centered approach (Armstrong, 1989).

In the 1950s, Flesch vigorously advocated a systematic code-emphasis approach to reading instruction (Adams, 1990; Flesch, 1955). In 1985, the U.S. Department of Education reported research that confirmed that children should be taught systematic phonics and have experience with reading words in meaningful texts (Anderson, Hiebert, Scott \& Wilkinson, 1985).

Anderson et al. (1985) supported this research, "The right maxims for phonics are: Do it early. Keep it simple. Except in cases of diagnosed individual need, phonics instruction should have been completed by the end of the second grade" (p. 43). "Learning to read appears to involve close knitting of reading skills that complement and support one another, rather than learning one skill, adding a second and so on" (p. 97).

Once again, the cultural, political and social requirements for reading have changed. In 1988, the California State Board of Education issued a curriculum reform document that emphasized the meaning-centered approach to language arts instruction. The curriculum reform solution to literacy problems, issued by the The California State Department of Education, is titled English-Ianguage irts Eramework for California Public Scheols Kindergarten Through Grade Twelve (California State Board of Education, 1987). This state reform effort emphasizes a systematic literature 
centered program with a meaning-centered approach based on intensive reading, writing, speaking, and listening.

The framework emphasizes the "integration of listening, speaking, reading, writing and the teaching of language skills in meaningful contexts" (California State Department of Education, 1987, p. 3). The past emphasis on phonic and decoding instruction is reduced to three statements in the framework; one statement uses phonics with the "ought to" context; the second statement implies implicit phonic instruction of letting students induce letter-sound relationships from meaningful contexts; and the third statement is included with several alternative instructional decoding techniques. Not one of the statements clearly links a balanced instructional program of systematic phonic and decoding instruction and the integration of listening, speaking, reading and writing instruction with exceptional students who have individual needs.

The California State Department of Education (1987) suggests the following: "Phonics during the early grades should help students understand the relationships between letters and sounds so that they understand meaning" (p. 28); "Effective features of the framework calls for a phonics program taught in meaningful contexts, kept simple, and completed in the early grades" (p. 4); and, "Reading instruction includes many decoding strategies, such as: a systematic phonics program taught in the early grades, using meaningful context" (p. 43). 
The California state reform solution in the language arts curriculum created a need to focus on principal targets for successful intervention. The principal targets of intervention designed to create reform are "curriculum materials, teacher centered behaviors, and school organization" (Chall et al., 1990; Timar \& Kirp, 1989, p. 510). In response to the California state reform effort in curriculum, the first target of reform was the implementation of large numbers of literature based curriculum programs in school districts. Research evidence dating from 1910 to 1982 does not support the effectiveness of this meaning-emphasis approach over a code-emphasis approach for students at the beginning reading levels and students reading at grade level or below (Chall, 1989; Chall et al., 1990). Follow Through studies conducted in the early 1970s, found that disadvantaged sixth grade students participating in a codecentered approach outperformed their sixth grade peers participating in a meaning-centered approach (Stahl, Osborn \& Lehr, 1990). Research is not conclusive as to whether the learning processes used by successful and competent people can be made explicit enough for others to use (Brandt, 1989). Furthermore, both approaches, code-centered and meaningcentered, are deeply rooted in the nature of our writing system (Adams, 1990). School districts expended much effort in selecting meaning-centered curriculum materials that provided guidance for efficient and effective instruction that best supported comprehension. The curriculum dilemma 
became how to impart to all students: (a) the comprehensible, cognitive, meaningful, creative, and joyful aspects of literature integrated into listening, speaking, reading, writing activities, and (b) the skills related to writing, to recognizing letters, spelling patterns, and whole words, to decoding through phonemic and morphemic translations, to orthographic knowledge, and to vocabulary development.

The second target of reform is teacher-centered behaviors. These teacher behaviors include team functions, instructional management, program delivery, and teaching techniques that address individual learning and cultural differences. Team functions are designed to develop collegiality between teachers. Coaching sessions provide a means for personalizing the knowledge gained through the course of instruction. Regular classroom observations by peer teachers provide specific feedback for the teachers implementing new teaching strategies or changing and altering ineffective teaching strategies.

Teacher behaviors related to instructional management include instructional time, lesson pacing, student reinforcement, distractions, student feedback, and student evaluation procedures. Instructional time may be devoted to group instruction more often than to individual instruction. A greater percentage of instructional time may be allowed for the primary lesson rather than the enrichment activities, seatwork activities or follow-up activities. 
The extent and degree to which a teacher followed the recommended lesson format recommended by the text's publisher is called program delivery. Program delivery is unique to the individual teacher's experience, expertise and background. The teacher's actual lesson plan preparation may be more or less extensive than the publisher recommends. Teaching techniques are unique to teachers' educational experiences, education, background and training. Teachers may or may not know how to assess a student's learning problem, how to teach in a way to help solve the problem, how to help avoid behavior problems, and how to provide explanations and examples that enhance learning instead of creating ambiguities for the student. Teachers may or may not be able to acknowledge, understand or effectively teach children with the cultural differences in their classroom. Districts provide staff development programs that target specific strategies for their teacher training programs. A concern that addresses teaching techniques is how to observe, support and maintain effective teaching techniques.

The third target of reform is the organizational competence of the school. Excellent education comes from sound public institutions. Timar and kirp (1989) noted that institutional authority supports the belief that everyone in the school is responsible for planning curriculum, program evaluation, and what matters in the organizational life of the school. Quality education programs and qualified 
teachers cannot exist in "unhealthy institutions" (Timar \& Kirp, 1989, p. 510).

This research study provided an opportunity to learn whether the complex targets of educational reform in the language arts curriculum had an impact on the academic performance of a rapidly changing student population. This study of the first year implementation of the California English-Language Arts Framework offered the opportunity to learn about the differences between classrooms using a meaning-centered approach to teach an integrated language arts versus those using a code-centered approach to teach an integrated language arts in grades one, three and six.

This study also offered the opportunity to gain insight as to whether the emphasis on an integrated literature approach will improve learning for all students in California. The alternative choices for improving learning currently considered are: (a) a balanced blending of structured and systematic phe iics and skills in a way that associates skills and meaning with connected reading, and (b) a combination of strategies forming a more eclectic language arts program. Adams who emphasized a balance between meaning and code centered approaches, noted that "In order for the connections and even the connected parts, themselves, to develop properly, they must be developed conjointly. They must be linked together in the very course of acquisition" (Adams, 1990, p. 6). Bloom, the respected educational theorist, claimed that "No single method of improving 
learning will work well for all teachers, all school subjects, and all students" (Salvin et al., 1988, p. 28). Written language is the one consistent connection to reading and language arts instruction that educators agree upon as being an integral component of learning. "Through writing, children learn that the purpose of text is not to be read but to be understood. They learn that reading is about thinking" (Adams, 1990, p. 405). "Children teach, solve problems, answer impossible questions, or discover new information hidden in the recesses of experience. The children can do this when their teachers know it is the child's action that produces the learning" (Graves, 1983, p. 119).

The Issue

Curriculum implementation depends on a solid researci base (Joyce, Bennett, \& Rolheiser-Bennett, 1990; Stahl et al.,1990). There is a serious void in educational research concerning how a meaning-centered approach versus a codecentered approach to the teaching of language arts affects the performance of students of diverse cultural and sociological influences (Chall, 1989; McGoldrick, Pearce \& Giordano, 1982). This void in educational research is due to two historical concerns: (a) the number of research projects undertaken after the widespread use of modern statistical techniques, and (b) the social thinking concerning diverse cultural influences (Stahl et al., 1990; Adams, 1990; Tikunoff, 1985). 
In 1964 and 1967, studies from The U. S. Office of Education (USOE) Cooperative Research Program in First-Grade Reading Instruction concluded that the most effective approach on first-grade reading achievement included both code-centered and meaning-centered emphasis. Systematic phonics instruction, an emphasis on meaning, language instruction, connected reading and writing were more effective than basal approaches (Chall, 1967; Bond \& Dykstra, 1967; Stahl et al., 1990).

Stahl et al. (1990) reports that the University of Oregon's Follow Through studies in the 1970 s found that a systematic code-centered approach yielded the highest reading achievemert among disadvantaged first graders and sixth graders. The unusual success of one school was due to the integration of a meaningful connected reading in addition to learning how to decode. The majority of studies indicated that reading achievement is superior with approaches that integrate a systematic code instruction with meaningful connected reading.

A quantitative literature synthesis was conducted by Pflaum, Walberg, Karegianes, and Rasher in 1980 (Adams, 1990). These program comparison studies indicated that instruction that included both code-centered approaches and meaning-centered approaches resulted in superior reading and achievement. These conclusions were valid for both low reading-readiness profiles and more autintaged peers (Adams, 1990). Although, there are many differences in the outcomes 
of reading and literature program comparisons depending on schools, teachers and students; a systematic phonic instruction emphasis appears to be the only instruction of "substantive and lasting value" (Adams, 1990, p. 49). Furthermore, it appears that a systematic emphasis on phonic and/or decoding instruction is more effective on student performance than the implicit instructional philosophy of letting students induce letter-sound from whole words. Research evidence has clearly supported a systematic codeoriented instruction in the primary grades in the context of connected reading, language instruction and meaning emphasis (Resnick \& Weaver, 1979; Chall, 1983; Anderson et al., 1985; Adams, 1990; Chall et al.,1990).

The philosophy underlining the California EnglishLanguage Arts Framework treats reading, writing, listening and speaking as a integrated behavior emphasizing meaning with materials that are real and relevant. A focus on skill instruction would interfere with meaning (Goodman and Goodman, 1981).

Computer searches were executed within the Educational Resource Information Center (ERIC), subfiles Cummulative Index to Journals in Education (CIJE) and Resources in Education ( $R I E$ ) comparing the meaning-centered approach to the code centered approach in language arts and reading in the first, third and sixth grade cultural diverse classrooms from 1983 through 1989. The first, third and sixth grade descriptors were used to eliminate the pre-school, 
kindergarten, high school and college articles and focus on the elementary grades; however, the search was also narrowed with an elementary descriptor. The descriptors used were (a) language experience approach, (b) emergent literacy, (c) whole language, (d) code-centered, (e) meaning-centered, (f) systematic approach to reading instruction, and $(g)$ multicultural education.

In the computer searches, four papers were found related to meaning-centered approach and/or code-centered approach in elementary schools. Edelsky (1983) described in a research report how a sixth-grade inner-city teacher succeeded in encouraging children to act according to new expectations through the whole language approach before the first day of school was over. Manning (1988) discussed the effects of phonics instruction on the literacy development of a six year old girl in a case study. Wray (1989) described in a journal article the major contributions of both meaning-based and code-based approaches and argued that a tentative evaluation of the evidence favored meaning-based approaches in beginning reading. Carbo (1987) illustrated that many poor readers are dropouts of programs requiring analytic/auditory reading styles. She recommended the whole language approach for today's global learners in her article.

A total of four papers drawn from research reports, position papers, journal articles, teaching guides, and project descriptions were found relating a meaning-centered approach to a code-centered approach in reading and/or 
language arts in public elementary schools in the computer search. This limited number of reports may be due to several reasons: (a) the California English-Language Arts Framework represents the first prescribed whole-language program in California, preceded by the basal approach; (b) the implementation of the whole-language philosophy into the classroom represents the teachers" first attempt at teaching two philosophical perspectives during the same year; (c) field research in public schools is very difficult; and (d) the California English-Language Arts Framework emphasizes the whole-language approach and appears to ignore the 80 years of research that suggests that word-attack strategies are a crucial step in learning to read for comprehension and pleasure for beginner readers and for older students who have not mastered skillful reading and writing.

A computer search of the National ERIC, Dissertation Abstracts International from 1851, was activated. The descriptors used were (a) language experience approach, (b) emergent literacy, (c) whole language, (d) code-centered, (e) meaning-centered, (f) public school, (g) low-income, (h) ethnic minority, (i) learning handicapped, and (j) phonic, systematic, or skill approach. There were no dissertations found in the search related to code-centered or meaningcentered approaches to language arts in public, regular elementary classrooms.

However, there were two dissertation studies of codecentered and meaning-centered approaches with kindergartners 
and transition bilingual Spanish students. One dissertation by Putnam (1981) was a descriptive study of two philosophically different approaches to reading readiness used in kindergarten from the University of Pennsylvania. A second dissertation by Fuller (1989), from the University of Boston, related phonics emphasis versus meaning emphasis approach to teaching beginning reading in English to bilingual Spanish readers. A meaning emphasis approach was found to be more effective in developing the second and/or third grade pupil's comprehension ability. However, the decoding ability was developed regardless of which emphasis was employed. This may be explained by the theory that decoding strategies may be a process acquired through learning to read in spanish. Fuller recommended that a meaning approach should be used to emphasize the development of English reading comprehension ability for transitional bilingual students.

The school factors that are linked to reading achievement have been continually studied for nearly a century so that policy and practice is based on the best available knowledge used to improve educational practice. With the adoption of the California English-Language Arts Framework in May, 1986, recommending that a meaning-centered approach to language arts instruction is based on the best available knowledge, it appeared that many dedicated educators began writing journal articles supporting, disagreeing, arguing and discussing the validity of the 
research upon which the meaning-centered approach and the code-centered approach is based. One such discussion on the validity of educational research was between Chall (March, 1989; October, 1989) and Carbo (November,1988; October, 1989). Carbo indicates that the best conclusion on phonics is no conclusion. Chall writes that there is "nearly 80 years of empirical and theoretical support of phonics" (Chall, 1989, p. 160).

Another discussion on the validity of research was between Weaver (March, 1990; May, 1990) and Gersten (April, 1990). Weaver wrote that 5 th and 6 th graders who were in the Follow Through program scored considerably lower in reading comprehension (March, 1990).

Gersten (1990) responded that she was wrong:

In the 18 evaluations conducted, there are no instances of comparison-group students performing at a higher level than those who had been in the Follow Through program on the measure of reading comprehension, the Metropolitan Reading subtest. Follow Through students' reading careers began with intensive instruction in word-attack strategies during the first two years of school. Recent longitudinal research indicates that the students experienced long-term benefits in reading up until the 9 th grade. (p. 36)

Weaver apologized to Gersten and Becker and explained that she inferred this difference in reading comprehension. Weaver (1990) went on to write, "I would still argue, then, 
that research does not clearly show the superiority of phonics in comparison to the typical basal and whole-word approaches, much less a whole-language approach" (p. 41).

Chall (1990) reports that "a synthesis of the research on beginning reading methods found that systematic and direct teaching of phonics in the early grades was effective in general and especially for those at risk and/or low-income children and those with reading or learning disabilities" (p. 6).

It appears that the California English-Language Arts Framework recommendation to emphasize a meaning-centered approach in language arts instruction without an equal emphasis on a code-centered approach, which is supported by available research knowledge, is disregarding the needs of the low-income, learning handicapped, and ethnic-minority students of all ages. It also appears that the Framework's emphasis on a meaning-centered approach, which is student centered instruction, can be interpreted to suggest an implicit approach to teaching decoding skills rather than a systematic or a developmental explicit approach. "Exercises and activities for teaching these skills may be part of the students' texts to be used as needed in the integrated program or they may be bound separately" (California State Department of Education, 1987, p. 43). Productive reading, writing, listening and speaking involves a process of discovering higher-order relationships. These higher-order meaning relationships depend on a thorough familiarity with 
the lower-order units and their relations to the text (Adams, 1990).

Adams (1990) noted that the great challenge for educators is to understand the parts of the system and their interrelations. "One cannot properly develop the higherorder processes without due attention to the lower. Nor can one focus on the lower-order processes without constantly clarifying and exercising their connections to the higherorder ones" (p. 6).

In addition to the void in educational research due to the number of research projects undertaken after the use of modern statistical techniques, the second concern that caused a historical void in research was due to the social thinking related to diverse cultural influences. Tikunoff (1985) indicated that this social thinking influenced school district policies, educational philosophies, and teachers" theories with respect to the instructional approaches thought to be most appropriate for developing language proficiency among diverse ethnic student populations. History notes that educational research and policy making were performed under the "melting pot" viewpoint proposed by social theorists in the 1960s, and fostered by the premise of equality, on which our country was founded (McGoldrick et al., 1982, p. 3). Evidence that supported the notion that ethnic values and identification are retained for many generations after immigration forced education to move toward a complex view that considered group differences within the whole. Social 
thinking then shifted to a concept of cultural education which considered the cultural system of families who share a common history and traditions (Charter, 1989; McGoldrick et al.,1982). Attempts to meet the complex needs of all students within the cultural education view has not been successful and therefore student dropout rates have increased.

Currently, there is a shift in social thinking to an even more complex view of education for the ethnic populations. In addition to addressing religion, race, national and geographic origin, family and community, the emerging view of ethnic education involves conscious and unconscious processes that fulfill a psychological need for identity, historical continuity and cognitive learning (Charter, 1989; Mcioldrick et al., 1982). MCGoldrick (1982) noted two major resistances to an ethnicity focus in education that may have clogged the research and educational policy making process for immigrants: (a) the attitude that ethnicity is a subject that is understood by all individuals, and (b) the existence of an active reluctance to define ethnic differences. The social thinking for research and education policy making has evolved from a "melting pot" focus to a cultural focus to the present ethnicity focus.

Recent research and theory have supported evidence of the last 20 years which indicated that a code-centered approach seemed to produce better readers and fewer reaciing problems than a meaning-centered approach with students in 
early grades and those at risk. This trend was supported by research evidence through grade six. However, educational philosophies and teachers' theories have continued to view a meaning-centered approach as most appropriate for greater cognitive development, and a greater love of reading and learning (Chall, 1989, Chall et al., 1990).

Adams (1990) proposed possible answers to the divisiveness over code-emphasis versus meaning-emphasis in reading instruction that related to the realities of the language arts application in classroom instruction:

My best guess is that by virtue of human nature, people tend to conceive of some instructional activities as 'key' and others as 'support.' But the process of reading cannot be divided into key and support activities. All of its component knowledge and skills must work together within a single integrated and interdependent system. (p. 423)

Adams suggested that effective reading instruction was hindered by the imbalance of reading activities such as the different curriculum of the pull-out reading programs, the limited classroom reading time for low achievers, the classroom seatwork, the way in which the pieces of the reading instruction fit together that should complement and support one another always considering the needs and progress of the young readers, and the curriculum implementation that guides the depth and quality of understanding (Stahl et al., 1990). 
The many changes in student demographics are new phenomena to California educational systems. It was my view that without an understanding of the obstacles and the factors that account for academic performance among diverse groups of student populations, attempts at educational reform were likely to fail. "If you want the greatest possible benefits from a new program, begin by converting the converters" (Adams, 1990, p. 48). Missing in the literature was a comprehensive understanding of how teacher behaviors, curriculum materials and organizational processes actually impacted academic performance among diverse cultural and social student populations. The California English-Language Arts curriculum reform was thrown into a well of possibilities which was derived from what educators comprehended from written words on paper, what was in their hearts and minds, what they were told to do and how they actually did it. Therefore, it was important that scholars seek to better understand the processes of educational reform so that leadership can effect real and intended change and can transform educational organizations to cause higher levels of student performance for all students.

Purpose of the Study

The purpose of this study was to determine how a meaning-centered approach versus a code-centered approach to the teaching of language arts affected student performance in regular education classrooms containing low achieving, low 
socio-economic, multi-ethnic and learning handicapped students.

Historically, California stands in the midst of phenomenonal cultural changes in its student population. The decisions to change and/or alter the direction of curriculum and instruction must consider the increasing variety of cultural and social influences that teachers face in classrooms today. How would a meaning-centered approach and/or a code-centered approach to the teaching of language arts affect student academic performance in an environment of increasing cultural and social changes?

Utilizing descriptive statistical methods, this one year study described relationships among teacher centered behaviors, curriculum materials, organizational processes and student performances in grades one, three, and six in meaning-centered and code-centered approaches to language arts instruction. Through the use of both qualitative and quantitative data--interviews, surveys, observations, standardized test scores and criterion referenced scores-this researcher discovered how a meaning-centered approach versus a code-centered approach to the teaching of language arts affected student performance in a low achieving, low socio-economic, multi-ethnic and/or learning handicapped student population.

Three interrelated dimensions of school reform were applied to the implementation of the California EnglishLanguage Arts Fr mework. The following three reform 
dimensions precipitated eight questions which guided the examination of how a meaning-centered approach versus a codecentered approach to the teaching of language arts affected student performance.

Dimension I. Dimension I examined the differences between classrooms using meaning-centered and code-centered published larguage arts curriculum materials. The extent to which the presentation requirements of the published language arts meaning-centered, code-centered and related materials were followed by the classroom teacher was explored in this study.

Dimension II. Dimension II examined the differences between teacher centered behaviors used in a meaning-centered classroom and a code-centered classroom. There were five categories of teacher behaviors which were explored for this study: (a) instructional management, (b) content specific behaviors, (c) instructional behaviors specific to learning strategies, (d) individual teacher behaviors, and (e) interpersonal behaviors.

Dimension III. Dimension III examined the differences between the effects that organizational processes have on teacher centered behaviors and on the intervention model of the California English-Language Arts Framework in codecentered and meaning-centered classrooms. Four interrelated categories of organizational processes that affected organizational change were looked at in this study: (a) individual and interpersonal teacher behaviors; (b) 
commitment; (c) administrative support; and (d)

organizational development.

Relevance of the Issue to Leadership

It is the position of this researcher that the process of educational reform initiated by the California EnglishLanguage Arts Framework should be examined by those who practice the process of transformational leadership. Educational organizations exist and continuously change in order to accomplish their intended goals. The results of this research study may contribute to a new focus in the conceptualization of educational reform and the language arts curriculum by the way education theorizes about and practices behavioral and organizational chenges.

The primary criterion for effective organizational change is change in behavior (Argyris, 1982, p. 47). Individuals, acting as members of the organization, produce the behavior that leads to their learning that leads to their behavior change. Therefore, the individual learning is the core process in organizational change. This study of a meaning-centered approach versus a code-centered approach to the teaching of language arts and the effects on student performance examined critical themes that led to individual learning. The information gained from this study should be useful for those who are interested in the interrelated process of transformational leadership and educational reform in the language arts curriculum. 
Definition of Terms

The definitions of the following terms that were used throughout the research project serve to clarify the meanings of key concepts:

Code-centered aporoach to language arts instruction. The emphasis is on a systematic, direct approach to teaching decoding and/or comprehension skills within the context of a meaning-centered language arts program; reading, writing, listening and speaking (Chall, 1989). Learning objectives are predetermined, practice is directed on individual skills and the program design is cumulative, systematic and developmental (Paterson, 1989). Examples of decoding skills include: sound/symbol correspondence and initial letter/sound in a word. Examples of general comprehension skills include: reasoning, main idea, details, compare and contrast, drawing conclusions, making inferences, sequencing of events, and summarizing.

California English-Language Arts program. The integration of all the elements of language and thinking: listening, speaking, reading, and writing. The language arts program in California is a systematic meaning-centered literature program for all students (California State Department of Education, 1987).

Intervention model. In this research paper, the intervention described is the English-Language Arts Framework for California Public Schools Kindergarten Through Grade Twelve (California State Department of Education, 1987). The 
definition of model is borrowed from Timar \& Kirp's (1989) discussion of an implementation strategy that is formulated and built at the discretion of each school district. The California English-Language Arts Framework defines the emphasis, effective instruction, essential elements, exemplary practices, and material standards for language arts instruction. However, within the guidelines of the California English-Language Arts Framework's meaning-centered approach emphasis, each school district and/or each school can implement the language arts curriculum with the emphases, instruction, practices, and materials as believed to be a model of effective instruction thus creating a unique language arts model.

Learning handicapped student. A student who demonstrates a significant discrepancy, 1.5 standard deviation from the norm, between his/her expected level of performance and actual learning performance in academic areas such as reading, mathematics, language, and social studies. Low secio-economic student. A child who is from a low socio-economic family or low income family. Sometimes, low socio-economic students are "referred to as 'culturally deprived,' 'culturally different,' 'urban disadvantaged,' or as living in inner cities. Children who are from low socioeconomic families tend to perform below norms in literacy on national, state, and school assessments" (Chall et al., 1990, p. 1). Many of these children enter school without a base of prereading skills, without extensive experiences and without 
a knowledge of literary language and styles (Adams, 1990). Children from low socio-economic families are also referred to as "children at risk" (Chall et al., 1990, p.1).

Low performing student. A low performing student tends to perform below norms in literacy on national, state, and school assessments" (Chall et al., 1990, D. 1). They tend to consistently perform well below the class average in reading, writing, speaking and/or listening.

Mainstreaming. The practice of providing learning disabled students an education with their non-handicapped peers to the greatest possible extent (Library of Congress, 1983). The practice of providing day-to-day language arts instruction for the learning disabled student in a regular classroom setting without specific services offered in a pull-out program for language arts instruction.

Meaning-centered apereach to language arts instruction.

The meaning-centered approach suggests that reading and writing skills emerge in a natural fashion when the classroom environment is filled with good literature that is intensively read, discussed, listened to and written about (Paterson, 1989). The meaning-centered approach requires a sense of wholeness and a sense of the interconnectedness of parts. The meaning-centered approach to language arts instruction is associated with the natural and developmental concepts of language experience instruction and whole language instruction (Chall, 1989). In the early grades, 
meaning-centered is viewed as containing less phonic instruction or none (Chall, 1989).

Multi-ethnic student. A student who views himself or herself as alike to a group of common ancestry, and who is so regarded by others as being a member of a group of common ancestry is an ethnic student. An ethnic student can be second-, third-, and even fourth-generation American as well as a new immigrant. An ethnic student may differ from the dominant culture in values, life-styles, and behavior (McGoldrick et al., 1982). A classroom that contains several different ethnic students is referred to as a classroom of multi-ethnic students.

Organizational change. Organizational change occurs when an external change agent (such as the California state Department of Education) who, in a collaborative relationship with individuals within the system (such as an educational system) intervenes in ongoing organizational processes in order to produce certain anticipated changes in these processes and in organizational effectiveness (Katz \& Kahn 1978; Benne, 1985).

Student performance. In this research study, student performance is defined as the extent to which students demonstrate the following: (a) the ability to handle a variety of writing tasks with confidence, ease and insight; (b) the extensive reading of recreational books; (c) the interest and willingness to prepare uut of class language arts assignments in speaking, reading and writing; (d) the 
participation and level of success on criterion testing efforts; (e) the level of success in the areas of language arts and reading on a standardized test; and (f) a positive attitude towards language arts instruction, indicated by class attendance and the extent of parental support (California State Board of Education, 1989).

Theories-in-use. Values and premises about human behavior that are established early in life. They are created and developed from our earliest socializing experiences and they continue to shape our behavior (Kahn, 1984).

Limitations of This Study

There were some limitations to this study. The following points define what could have been expected to occur with this research and what may have been constraints of the research design.

1. This study included interviews and observations of only 12 classroom teachers which represented approximately $12 \%$ of the total number of first, third and sixth grade teachers who may have implemented the California EnglishLanguage Arts Framework during the 1989-1990 school year in the two school districts represented in this study. The findings may not be generalizable to the total population of teachers.

2. The study was conducted in two urban school districts in southern California and may not represent dissimilar districts. 
3. Anecdotal information was subject to researcher assumptions and interpretations. 


\section{REVIEW OF THE LITERATURE}

\section{Introduction}

The purpose of this study was to determine how a meaning-centered approach versus a code-centered approach to the teaching of language arts affects student performance in a regular education classroom containing low achieving, lowincome, multi-ethnic and learning handicapped students. Foundations of a meaning-centered approach are educational models derived from the highest ideals of citizenship in a democracy. These models propose to lead students to the wisdom and virtue of the examined life, to deepen their sense of ethical responsibility, and to develop allegiance to the highest ideals of citizenship in a democracy (California State Department of Education, 1987). Plato, Aristotle, Augustine, Thomas More, Locke and Dewey have provided blueprints for this kind of educational program (Joyce \& Weil, 1986).

Paterson (1989) rediscoved Dewey's historic naturalistic philosophy, "All of us learn most willingly and best when we acquire our skills in the course of doing something that we ourselves find useful" (p. 4). In 1902, Dewey (1956) 
asserted to the teacher that day to day conditions should "let the child's nature fulfil its own destiny, revealed to you in whatever of science and art and industry the world now holds as it own" (p. 31). The idea of continuous reconstruction in a literate environment was formulated by Dewey (1956) who wrote that school life should organize itself on a social basis.

Continuous reconstruction suggests that students should have the opportunities to collaboratively discuss, in a spirit of free communication, through an interchange of ideas, of suggestions, and of successes and failures of previous experiences, literature within their understandings and the understandings of others. These collaborative discussions among students create new meanings which lead to restructuring of students' understandings and to a reconstructioning of the literate environment for the entire group.

Meaning-centered is child-centered education viewed as natural, developmental, and self directed. Motivation is created from within the student. Therefore, reading, writing, speaking and listening activities are central to student's own lives (Chall, 1989). Knowledge is conveyed to students through sensory interactions with the environment and literature and through interactions with experiences to produce knowledge. Therefore knowledge has a personal quality and is unique for each student (Joyce \& Weil, 1986). 
Theoretical foundations of the code-centered approach are behavioral psychology, cognitive psychology, developmental psychology, psycholinguistics, and neurology (Chall, 1989; Engelmann \& Carnine, 1982). The advocates of the code-centered approach support one or more of three notions: (a) that knowledge should be logically organized so that relatively efficient communications are possible for related knowledge, (b) that empirically-based principles determine universal ways in which the environment influences behavior for different classes of learners, and (c) that there are principles for a logical design of communications that transmit knowledge (Engelmann \& Carnine, 1982).

Advocates of the code-centered approach to language arts instruction view decoding or facility with phonics as a necessary step in the acquisition of reading comprehension and higher-level reading processes. Development of this sensitivity to the sounds of words results from a systematic, direct design of tasks. This systematic, direct instruction is the responsibility of the teacher. Baxter (1989) noted that student failure is the responsibility of the teacher. If the student has not learned it, the teacher has not taught it. Chall (1989; Chall et al., 1990) found that programs that include systematic instruction lead to higher achievement in both spelling and decoding. Chall (1989; Chall et al., 1990) reported on several studies that support the notion that inadequate word recognition can lead to inadequate reading comprehension. Advocates of the code- 
centered approach to language arts instruction support the notion that a systematic, structured skill program, sustained in an appropriate supportive literature environment in which conditions are created to encourage students to want to read and write, is more effective than a natural, developmental and student directed environment that exposes students to the finest literature and encourages a continuous reconstruction and creation of a literate environment in which students want to read and write (Dewey, 1956; Chall et al., 1990; Paterson, 1989).

The findings from educational research and organizational change research linked student performance with selected curriculum materials, teacher behaviors and organizational change processes (Adams, 1990; Chall et al., 1990). Timar \& Kirp (1989) identified curriculum materials, teacher behaviors and organizational processes as the three interrelated targets that lead to organizational change. These three interrelated targets of organizational change were developed into three related themes in the review of the literature: (a) language arts curriculum materials, (b) teacher centered behaviors, and (c) the organizational change processes.

Language Arts Curriculum Materials

The contents and manageability of textbook programs and related instructional materials influence the information that teachers teach and the information that students practice (California State Department of Education, 1987; 
Duckworth \& Fielding, 1985; Loucks \& Zacchei, 1983). In this study, curriculum materials designed for the implementation of the California English-Language Arts Framework were used with either a meaning-centered approach emphasis or a code-centered approach emphasis. Meaning-Centered Aporoach

The meaning-centered approach emphasizes curriculum materials that present literature, listening, speaking, reading, writing, with supporting skills of grammar, spelling, and handwriting (California State Department of Education, 1987). Meaning-centered curriculum materials do not distribute a review of the skills previously learned or present phonic lessons in any systematic, direct order supported by previous research (Durr, 1989). Meaningcentered curriculum materials encourage students to take an active role in their learning, to share ideas, to ask questions, to write, to discuss, to make presentations and to read great literature (California State Department of Education, 1987).

Code-Centered Approach

The code-centered approach emphasizes curriculum materials that present a systematic, direct design of tasks and strategies to be learned, and the use of good literature and writing, with supporting skills of accuracy, fluency and automaticity (Paterson, 1989). Code-centered curriculum materiais emphasize a mastery of skills, a cumulative introduction of new members of a related schema or set, and a 
distributed review of older learning. Since the responsibility for student learning is on the teacher, curriculum materials include suggested lesson presentations for the teacher (Baxter, 1988). Manageability of Intervention Model

The curriculum components of a language arts intervention model can be managed if the components contain materials that are similar to current practices and if the materials are reasonable to implement in a classroom (Duckworth \& Fielding, 1985; Loucks \& Zacchei, 1983). An intervention model can be managed by the teacher if the model is composed of manageable and comprehensible day-to-day details of classroom instruction (Carnine \& Gersten, 1985; Fullan, 1982). The California English-Language Arts Framework intervention model requires that the teacher attend to reading, witing, speaking and listening activities in much detail. Both the code-centered and meaning-centered approaches require instructional discipline so that the purposes are not neglected and a student's progress is continuously assessed and evaluated (California state Board of Education, 1987; Engelmann \& Carnine, 1982; Durr et al., 1989).

\section{Teacher Centered Behaviors}

The most important key to a successful educational program is a motivated and knowledgeable teacher who finds ways to promote learning. The demands to involve and promote learning require that teachers be sensitive, creative and 
flexible in the use of methods and in their attitudes. Teachers draw on instructional methods and strategies available to involve and stimulate the diverse interests of students (California State Board of Education, 1987). Adams (1990) reported that Chall found that teachers tended to carry learned practices and philosophies to the new programs. Students were likely to receive the best of instructional approaches during the transitional period as their teachers were addressing the novel aspects of the new program while memories of their old practices were still active (Chall et al., 1990).

After reviewing the literature on teacher centered behaviors, five categories were formulated for the purposes of this study:

1. Instructional management behaviors. Three areas of management were identified for examination. Foster (1986) noted that teachers resolve three areas of classroom management: (a) control: examples were discipline, positive reinforcement, student feedback, and time on task variables; (b) curriculum: examples were design of lesson presentation, organization of guided classroom practice, and corrective feedback; and (c) societal: examples were individual differences among low- achieving, low-income, multi-ethnic and learning disabled students.

2. Content-specific instructional behaviors. The criteria identified to examine content-specific teaching behaviors were the teacher's individual experiences, 
education and understandings. Content-specific behaviors are teaching behaviors that affect classroom instruction. These behaviors reflect the knowledge unique to the individual teacher. Teacher understandings and skills reflect preparation and experience and transcend mere knowledge of the subject matter (Shulman, 1988).

\section{Instructional behaviors specific to learning} strategies. The criteria identified to examine the use of learning strategies were student self-monitoring and motivation (Brandt, 1989). Learning strategies are taught to students through teacher instructional behaviors. Learning strategies are mental processes that learners deliberately use to help themselves learn or understand something new (Brandt, 1989). The learning strategies taught through teacher instruction in the code-centered approach and the meaning-centered approach fall into different stages of reading acquisition models. The learning strategies stressed in a meaning-centered approach appear to fall into a practice phase of performing skills through various communication modes, speaking, reading, writing, and listening. The systematic code-centered approach stressed a mastering phase where skills were practiced (Downing, 1979; Chall, 1983). Both approaches support the notion that reading and learning are co-dependent with content and a wide variety of reading and writing activities. Resnick (1989) explained that competence is not only knowing the strategies, but competence 
also involves knowing when to use the strategies and having the motivation to use them.

4. Individual teacher behaviors. Teacher values, behaviors and perceptions were the criteria identified to examine levels of individual changes. Burns (1976) noted that teachers have the responsibility to provide a social and intellectual environment in which students can learn, to extend an awareness of human needs, and to provide the means of gratifying these needs necessary to improve a larger social situation. This individual responsibility is linked to the continuing interaction of perceptions and behaviors monitored by values, thus allowing real change and growth. Foster (1986) supported the notion that one dimension of a planned intervention strategy, such as the California English-Language Arts Framework, was the assumption that change begins on the individual level.

5. Interpersonal teacher behaviors. The emotional needs of teachers were considered necessary criteria for the success of an intervention model (Loucks \& Zacchei, 1983). Argyris (1971) linked the degree of interpersonal competence with organizational effectiveness. As each individual's potential is realized, students, teachers, and parents within the organization benefit. The degree of interpersonal development, personal development and the nature of the organization transform individuals to higher levels of consciousness. 


\section{Instructional Management Behaviors}

The selection of the variables that represented each of the three areas of classroom management--control, curriculum, and societal considerations--was guided by meaning-centered approach and code-centered approach to language arts instruction, available theory and data. Discipline, time-ontask, positive student reinforcement and positive student feedback are components of classroom control (Jones, 1987; California State Department of Education, 1987). Effective procedures in classroom discipline allow exciting and dynamic learning for the teacher and the students. Classroom discipline allows students and teachers to care about themselves, their classmates, and their opportunity to learn (Jones, 1987).

A component of a classroom control plan is the act of giving positive student feedback regarding academic and behavioral performance. Sprick (1981) wrote that positive feedback teaches each student that his or her hard work and efforts are recognized. Giving positive feedback requires that the teacher be well organized and efficient. The California English-Language Arts Framework (1987) suggested that students receive feedback from a variety of activities: individual consultations with teachers, written essay tests, writing samples, and oral presentations.

Positive reinforcement is part of the learning process and environment. Sprick (1981) defined reinforcement as any stimulus that follows a behavior and causes that behavior to 
happen more often. Effective reinforcement is used to teach a new skill, to foster positive feelings, to develop intrinsic and extrinsic motivations, and to encourage students to experience the joy of learning (Sprick, 1981). Time on task is defined as the relationship between the time that is spent learning and the amount of learning a student acquires. Jones (1987) noted that three variables affected learning: (a) the allocated time set aside for the subject, (b) the amount of time the student is actually engaged with the subject, and (c) the success rate of the students while they are working on the subject. Students and adults do not like to have their time wasted because of classroom interruptions. There is a high correlation between academic learning time (time on task) and achievement (Brophy \& Good, 1986).

Teachers managed the language arts curriculum with their plan of the lesson presentation, the organization of guided classroom practice, ard corrective feedback. In planning the lesson presentation, teachers interrelated several emphases in their lesson presentation format: (a) clinical model of instruction, the six step lesson plan (Hunter, 1976); (b) Direct Instruction format (Engelmann, Bruner, Hanner, Osborn, \& Zoref, 1988); (c) California English-Language Arts Framework effective instruction guidelines (California State Department of Education, 1987; and (d) the lesson plan recommendations for presentation from the language arts textbook publisher (Durr, et al., 1989). A lesson plan 
design, emphasizing a meaning-centered approach to instruction and that focuses on the California EnglishLanguage Arts Framework, showed a greater percentage of time devoted to students sharing ideas, asking questions, writing, discussing, making presentations, developing composition shills, developing oral language skills and reading great literature than did a lesson plan design that emphasized a code-centered approach to language arts instruction. The code-centered approach lesson plan devoted a percentage of language arts instructional time to the teaching of systematic skills, from an additional program other than the prescribed literature program, with the teacher as the center of learning rather than the student as the center of learning (California State Department of Education, 1987; Ferguson, 1989). The lesson plan design of both approaches included plans to present learning strategies, conventions of language, and literature reading both orally and silently. The goal of instruction was for the student to transfer newly acquired meanings to old knowledge, and to be able to perform the task effectively, fluently, easily and confidently through guided classroom practice (California State Department of Education, 1987). Classroom practice activities in a meaning-centered approach put the responsibility on the learner to engage in various activities such as the extensive reading of books, magazines, and newspapers, writing new or original endings to a literary work, and reading various types of literature (California 
State Department of Education, 1987; Goodman, 1986). Goodman (1986) noted that "self-evaluation is integrally involved in the process and is encouraged" (p. 61).

A percentage of classroom practice activities in a codecentered approach is related to a mastery expectation of a particular learning strategy or skill. Guided practice is related to corrective feedback to insure that the learner performs correctly in subsequent presentations of the activity. The greater percentage of time spent on guided classroom practice indicates a more successful language arts program than a classroom not allowing classroom practice (Adams, 1990). Engelmann and Carnine (1982) explained that the simplest technique in expanding the practice situation to the transfer situation is to design the practice so that the first steps in both situations are identical. Ausubel (1967) was quoted by Adams (1990) as saying, "research has confirmed that prior learnings are not transferable to new learning tasks until they are first overlearned " (p.239). Ausubel continued with the idea that overlearning required an adequate number of adequately spaced repetitions and reviews and an opportunity for differential practice of the more difficult components of a task (Adams, 1990).

Societal needs demand that teachers adapt their instructional behaviors to the characteristics of their student populations. The California State Department of Education (1987) recommended that students who are lowachieving, learning disabled, or from a multi-ethnic group 
must be provided with good literature, and integrated language arts instruction. A meaning-centered approach to language arts instruction structures group work so that students can work cooperatively rather than be isolated in groups. Working cooperatively in a meaning-centered classroom takes place when students, regardless of academic ability, work together on one common task that requires group discussion, planning, designing and creating before the task can be completed as a group effort. Dewey (1956) wrote that the school life organizes itself on a social basis. Dewey (1956) remarked that "a spirit of free communication, of interchange of ideas, suggestions, results, both successes and failures of previous experiences, becomes the dominating note of the recitation" (p. 16).

A code-centered approach to language arts instruction structures group work both cooperatively, with skill development and strategy development designed for students with special needs. Working cooperatively in a code-centered classroom takes place when students, of similar academic abilities, are given the responsibility to discuss, encourage, teach, help and support one another in completing common skills or objectives. Ferguson (1989) noted that these isolated groups require different pacing, assignments, literature books, and skill level work than other students in the classroom. 


\section{Instructional Techniques}

Effective learning strategies were identified from research on successful students. Resnick (1987) confirmed that teachers translate the research knowledge of learning strategies into effective instructional behaviors. The effective teaching research emphasized in this study is organized into five instructional approaches borrowed from Joyce \& Weil (1986):

1. Techniques designed to affect information processing. For example: (a) key elements of teaching (Bloom, 1976, 1971, 1956), (b) whole language (Goodman, 1986), and (c) elements of effective teaching (Hunter, 1976, 1971, 1969, 1967).

2. Techniques designed to focus on the person. For example: (a) teaching thinking (Costa, 1985), (b) classroom writing instruction (Graves, 1984, 1982), and (c) problem solving (Whimbey, 1985).

3. Techniques designed to focus on cooperative learning. For example: (a) groupwork (Cohen, 1987), and (b) cooperative learning environment (Slavin, 1980, 1978).

4. Techniques designed from behavioral theory approach. For example: (a) mastery learning (Bloom, 1971; Carroll, 1971), and (b) Direct Instruction (Engelmann \& Carnine, 1982).

5. Techniques designed to focus on individual differences. For example: (a) environmental relationship to learning (Hunt, 1971); (b) cultural differences (Ovando, 
1983; SERN, 1985; Chall et al., 1990); (c) intellectual differences (Springer, 1985); (d) different learning styles (Hunt, 1974); and (e) non-directive teaching (Rogers, 1969). Many of these instructional approaches are interrelated. The teacher's perception of learning, training experiences and/or cognitive understanding of techniques determine the degree of emphasis or absence of approaches in his/her content specific instructional behaviors. Instructional Behaviors Specific to Learning Strategies The goal of reading instruction in the stage models of reading acquisition is to facilitate word recognition and fluency which is followed by reading comprehension. Basic word recognition and decoding allow the development of reading comprehension and metacomprehension (Chall, 1989). It then follows that organized knowledge systems or background information developed from performing reading comprehension and efficient communication enables learners to relate new information and build larger knowledge systems (Engelmann \& Carnine, 1982). Literacy becomes knowledge and independent thought for low-achieving, low-income, multiethnic and learning-handicapped students.

The learning strategies that are taught in the meaningcentered approach are strategies for synthesizing and integrating information. The strategies are constructed over time as part of comprehending a world interrelated with others (Estes, Gutman, \& Harrison, 1989). Students are prepared to use strategies to analyze issues, make decisions, 
solve problems, and communicate effectively. Students are able to overcome the difficulties of style in literature and appreciate the work for its thought, imagination and statement about the human condition. Skills are not taught directly but acquired from more natural reading and writing activities. California State Department of Education (1987) stated that "children can learn to spell and handwrite their favorite words on the chalkboard making words personal and meaningful from the start" (pp. 16-18).

The learning strategies that are emphasized in the codecentered approach are also strategies for synthesizing and integrating abstract information. Engelmann \& Carnine (1982) identified two objectives for developing knowledge systems: (a) to provide an exhaustive system for classification of any cognitive operation; and (b) to link the classification system with variations of the same communication form. The strategies follow a systematic scheme of reading and writing stages beginning with pre-reading, then mature reading, and finally to skilled reading and writing. The strategies are acquired through direct teacher instruction.with follow up practice.

Individual Behaviors

According to Schein (1986) and Argyris (1987), values, behaviors and perceptions of organizational members are factors that were determined to lead to individual change which allows organizational change. Teacher and principal values, behaviors and perceptions were the criteria that were 
identified to examine levels of individual change (Argyris, 1987; Rokeach, 1968, 1973; Schein, 1986). Schein (1986) defined values as a "sense of what 'ought' to be, as distinct from what is" (p. 15). Schein (1986) and Argyris (1987) noted that values were discriminated between those that were congruent with behaviors and those that were aspirations for the future. Schein (1986) claimed that values that are susceptible of social validation may undergo a process of cognitive transformation. During this process, values gradually become beliefs and basic assumptions. Basic assumptions tend to be nonconfrontable, and nondebatable. Schein's (1986) concept of basic assumptions that actually guide behavior is congruent with Argyris (1987) and Schon's "theories-in-use" (p.180). Behaviors are guided by the following three norms:

1. Action is taken on valid information that is openly obtained. Individuals confront their own basic assumptions and take part in testing them in public. Confrontation with own basic assumptions in public testing allows commitment and change (Argyris, 1987; Costa \& Garmston, 1987; Costa, 1985; Glatthorn, 1987; Schein, 1986).

2. Action is taken on free and informed choice with all who are competent and relevant. The open discussion of empirical research, issues, concerns, clarifications, ideas, and evaluations with competent individuals allows commitment and change (Argyris, 1987; Argyris \& Schon, 1978; Glatthorn, 1987). 
3. Action is taken to monitor the implementation and to prepare for the change. Internal commitment is generated with the monitoring of the implementation and the preparation for the change (Argyris, 1987; Joyce, Bennett, RolheiserBennett, 1990).

Rokeach (1968, 1973) considered that values are greater in depth, permanence, and comprehensiveness than are attitudes. Once internalized, values provide the day-to-day operating principles by which behavior is guided. Therefore, values predict observable behavior.

Many values are aspirations for the future, and they remain conscious and articulated. These values are incongruent with observed behavior. Schein (1986) commented that these values may be "called 'espoused values' which predict what people will say in a variety of situations but which may be out of Iine with what they actually do in situations where those values should be operating" (p. 17). The following norms of behavior were identified and examined:

1. Members of the organization work by themselves to accomplish goals unrelated to other members and their goals. The managers will design goals unilaterally. The proposed action is to try to achieve them (Argyris, 1987; Glatthorn, 1987; D. Johnson \& R. Johnson, 1987; Schein, 1986).

2. Discussion among members of the organization is guided and controlled. The managers will maximize winning by controlling the task with as little dependence on others as 
possible (Argyris, 1987; Glatthorn, 1987; D. Johnson \& R. Johnson, 1987; Schein,.1986).

3. Open discussion of negative and frustrating issues among members of the organization is avoided. The managers will minimize negative feelings in public (Argyris, 1987; Costa, 1985; Glatthorn, 1987; Schein, 1986).

4. Open discussion of issues by members of the organization is avoided. Belief systems are not acknowledged, understandings are not formulated and personal knowledge is not discussed. The managers will suppress the voicing of feelings by others in order to remain rational and objective (Argyris, 1987; Costa, 1985; Glatthorn, 1987; Schein, 1986).

Argyris (1987) noted that the only learning that occurs is learning how to conform.

Hume discussed the nature of man's perceptions (Aune, 1970). According to Aune (1970), Hume called perceptions "ideas" and "impressions" (p. 41). A complex idea is one that is built up from simple ideas by "compounding, transposing, augmenting, or diminishing" them (Aune, 1970, p. 41). Ideas are produced by experiences and intuitions. Impressions are all our experiences: our feelings, emotions, volitions and desires (Eune, 1970). Aune (1970) and Schein (1986) explained that through observations we determine which perceptions form a sense of what ought to be, the status of values. Values that are susceptible of social validation may undergo a process of cognitive transformation as a group 
collectively determines what is real and factual. Dewey (1956) argued that human knowledge has no indubitable foundation. Neither is it pure reason or pure experience. All ideas are subject to change. Any item of knowledge including perceptual knowledge depends on other elements for its justification in our overall system of beliefs. A belief is justified when it fits into the overall system of beliefs. We choose the belief that is most successful in organizing the ongoing experience and facilitating the action (Aune, 1970). Values that gradually become beliefs guide behaviors. Values that become beliefs predispose an individual to respond in some preferred, selective manner.

A change in perceptions and values results from development, education, therapy, relearning, and reexamining, therefore causing a change in behavior (Rokeach, 1968; Argyris, 1985). Showers, Joyce \& Bennett (1987) referred to changes in perceptions and values by noting that intervention efforts that interrelate modeling, practice and cognitiveconceptual development, tend to have a greater effect on teacher practices than program efforts that merely train teacher practices. Schein (1986) explained that values that remain conscious and articulated are incongruent with observed behaviors. Showers et al., (1987) concluded that "what the teacher thinks about teaching determines what the teacher does in the classroom" (p. 85). Kauffman, Gerber and Semmel (1988) indicated that an intervention strategy, such as the California English-Language Arts Framework, will only 
succeed if the model is realistic and reflects how teachers think and believe.

\section{Interpersonal Behaviors}

Teaching knowledge is learned through a series of trials and errors. If the transformation to a sense of commitment to the intervention model is not encountered, the teacher will revert back to a hard-earned sense of stability gained through successful personal experiences in the classroom (Gersten \& Woodward, 1988). Argyris (1987) suggested that individuals will find excuses for what they do, or they will not notice the effect of their behavior on others; they continue to stick to their habitual ways and never try new approaches. Argyris (1987) indicated that if individuals stick to their habitual ways and never try new approaches, then true commitment to their job will be missing. Staw (1984) suggested that the study of commitment is concerned with counterforces to change. His commitment framework examined why it was difficult for organizations to change or adapt and related commitment to the length of time an intervention model persists in organizational settings. Instructional feedback and collegial feedback were the concepts that were determined to lead to interpersonal development and commitment which allows organizational change (Argyris, 1987; Berman \& McLaughlin, 1976; Bird \& Little, 1986; Glatthorn, 1987). Instructional feedback occurs when teachers receive specific and practical feedback on their instruction from a trained facilitator, knowledgeable 
consultant, or master teacher (Gersten, Davis, Miller \&
Green, 1986; Glatthorn, 1987; Loucks \& Zacchei, 1983).
Collegial feedback occurs when teachers work together in a collegial fashion. They share ideas, discuss and analyze successes and problems. Argyris' (1987) research suggested that if the causes of these problems are not discussed, the situation tends to breed mistrust and conformity. Interpersonal competence is greater when individuals are honest and open about their own feelings than when they exhibit decreasing openness, and a scarcity of risk taking and trust. This expanding awareness of different views, feelings and attitudes expands individual reasoning and leads to commitment and interpersonal development and allows organizational learning and change.

The following behaviors were identified to examine levels of interpersonal development:

1. The use of shared language. When working together in a collegial fashion, a common language emerges among the teachers. This common language helps teachers conceptualize and analyze the intervention model (Bird \& Little, 1986). Loucks and zacchei (1983) found that the process of purposely scheduling the opportunity to develop a shared language between teachers over a period of time was effective.

2. The level of collegial bonding. Collegial bonding exists when members work together to achieve joint goals. Teachers working together accept responsibility for continuously improving their own productivity and that of 
their colleagues. D. Johnson and R. Johnson (1987) suggested that working together is important because much of what teachers need to learn is procedural, "similar to learning how to play tennis or how to perform surgery" (p. 28). Collegial bonding leads to interpersonal development (Argyris, 1987). D. Johnson and R. Johnson's (1987) research found that cooperation among adults promotes the following outcomes: (a) "more positive interpersonal relationships than do competitive or individualistic efforts" (p. 28), (b) greater social support than do competitive or individualistic efforts, and (c) higher self-esteem than competition. One purpose of feedback is to provide common collegial bonds among teachers and administrators (Bird \& Little, 1986). Bird and Little's (1986) research found that high levels of achievement growth occur most frequently in schools with teachers who worked together in a collegial fashion.

3. The use of research-based teaching strategies. Berman \& Mclaughlin (1976) and Guskey (1984) found that teacher commitment is generated if the teachers see that the intervention model is effective with their own students. Teachers are reluctant to change their teaching behaviors in order to try new innovative, effective, research-based teaching practices. One key purpose of feedback contained in the concept of coaching is to enhance the teachers' use of research-based teaching strategies proven to be effective with low achieving, multi-cultural and learning handicapped students (Showers et al., 1987; Stalings, 1980). 
The use of shared language, the level of collegial bonding, and the use of research-based teaching strategies were the criteria identified that allows organizational learning and change. Organizational learning reflects a process of cognitive transformation and interpersonal development as a group collectively determines what is real and factual.

Organizational Change Processes

The kind of change that is possible in an organization affects the success of the intervention model and student performance (Costa \& Garmston, 1987). Organizational change is made possible through the following interrelated variables: (a) interpersonal behaviors and individual behaviors, (c) commitment, (d) administrative support, and (e) the developmental stage of the organization and the degree to which the organization is ready to change (Argyris, 1987; Argyris \& Schon, 1978; Benne, 1985; Berman \& Mclaughlin, 1976; Bird \& Iittle, 1986; Burns, 1987; Costa \& Garmston, 1987; Costa, 1985; Gersten \& Woodward, 1988; Huberman \& Miies, 1984; Rokeach, 1968, 1973; Schein, 1986). Benne (1985) suggested that organizational change occurs through the small group relations, interpersonal relations and through intergroup relations. Schein (1986) noted that organizational change occurs when a member of the group is personally affected by a set of events, and when the change agent deliberately attempts to produce new and different responses in members of the group. For example, the change agent, acting as the California state Department of 
Education, deliberately attempted to produce new and different responses in the language arts curriculum. Commitment is related to the degree of motivation and involvement that members of the organization exhibit toward the organization's aims and purposes. If an individual is intensely involved in the organization, the individual will be more committed to the realization of its goals (Etzioni, 1987). According to Bennis' (1989) language, empowerment is related to commitment. Empowerment is the collective effect that members of the organization exhibit toward the organization's aims and purposes. Bennis (1989) identified four themes:

1. Members feel significant. "People feel that what they do has meaning and significance" (p. 23).

2. Learning and competence makes a difference. Leaders use feedback and value learning and mastery.

3. Members are part of a community. There is a sense of community, family, team and unity among members of the organization.

4. Members are excited about the visions and goals. An essential ingredient in organizational leadership is pulling members toward a goal. Goals are articulated and ideals are embodied. Members are motivated to be involved in striving toward the goals.

Research from the 1980 s indicated that active administrative support at all levels was crucial to the success of proposed changes introduced by an intervention 
model (Huberman \& Miles, 1984). Additional studies indicated that a configuration of participants was necessary for organizational change to occur. One participant may take the role of the facilitator. However, Gersten \& Woodward (1988) noted that the facilitator relies on the principal, the superintendent's office, and the linking resource offices for support and commitment. Burns (1987) suggested that the facilitator, in collaboration with teachers, consultants, and administrators, will provide direction, purpose, shape values, establish empathic relationships, recognize real need and build a strong organizational culture.

Schein (1986) asserted that the kind of change that is possible in an organization "depends not only on the developmental stage of the organization but on the degree to which the organization is unfrozen and ready to change either because of externally induced crisis or because of internal forces toward change" (p: 271). Schein (1986) identified three developmental stages: (a) early growth in which the culture is a source of identity and socialization; (b) organizational midlife in which subcultures exist and there is a loss of key goals and values; and (c) organizational maturity in which the culture change is necessary but not all elements can change. Foster (1986) noted that unfreezing occurs "when the selfimage is 'disconfirmed' by any number of processes: for example, when it becomes clear that how you think about yourself radically differs from how others perceive you" ( $p$. 
153). According to Schein (1986), one force that might unfreeze an existing situation, disconfirmation, and lead to a situation in which change is possible is an external crisis of survival. According to Foster (1986), "basic assumptions and beliefs may be reexamined, and new information about the situation accepted" (p. 153). This acceptance will then lead to cognitive redefinition. Basic assumptions, beliefs and values are redefined in new ways and revised contexts. The change process involves unfreezing forces, the creation of psychological safety, cognitive redefinition, and the development of new assumptions.

The following criteria were identified to examine the kind of change that was possible in an organization because of an externaliy induced attempt to produce new and different responses in members of the group:

1. Interpersonal and individual behaviors. The degree of collaboration among group relationships. D. Johnson and R. Johnson's (1987) research found that "a cooperative structure exists when members work together to achieve joint goals (p. 28). Argyris (1987) noted that collegial bonds lead to commitment and interpersonal development. Individuals confront their own basic assumptions and take part in testing them in public. Confrontation with one's own basic assumptions in public testing allows commitment and change (Argyris, 1987; Costa \& Garmston, 1987; Costa, 1985; Glatthorn, 1987; Schein, 1986). The open discussion of empirical research, issues, concerns, clarifications, ideas, 
and evaluations with competent individuals allows commitment and change (Argyris, 1987; Argyris \& Schon, 1978; Glatthorn, 1987). An individualistic structure exists "when members of the organization work by themselves to accomplish goals unrelated to the goals of others" (D. Johnson \& R. Johnson, 1987, p. 28).

2. Commitment. The degree of administrative commitment to the California English-Language Arts implementation. Internal commitment is generated with the monitoring of the implementation and the preparation for the change (Argyris, 1987; Joyce, et al., 1990). The monitoring of the implementation was determined by the degree of support in the areas of adequate curriculum materials, school activities, publication resources, student academic knowledge, teacher reinforcement and feedback, parent involvement and coordination.

In this study, preparation for the change generated by the California English-Language Arts implementation was examined by the 1989-1990 school goals. Burns (1976) discussed the classical view of goal as representing some kind of intent, "Leadership brings about real change that leaders intend" (p. 414). Goals are indispensable to the theory and practice of of leadership. Goals affect the organization and "may be pursued with varying degrees of intensity and commitment" (Burns, 1976, p. 375). Although goals are ambiguous, failure to identify the predominant and persisting goals "would be to thwart any real understanding 
of the relation of individual and organizational goals" (Burns, 1976, p. 376). The original set of proposed priority goals may give way to specialization and routine. Managers may design goals unilaterally. The proposed action is to try to achieve them with bargaining, negotiating and/or authority techniques (Burns, 1976). Members of the organization may work by themselves to accomplish goals unrelated to other members and their goals (Argyris, 1987; Glatthorn, 1987; D. Johnson \& E. Johnson, 1987; Schein, 1986).

3. Administrative support. Administrative support was examined by the the change mechanisms used by the administration and the willingness, in collaboration, to provide directior, purpose, and shape values in support of the California English-Language Arts Framework. Change mechanisms that maximize personal gain at the expense of collaborative development among organizational members were identified by the following concepts: (a) discussion among members of the organization is guided and controlled. Administrators maximize winning by controlling the task with as little dependence on others as possible (Argyris, 1987; Glatthorn, 1987; D. Johnson \& F. Johnson, 1987; Schein, 1986); (b) open discussion of issues, negative and frustrating, by members of the organization is avoided. Negative feelings are minimized in public (Argyris, 1987; Costa, 1985; Glatthorn, 1987; Schein, 1986); and (c) belief systems are not acknowledged, understandings are not formulated and personal knowledge is not discussed. The 
voicing of feelings is suppressed by others in order to remain rational and objective (Argyris, 1987; Costa, 1985; Glatthorn, 1987; Schein, 1986).

4. Developmental stage. The number of years the participants were with the organization. The developmental stage of the organization, and the degree to which the organization was ready to change and support the California English-Language Arts Framework would affect the success of the intervention model.

The four criteria that were identified to examine the kind of change that was possible in the organization were interrelated with the criteria identified to examine individual behaviors and interpersonal behaviors. The purpose of this study was to determine how a meaning-centered approach versus a code-centered approach to the teaching of language arts affects student performance in a regular education classroom containing low achieving, lowincome, multi-ethnic and learning handicapped students in the first year of the California English-Language Arts Framework. The California State Board of Education (1987) made the decision to alter and/or change the direction of California English-Language Arts curriculum and instruction. This educational reform effort will affect curriculum materials, teachers behaviors, organizational processes and student performance. An overview of the interrelated reform targets, the specific aims of each target, and the points of focus 
that were identified for research purposes are demonstrated in Figure 1. 
Eigure 1. An overview of the three interrelated reform dimensions that guided the examination of the differences between a meaning-centered approach and a code-centered approach in language arts instruction.

REFORM

DIMENSIONS

AIMS

FOCAL

POINTS

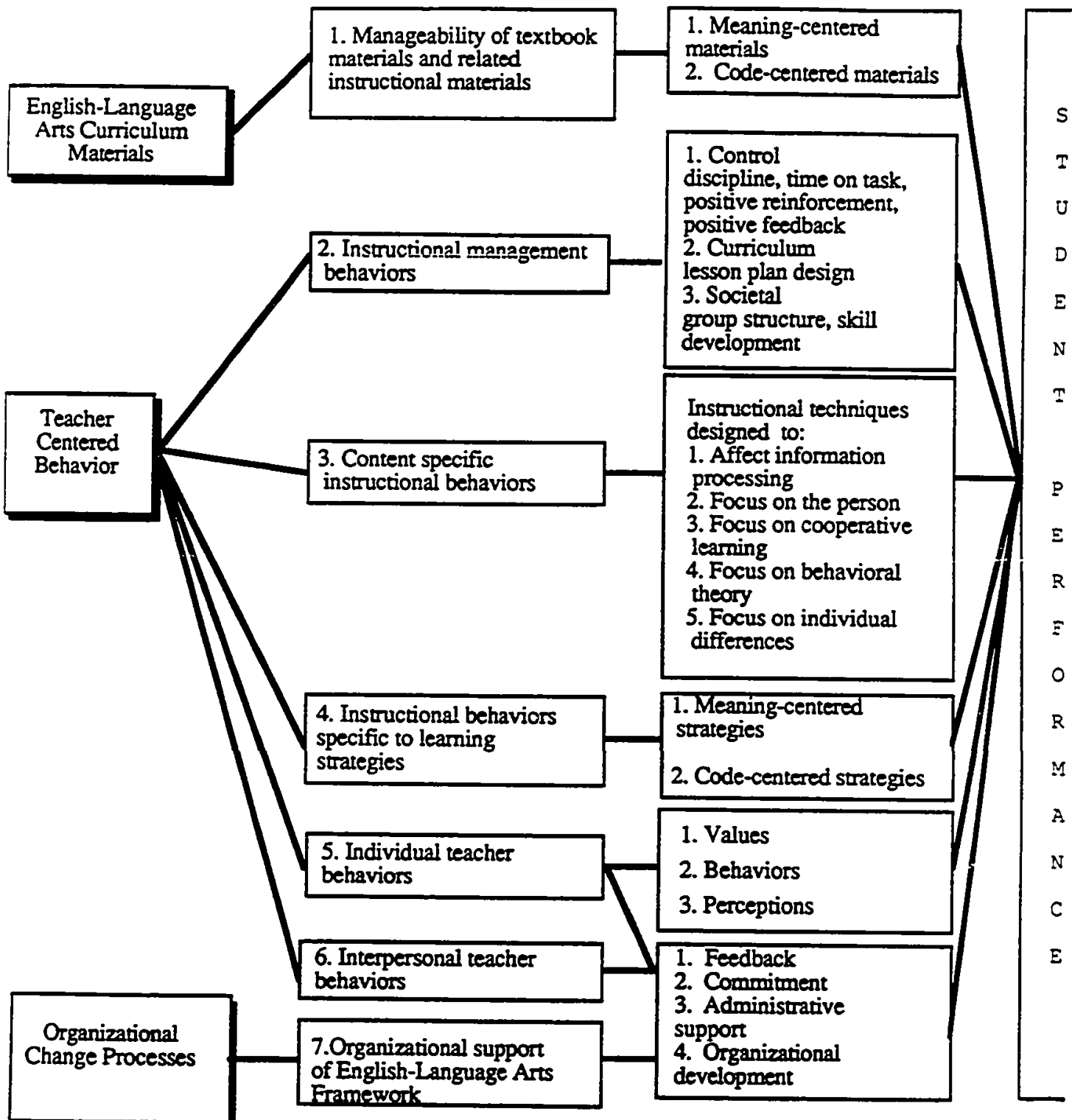




\section{CHAPTER III}

\section{RESEARCH DESIGN}

\section{Introduction}

The purpose of this study was to determine how a meaning-centered approach versus a code-centered approach to the teaching of English language arts affects student performance in regular education classrooms containing low achieving, low-income, multi-ethnic and learning handicapped students. The first year implementation process of the California English-Language Arts Framework generated a possibility for the two teaching approaches, code-centered and/or meaning-centered, to be used in classrooms. To accomplish the purpose of determining how the two teaching approaches affected student performance, this research focused on the three interrelated targets of organizational change, noted by Timar and Kirp (1989) and Adams et al. (1990), that link student performance with selected curriculum materials, teacher behaviors and organizational change processes.

A range of both qualitative and quantitative techniques were used to support and describe the richest possible picture of how the teaching approaches associated with the 
implementation of the California English-Language Arts Framework affected student performance. The research analysis described and analyzed how code-centered and meaning-centered approaches in elementary grades one, three and six, affected student performance.

This research study extended over a one year period, September 1989 through June, 1990. According to Fullan (1984) evaluation procedures on school improvement and change indicate that a minimum of two years are necessary for schools to seriously and comprehensively implement intervention programs. However, it is the belief of this researcher that decisions concerning the education of students should not wait two or three years. Therefore, it is this researcher's hope that this descriptive study of the effect of the teaching approaches associated with the first year implementation process of the California EnglishLanguage Arts Framework on student performance will offer some indicators for future decisions.

\section{Research Design}

The three interrelated reform dimensions, referred to in the section titled Purpose of the Study, precipitated eight specific research questions. Three dimensions and eight questions guided the examination of both qualitative and quantitative data in order to determine how a meaningcentered approach versus a code-centered approach to the teaching of language arts affects student performance in 
regular education classrooms containing low achieving, lowincome, multi-ethnic and learning handicapped students. Research Questions

Curriculum materials.

Dimension I which examined the differences between classrooms using meaning-centered and code-centered published language arts curriculum materials prompted the following research question numbered one:

1. To what degree were the published code-centered and meaning-centered Language arts curriculum materials presentation recommendations followed by the classroom teacher?

Teacher centered behaviors.

Dimension II which examined the differences between teacher centered behaviors used in a meaning-centered classroom and a code-centered classroom prompted the following research questions:

2. What teacher behaviors related to the instructional management factors--control, curriculum, and societal--were performed in a code-centered and meaning-centered English language arts classroom?

3. What were the differences between instructional techniques used in a code-centered classroom and a meaningcentered classroom?

4. To what extent were students able to exhibit learning strategies acquired from being taught by teacher 
instructional behaviors specific to code-centered strategies and meaning-centered strategies?

5. To what extent did teacher values and perceptions guide teacher behavior in a code-centered classroom and/or a meaning-centered classroom?

6. To what degree was the classroom teacher committed to implementing and using a code-centered approach or a meaning-centered approach to teach the English language arts curriculum?

Organizational orocesses.

Dimension III which examined the differences between the effects that organizational processes have on teacher centered behaviors and on the intervention of the California English-Language Arts Framework in code-centered and meaningcentered classrooms prompted the following research question:

7. To what degree did the organization support the changes introduced by the California English-Language Arts Framework?

Student performance.

The final research question interrelated the three reform dimensions, the preceding seven questions and student performance.

8. How did the differences in materials, teacher behaviors and organizational processes between classrooms using a meaning-centered approach and those using a codecentered approach in language arts affect student performance? 


\section{Site Selection}

Two school districts in southern California were

selected for this study. District I was an elementary school district of approximately 5,815 students, with grades ranging from kindergarten through sixth. The district's census data reflected that more than $25 \%$ of the school age children fall below the poverty level indicator line (Market Data Retrieval, 1990). The district serves a culturally and ethnically diverse community that is growing.

District II was a school district of approximately 3,162 students, with grades ranging from kindergarten through sixth. The census data reflected an average range of community wealth which would reflect the following range, $5 \%$ to $24.9 \%$, of school age children following below the poverty level indicator (Market Data Retrieval, 1990). Three schools within the district service a culturally and ethnically diverse population.

A total of seven school sites represented ethnically diverse communities that have been constantly growing and changing. The seven sites also represented a diversity of organizational processes due to the interrelated differences in the teaching staff and their principals. Three school sites were selected from District I: (a) School Site 1, one first grade class and two third grade classes; (b) School Site 2, two sixth grade classes; and (c) School site 3, one first grade class. These three school sites provided six teachers, 168 students and two principals for my study. I 
was unsuccessful in scheduling an interview with one principal.

Four school sites were selected from District Two: (a) School Site 4, one sixth grade class; (b) School site 5, one first grade class and one third grade class; (c) school site 6 , one first grade class and one third grade class; and (d) School site 7, one sixth grade class. These four school sites provided six teachers, 154 students and three principals. I was unsuccessful in scheduling an interview with one principal.

In summary, District I and District II, together, provided a total of seven school sites, twelve classes and teachers, 322 students, and five principals. The selection of the regular education classrooms within each school was contingent upon the verification that the 1989-1990 school year was the first year of their California English-Language Arts Framework implementation.

Criteria for the Selection of Participants

Participating districts were intentionally targeted for two reasons:

1. In both school districts, the instructional history and curriculum design related to a meaning-centered approach vs. a code-centered approach to English language arts curriculum were similar in grades one through six. Before 1989, the language arts curriculum followed a code-emphasis approach in both districts. Both districts did boast of exemplary schools. Teachers in District II used the basal 
approach and integrated their lesson plans with writing, listening and speaking activities and a continuous assessment program titled Target Teach.

Target Teach is a curriculum alignment and instructional management program which identifies specific reading and language skills that are to be mastered at each grade level and those skills that need to be directly taught for mastery in each grade level. The skills are arranged in a systematic order of difficulty, aligned with the basal reader and aligned with the skills tested by the standardized testing program for each grade level. The computerized assessment program directly correlates with the district's standardized testing achievement program. Classroom teachers were expected to follow the Target Teach guidelines with their students.

Teachers in District I taught a systematic, direct instruction decoding approach in kindergarten through second grade. In third grade through sixth grade, students learned from a basal approach and teachers integrated their lessons with writing, speaking, and listening activities. Specific skills from the standardized testing program were targeted for additional classroom instruction. District I did not have the help of a computerized program that aligned standardized test skills with basal textbook skills.

Both school districts were implementing the California English-Language Arts Framework this school year, 1989-1990, in grades one through six. All teachers in District I were 
using the new prescribed curriculum materials. They were directed to implement the California English-Language Arts Framework by their district administrators using a meaningcentered approach supported by their prescribed literature series.

However, teachers in District II were directed by district administrators to implement the California EnglishLanguage Arts Framework and maintain a code-centered approach. That is, they were using the prescribed literature program and also the Target Teach instructional management program which emphasized skill objectives, which determines a code centered approach. All teachers who volunteered for this study were using the new prescribed literature program for the first year. However, since the 1989-1990 school year was the literature series pilot year for District II, several teachers in District II were not using the prescribed literature program. They were continuing to use the old basal reading series with the Target Teach instructional management program.

A second common element was that classrooms in both districts were using the new literature Houghton Miffin textbook series in their implementation. This new series was aligned with the California English-Language Arts Framework philosophy. District $I$ is emphasizing the meaning-centered approach recommended by the California State Department. District II is continuing to use Target Teach in grades one through six, thus emphasizing the code-centered approach 
while attempting to integrate a code-centered instruction with the meaning-centered instruction recommended by the California State Department.

2. There is limited research available on reading development and the language arts program with language minority students and low-income students (Chall, 1989; Chall et al., 1990; California State Board of Education, 1987). Therefore, the selected classrooms in both districts exemplified multi-ethnic and low-income student populations in grades one through six.

The guidelines for the school identification of low achieving, low-income, multi-ethnic and learning handicapped students will follow State and local guidelines to avoid confidentiality or sensitive concerns among individual members of the communities. That is, information concerning classroom attendance numbers, without student names, is available information to the public. Low achieving students were identified from previous standardized test scores. Low income students were identified by the number of full free lunches furnished by government funding. Multi-ethnic and language minority students were identified by the ethnic code from school survey files and the Primary Ianguage in Home surveys. Mainstreamed learning hardicapped students were identified by the Federal definitions specified in PI 94-142. Students' identification data were collected from principal surveys following Education Codes 44049 and 49000 concerning confidentiality. 
Grade levels one, three and six were selected for three reasons: (a) the limited research in reading and language development on language minority students and low-income students cited by Chall (1989), Chall et al., (1990) and California State Board of Education (1987); (b) the amount of research indicating the effectiveness of the code-centered approach in grade one and the combined effectiveness of the code-centered and meaning-centered approaches in grades one, three and six (Chall, 1989; Chall et al., 1990; Anderson et al., 1985); and (c) the availability of quantitative reading and language arts achievement data from the district's standardized testing programs.

The regular classrooms of grades one, three and six that were selected for this study included the following five student populations: (a) male and female students; (b) students with advanced, average and low levels of academic performance abilities; (c) students using English as a second language; (d) special education students; and (e) students of ethnic diversity: Asian, Indochinese, Black, Hispanic, American Indian, Pacific Islander, Filipino, Portuguese and Caucasian.

Chronological Summary of Research Procedures

The California State Board of Education (1987) published the English-Language Arts Eramework for California Public Schoels Kindergarten. Through Grade Twelve in an effort to implement curriculum reforms. In 1987-1988, the California State Board of Education, following the state's 
Administrative Procedure Act guidelines of 1988, selected and listed reading textbooks that aligned with the literature theme and teaching approach recommended in the EnglishLanguage Arts Framework (California State Board of Education, 1987). In November, 1989, Superior Court Judge James I. Long ruled that the State Board, the Department of Education and the State Curriculum Commission violated the Administrative Procedure Act guidelines by not adopting regulations that require textbook publishers to show their textbooks are effective based on actual experience with students. Therefore, "the 'policies and procedures, standards and evaluation instruments' used by the board to review reading textbooks were ruled void and ineffective" (Rothman, 1989). However, many California school districts had selected their reading textbooks from the State Board of Education's recommended lists before september, 1989. In 1989-1990, many California school districts implemented the California English-Language Arts Framework and their new reading textbooks in their schools.

The classrooms selected for this study used prescribed language arts curriculum materials that were not based on actual experience with students. The effectiveness of the materials on student performance was not a consideration during the selection process. The prescribed curriculum materials were designed and written with collaboration of the publisher and the Department of Education to align with the philosophy of the California English-Language Arts Framework. 
In September, 1989, I began making arrangements with the two school districts that I would use for the selection of the twelve classroom teachers. I contacted the Superintendent and the Curriculum Director in two Southern California school districts to determine whether I could have their permission to ask their principals and teachers to volunteer to participate in my research study concerning the differences in approaches in their first year implementation of the English-Language Arts Framework. After I received district administrative permission, I began calling principals on the telephone and asking them to volunteer to participate in my study. I met with the first four principals who volunteered to listen to my study proposal. All four principals agreed to allow me to present my proposal to their first, third and sixth grade teachers and ask for their volunteer participation. Not enough teachers volunteered from this source of four schools to be observed, so I had to contact and meet with three additional principals and their staff members within the identified districts to find additional teachers to volunteer. I was finally able to find a total of twelve classroom teachers at seven school sites to volunteer: (a) four first grade teachers; (b) four third grade teachers; and (c) four sixth grade teachers. During this same period of time, I was field-testing the interview and questionnaire instruments. To ircrease content validity, refinements and adjustments were made to the instruments based upon the feedback from data gathered from 
three principals and four teachers who were not identified for the research study. However, all participants in the field-testing were involved in the implementation of the California English-Ianguage Arts Framework in their districts.

Also during this same period of time, I was gathering individuals who would act as data-collectors. These individuals would be paid by the hour to observe classrooms during the time of their language arts instruction. Five individuals originally agreed. However, due to various individual obligations, I began my study with two individuals. We field-tested the observation instrument in two classrooms. The specific definitions of each teacher behavior observed were discussed. Changes and refinements were made to the observation instrument.

In February, 1990, I began to administer the principal and teacher interviews. Although, seven principals originally volunteered, I was unsuccessful in scheduling an interview for two principals. The five principal interviews lasted from 20 minutes to 45 minutes. Each principal was interviewed on two separate occasions with the same instrument: (a) one time in March, and (b) one time in June. I used the field-tested instrument, and I also audio-taped the interview so that all comments would not be overlooked. I used two copies of the instrument during the interview session: (a) one for the principal to look at while the 
questions were being asked, and (b) the second copy for my recording of responses.

Teacher interviews lasted from 15 minutes to 25 minutes. Each teacher was interviewed on two separate occasions with the same field-tested instrument: (a) one time in March, and (b) one time in June. I also audio-taped the interview so that comments would not be overlooked. I used two copies of the instrument during each interview session: (a) one for the teacher to look at while I read the questions, and (b) the second copy to record their responses.

The twelve teachers who volunteered also completed a field-tested survey on two separate occasions: (a) one time in March, and (b) one time in June. This survey was left with the teacher and collected during the first classroom observation time. One of the teachers mailed the survey to me.

The most difficult observations to schedule and to attend were the grade level meetings. My goal was to observe 24 grade level meetings. However, many times, grade level meetings became a natural break from the scheduled stafi meetings, and grade level meetings were left to the teacher groups to schedule at their convenience. I was able to observe a total of nine meetings, five grade level meetings and four staff meetings. Each grade level observation lasted 20 minutes. Several reasons accounted for this difficulty:

1. This instrument was not field-tested. Principals were reluctant to allow me to observe their teacher meetings 
without being an actual study participant. Therefore, I added all possible criteria to the instrument.

2. Teachers who were not involved in the study became very anxious when I began to listen, write and audio-tape their meetings. Since grade level meetings included teachers not involved in the study, intuitively, I determined that my purpose of collecting teacher interactions would be more valid if I were the person to attend each grade level meeting each time.

3. Staff meetings and grade level meetings were found to be generally scheduled on Mondays. It was physically impossible to attend more than one meeting during the same time, same day and in different places. District one and District Two coordinated their staff meetings so that every teaching staff covered similar issues during the same week. Grade level meetings were generally an extension of these staff meetings. Furthermore, many scheduled grade level meetings were cancelled for various reasons among their members.

4. My audio-recorder didn't pick up individual remarks. The majority of staff meetings and grade level meetings were actively noisy and held in empty classrooms. My audio-tape recorder picked up all sounds from the environment which severely muddled audio-taped conversations.

Data Gathering Techniques

The eight research questions, noted in the Research Design section, were constructed to help me examine both 
qualitative and quantitative data in order to determine how a meaning-centered approach versus a code-centered approach in the language arts curriculum affects student performance, and to help me describe specific teacher behaviors, curriculum materials and organizational processes that affect student performance. Data gathering tools were constructed by this researcher to help me examine the eight research questions. The data gathering tools are appended to this dissertation. These tools were designed by this researcher in collaboration with the following sources: Goodlad, 1984; Peterson, 1983; Madigan et al., 1986; Joyce et al. , 1980; Showers, 1985; Sprick, 1981; Hunter, 1976; California State Board of Education, 1987. A brief description of the data gathering approaches and protocols that were used is following:

1. Classroom observations. Observations were conducted by Houston, Allen and myself. Houston has a Multiple subject teaching credential, a Learning Handicapped Specialist credential, and a Resource Specialist certificate. She has taught a total of fourteen years in kindergarten through sixth grade, five years in regular education, five years in an alternative education school with learning disabled students and seriously emotionally disturbed students, two years as a Resource specialist and two years as a substitute teacher. She has trained classroom teachers in Engelmann's (1988) Direct Instruction mastery learning program. Allen taught three years before she trained with Engelmann's Direct Instruction mastery learning program at 
the University of Oregon. For the last nineteen years, she has worked as a consultant and teacher. As a consultant, Allen instructs teachers in effective teaching stratagies, direct instruction, coaching, and modeling techniques. She has taught teachers in Special Education graduate and undergraduate programs at San Diego State, University of California Los Angeles, California Polytechnic, California State Dominguez Hills, and at the University of Oregon.

I taught language arts programs in regular education for seventeen years in fourth grade through eighth grade and reading at the high school grade levels. I hold a General Teaching life credential, a Reading specialist credential and an Administrative credential. As administrator, I created and operated a private reading school for three years for pre-school children through adults. I have taught and lectured on effective teaching strategies. For five years, I worked for an educational publishing company, consulting with teachers and administrators in school districts concerning curriculum materials and effective teaching strategies. Following were my background assumptions concerning effective language arts instruction during the time of this study: (a) theoretical assumption is that language learning is a developmental process which occurs in a harmonious, literate environment permeated with the freedom to discover and create and which is supported with a systematic, direct instruction of language skills that connect cognitive and affective thought schemes; and (b) instructional assumption 
is that children need to actively engage in the natural process of speaking, listening, reading and writing, to be encouraged to take risks, to be guided to higher levels of understandings, to be provided with the skills to fulfill their natural destiny and to be self directed in a connected community.

Observations focused on teacher centered behaviors and the academic engagement of students. The data collection instrument used to observe the classroom teachers and students, the explanation of each observed behavior and the classroom observation time schedule is presented in the Appendix E (p. 412). Twelve teachers were observed during their classroom language arts instruction one time each month for a total of sixty observations. Each classroom observation lasted approximately 45 minutes.

The teacher centered behaviors that were observed are related to instructional management that is defined by the three areas: control, curriculum, and societal. The set of instructional teaching behaviors identified were based on the effective teaching research. Stallings (1980) noted that there is a high correlation between specific empirically validated teaching techniques and the academic engagement of low achieving students. Observations focused on what teachers and students actually do in the classroom.

2. Teacher meeting observations. Observations of staff meetings, teacher meetings and grade level meetings were conducted by Kruger and me. Kruger has a Masters degree in 
psychology and has taken an active part in community issues and local and national politics. She has taught at the secondary level of education for more than 15 years. Her class instruction has recently emphasized women issues. Observations focused on individual and interpersonal teacher behaviors, organizational support and commitment to the California English-Language Arts implementation model. Observations described the degree of relationship building, sharing, openness, bonding and organizational support. The observations reflected areas of resistance, changes in attitudes and behaviors. Each teacher meeting observation lasted approximately 25 minutes. The teacher meeting observation instrument is noted in the Appendix A (p. 400).

3. Structured interviews. Two interviews with the classroom teacher, one in February and one in June, examined changes in feelings and perceptions concerning the implementation process and the performance of their students. Interviews followed a structured format that encouraged participants to talk about additional information concerning the topics. Teachers were asked questions concerning the strengths and weaknesses of the California English-Language Arts Framework implementation model, the academic needs of their ethnic students, and the degree of organizational support they perceived they had. The intent was to elicit candid perceptions of the effectiveness of the EnglishLanguage Arts Framework implementation on student performance in the teacher's own words and the order in which matters 
were important to them. Each teacher interview was audiotaped and lasted approximately 15 to 25 minutes. The Teacher Interview instrument that was used in February and June is noted in the Appendix C (p. 404).

Two interviews with the school principal, one in February or March and one in June, examined changes in their feelings and perceptions concerning the implementation of the California English-Language Arts Framework curriculum. The intent of the interview was to elicit perceptions concerning the organizational processes that related to the personal and interpersonal relationships of staff members, and processes that related to the degree of administrative support and commitment of the organization. Each principal interview lasted approximately 20 to 35 minutes. The Principal Interview instrument that was used in February and June is contained in the Appendix B (p. 402).

Principal interviews and teacher interviews were conducted at the interviewee's convenience and at the location of the person's choice, usually at the school site. Several June interviews were conducted by audio-taped telephone interviews due to the convenience of working around difficult schedules at the end of the school year.

4. Teacher questionnaires. Questionnaires are contained in the Appendix D (p. 407). In February and June, Questionnaire \#I asked teachers to identify their most effective teaching and management approaches in their classroom, and Questionnaire \#2 asked teachers to respond to 
questions concerning their teaching experience, their language arts lesson plans, and their organizational support. 5. Surveys. Principal Surveys are found in Appendix F (p. 425). In June, school principals were asked to respond to three survey forms: (a) by providing the responses to four questions concerning student population and student attendance each month for each classroom identified in the study, Principal Survey \#I; (b) by providing the standardized testing results in reading and language arts for student groups identified in the study from the 1989 and 1990 testing program, Principal Survey \#2; and (c) by providing 1989 and 1990 standardized test results in the subjects of reading and larguage arts for 10 random students in each first grade class, third grade class and sixth grade class identified for the study, Principal Survey \#3. Test results for the first grade students were available for only the 1990 testing program. In summary, the test results from four, third grade classrooms and four, sixth grade classrooms totaled 80 students with recorded past standardized test results in the subject areas of language arts and reading. The test results from four, first grade classes were compared against the 1989 district and 1989 school scores. The Comprehensive Test of Basic Skills (CTBS), and the Metropolitan were administrated in the spring. Results were returned to the school in the beginning of June.

The data collected from classroom observations, teacher meeting observations, teacher questionnaires, population 
characteristic surveys, teacher interviews and principal interviews were ccmbined to develop a triangulated picture of how the code-centered approach versus the meaning-centered approach affects student performance. An overview of the data sources that guided the examination of the differences between a meaning-centered approach and a code-centered approach are demonstrated in Figure 2 .

The data gathering tools were constructed by this researcher to help me examine the eight research questions. The data gathering tools, which are appended to this proposal, were piloted with four principals and four teachers not identified for the study. This pilot study did generate changes in the collection tools. The only tool not piloted was the teacher meeting form (Appendix, A). confidentiality

One confidentiality agreement form was created by this researcher and reviewed by her dissertation committee and the San Diego University's Protection of Human Rights Committee (Appendix G, p. 430). This agreement assured all participants, principals and teachers of the confidentiality of their participation and their anonymity in this study. This form was signed by participants at the time of their first interview.

Voluntary Participation

One voluntary participation form was created by this researcher and reviewed by her dissertation committee and the San Diego University's Protection of Human Rights Committee 
Eigure 2. An overview of the data sources that guided the examination of the differences between a meaning-centered approach and a code-centered approach.

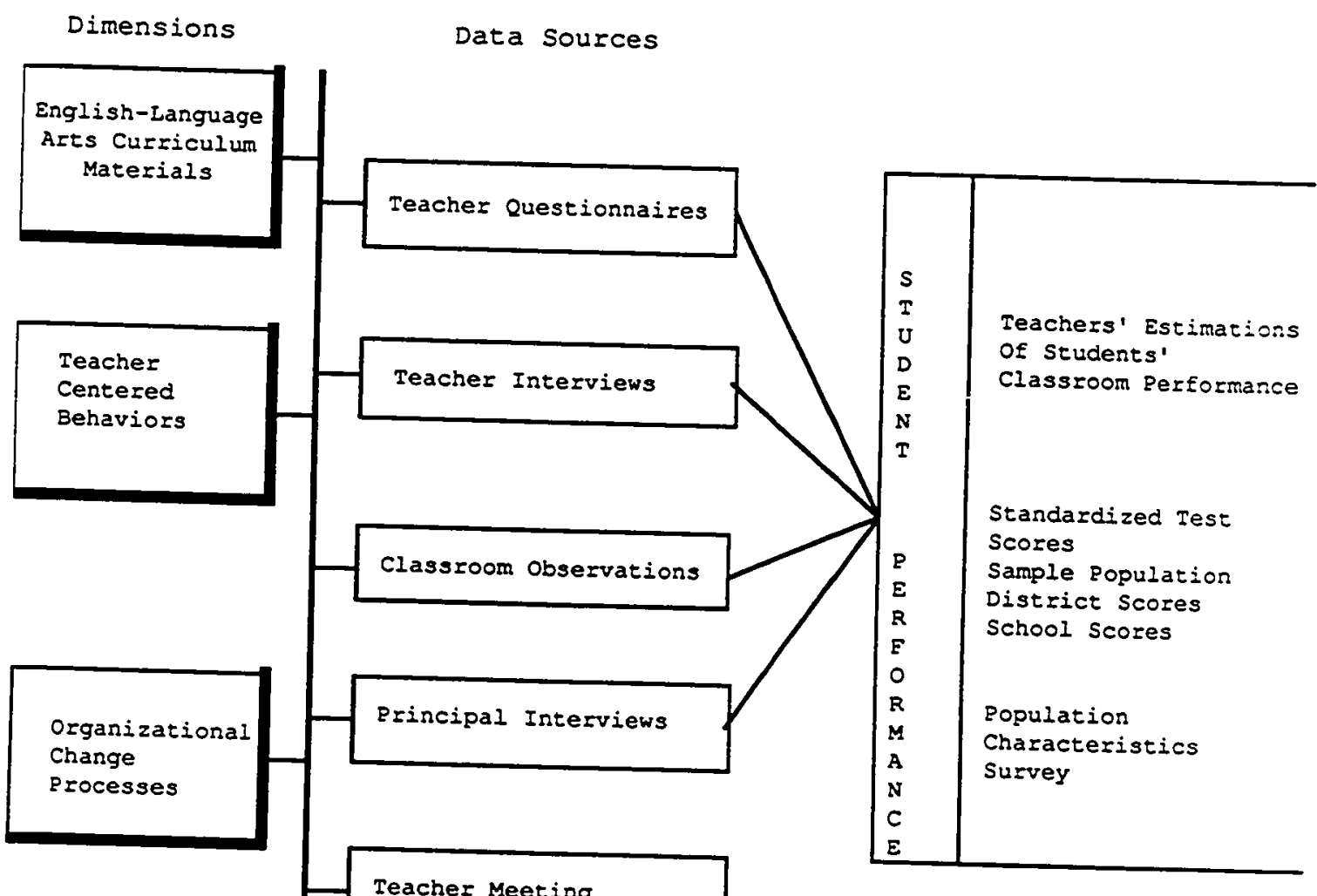

Observations 
(Appendix G). This form represented an invitation to participate in the study and was signed by all participants at the time of their first interview.

Data Analysis

Data collected were analyzed to focus on the eight questions related to how a meaning-centered approach versus a code-centered approach in the language arts curriculum affects student performance. Appendix H (p. 435) presents an overview of the eight research questions, the related instrument questions that were designed to gather information that answered the research questions, and the Tables that correspond to each question. When appropriate, responses were tabulated, percentages recorded, organized, classified and descriptive narratives of findings were written for each question.

Qualitative Analysis

A total of 17 persons were interviewed at the beginning of the study and at the end of the study from the two populations: 12 classroom teachers and five principals. Separate interview protocols were designed for each of the populations.

Interviews followed a structured format that encouraged participants to freely talk about specific topics. Additionally, all interviews were audio-recorded to provide researcher with exact statements in reply to the questions in the protocols. The interviews were conducted at the 
interviewee's convenience and usually at the location of the person's school site.

Questiennaire Analysis

A total of 12 classroom teachers were interviewed at the beginning of the study and at the end of the study. The research objective of the questionnaire was to reveal similarities and differences of educational experiences, teaching techniques, management approaches and perceptions on issues related code-centered and meaning-centered instruction, student progress and organizational support among teachers. An analysis of the questionnaire determined what the similarities and differences were between codecentered and meaning-centered approaches relating to one or more of the eight research questions.

The SPSS-X Release 3 computer program provided descriptive data in the form of percentages, frequency tabulations and mean scores, summaries of numerical data for specific items on the questionnaires, and response differences that were tabulated within populations and across populations for specific questions. A descriptive narrative further described the data displayed in the tables. observation Analysis

A total of 60 classroom observations were collected during five months of the 1989-1990 school year. The research objective of the classroom observations was to reveal similarities and differences in the level of performance of instructional management in the areas of 
discipline, feedback, time on task behavior and curriculum. An analysis of the observations determined what the similarities and differences were between code-centered and meaning-centered approaches relating to one or more of the eight research questions.

A total of 10 teacher meeting observations were collected during five months of the 1989-1990 school year. The research objective of the teacher meeting observations was to reveal similarities and differences in the level of organizational support and commitment identified by relationship building, sharing, openness, bonding and feedback. An analysis of the observations determined what the similarities and differences were between code-centered and meaning-centered approaches relating to one or more of the eight research questions.

\section{Repulation Analysis}

Data focusing on the student population characteristics, were collected from a total of 322 students during five months of the 1989-1990 school year. The research objective of the classroom population survey was to determine the percentages of low-income, low achieving, multi-ethnic and learning handicapped students identified in the research study. An analysis of the student population surveys determined what the similarities and differences were between code-centered and meaning-centered classrooms relating to one or more of the eight research questions. 
Quantitative Analysis

The Normal Curve Equivalents (NCE) standardized

achievement test scores in total reading scores and total

language arts scores were collected on a total of 120

students: (a) 40 sixth graders, two years of scores; (b) 40

third graders, two years of scores; and (c) 40 first graders,

one year of scores. Additionally, 10 total group

standardized achievement test scores in the areas of total

reading and total language arts from 1989 and 1990 were

collected; (a) 4 first grades, (b) 4 third grades, and (c) 4

sixth grades. The research objective was to reveal the

similarities and differences among student achievement

between code-centered and meaning-centered classroom approaches.

Summary

This research design provides a framework in which to examine specific qualitative and quantitative data collected from the classroom observations, teacher meeting observations, structured interviews, teacher questionnaires and principal surveys of student population characteristics designed by this researcher. The data will be explored using eight research questions to determine how a meaning-centered approach versus a code-centered approach to the teaching of language arts affects student performance in regular education classrooms containing low achieving, low-income, multi-ethnic and learning handicapped students. 
Chapter 4 will show an analysis of the data that were collected through the use of descriptive tables and narrative summaries.

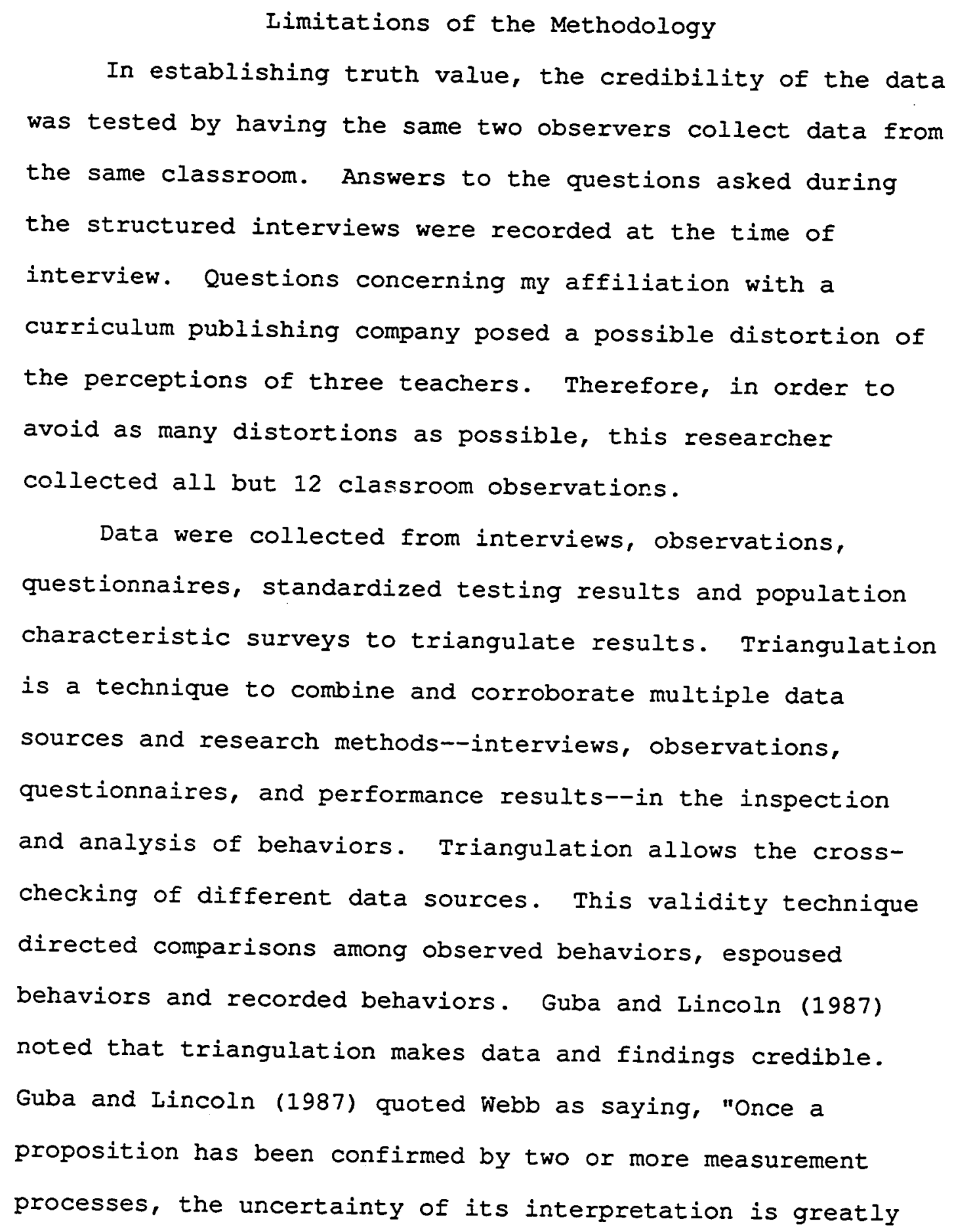


reduced. The most persuasive evidence comes through a triangulation of measurement processes. If a proposition can survive the onslaught of a series of imperfect measures, with all their relevant error, confidence should be placed in it" (p. 107).

The effect of materials, teachers behaviors and organizational processes on student performance was determined from two sources of data: (a) standardized testing, and (b) teacher estimations of student classroom performance. Teacher estimations were an evalution approach that was determined to be useful for the study of the language arts program. Although teacher estimations are not percise measurements, they are responsive to different value perspectives. These value perspectives may be subject to self-fulfilling prophecies and teacher biases.

In establishing consistency, data were gathered and analyzed from a total of 17 persons--five principals and 12 ciassroom teachers--80 random students from grade levels three and six and from a total population of 322 students in 12 classrooms: grade levels one, three and six from seven schools provided some reliability.

In order to establish the degree of neutrality, I purposely chose districts whose administrators did not request that teachers use Reading Mastery in their language arts implementation. I had no biases, motives or interests concerning the implementation process of the California English-Language Arts Framework in regular classrooms. 
CHAPTER IV

\section{ANALYSIS OF DATA}

\section{Introduction}

The purpose of this study was to determine how a meaningcentered approach (District I) versus a code-centered approach (District II) to the teaching of language arts affects student performance in a regular education classroom containing low achieving, low socio-economic, multi-ethnic and learning handicapped students. To accomplish this purpose of determining how a meaning-centered approach or a code-centered approach affects student performance during the first 1.989-1990 school year of the implementation process of the California English-Language Arts Framework, this research focused on three interrelated dimensions of organizational change which are linked to student performance: curriculum materials, teacher behaviors and organizational change processes.

Classrooms using a meaning-centered approach were represented in District $I$, and classrooms using a code-centered approach were represented in District II. The curriculum mission directed to all schools and teachers in District I was to implement the prescribed literature series which reflects the philosophy of the California English-Language Arts 
Framework in classroom instruction. The curriculum mission directed to all schools and teachers in District II was to implement the prescribed literature series, reflecting the new language arts philosophy, and to continue using the systematic skill assessment program in classroom instruction. This study examined the differences within and between organizations and among teachers and administrators who followed their mission and implemented the prescribed literature series, and the effects of this implementation on student performance. The task of the study was to examine, through the three interrelated dimensions of organizational change, how the differences between classrooms using a code-centered approach and a meaning-centered approach affect student performance. Data originated from the following seven sources: (a) pre and post structured interviews of teachers and principals; (b) observations of teacher meetings; (c) pre and post questionnaires of teachers; (d) classroom observations of teachers teaching language arts; (e) examination of pre and post standardized test scores in the subject areas of reading and language arts at grade levels one, three and six using school mean scores and district mean scores; (f) examination of pre and post standardized test scores of individual students in grades three and $\mathrm{six}$ and post standardized test scores of individual students in grade one from classrooms identified for the study in the two districts, one code-centered and one meaning-centered; and ( $g$ ) examination of population characteristics. 
The three interrelated reform dimensions, referred to in Chapter I in the section titled Purpose of the Study, precipitated eight specific research questions. The interrelated dimensions and eight questions guided the examination of both qualitative and quantitative data. Research Questions

Curriculum materials.

Dimension I which examined the differences between classrooms using meaning-centered and code-centered published language arts curriculum materials prompted research question numbered one:

1. To what degree were the published code-centered and meaning-centered language arts curriculum materials presentation recommendations followed by the classroom teacher?

Teacher centered behaviors.

Dimension II which examined the differences between teacher centered behaviors used in a meaning-centered classroom and a code-centered classroom prompted the following research questions numbered two, three, four, five and six:

2. What teacher behaviors related to the instructional management factors--control, curriculum, and societal--were performed in a code-centered and meaning-centered English Language Arts classroom?

3. What were the differences between instructional techniques used in a code-centered classroom and a meaningcentered classroom? 
4. To what extent were students able to exhibit learning strategies acquired from being taugit by teacher instructional behaviors specific to code-centered strategies and meaningcentered strategies?

5. To what extent did teacher values and perceptions guide teacher behavior in a code-centered classroom and/or a meaning-centered classroom?

6. To what degree was the classroom teacher committed to implementing and using a code-centered approach or a meaningcentered approach to teach the English language arts curriculum?

\section{Organizational processes.}

Dimension III which examined the differences between the effects that organizational processes have on teacher centered behaviors and on the intervention of the California EnglishLanguage Arts Framework in code-centered and meaning-centered classrooms prompted research question numbered seven:

7. To what degree did the organization support the changes introduced by the English-Language Arts Framework?

Student performance.

The final research question number eight interrelated the three reform dimensions, the preceding seven questions and student performance.

8. How did the differences in materials, teacher behaviors and organizational processes between classrooms using a meaning-centered approach and a code-centered approach in language arts affect student performance? 
Overview of Analysis

A range of both qualitative and quantitative techniques were used to support and describe the richest possible picture of how the code-centered approach and meaning-centered approach associated with the implementation of the California EnglishLanguage Arts Framework affected student performance. Student Populations

A total number of 322 students were observed for 38 hours during their language arts instruction. Each language arts class was observed for a total of 3 hours and 45 minutes over a five month period of time. Of the 322 students, 120 students from the 12 classes were randomly selected for individual standardized test analysis. This population represented an equal number of male and female students in each grade level, who were in attendance at the same school for two consecutive years, and who possessed complete reading and language arts test scores from the same standardized test in their cumulative record folders. The first grade students generated one standardized test score. Due to this researcher's discretionary procedures and confidentiality agreements in collecting data from cumulative folders, only three students in this population were noted to have been retained. There may have been additional students retained.

The school secretary provided the population data relating to the number of students who receive free lunches, who are in special education and who are multi-ethnic for each of the classrooms observed in this study (Appendix F, item numbers 1 , 
3 and 4). The number of students receiving free lunches was determined from the school's cafeteria list which listed each student and an identifying number: (a) number 1 indicated the number of full lunches paid for by parents, (b) number 2 indicated the number of reduced lunches paid for by parents, and (c) number 3 indicated the number of full free lunches. This study uses the number 3 count to identify the number of students in the low socio-economic population in each classroom. The ethnicity of each student was determined from five sources: (a) the parent's response to a questionnaire provided by the school district asking for the primary language spoken in the home, (b) an information card provided by each teacher on each student which indicated ethnicity, (c) the notations concerning ethnicity found in student's cumulative record folder, (d) the school's secretary record of observation, and (e) the classroom teacher's response to ethnic knowledge or observation about students. The number of students identified for special education was available from the school office records.

The classroom teacher provided the number of students who fall below the national norm in language arts and reading on the teacher questionnaire (Appendix D, item number 10). This number represents the number of low achieving students in February of 1990 school year in each of the 12 classrooms. Table 1 displays mean percentage distributions of characteristics of student population representative of low socio-economic, low achievement, multi-ethnic and learning 
Table I

Population characteristics of Representative Students by Grade Ievel (Feb. 19901

\begin{tabular}{|c|c|c|c|c|}
\hline \multirow[b]{2}{*}{ Characteristics } & \multicolumn{4}{|c|}{ Percent of sample } \\
\hline & Grade 1 & Grade 3 & Grade 6 & Mean Total \\
\hline & \multicolumn{4}{|c|}{ District IC } \\
\hline Low socio-economic & 39.0 & 12.0 & 47.0 & 33.0 \\
\hline Low achievementa & 22.5 & 32.5 & 32.5 & 29.0 \\
\hline Multi-ethnic & 51.0 & 32.0 & 45.0 & 43.0 \\
\hline \multirow[t]{2}{*}{ Iearning handicapped } & 7.0 & 7.0 & 7.0 & 7.0 \\
\hline & \multicolumn{4}{|c|}{ District IId } \\
\hline Low socio-economic & 59.0 & 59.0 & 59.0 & 59.0 \\
\hline Low achievementb & 32.5 & 32.5 & 22.5 & 29.0 \\
\hline Multi-ethnic & 83.0 & 86.0 & 78.0 & 82.0 \\
\hline Learning handicapped & 25.0 & - & - & 8.0 \\
\hline
\end{tabular}

Note. The values represent mean percentages of student population.

a, bihe percent of low achievement students in a a given class was

estimated by the teachers' response to the following question: "What

percentage of the students in your language arts class would you identify

who fall below the national norm in language arts and reading?

CThe total students per grade level for District I were as follows: (a)

Grade 1, 61; (b) Grade 3, 49; (c) Grade 6, 58; and (d) total sample, 168.

dThe total students per grade level for District II was as follows: (a)

Grade 1, 58; (b) Grade 3, 57; (c) Grade 6, 39; and (d) total sample, 154. 
handicapped. Table 1 reports that the mean number of learning handicapped and low performing students were represented equally in classrooms in both districts. Classrooms in District II contained almost two times as many multi-ethnic and low socio-economic students as classrooms in District $I$. Teachers are required to apply instructional intents that address the weaknesses in reading and language performance to these high percentages of low socio-economic and multi-ethnic students. Waiting for reading and language difficulties to correct themselves may lead to even greater problems. An unattended lag of six months may develop into greater lags of two or more years later. Specific instructional intents that address low-income children are to: (a) nourish strong home and school environments, (b) provide opportunities to read different genre of literary works accompanied by instruction, (c) provide structured, direct and challenging learning activities that address reading, writing, listening and speaking, (d) assess the learning progress regularly and address the weak areas as soon as identified, (e) provide the instruction necessary for students to make the literate transition to more mature reading at third through sixth grades, (f) communicate high expectations for student learning and ( $g$ ) develop and nourish students' feelings of success with reading and language arts.

Instructional intents that address the weaknesses of multi-ethnic students are to: (a) exhibit multi modality approaches to teaching, (b) exhibit clear communication skills 
by explaining, outlining, demonstrating and modeling, (c) nourish strong home and school environments, (d) pace instruction and communicate expectations for student success in competing instructional tasks, (e) provide immediate feedback and monitor student progress, (f) provide structured academic skill development, ( $g$ ) respond to home cultures, values and norms, (h) communicate high expectations for student learning, and (i) develop and nourish students' feelings of success with reading and language arts.

Interview Ropulations

A total of seventeen persons accepted the invitation to be interviewed twice, once at the beginning of the study and again at the end of the study. These populations included six classroom teachers and two principals in District 1 and six classroom teachers and three principals in District II. A total of twelve teachers were interviewed: two teachers at first, third and sixth grade levels in both districts. The twelve teachers were represented in a total of seven schools. Five of the seven principals accepted the invitation to be interviewed. The remaining two principals who graciously volunteered their school for this study elected not to be interviewed for unknown reasons.

Tables two and three display two configurations of distributions of the interview populations: (a) Table 2 displays the years of teaching experience and grade level distributions, and (b) Table 3 details the years of principalship. During the interview, teachers and principals 
were asked about their number of years of experience (Appendix D, item numbers 1 and 2, and Appendix B, items $A$ and $B$ ). Table 2 reflects that first and third grade teachers in District II have five years more teaching experience in language arts than teachers in District $I$. Sixth grade teachers in District I have three years more experience in language arts than teachers in District II. Teachers with more years of experience have had more time to confront basic assumptions about the process of teaching and these assumptions

Table 2

Years of Teaching Experience of Teacher Population by Grade Level

\begin{tabular}{lcccc}
\hline & \multicolumn{5}{c}{ Mean no. of years } \\
\cline { 2 - 5 } Experience & Grade I & Grade 3 & Grade 6 & Total average \\
\hline & 9 & District I & 9.0 \\
Total years & 9 & 3 & 15 & 9.0 \\
Language arts & 9 & 3 & 15 & 14.0 \\
\hline Total years & 14 & District II & 11 & 11.0 \\
Language arts & 14 & 16 & 12 & \\
\hline
\end{tabular}

Note, $\mathrm{n}=12$ teachers.

Sample size in each grade level is two teachers. 
often serve as a guide for dealing with new experiences and uncertainty.

Teachers who have more classroom experience are generally able to develop a greater repertory of teacher behaviors that have dropped out of consciousness. Therefore, they are able to draw on new behaviors to be tested while continuing to maintain successful behaviors.

Teachers with less experience are still testing a greater number of solutions so as to get the desired result which is increased student performance. If the selected action yields desired results, then it follows that the action was successful and will be repeated.

Table 3 reflects a range of principalship experience among the five principals who participated in the study. Principals

Table 3

Years of Principalship Experience by District

\begin{tabular}{lcc}
\hline & \multicolumn{3}{c}{ Mean no. of years } \\
\cline { 2 - 4 } Experience & District I $(2)$ a & District II (3)b \\
\hline Total years & 6 & 20 \\
Years at school & 6 & 3 \\
in study & & \\
\hline
\end{tabular}

Note, $n=5$ principals.

$a, b$ The number in parenthesis represents the number of principals interviewed in sample. 
in District II reported more principalship experience; however, principals in District I have been with their community and teachers longer than principals in District II. District I principals have been with their one school throughout their years of principalship experience. District I principals have had more time to build and develop an environment that could be ready to accept change. In this environment, collaborative support could lead organizational members to commitment to the language arts implementation.

Analysis Process

As noted in Chapter III, research questions are answered primarily through the analysis of questionnaires, interviews, observations and standardized test examinations. This researcher grouped specific questions to analyze from the questionnaires, interviews, and observations. These specific questions were selected to analyze information for each of the eight research questions which centered around the differences between classrooms using a meaning-centered approach (District I) and a code-centered approach (District II).

Qualitative data collected from the structured interviews, questionnaires, classroom observations, teacher meeting observations and population examinations (Appendixes A, B, C, $D, E$ and F), and designed by this researcher provide the number and frequency of responses within and across grade levels. The interviews and questionnaires encouraged participants to respond to selected questions outside the structure of the interview and questionnaire. When data are used for an 


\begin{abstract}
analysis, tables frequently display information that provides a synthesis of the participants' responses. A narrative summary accompanies and expands upon each table. When a table is not an appropriate way to present data, a narrative summary provides the data analysis.

Quantitative data collected from the school districts' standardized test scores reveal commonalties and differences of student performance issues not apparent through the questionnaires, interviews and classroom observations. When data are used for an analysis, tables with descriptive statistics frequently display the number of responses and percentages of responses within and across populations and grade levels. A narrative summary accompanies each table and expands upon the data. Appendixes at the conclusion of this study display copies of all of the interview protocols, questionnaires, observation instruments, population and testing examination instruments that were used in this study.
\end{abstract}

\author{
Research Question One \\ To What Degree Were the Published \\ Code-Centered and Meaning-Centered Language Arts \\ Curriculum Materials Presentation Recommendations \\ Followed by the Classroom Teacher?
}

This research question focuses on the manageability of the curriculum program materials that address and support the 
English-Language Arts Framework. The contents and manageability of textbook programs and related instructional materials influence the information that teachers teach and the information that students practice. Meaning-centered materials encourage students to take an active role in their learning, to share ideas, ask questions, write, and read great literature. Code-centered materials emphasize a mastery of skills supporting accuracy and fluency. The responsibility for student learning is on the teacher. One goal for implementing a new literature program that supports The California EnglishLanguage Arts Framework is to create a program that is manageable, with comprehensible day-to-day details for classroom instruction, a program that integrates materials that are similar to current practices for the teacher and a program that increases student performance. This question explores how closely the presentation recommendations of the published materials used were followed by the classroom teachers. To analyze this question, two pieces of data are used, originating from the post teacher interview (Appendix $C$, item number 2). Teachers interviewed were asked to give two responses to the question: "How closely do you follow the English-Language Arts program presentation requirements in your class instruction?" The respondent answered by commenting on the question and marking on a scale of $1-10,1$ is low and 10 is high.

Tables 4 and 5 present an analysis of the information contained in this question and display distributions of the 
interview populations. Table 4 details the frequency rating of how closely the respondents followed the presentation requirements of the prescribed program in class instruction at the end of the study in District I and District II.

Table 4 reports that teachers in the code-centered

Table 4

Adberence to Prescribed Language Arts Curriculum Recommendations by Grade Level.

\begin{tabular}{|c|c|c|c|c|c|c|}
\hline \multirow[b]{2}{*}{ Grade } & & \multicolumn{5}{|c|}{ Scale of adherence } \\
\hline & & $\begin{array}{l}\text { high } \\
(10-9)\end{array}$ & $(8-7)$ & $(6-5)$ & $(4-3)$ & $\begin{array}{l}\text { low } \\
(2-1)\end{array}$ \\
\hline & & \multicolumn{5}{|c|}{ District I } \\
\hline Grade 1 & $1(2)^{a}$ & - & 1 & 1 & - & - \\
\hline Grade & 3 (2) & 1 & - & 1 & - & - \\
\hline \multirow[t]{3}{*}{ Grade } & $6(2)$ & - & 2 & - & - & - \\
\hline & Total & 1 & 3 & 2 & 0 & 0 \\
\hline & & \multicolumn{5}{|c|}{ District II } \\
\hline Grade & 1 (2) & - & 2 & - & - & - \\
\hline Grade & $3(2)$ & 2 & - & - & - & - \\
\hline \multirow[t]{2}{*}{ Grade } & 6 (2) & - & 2 & - & - & - \\
\hline & Total & 2 & 4 & 0 & 0 & 0 \\
\hline
\end{tabular}

Note, a Sample size in grade level. 
classrooms (District II) followed the prescribed language arts program more closely than teachers in the meaning-centered classrooms (District I) reflected on a scale 7-8 or 9-10. Only two teachers in the meaning-centered classrooms followed the prescribed recommendations on a 5-6 scale.

It appears that a sense of stability gained with successful experiences in the classroom was not transferred to the new prescribed program. Referring to Table 2, it is noted that teachers with the least experience in language arts followed the program more closely than those teachers with more experience, indicated on the 9-10 scale. All twelve teachers in this study were willing to try the new approach. However, since teaching knowledge is learned through a series of trails and errors, it is apparent that the more experienced teachers continued to use materials that they knew to be successful with their students.

Teacher comments about Prescribed Curriculum Materials

"In spite of the fact, it's jammed pack full of ideas, it still follows a routine. After a few weeks of the routine, you have to find new ways to have kids summarize the story. You have to constantly keep the old imagination going to make it interesting."

This comment by a teacher in District II reflects how the translation of the program requirements into instruction continues to be the responsibility of the classroom teacher.

One of the teachers in District I who follows the program closely stated, "It's a pain to do the preparation." This 
comment reflects a concern about the amount of time that must be taken to prepare lessons for class instruction with the new prescribed program.

Table 5 reports the comments given by the respondents that address the question about following the prescribed program requirements. These responses correspond to the scaled frequency of how closely the program requirements are followed. Six comments made about following the prescribed language arts program were repeated more than once by teachers from both districts. From a total of 15 comments reported, three of the comments, stated eight times, shared that the prescribed program was supported with additional activities selected by

Table 5

comments About Prescribed Language Arts Curriculum

You have to pick and choose from the activities. 2

I like the program a lot. I think it's good. 3

I need to lean on it, it's new to me. 2

I do some of my own things. 3

I wasn't clear about how to use the program. 2

I use a more structured program with some of my kids. 3

Total 15

Note. $\underline{\mathrm{n}}=12$ teachers 
the classroom teacher. With the exception of the second comment, responses reflected that teachers are not secure with the new program. Teachers in both districts noted that the new prescribed prograr. requires teacher preparation, teacher translation into instruction and teacher selection of materials for additional support.

Summary: To what degree were the published code-centered and meaning-centered language arts curriculum materials

presentation recommendations followed by the classroom teacher?

This summary reflects those aspects in the data that provide insight into whether or not teachers find the language arts curriculum materials manageable, comprehensible and effective in classroom instruction.

Table 5 indicates that teachers in both districts find the curriculum materials somewhat difficult to manage and to understand. The comments indicate that teachers are not secure with the new program. Teachers in both districts have indicated that the new prescribed program requires that teachers prepare lessons, translate suggestions into instruction and select additional materials to support the program. Table 4 reports that only two teachers in District II and one teacher in District I followed the prescribed program closely. Referring to Table 2, these three teachers had the least number of years of teaching experience in the subject of language arts than the number of years of the remaining nine teachers. Teachers with 12 years of experience and more 
followed the recommendations closely. In spite of the comments teachers made about the prescribed program or what they believed, they appeared to follow the program recommendations closely.

The effectiveness of the prescribed materials in classroom instruction was not validated during teacher interviews. One teacher from each district indicated that they liked the program "a lot." One teacher wasn't sure. It appeared that all respondents liked teaching with the prescribed program. However, teacher comments appeared to indicate an uncertainty about the effectiveness of the program and a reluctance to express feelings of excitement about the effectiveness of the program with student performance. Perceptions of the success of the prescribed program was not formed.

\section{Research Question Two}

What Teacher Behaviors Related to the Instructional Management Factors--Control, Curriculum, and Societal-Were Performed in a Code-Centered and Meaning-Centered English Language Arts Classroom?

\footnotetext{
This research question concentrates on three areas of classroom management: (a) control--examples are teacher behaviors that relate to discipline, positive reinforcement, student feedback, and time on task variables; (b) curriculum-examples are design of lesson presentation, organization of
} 
guided classroom practice, and practice of corrective feedback; and (c) societal--examples are teacher behaviors that address individual differences among low-achieving, multi-ethnic, low socio-economic, and learning disabled students. A successful program requires that teachers create harmony with the language arts curriculum materials and with factors related to classroom management. The demands to involve and promote learning among students with individual differences require that teachers be knowledgeable, sensitive and flexible in their classroom management behaviors. Classroom management behaviors form a framework for classroom instruction and promote effective classroom instruction, student learning and student performance.

This question explores the differences between instructional management behaviors used in a code-centered classroom and a meaning-centered classroom during the first year of the English-Language Arts Framework implementation. To analyze this question, 28 pieces of data are used originating from the pre and post teacher interview, pre and post teacher questionnaire, and classroom observations.

Tables 6 through 12 present an analysis of the observation and questionnaire information for this research question: (a) Table 6 displays distributions of instructional management behaviors of the observed teacher populations, (b) Table 7 describes time on task factors through observed student behaviors, (c) Table 8 displays information about the percentage of time teachers were observed giving positive 
reinforcement to students during instruction, (d) Tables 9, 10, and 11 report the number of assessment strategies that classroom teachers indicated they use during one week of classroom instruction, and (e) Table 12 displays the instructional management factors that teachers reported to be effective in their classroom instruction. classroom Observations of Instructional Management Factors

Tables 6 through 8 detail the observations related to control, societal groups and curriculum. Language arts lessons were observed for a total of 45 hours during the duration of this research study. The teachers were aware of the time of each scheduled observation. They were given an observation schedule at the beginning of the study; therefore, they knew the instructional factors that were observed during their classroom instruction (Appendix E, teacher observation, item numbers $1,2,3,4,5,6,7,10,12,13$ and 15). A definition of each behavior to be observed was provided for the observer (Appendix E, observation explanation, item numbers 1, 2, 3, 4, $5,6,7,10,12,13$ and 15). The 60 classroom observations generated instructional management information that addressed the differences in teacher behaviors between code-centered (District II) approaches and meaning-centered (District I) approaches. Specific behaviors that were observed are the following: (a) control, that is teacher behaviors related to discipline, positive reinforcement, and time on task variables; (b) curriculum, that is a lesson presentation that involves sharing ideas and cooperative learning; and (c) societal 
groups, that is teacher behaviors that address individual differences among low-achieving, multi-ethnic, low socioeconomic, and learning disabled students. The observers recorded teacher behaviors using three possible responses:

not yet performed, (b) performed at a satisfactory level, and (c) performed at a high and exemplary level.

Table 6 reflects the frequency of the teacher behaviors observed that related to instructional management and how consistently these behaviors continued to be observed during the months of this study in District I and District II. Discussion of the instructional management behaviors reflected in Table 6 follows the sequence of the behaviors displayed in Table 6 which address control, curriculum and societal group behaviors. In this study, the identified instructional management behaviors are considered to be effective behaviors for all grade levels. Therefore, the similarities and differences are noted between districts and not between grade levels.

Teachers in both districts were observed to perform control behaviors at an exemplary and satisfactory level. Table 6 reports that three of the four instructional management factors related to control--arrangement of furniture, posted goals and objectives and teacher preparation--were performed satisfactorily and exemplary in both districts during the 30 observations in each district: $100 \%$ in District I and $98 \%$ in District II (the number of satisfactory and exemplary observations for the three control factors in each district 
divided by 30 possible observations for each of the three factors). Display of student work occurred satisfactorily and

Table 6

Teacher Behaviors That Reflect Instructional Management by Ievels of Rerformance

\begin{tabular}{|c|c|c|c|c|c|c|}
\hline \multirow[b]{3}{*}{ Behaviors } & \multicolumn{6}{|c|}{ No. of observed performancesa } \\
\hline & \multicolumn{3}{|c|}{ District I $(n=6)$} & \multirow{2}{*}{\multicolumn{2}{|c|}{$\begin{array}{l}\text { District II (n } \\
\text { Not } \\
\text { Performed Satisfactory }\end{array}$}} & \multirow{2}{*}{$\begin{array}{l}2=61 \\
\text { Exemplary }\end{array}$} \\
\hline & $\begin{array}{l}\text { Not } \\
\text { Performed }\end{array}$ & \multirow{2}{*}{$\frac{\text { Satisfactory }}{7}$} & \multirow{2}{*}{$\frac{\text { Exemplary }}{23}$} & & & \\
\hline $\begin{array}{l}\text { Arrangement of } \\
\text { furniture }\end{array}$ & - & & & - & 9 & 21 \\
\hline $\begin{array}{l}\text { Posted goals } \\
\text { and objectives }\end{array}$ & - & 6 & 24 & 2 & 10 & 18 \\
\hline $\begin{array}{l}\text { Display of } \\
\text { student work }\end{array}$ & 4 & 10 & 16 & 3 & 15 & 12 \\
\hline $\begin{array}{l}\text { Teacher } \\
\text { preparation }\end{array}$ & - & 22 & 8 & - & 2 & 28 \\
\hline Ideas are shared & 8 & 3 & 19 & 9 & 1 & 20 \\
\hline $\begin{array}{l}\text { Cooperative } \\
\text { groups }\end{array}$ & 27 & - & 3 & 19 & 1 & 10 \\
\hline $\begin{array}{l}\text { Recognition of } \\
\text { cultures }\end{array}$ & 24 & 2 & 4 & 23 & 3 & 4 \\
\hline $\begin{array}{l}\text { Multimodal } \\
\text { application }\end{array}$ & 2 & 15 & 13 & 4 & 12 & 14 \\
\hline Total & 65 & 45 & 130 & 60 & 53 & 127 \\
\hline
\end{tabular}

Note. aFive observations with six teachers in each district equals 30 classroom observations for a total of 60 observations in both districts. 
exemplary in both districts: $87 \%$ in District I and $90 \%$ in District II.

The arrangement of classroom furniture and teacher preparedness for a lesson presentation were two control factors that were performed the most consistently among the four factors listed in Table 6 by teachers in both districts. Teachers in District II appeared to be prepared more often for class instruction than teachers were prepared in District I.

The practice of posting goals and objectives was observed in all twelve classrooms. It was apparent that all teachers practiced assertive discipline procedures. Three charts were posted: (a) one listing the school rules, (b) one reflecting classroom rules, and (c) one detailing the consequences for broken rules. However, teachers used various systems to manage and reinforce the control program: (a) tickets were passed out for appropriate behavior and used to select items from a treasure box; (b) happy and sad faces were hung under the names of students, (c) names were marked on the chalk board under happy or sad faces, and (d) the frequent use of positive verbal reinforcement. Two teachers taped the class rules to each desk. The awards that were given for good behavior reinforced students for their efforts and focused on improving their selfconcept. Posting goals and objectives, as one factor of control, allows a safe, accepting and educational environment to support effective instruction.

The display of student work was observed to be satisfactory almost as often as exemplary in classrooms in both 
districts. A classification of satisfactory indicated that the display of student work was not changed often, so that new accomplishments of students could be reflected or the colorful display of posters and maps took the place of displaying student work. The four observations in District $I$ and the three observations in District II indicate that the display of colorful posters and maps took the place of student work. There were many variations in the display of student work among the classrooms. Iimited display space was not reflected in the recording of the observations. However, most of the display space was used for posters, progress charts and behavior charts. It appeared that work displayed from all students in the class was occasional. Additionally, classrooms did not reflect an integrated, one theme environment suggested by the language arts philosophy. The purpose of displaying student work is to show that there is an interest in his or her work, that his or her work is appreciated, and the work is worthy of the time and effort to display it for others to share. Displaying student work builds and improves self-image which is a primary target for teachers before effective instruction can take place.

Factors related to curriculum--sharing ideas and cooperative learning--were performed satisfactorily and exemplary during $42 \%$ of the observations in District I and during $53 \%$ of the observations in District II. Opportunities for students to express themselves, formulate, discuss and share ideas with each other were limited in both districts, but 
occurred slightly more often in District II than District I. Students were not observed taking an active role in their learning during $58 \%$ of the observations in District $I$ and $47 \%$ of the observations in District II (percentages were computed by adding the number of times that sharing ideas and cooperative group activities were not performed, then dividing the total by 60 possible observations). Talking, listening, sharing, discussing and reflecting about what students think about a piece of literature helps them develop positive attitudes toward learning and understandings about cultural and ethnic relations.

Management factors related to societal considerations-recognition of cultures and multimodal applications--appeared to be disproportionally performed by teachers in both districts. That is, considerations that addressed individual differences in the recognition of cultures were performed satisfactorily and exemplary during only $20 \%$ of the observations in District I and only 23\% of the observations in District II. However, multimodal applications were performed during $93 \%$ of the observations in District $I$ and $87 \%$ of the observations in District II.

Opportunities for students to recognize ethnic differences, minority languages and other cultures through language arts activities and assignments were very limited in both districts. The subject and/or the purpose of the lesson that was taught or the story that was read was recorded by the observer on each of the 60 observations. Only two stories that 
were read to a class during the observations, remotely addressed cultural differences. It appeared that activities and assignments that addressed minority languages and cultures were not integrated into the instruction nor were they addressed through the prescribed literature selection or the literature selected by the teacher to share with the class. Opportunities for cooperative learning, sharing ideas about cultural differences and frequent literature references to cultural differences that support and reinforce self-esteem, friendship and language acquisition were seldom observed in classrooms in both districts.

Table 7 describes the observed performance of students assigned to language arts activities. The following performances were observed: (a) the actual engaged time students were involved in specific tasks in an academic atmosphere; (b) the student's success rate in learning while engaging in assigned task by receiving feedback from teacher, peers, discussion, consultations, reading aloud or selfcorrection; and (c) the student's disruptive behaviors exhibited when taking a break from the classroom assignment. During the 45 minutes of classroom observations, seven random students were observed for 15 minutes exhibiting their time on task behaviors. Students exhibited on-task learning behaviors satisfactory and exemplary equally in both districts during observations: $83 \%$ in District II and $82 \%$ in District I.

Table 7 notes that students did not exhibit disruptive behaviors during independent, structured practice during $93 \%$ of 
the observed time in District $I$ and $87 \%$ of the observed time in District II. Disruptive behaviors were defined as talking to neighbors, pencil tapping, note passing, playing with objects and/or taking a break from assignments. Therefore, participating satisfactorily or exemplary during the time allowed for structured practice, following the explanation and modeling of the concept or lesson, means that students did not take a break from their assignments to talk, tap pencils, pass notes or play with objects more than five minutes of their scheduled independent practice activity time. Students in first and sixth grades appeared to exhibit disruptive behaviors more often than did students in third grade classes in both districts. If disruptions were observed to be minimal, that is the disruptions occurred less than five minutes, then the observation was marked satisfactory or exemplary. Satisfactory and exemplary marks reflected that students were held accountable and were involved in specific tasks in an academic atmosphere.

The weakest area of the time-on-task performance in both districts was the student's success rate in learning while completing an assignment. Students were observed receiving feedback from an adult, from participating in self-correction or from participation with peers satisfactorily or exemplary during only $60 \%$ of the observed time in District I and $70 \%$ of the time in District II (percentage was computed by adding success rate observations in each district and dividing by the 
Table 7

Student Time on Task Behaviors by Leveis of Performance and observed Student Behaviors

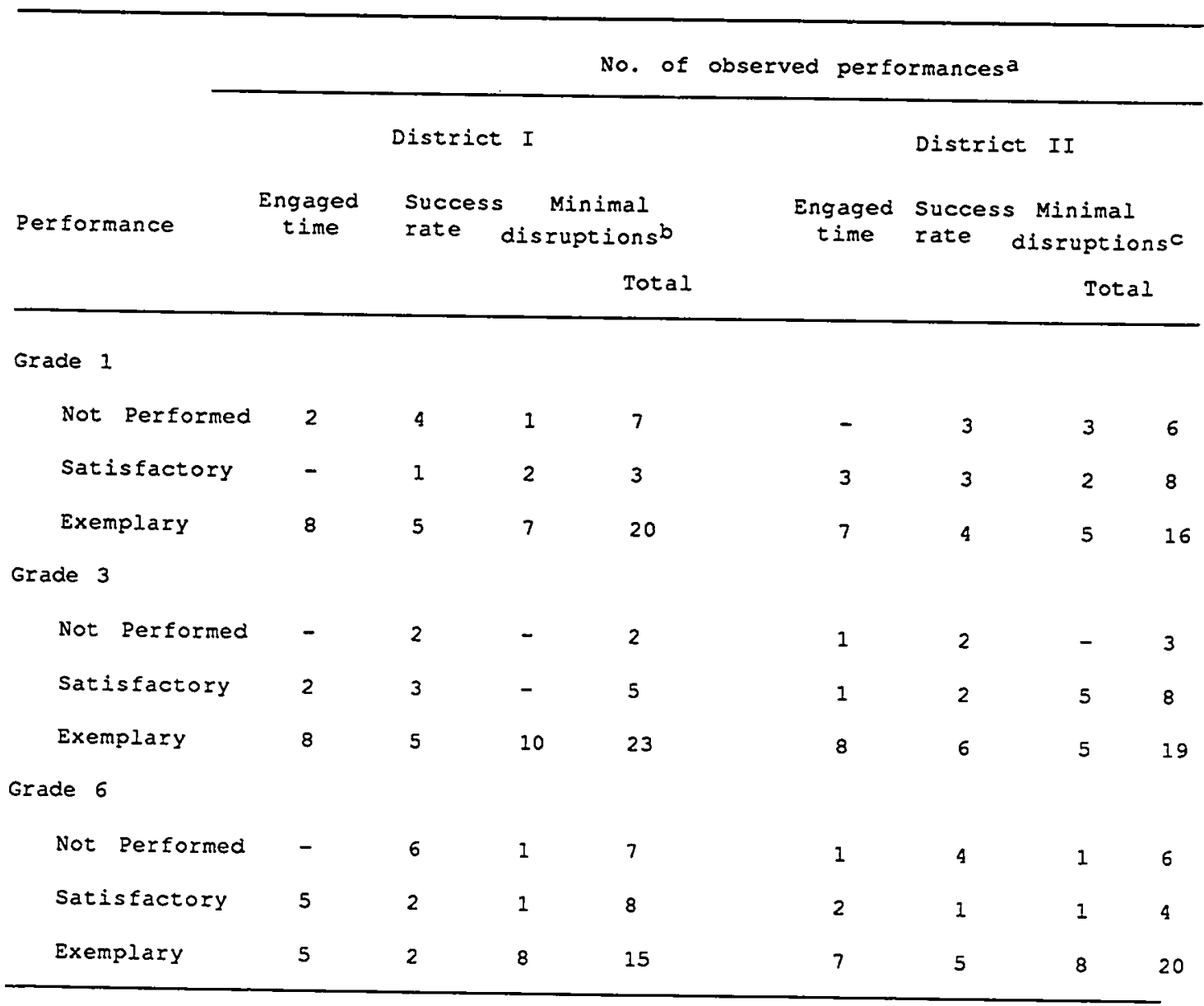

Nete. A minimum of 84 random students were observed at least once, and a maximum of 322 students may have been observed.

$a_{1}=$ seven random students were observed in each classroom, with two classrooms per grade level.

b, cMinimal disruptions not performed means that students were observed exhibiting disruptive behaviors during the scheduled time for independent practice for a duration of more than five minutes during 15 minutes of classroom observation. 
number of possible observations which was 30 in each district: 18 divided by 30 equals $60 \%$ in District I). One example of exemplary feedback was observed in District II in an active, multi-ethnic sixth grade class. The teacher moved from group to group throughout the independent activity asking questions, supporting, reinforcing and encouraging success among students. This component of the time-on-task performance is most closely related to learning and building self-concept. During this time teachers and/or peers have the opportunity to be supportive and provide personal and frequent help. Additionally, students can be encouraged to complete the activity with the least amount of mistakes that would otherwise have to be corrected at another time with more difficulty. During the observations, students who were writing, drawing, composing a poem or completing another assignment generally received limited supportive and corrective feedback.

Table 8 (Appendix $E$, item number 8 ) reflects the frequency in which teachers were observed giving positive and negative reinforcement to students during class instruction. Reinforcement is a stimulus, verbal remark, token or body language that follows a behavior and causes that behavior to happen more often. Reinforcement communicates teachers' expectations for students' success in completing instructional tasks. Positive reinforcement fosters positive feelings, develops intrinsic and extrinsic motivations and is used to teach new skills. During the 45 minutes of each classroom observation, 10 minutes were used for recording verbal 
responses that reflected positive and negative reinforcement (Appendix E, item number 8). Tally marks, recorded by the observer, indicated the number of times within two five minute periods of time that teacher reinforcement was seen or heard being given to students.

Table 8 indicates that there is more than a one-to-one ratio of positive to negative interactions that were reccrded during 10 hours of classroom observations in both districts. There is nearly two-to-one ratio of positive to negative interactions in the third and sixth grade language arts classes represented in District II. The students in the sixth grade classes in District I displayed more than a two-to-one ratio of positive to negative interactions. Students in the third grade

Table 8

Positive to Negative Interactions Between Students and Teachers by Reinfercement and Grade Ievel

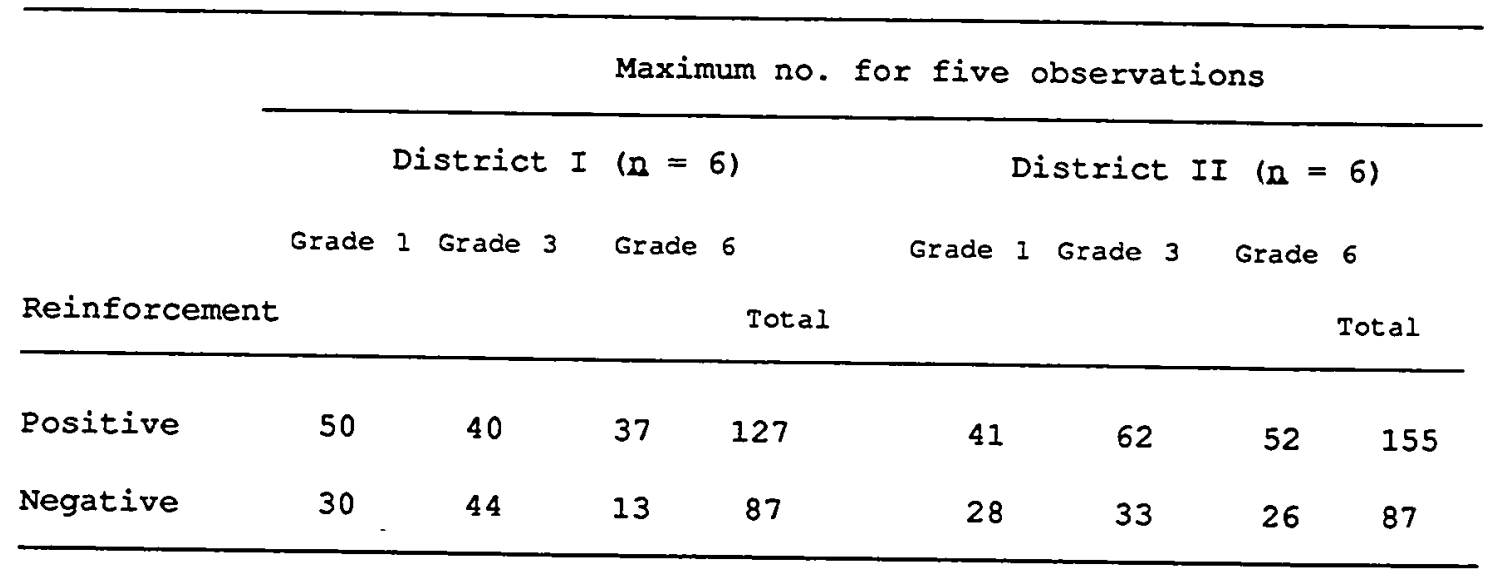


classrooms in District I received more negative than positive interactions from their teachers.

Sprick (1981) noted that, "The key factor to examine is the ratio of times spent attending to positive behavior versus times spent attending to negative behavior in a classroom" ( $p$. 2). The significance of reporting student and teacher interactions by ratio is that past research indicated that a one-to-three ratio of positive to negative interactions was unfortunately the norm in an average classroom. Before 1981, more attention was given to the negative than the positive interactions, thus setting an environment for self-image problems resulting in possible behavior problems. Ideally, students should receive at least three positive interactions with their teacher for every negative interaction (Sprick, 1981).

A student's ability to learn is directly related to the way the teacher interacts with him or her. The nearly twoto-one ratio of positive to negative interactions in language arts classes represented in third and sixth grade classrooms in District II and one sixth grade class in District I set a positive tone in the classroom. These teachers have more classroom experience than teachers who were observed to practice a little more than a one-to-one ratio of positive to negative interactions. Through a series of trials and errors and the awareness of research based teaching practices, the more experienced teachers appeared to exhibit habits that 
attended to positive interactions that reinforced and/or encouraged student behaviors.

A goal of maintaining positive and supportive behavior at least three times as often as attending to negative behavior should be set to address the self-concept of students and to set a more positive interaction cycle in classrooms. In a more positive environment more learning results, and students learn to follow a more positive model of interactions among themselves.

\section{Classroom Assessment Practices}

Tables 9, 10 and 11 present the number of times per week that teachers give student feedback regarding students' academic performance in first, third and sixth grade (Appendix D, item number 6). Feedback recognizes and reinforces the students' academic efforts and provides instructional direction for the teacher. Frequent assessment of both formal and informal performances, reflects the purposes of classroom instruction and creates an environment in which students can succeed. Formal performance assessment strategies are represented by criterion referenced tests, academic progress on skills, letter grades, and written essay tests. Informal assessment strategies are individual consultations, scoring of writing samples, oral presentations, portfolio consultations, and other methods. Reading, writing and oral language inform and support one another. An exemplary assessment practice would be to daily assess reading, writing and oral language processes. Teachers were asked to indicate on the post 
questionnaire the number of times during a week they give student feedback (Appendix D). A variety of nine choices were displayed. Six choices reflected meaning-centered approaches and were suggested by the California State Board of Education: (a) individual consultations, (b) written essay tests, (c) scoring writing samples, (c) oral presentations, (d) criterion referenced tests, and (e) portfolio consultations. Five choices reflected code-centered approaches: (a) individual consultations, (b) written essay tests, (c) scoring writing samples, (c) criterion referenced tests, and (d) academic progress on skills. The teachers answered this question by marking one of the four possible choices: (a) (0-1) times per week, (b) (2-3) times per week, (c) (4-5) times per week, and (d) (>5) times per week.

Table 9 reports that first grade teachers in the codecentered classrooms appear to use a greater variety of assessment strategies than teachers in meaning-centered classrooms. Teachers in District II indicated that they use formal performance assessments, that is, criterion referenced tests, written essay tests and academic progress on skills more often than District I. First grade teachers in District II appeared to assess the progress of their students toward objectives more frequently than teachers in District I. First grade teachers from both districts used informal assessments, that is portfolio consultations, individual consultations and oral presentations. However, District II teachers appeared to 
Table 9

Assessment Strategies Used by Teachers Each Week in Grade one

\begin{tabular}{|c|c|c|c|c|c|c|c|c|c|}
\hline \multirow[b]{2}{*}{ Strategies } & \multicolumn{9}{|c|}{ Frequency per week } \\
\hline & \multicolumn{2}{|c|}{ District } & $\begin{array}{l}I \quad(n)= \\
(4-5)\end{array}$ & $\begin{array}{l}\text { 2) } \\
(>5)\end{array}$ & Grade & \multicolumn{2}{|c|}{ District } & $\begin{array}{l}\text { II }(n) \\
(4-5)\end{array}$ & $\begin{array}{l}=2) \\
(>5)\end{array}$ \\
\hline $\begin{array}{l}\text { Individual } \\
\text { consultations }\end{array}$ & 1 & - & 1 & - & & - & 1 & 1 & - \\
\hline Written essay tests & 2 & - & - & - & & 1 & 1 & - & - \\
\hline $\begin{array}{l}\text { Scoring writing } \\
\text { samples }\end{array}$ & 2 & - & - & - & & 1 & - & 1 & - \\
\hline Oral presentations & 1 & 1 & - & - & & - & 2 & - & - \\
\hline $\begin{array}{l}\text { Criterion } \\
\text { referenced tests }\end{array}$ & 2 & - & - & - & & 1 & 1 & - & - \\
\hline $\begin{array}{l}\text { Academic progress } \\
\text { on skills }\end{array}$ & 2 & - & - & - & & - & 1 & 1 & - \\
\hline Letter grades & 1 & - & 1 & - & & 1 & - & - & 1 \\
\hline $\begin{array}{l}\text { Portfolio } \\
\text { consultations }\end{array}$ & 1 & - & 1 & - & & - & 1 & 1 & - \\
\hline Other methods & 1 & - & - & - & & - & - & - & 1 \\
\hline Totala & 13 & 1 & 3 & 0 & & 5 & 7 & 3 & 2 \\
\hline
\end{tabular}

Note. The number of times assessment strategies were used each week was reported by two teachers in each grade level on the post questionnaire. aThe total numbers represent an overview of the weekly frequency of assessments for each district. 
informally assess the progress of their students almost daily which is a goal for good assessment practices. Code-centered teachers assessed writing almost every day. This emphasis on students' meaning by recognizing and reinforcing the students' academic writing provided students with the environment to connect ideas, comprehend a subject, test their reasoning, articulate insights, think and read. First grade teachers in code-centered classrooms appeared to reflect the purposes of classroom instruction, and they created an environment in which students could succeed by using good informal and formal assessment practices.

Table 10 shows that third grade teachers in meaningcentered classrooms used assessment strategies more frequently than teachers in the code-centered classrooms. District II teachers used informal assessments of students' performance, that is individual consultations and oral presentations more often than did District I teachers. Teachers in both districts used formal assessment strategies, that is criterion referenced tests, written essay tests, letter grades and academic progress on skills, more often than informal assessments. It appeared that third grade teachers in District I reflected the purposes of their classroom instruction and created an academic environment for students more often than did teachers in District II with frequent assessment practices. However, one teacher in District II formally assessed the academic progress of students daily. Formal assessment practices appeared to be 
Table 10

Assessment Strategies Used by Teachers Each Week in Grade Three

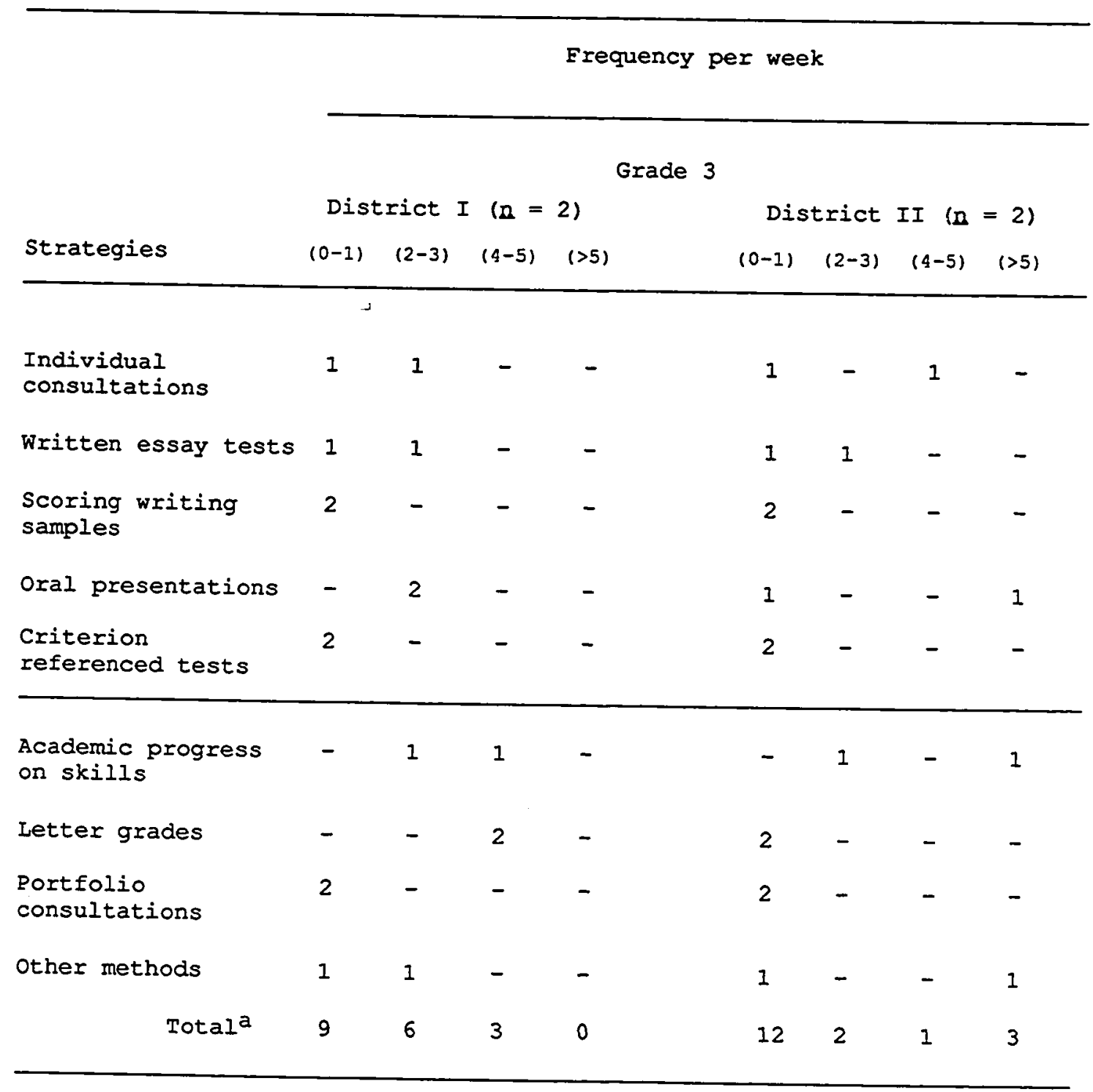

Note. The number of times assessment strategies were used each week was reported by two teachers in each grade level on the post questionnaire. aThe total numbers represent an overview of the weekly frequency of assessments for each district. 
balanced in both districts: that is teachers in both districts indicated that they assessed the academic progress of their students by using written essay tests, scoring writing samples and using criterion referenced tests an equal number of times each week. The major difference between the districts was the more frequent use of letter grades by teachers in District I. Informal assessment practices reflected an emphasis on students' meaning by recognizing and reinforcing the students' academic writing, speaking, and listening efforts. Formal assessment practices emphasized a mastery of objectives and a direction for instruction toward objectives.

Table 11 reports that sixth grade teachers in both districts emphasized formal assessment strategies more than informal strategies. However, the total numbers reflect that teachers in the code-centered classrooms use formal strategies almost daily. The daily formal assessments, that is academic progress on skills, criterion referenced tests and letter grades, in both districts indicate that teachers emphasized a mastery of objectives and a direction for their instruction toward objectives.

Teachers in both districts appeared to use informal strategies with about the same frequency each week ranging from once each week to daily. Teachers in District II reported that the only informal assessment strategy that was not used more than two to five times each week was portfolio consultations. Sixth grade teachers in the code-centered classrooms informally assessed writing and speaking performances more often than 
Table 11

Assessment Strategies Used by Teachers Each Week in Grade Six

Frequency per week

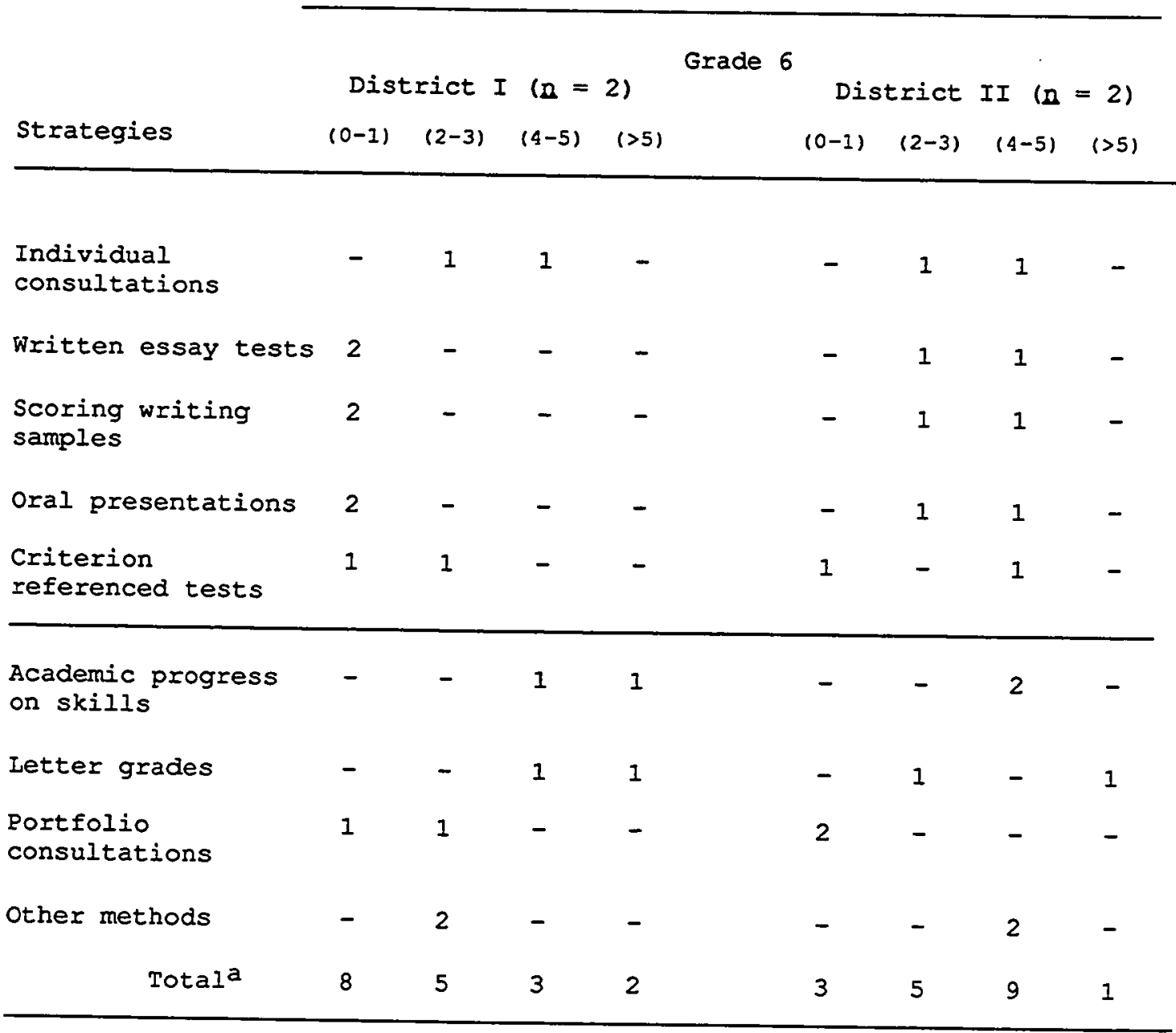

Note. The number of times assessment strategies were used each week was reported by two teachers in each grade level on the post questionnaire. aThe total numbers represent an overview of the weekly frequency of assessments for each district. 
teachers in District I. This emphasis on students' meaning by recognizing and reinforcing the students' academic writing and speaking efforts provided students with the environment to connect ideas, comprehend a subject, test their reasoning, articulate insights and think.

Management Approaches

Table 12 displays the instructional management approaches that teachers marked as effective in their classroom instruction. Teacher behaviors reflect the management approaches that teachers believe to be effective in classroom instruction. The post questionnaire asked teachers to describe management approaches used in their classrooms by marking one of the choices that ranged from very effective to ineffective and not used (Appendix D, item number 3).

Twelve responses from teachers in the meaning-centered classrooms (District I) marked instructional management approaches as very effective or effective. On the other hand, twelve responses from teachers in the code-centered classrooms (District II) marked the approaches as somewhat effective and ineffective. Assertive discipline practices were marked as somewhat effective and ineffective by four teachers in District II, specifically by one sixth grade teacher. Since goals and rules were posted in every classroom and teachers were observed using various reward and punishment systems to reinforce rules, it may be considered that the continuous reward and punishment system was not effective with all students in District II for 
several reasons: (a) the system was not supported by parents and/or administration, (b) the system was not consistently or

Table 12

Instructional Management Approaches and Instructional Effectiveness

Determined by Teacher

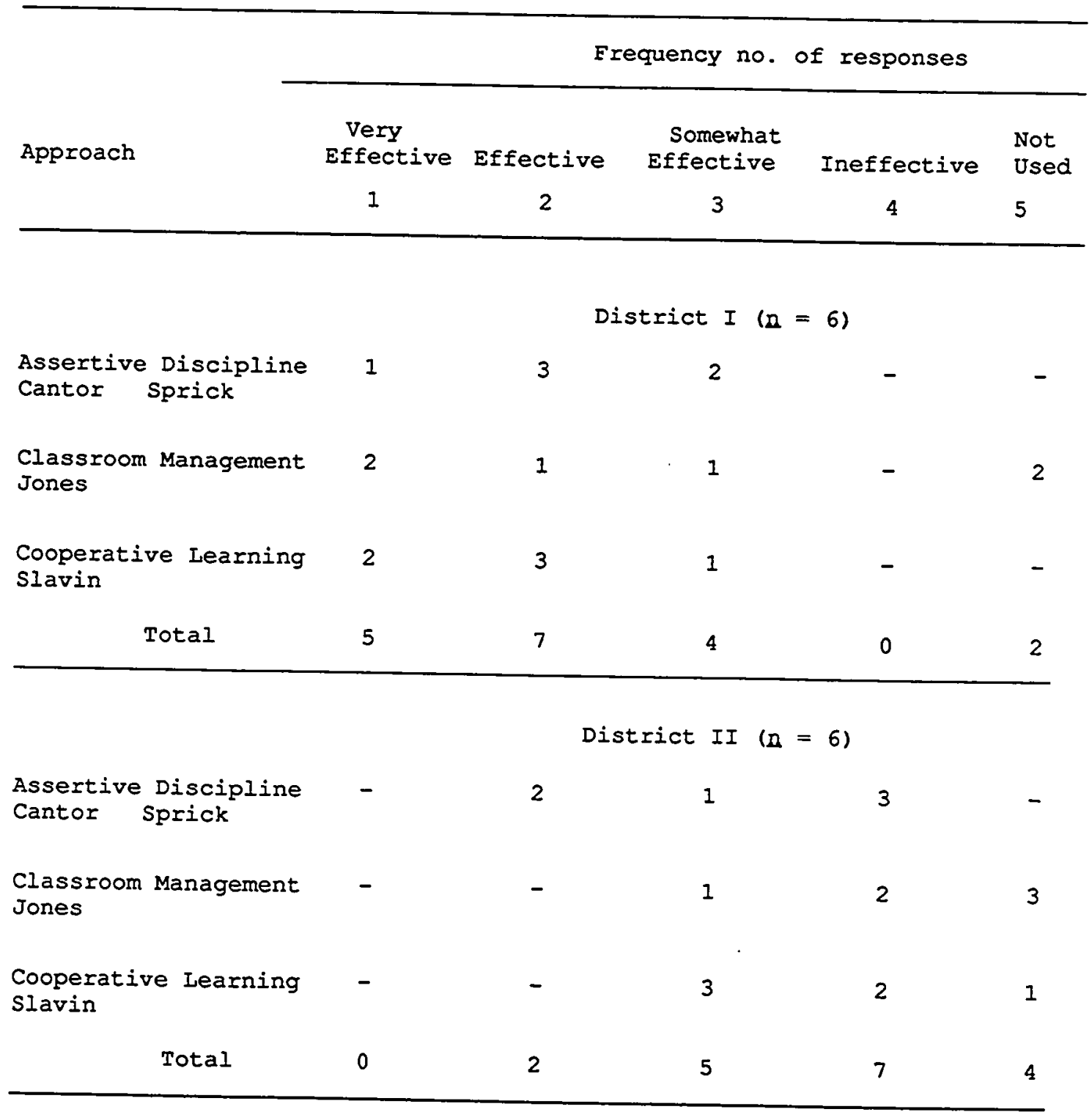

Reproduced with permission of the copyright owner. Further reproduction prohibited without permission. 
accurately used by the classroom teacher, or (c) the positive, negative system pays too much attention to negative behavior for the population of students identified for the study, therefore becoming ineffective.

An alternative explanation of the somewhat effective and ineffective marks concerning assertive discipline may be that the teachers were not aware of the nomenclature used to describe assertive discipline. However, this researcher will take the position that the punishment component of the assertive discipline model generated negative interactions among students and teachers. This punishment component focused too much on negative behaviors and not enough acknowledgment was given for positive behaviors. Negative interactions, as discussed in Table 8 , tend to reinforce a low estimation of self-worth for students with poor self-concepts, with insecure feelings of one's place among peers, and with confusion about norms and values expressed at school. Teachers with more teaching experience noted the effects of negative assertive discipline interactions on the self-worth of students and determined that the results of negative interactions were somewhat effective or ineffective: therefore, they marked the questionnaire somewhat effective or ineffective.

Five teachers in meaning-centered classrooms marked cooperative learning as very effective and effective. However, cooperative learning groups were observed only three times during 30 observations in meaning-centered classrooms. On the other hand, five teachers in code-centered classrooms marked 
cooperative learning as somewhat effective and ineffective. Cooperative learning groups were observed 10 times during 30 observations. Two explanations are proposed: (a) teachers in District I were told that cooperative learning develops students capacity to use language creatively and critically, to perform higher academically, and to have more positive attitudes toward school and learning, therefore they marked effective; whereas teachers in District II practiced cooperative learning and found it was ineffective in developing students academically, creatively and critically; and/or (b) cooperative learning groups are new classroom practices and teachers in District II are continuing to stick to their habitual ways and are not committed to cooperative learning; whereas teachers in District I are forming habitual teaching habits and find cooperative groups effective, but limited in use.

Instructional Intent and High Expectations

Instructional intent is congruent with how teachers communicate high expectations for students in terms of learning. Fifteen comments cited specific insights into teachers' perceptions about maintaining or not maintaining high expectations for all students in language arts instruction. The teacher's instructional intent determines how he or she manages classroom instruction. Teachers communicate their expectations for learning to students through behaviors related to instructional management. A sense of efficacy in terms of their own ability to teach all students is communicated through 
expectations for their students. During the pre and post interviews, teachers were asked to respond to the following question: "To what degree do you maintain high expectations for all students in your classroom?" The respondents answered in two ways: (a) by marking one of the five possible choices on a 10 point scale, high (10-9) and low (2-1); and (b) by a narrative response. Table 13 details the scaled responses from the post interview (Appendix $C$, item number 3).

Table 13

Performance Expectations for Students by Grade and Level of Expectations as Reported by Teachers

\begin{tabular}{|c|c|c|c|c|c|}
\hline \multirow[b]{2}{*}{ Grade } & \multicolumn{5}{|c|}{ Frequency of expectations } \\
\hline & $\begin{array}{c}\text { high } \\
(10-9)\end{array}$ & $(8-7)$ & $(6-5)$ & $(4-3)$ & $\begin{array}{l}\text { low } \\
(2-1)\end{array}$ \\
\hline & \multicolumn{5}{|c|}{ District I $(n=6)$} \\
\hline Grade 1 & 1 & 1 & - & - & - \\
\hline Grade 3 & - & 2 & - & - & - \\
\hline \multirow[t]{2}{*}{ Grade 6} & - & 2 & - & - & - \\
\hline & \multicolumn{5}{|c|}{ District II $(n=6)$} \\
\hline Grade 1 & 2 & - & - & - & - \\
\hline Grade 3 & 1 & - & 1 & - & - \\
\hline Grade 6 & 2 & - & - & - & - \\
\hline
\end{tabular}


Teachers in both districts indicated that they have high expectations for their students. A total of eleven teachers exhibited a sense of efficacy in terms of their own ability to teach their students by expecting students to learn. Five of six teachers in District II reported that they have high expectations for their students in terms of learning. Teachers in the code-centered classrooms expected their students to learn from classroom instruction. Teachers organized, paced and delivered instruction with the belief that students were capable of producing the desired results.

Comments that clarify the respondents' responses to maintaining high expectations for all students were as follows: Meaning-centered classrooms (District I).

1. I do have high expectations, but I want them to be realistic. We are not retaining kids, because studies are showing that retention isn't good.

2. A few (students) work with aides.

3. A few students I don't have very high expectations for.

4. I think I do that.

5. I suppose.

6. More this year, because I have a good class.

7. My Spanish speakers get additional reinforcement with an aide.

code-centered classrooms (District II).

8. I expect that they can do it; they can learn, even my limited proficient children. 
9. I expect them all to do the same assignments, but I don't push them.

10. They are all expected to do the same type of work.

11. I expect a lot of them.

12. English speakers, I have very, very high expectations. Spanish speakers you just vary it a little bit and in some cases, quite a bit less.

Comments, 8-10, from teachers in District II reinforce Table 13 with the intensity of the remarks espousing high expectations for all students. Comments from teachers in District I displayed a weaker sense of efficacy in terms of their own ability to maintain high expectations.

Summary: What teacher behaviors related to the instructional management factors--control, curriculum, and secietal--were performed in a code-centered and meaning-centered English Language Arts classroom?

This summary reflects those aspects in the data that provide insight into what instructional management behaviors teachers use and find effective in code-centered and meaningcentered language arts classrooms in the first year implementation of the California English-Language Arts Framework.

Teachers used instructional management behaviors related to control very effectively with discipline, effectively with positive reinforcement and somewhat effectively with time on task variables. Discipline, arrangement of furniture, posted 
goals, display of student work and teacher preparedness were observed to be used more than satisfactorily in both districts in all classrooms.

Teachers in District II used positive reinforcement with a two-to-one ratio of positive to negative interactions which fostered a more positive learning environment than the one-toone ratio of positive to negative interactions in District $I$. Five teachers in District II indicated that they believed assertive discipline to be ineffective or somewhat effective which provides insight into the observed use of more positive interactions than negative interactions.

The practice of providing student feedback in first and sixth grade classrooms during independent activities was Iimited in both districts. However, teachers in District II provided more student feedback with feedback from an adult and from other students more often than did teachers in District I. Providing student feedback is closely related to learning and building self-concept. During this independent time on task activity teachers and/or peers have the opportunity to be supportive and provide personal and frequent help. Students in both code-centered classrooms and meaning-centered classrooms were observed to engage in independent activities with minimal disruptions in third and sixth grade levels in both districts. First grade classes appeared to have the most difficulty engaging in independent activities with minimal disruptions. Third and sixth grade student participation in minimal disruptions and engaged time displayed the teachers' intent to 
create an academic atmosphere and encouraged student accountability.

Management factors related to societal considerations that address individual differences in the recognition of cultures was limited in use by teachers in both districts. Cultural referents to values and norms were not noted during observations and literature lesson presentations were not organized to build upon referents to home cultures representative of ethnic populations in classrooms.

The practice of considering societal differences appeared to be limited by the minimal use of cooperative learning groups. The opportunity to talk, listen, share, discuss, reflect and think about a piece of literature helps students develop positive attitudes toward learning and understandings about cultural and ethnic relations. Cooperative learning increases productivity, student achievement, committed relationships, an understanding of different perspectives, positive peer relationships, social support, social skills, and higher self-esteem. The use of cooperative learning groups was limited to less than $10 \%$ of the classroom observation time in District $I$ and $37 \%$ in District II. Teachers in District I indicated that cooperative learning was effective or very effective. Teachers in District II, who were observed to use cooperative learning more than teachers in District $I$, indicated that cooperative learning was somewhat effective, effective or not used. It appears that the use of cooperative 
learning groups has not been engineered into practice in the classroom management system in both districts.

Corrective feedback practices recognize and reinforce students' academic efforts. Frequent feedback practices identify students' strengths and accomplishments, reflect the purposes of curriculum and provide information about student progress. A variety of feedback practices allows both formal and informal assessment practices. Formal assessment practices emphasize a mastery of objectives and a direction for instruction toward objectives. Informal assessment practices emphasize meaning by recognizing and reinforcing the students' academic writing, listening and speaking performances. First grade teachers in code-centered classrooms used formal and informal corrective feedback more frequently throughout the week than teachers did in meaning-centered classrooms. They assessed writing performances and practiced portfolio consultations with their students daily.

Third grade teachers in meaning-centered classrooms used formal corrective feedback, letter grades and progress on skills, more frequently than teachers did in code-centered classrooms. Teachers in both districts did not assess writing performances or practice portfolio consultations more than two times each week.

Sixth grade teachers in code-centered classrooms used informal corrective feedback more often than did teachers in meaning-centered classrooms. Writing and speaking performances were assessed almost daily. Formal corrective feedback, letter 
grades, progress on skills, and criterion referenced tests, were used daily by teachers in both districts with students. The daily formal assessments, that is academic progress on skills, criterion referenced tests and letter grades, in both districts indicate that teachers emphasized a mastery of objectives and a direction for their instruction toward objectives.

Teachers communicate their expectations for learning to students through behaviors related to instructional management. With the exception of one teacher, teachers in the codecentered classrooms supported their scaled responses indicating high expectations with verbal statements that reflected higher expectations for their students than did teachers in meaningcentered classrooms. Comments from teachers in District II displayed a strong sense of efficacy in terms of their own ability to maintain high expectations. Teachers in codecentered classrooms appeared to organize, pace and deliver instruction with the belief that students were capable of producing the desired results. 


\author{
Research Question Three \\ What Were the Differences Between \\ Instructional Techniques Used in a \\ Code-Centered Classroom and a Meaning-Centered Classroom?
}

This research question concentrates on effective learning strategies that teachers translate into instructional

behaviors. The teacher's perception of student learning, their training experiences and their cognitive understanding of learning strategies will determine the degree of emphasis or degree of absence of instructional techniques used in a codecentered classroom or meaning-centered classroom. The instructional strategies that were identified for this research study are organized into five instructional techniques: (a) techniques designed to affect information processing, (b) techniques designed to focus on the person, (c) techniques designed to focus on cooperative learning, (d) techniques designed from behavioral theory approach, and (e) techniques designed to focus on individual differences.

This question explores the differences between instructional techniques teachers use in a code-centered classroom and a meaning-centered classroom during the first year of the English-Language Arts Framework implementation. To analyze this question, 23 pieces of data are used originating from the pre and post teacher questionnaire, teacher interview and 60 classroom observations. 
Tables 14 and 15 present an analysis of the observation and questionnarie information for this research question: (a) Table 14 reflects the observed performance distributions of techniques that affect information processing and techniques that focus on the person; and (b) Table 15 displays the instructional techniques that teachers identified to be effective in classroom instruction that are designed to focus on cooperative learning, to focus on individual differences, to focus on the person, and are designed from behavioral theory approaches.

observed Instructional Techniques

Table 14 examines the stages of observed language arts lesson presentations. A sequence of steps in a lesson allows the gradual transference of information from teacher to student within the context of minimal performance anxiety for the student. Within this structure a high degree of precision and mastery is possible. With research, writing and teaching, Hunter, Bloom, Becker, Carnine and Engelmann have been pioneers in enriching understandings about these effective instructional techniques. These understandings about the sequence of steps in structured lessons have been presented with the teaching of skills. It was the purpose of these observations to discover if past knowledge about the transference of understandings, the performance of tasks effectively, and the mastery of learning goals were integrated with the present focus on the new literature based program, reading, writing, speaking, and 
listening. The discussion of Table 14 follows the sequence of the instructional techniques displayed in the table.

A total of 45 hours were spent observing language arts lessons between February and June of 1990. The teachers were aware of the date and time of each scheduled observation; however, they were not aware of the instructional techniques that were being observed. An explanation of each of the observed techniques was provided for the observer for each observation (Appendix E, item numbers 9, 11, 14 and 16). Three levels of performance criteria were used: (a) not yet performed, (b) performed at a satisfactory level, and (c) performed at a high and exemplary level.

Table 14 reports that structured practice was the last step, in the sequence of nine steps, of a lesson performed consistently during the 45 minutes of observed time-motivation, review, objectives, explanation, modeling, structured practice, guided practice, generalization and independent practice. Teachers in both districts limited or did not use guided practice, the stage that deals directly with issues of retention; generalization, the stage that deals with comparisons and contrasts of concepts; and independent practice, the stage that is related to the transfer of learning. Teachers in the code-centered classrooms were observed practicing the generalization stage during 12 observations of the 30 possible observations or during $40 \%$ of the observations. The use of guided practice and independent 
Table 14

Ianouage Arts Instruction by Techniques and observed tevels of Performance

\begin{tabular}{|c|c|c|c|c|c|c|}
\hline \multirow[b]{2}{*}{ Techniques } & \multicolumn{6}{|c|}{ No. of observed performancesa } \\
\hline & $\begin{array}{l}\text { Not } \\
\text { erformed } s\end{array}$ & Satisfactory & Exemplary & $\begin{array}{l}\text { Not } \\
\text { Performed }\end{array}$ & Satisfactory & Exemplary \\
\hline & \multicolumn{3}{|c|}{ District I $(n=6)$} & \multicolumn{3}{|c|}{ District II $(n=6)$} \\
\hline Motivation & 11 & 1 & 18 & 7 & 2 & 21 \\
\hline Review & 8 & 2 & 20 & 6 & - & 24 \\
\hline Objectives & 10 & 3 & 17 & 4 & 4 & 22 \\
\hline Explanation & - & 1 & 29 & 2 & 2 & 26 \\
\hline Modeling & 9 & 2 & 19 & 6 & 2 & 22 \\
\hline $\begin{array}{l}\text { Structured } \\
\text { eractice }\end{array}$ & 6 & 1 & 23 & 12 & 1 & 17 \\
\hline $\begin{array}{l}\text { Guided } \\
\text { practice }\end{array}$ & 26 & 1 & 3 & 23 & 1 & 6 \\
\hline Generalization & 23 & 1 & 6 & 18 & 1 & 11 \\
\hline $\begin{array}{l}\text { Independent } \\
\text { practice }\end{array}$ & 30 & - & - & 26 & - & 4 \\
\hline $\begin{array}{l}\text { Literature is } \\
\text { read aloud }\end{array}$ & 6 & 2 & 22 & 13 & - & 17 \\
\hline $\begin{array}{l}\text { Writing is } \\
\text { practiced }\end{array}$ & 15 & 5 & 10 & 13 & 8 & 9 \\
\hline $\begin{array}{l}\text { Systematic } \\
\text { skill program }\end{array}$ & 27 & - & 3 & 23 & 4 & 3 \\
\hline
\end{tabular}

Note, aFive observations with six teachers in each district equals 30 classroom observations and a total of 60 observations in both districts. 
practice was observed during less than $25 \%$ of the observations in both districts.

Teachers in both districts were observed following the first six of nine possible steps of a structured lesson. However, teachers in code-centered classrooms practiced the motivation, review, objectives, and modeling stages more often than did teachers in the meaning-centered classrooms. The following six stages were observed during language arts lesson presentations:

1. Motivation. The immediate relevance and importance of the story or the listening, writing or speaking assignment was explained.

2. Review. Previous lessons were related to the immediate lesson.

3. Goals and objectives. The theme of the story, the purpose for writing, for speaking, for listening was stated.

4. Explanation. The necessary steps that had to be taken to complete the assignment was explained. This stage was performed by teachers during all 30 observations in District I. This explanation stage took much of the 45 minutes. Art assignments that followed a reading presentation seemed to require much explanation.

5. Modeling. The steps necessary to complete the assignment were demonstrated by the teachers through pictures, outlines, examples, or other forms of visual and auditory modalities. 
6. Structured practice. Students were given the opportunity to practice the assignment with correct performance. Feedback from the teacher or an adult provided the maximum accuracy. If students were not given the opportunity to practice with feedback from an adult, the stage was observed as not performed. Teachers in District I performed this stage more often than did teachers in District II. This stage was reported in Table 7 in which time-on-task student performance was observed during scheduled independent activity time.

The English-Language Arts Framework suggests that students benefit from hearing good literature read aloud daily. During 45 hours of language arts classroom instruction, $80 \%$ of the 30 observations in District $I$ and $57 \%$ of the 30 observations in District II noted that literature was read aloud to students. Exemplary writing activities were performed when students practiced writing, their writing was reviewed, and some method of collecting their writing was observed. Exemplary writing practices were performed during $30 \%$ of the observations in District II and 33\% of the observations in District I (the number of observed times divided by 30 possible observations).

A systematic skill program, phonics program or the use of semantic and structural analogy strategies, was observed being taught during $10 \%$ of the observations in District $I$ and $23 \%$ in District II. 


\section{Effectiveness of Technioues in classroom Instruction}

Table 15 details the techniques that teachers identified to be effective in their classroom instruction. Twelve teachers completed the post questionnaire (Appendix D, item numbers $1-5)$. They were asked to describe the effectiveness of 13 instructional techniques displayed by marking one of the five choices: (a) very effective, (b) effective, (c) somewhat effective, (d) ineffective, and (e) not used. Of the 13 techniques displayed, "A" choices reflect techniques designed to affect information processing, "B" choices describe techniques that focus on the person, choice " $C$ " is a technique that is designed to focus on cooperative learning, " $D$ " choices present techniques designed from behavioral theory approaches, and "E" choices concentrate on techniques designed to focus on individual differences.

Table 15 reports that only two teachers in District I and one teacher in District II marked three learning strategies-writing, mastery learning and non-directive teaching--as very effective in classroom instruction. There was a noticeable difference between the teachers' perceptions of the effectiveness of the strategies in each district. The majority of teachers from the code-centered district marked most learning strategies as somewhat effective, ineffective and/or not used. The majority of teachers from the meaning-centered district marked most learning strategies as effective, somewhat effective and/or not used. The noticeable differences in 
Table 15

Degree of Effectiveness of Instructional Technicues Used in the classroom

\begin{tabular}{|c|c|c|c|c|c|c|c|c|c|c|}
\hline \multirow[b]{2}{*}{ Techniques } & \multicolumn{10}{|c|}{ Frequency of responses } \\
\hline & $\begin{array}{l}\text { Very } \\
\text { Eff } \\
1\end{array}$ & $\begin{array}{c}\text { Eff } \\
2\end{array}$ & $\begin{array}{c}\text { Some } \\
\text { Eff } \\
3\end{array}$ & $\begin{array}{c}\text { Ineff } \\
4\end{array}$ & $\begin{array}{c}\text { Not } \\
\text { Used } \\
5\end{array}$ & $\begin{array}{c}\text { Very } \\
\text { Eff } \\
1\end{array}$ & $\begin{array}{c}\text { Eff } \\
2\end{array}$ & $\begin{array}{l}\text { Some } \\
\text { Eff } \\
3\end{array}$ & $\begin{array}{c}\text { Ineff } \\
4\end{array}$ & $\begin{array}{l}\text { Not } \\
\text { Used } \\
5\end{array}$ \\
\hline
\end{tabular}

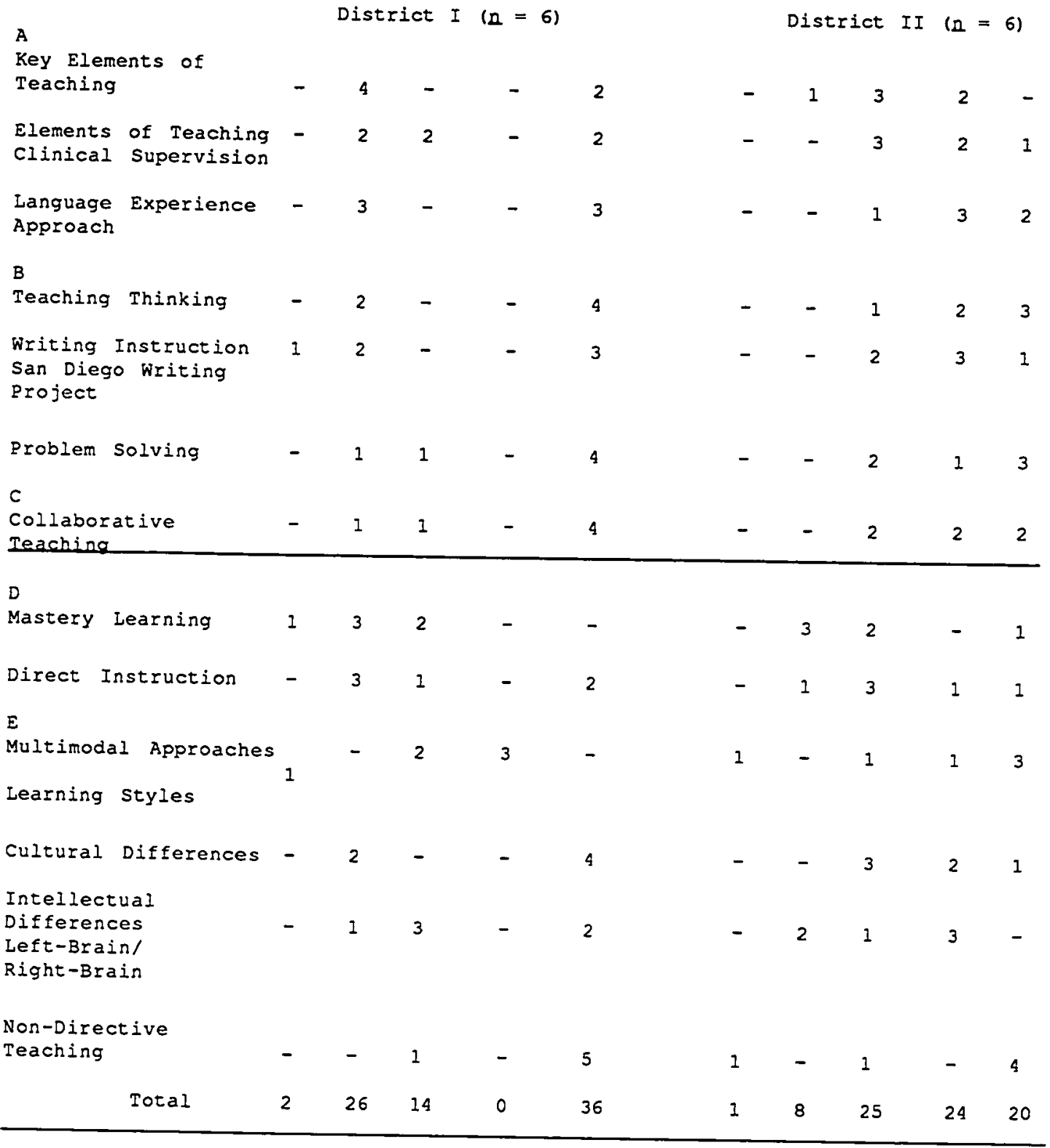


teachers' responses to learning strategies between districts may relate to three possible explanations: (a) teachers were not familiar with the nomenclatures for the instructional techniques listed and, therefore they didn't know what aspect of a technique leads to what student behavior and why the technique affects student behavior; (b) teachers were not familiar enough with the instructional techniques to allow the techniques to become part of their teaching habits, therefore, the technique became obsolete in their classroom instruction; and (c) teachers were not using the techniques, because they were following the prescribed curriculum materials which did not address the techniques by name and/or remind them to use specific effective instructional techniques. Discussion of the teacher responses to the effectiveness of the instructional techniques listed in Table 15 follows this researcher's assumption that the teachers had an understanding of the techniques, and they may have researched the techniques to review their memories before they marked the questionnaire. The instructional techniques that have received the most attention and advertising during the past six years through consultant activity, literature, published research, district trainings and follow up practice trainings--mastery learning, key elements of teaching, clinical supervision, direct instruction, multimodal approaches and intellectual differences--appeared to receive less "not used" marks from 
teachers in both districts than did those techniques that are recently receiving attention.

Teachers from meaning-centered classrooms marked the three "A" techniques which are designed to affect information processing as effective and somewhat effective. District I teachers viewed the possibility for all students to master a set of objectives, the concept of individualized instruction, the steps of a structured lesson that transfers a high degree of learning, and the discovery of meaning of human experience through reading, writing, listening, and speaking as effective and somewhat effective in classroom instruction. Teachers from the code-centered classrooms viewed the information processing "A" techniques as less effective than did teachers in District I.

Teachers in meaning-centered classrooms marked thinking, writing and problem solving very effective and effective in classroom instruction. "B" techniques, which are designed to focus on the person, were viewed as more effective in classroom instruction by teachers in meaning-centered classrooms than by teachers in the code-centered classrooms. Writing instruction-classroom writing instruction and the San Diego Writing Project--was marked the second most effective instructional technique by teachers in both districts.

Techniques designed to focus on cooperative approaches received similar reviews by teachers in both districts. Two teachers in code-centered classrooms and two teachers in the meaning-centered classrooms marked collaborative teaching to be 
effective. However two teachers in District II didn't use the strategy and two teachers marked it ineffective for classroom instruction.

The "D" techniques designed from behavioral theory-mastery learning and direct instruction--were judged by teachers in both districts to be more effective in class instruction than other strategies presented on the questionnaire. Mastery learning was judged to be the most effective instructional strategy for classroom instruction by teachers in both districts.

The "E" techniques which are designed to focus on individual differences were marked effective and somewhat effective in meaning-centered classrooms. Teachers in codecentered classrooms used these learning strategies more often than did teachers in District II, but they marked them as ineffective more often. One sixth grade teacher in a codecentered classroom marked Rogers' Nondirective Teaching as very effective. The role of the teacher in this instructional technique is to be a facilitator who guides students' growth and development. The teacher helps students explore new ideas about their lives, their schoolwork and their relations with others. Students are responsible for their own learning. This sixth grade teacher was observed using nondirective teaching very effectively.

There was a noticeable discrepancy between what instructional strategies teachers' marked as "not used" on the questionnaire, and the instructional strategies that were 
observed during classroom observations. Two teachers in District II and three teachers in District I indicated that Goodman's language experience instructional technique was not used in their classroom instruction; however, all classrooms were observed using the language experience approach within their prescribed literature program. Additionally, the same discrepancy occurred with writing instruction. Apparently, several teachers in both districts were not aware of the nomenclature assigned to the technique or with the researcher associated with the instructional technique they were observed using in their classroom instruction.

Teacher Perceptions of Instructional Techniques and Student Behavior

"The hippopotamus policeman falls on top of Foxy Loxy and says 'You're under arrest!' Eoxy Snaps, 'No, I'm under a big, fat hippopotamus!' They really got the joke. They were so excited! I hadn't expected the interest and the excitement and that's what I really like."

Thirteen comments from teachers cited specific insights into perceived differences in student behaviors resulting from the meaning-centered approach and code-centered approach to language arts instruction. During the pre and post teacher interview (Appendix $C$, item number 5), the respondents were asked to respond to the following question concerning student behavior: "How would you describe the different degrees of expected and not expected student behavior during your language arts class instruction?" There was not a noticeable difference 
between the comments given during the March interview and the comments given during the June interview about the differences in expected student behaviors. The comments are reported in an order of grade level sequence: that is, first, third and sixth grade teachers. However, each comment reported may reflect one or more comments of similar nature made by teachers from another grade level: that is, comments made by first grade teachers may be similar to the comments made by sixth grade teachers. The comments from teachers in both districts were as follows:

Meaning-centered classrooms (District I).

1. I guess this year, I'm seeing much more creativity in their writing and in their responding to what they are reading and relating it back to their own personal experiences.

2. They are paying better attention because they like the stories and they like the lessons that have to do with the stories.

3. They don't have a lot to contribute during discussion...they haven't had a lot of outside experience..for example, snow.

4. A marked increase in enthusiasm for finding out about authors and their lives. We're reading earlier in the year, there's a flow.

5. They're more relaxed about coming to reading. I'm thinking mostly the low kids. They seem happy with the program. But then, my high kids kind of blow it off. Does that make sense? 
6. Most of the kids responded very well. They really seem to like it. Except kids with language difficulties have to have a lot of things explained to them.

\section{cede-centered classrooms (District II)}

7. It's hard for some kids...concepts... the language. Some kids understand everything and some kids have difficulty. There is a big variety of responses.

8. The kids ask more questions and do a lot more writing.

9. They really work together and have good ideas. I encourage their ideas, but the clock is running and I have to teach the children.

10. The students who are not being successful feel they are successful. They have a good attitude toward reading and writing.

11. I don't have the full attention of the whole group. I am disappointed with the responses of some students to this approach.

12. Some of them still need some structure in developing skills.

13. There is a tendency to get off track a little bit in their cooperative groups, but that's expected.

Teachers in the meaning-centered classrooms noted that students appear to be more creative in their writing and in relating their reading to their personal experiences. However, one comment reflected the concern that limited home experiences limited student discussions. Comments reflected that students liked the stories, responded well, seemed happy, exhibited 
enthusiasm, were attentive and were more relaxed about coming to reading. However, several teacher comments noted that high performing students didn't seem to take reading activities seriously, and that multi-ethnic students needed additional explanation. The majority of the comments appeared to express noticeable differences in positive attitudes about language arts instruction. One teacher's comment expressed noticeable differences in the accelerated progress of student learning behaviors in writing. On the other hand, two comments expressed concern about the lack of progress in the learning behaviors among multi-ethnic students and high performing students.

Comments from teachers in the code-centered classrooms followed a similar pattern to comments from teachers in District I that addressed attitude, writing, speaking and learning behaviors. Three comments expressed a noticeable difference in positive attitudes about reading, writing and working together. Six comments expressed concern about the limited language concepts among students that hinders a successful discussion and a concern about the limited learning behaviors exhibited. The teachers offered solutions to their concerns by commenting that some students needed structure in developing skills and that skills needed to be taught. Teachers noted that students who were not successful in their academic performance, actually did feel that they were successful. Teachers indicated that they were disappointed and 
uncomfortable about this feeling of success among students who were not performing well in class.

Comments about writing indicated that teachers felt that writing was the only form of communication in which students actively participated and demonstrated success in both districts. Comments indicated that student writing was creative, was used frequently and generated good feelings more often with the new language arts approach than with the past instruction. Comments noted that students generally responded positively to reading, listening and speaking.

Summary: What were the Differences Between Instructional Technigues Used in a code-Centered Classroom and a MeaningCentered Classroom?

This summary reflects those aspects in the data that provide insight into the instructional techniques that teachers emphasize or neglect in code-centered classroom and meaningcentered classroom instruction.

Code-centered classrooms and a meaning-centered classrooms seemed to severely limit the use of learning strategies that affect information processing; that is guided practice, generalization and independent practice. However, four teachers in District I and three teachers in District II marked the strategies to be effective and somewhat effective in class instruction. Only two teachers in District $I$ and one teacher in District II reported that they didn't use the strategies. 
Two teachers in District II reported them ineffective in class instruction.

Students received limited opportunities to process a great amount of information and build schemas to organize the information. One sixth grade student in District I was overheard sharing with a friend that it was hard to keep all the titles, authors and story parts straight, because they were reading so many different stories at the same time from prescribed literature series, theme books and independent reading books.

A note of interest is how the teachers in both districts responded to Goodman's language experience approach, a major component in the foundation of the English-Language Arts Framework. Three teachers in District I and two teachers in District II recorded that they didn't use the technique. However, all 12 teachers were observed using the approach. Two teachers in District II marked the approach as ineffective in class instruction, which was supported with comments 11 and 12 . However, all 12 teachers indicated that they followed the prescribed literature program fairly close (Table 4). Five teacher comments in District $I$ and three comments in District II expressed support of the effectiveness of the literature approach with student attitudes and writing performances. More teachers in District I appeared to be unaware of the instructional techniques they were using than were teachers in District II. Teachers who are unaware of the instructional 
techniques they are using are unable to identify the instructional behaviors that affect student performance.

Four teachers in District II used collaborative teaching; however, they marked it somewhat effective or ineffective. Only two teachers in District I used the technique and noted it to be effective. In District I, one teacher, out of 12 total teachers, marked collaborative teaching as effective in class instruction. This instructional technique was pioneered by John Dewey to teach the social and intellectual processes of democracy and to provide students with the opportunities to reflect on concepts, beliefs and values. This technique is also integrated into the foundation of the English-Ianguage Arts Framework. Collaborative teaching does require the teacher to have a high level of interpersonal and instructional skills, is cumbersome to manage in that classroom groups must be organized for specific tasks, and requires a great deal of instructional time to allow the process to operate and flourish among students.

Learning strategies that are designed to focus on individual differences were used more often by teachers in District II than by teachers in District $I$. Teachers in District I and in District II marked these strategies as effective and somewhat effective. The use of multimodal approaches were observed to occur during most of the observations in both districts as reported in Table 6 .

The instructional techniques that were reported to be most effective in classroom instruction in both districts were 
instructional techniques designed to focus on the person and techniques designed from behavioral theory. Teachers in the meaning-centered classrooms indicated that writing instruction, mastery learning and direct instruction were effective. Writing instruction in meaning-centered classrooms was performed during $50 \%$ of the observations. However, mastery learning and direct instruction were observed only three times out of 30 observations.

A few teachers in the code-centered classrooms reported that mastery learning and direct instruction were effective. A systematic program related to the concept of mastery learning was performed during seven of the 30 observations. Two teachers indicated that writing was somewhat effective. Writing instruction was performed during $57 \%$ of the classroom observations in District II. However, two teacher comments, 8 and 10, supported the effectiveness of writing instruction. It appears that the language arts instructional techniques generated a reciprocal positive attitude among teachers and students. The students enjoyed the stories, writing, speaking and listening activities, and the teachers enjoyed the positive attitudes of their students. However, there appeared to be a general concern among teachers about not teaching students to overcome their weaknesses discovered through reading, writing, speaking and listening activities with structured objective instruction. Comments from teachers in both districts (with more conviction in the code-centered classrooms) indicated that they don't believe that high performing or low performing, 
multi-ethnic, and low-income students will be able to overcome their academic weaknesses by experiencing good attitudes about listening, reading and discussing literature. They also noted in their comments and responses to collaborative teaching and mastery learning that their population of students may not possess encugh experiences and language abilities to produce knowledge that is solely generated from feelings and beliefs of others.

The differences between instructional techniques in codecentered classrooms and meaning-centered classrooms were the following:

1. Teachers in meaning-centered classrooms read more literature, used structured practice and explanation more often than did teachers in code-centered classrooms.

2. Teachers in code-centered classrooms used a systematic skill program, collaborative learning, nondirective teaching, motivation, review, objectives, modeling, guided practice, independent practice, researched based instructional techniques and focused on the individual more often than did teachers in meaning-centered classrooms.

3. Teachers in both districts limited their use of the instructional techniques that affect information processing, but teachers in both districts used writing techniques with their students.

4. More teachers in District II were able to identify and repeat the instructional strategies that affect student performance than were teachers in District $I$. 


\begin{abstract}
Research Question Four
To What Extent Were Students Able to Exhibit Learning Strategies Acquired From Being Taught by Teacher Instructional Behaviors Specific to Meaning-Centered Strategies and Code-Centered Strategies?
\end{abstract}

This research question concentrates on the learning strategies that students exhibit in a meaning-centered classroom and a code-centered classroom in the first year implementation of the English-Language Arts Framework. The goal of language arts instruction is to facilitate an organized knowledge system with strategies for synthesizing and integrating information that allow the development of reading comprehension, writing, efficient communication, and metacomprehension. The process of developing this knowledge system enables learners to use strategies to analyze issues, make decisions, solve problems, communicate effectively, relate new information to a knowledge system and build a larger knowledge system. Iiteracy becomes knowledge and independent thought. This question examines the differences between exhibited learning strategies acquired from being taught by instruction specific to meaning-centered strategies or to codecentered strategies as they relate to reading and writing. To analyze this question, two pieces of data are used originating from the pre and post teacher interviews (Appendix D, item numbers 9 and 10). Tables 16 through 21 report an analysis of the interview information for this research 
question for grade levels one, three and six: (a) Tables 16, 17 and 18 reflect integrated writing performance distributions of high achieving and low achieving students, and (b) Tables 19, 20 and 21 detail the reading stage performance distributions of high achieving and low achieving students. Writing Performance

Tables 16, 17 and 18 detail stages of integrated writing performances and the writing stages students mastered as estimated by their teachers on the pre and post interview. Teachers were asked to identify at what stage of the writing process they believed that the majority of their high performing students and the majority of low performing students mastered at the beginning of the study and at the end of study. Two forms of responses were encouraged: (a) marking a numbered scale, and (b) explaining and clarifying their marked response. Each question was read aloud to make explicit the definition emphasized. An integrated writing ability was described as the ability to formulate ideas, to produce independent responses, to connect letters to form words, to form sentences with words, to select, compose, read, select, to display a knowledge of simple to complex grammar rules, to edit work, to rewrite for clarity and free from errors, and to display a voice which contributes to the development of the writer. Being free from errors was further explained to exclude inventive spelling. This description applies to each stage; however, as students develop their reading and writing abilities, their writing voice becomes more developed. The final stage displays the 
writing abilities that express ideas and concepts about human conditions and values. Teachers were asked the following question about the writing ability of their students: What stage of an integrated writing ability do you believe your advanced students have mastered and what stage have your low students mastered? The discussion of the differences in teacher estimations of students' writing performances follows the sequence of grade levels and high performing students writing progress to low performing students writing progress. Reading and writing are reciprocal activities, therefore teacher comments that cite specific insights into their perceptions of reading and writing performances follow the discussion of teacher estimations of students' reading progress.

Teachers represented in the meaning-centered classrooms (District I) indicated that their high performing first grade students mastered one writing stage, simple paragraphs in one class and expression of concepts in one class, within the three months of this study (Table 16). That is, in the beginning of the study, one first grade teacher estimated that his/her students had mastered the ability to formulate ideas, to produce independent responses, to connect letters to form words, and to form sentences with words, to connect sentences to form a paragraph, to display some knowledge of grammar rules, to edit work, to rewrite for clarity and error free and to display a voice in simple paragraphs. The second teacher

Reproduced with permission of the copyright owner. Further reproduction prohibited without permission. 
indicated that his/her high performing students began with a mastery of expression of concepts and remained at the same stage for three months. First grade low performing students mastered only simple sentences in three months.

Table 16

Stage of Mastery of Writing Performance Exhibited by First Grade High and Low Performing students

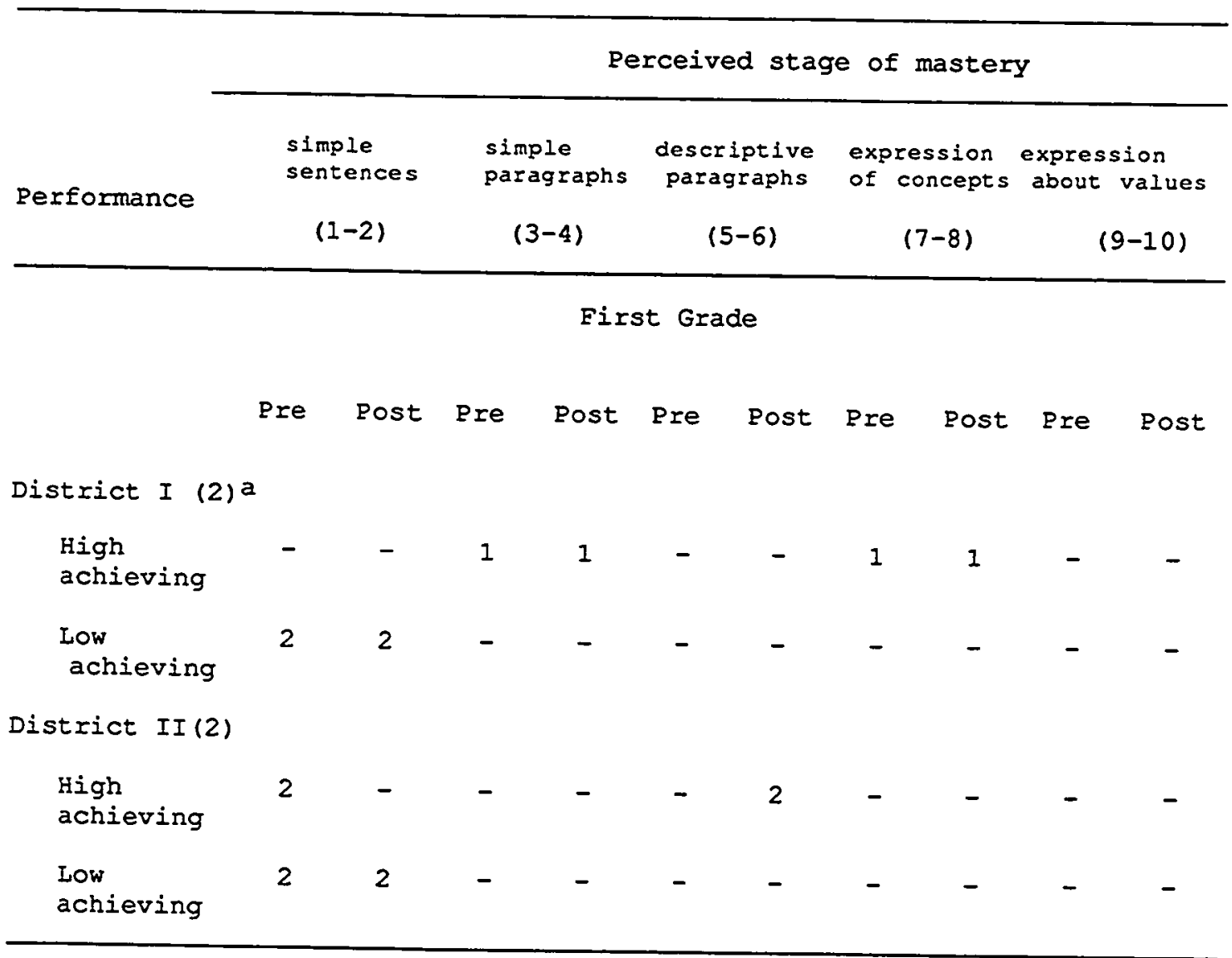

Note. $n=6$ teachers in District I population and 6 teachers in District II population.

asample size in parenthesis. 
Teachers in the code-centered classrooms (District II) indicated that their high performing first grade students mastered three writing stages: simple sentences, simple paragraphs and descriptive paragraphs within the thee months of the study. Low performing students progressed at the same rate as students in District I; however, observers noted that these students were writing more often than were students in District I. Three of the six teachers indicated that writing instruction was ineffective (Table 15).

Third grade high performers in both districts mastered the expression of concepts stage of writing (Table 17). One class in District I mastered two writing stages and one class in District II mastered three writing stages. The mastery of three writing stages in three months indicates that students in District II performed at a faster pace of writing development than did students in District I who mastered two stages of writing.

Third grade teachers from both districts reported that their low performers mastered identical writing stages during the three months of this study. Low performers mastered two stages: (a) simple sentences and simple paragraphs, and (b) simple paragraphs and descriptive paragraphs. 
Table 17

Stage of Mastery of Writing Performance Exhibited by Third Grade High and Low Performing students

\begin{tabular}{|c|c|c|c|c|c|}
\hline & & Per & seived stage & of mastery & \\
\hline Performance & $\begin{array}{l}\text { simple } \\
\text { sentences } \\
(1-2)\end{array}$ & $\begin{array}{l}\text { simple } \\
\text { paragraphs } \\
(3-4)\end{array}$ & $\begin{array}{c}\text { descriptive } \\
\text { paragraphs } \\
(5-6)\end{array}$ & $\begin{array}{l}\text { expression } \\
\text { of concepts } \\
(7-8)\end{array}$ & $\begin{array}{c}\text { expression } \\
\text { about values } \\
\qquad(9-10)\end{array}$ \\
\hline
\end{tabular}

Third Grade

Pre Post Pre Post Pre Post Pre Post Pre Post

District I (2) a

$\begin{array}{llllllllll}\text { High } & - & - & - & - & 1 & - & 1 & 2 & - \\ \begin{array}{l}\text { achieving } \\ \text { Low }\end{array} & 1 & - & 1 & 1 & - & 1 & - & - & -\end{array}$

District II (2)

\begin{tabular}{|c|c|c|c|c|c|c|c|c|c|}
\hline $\begin{array}{l}\text { High } \\
\text { achieving }\end{array}$ & - & - & 1 & - & - & - & 1 & 2 & - \\
\hline $\begin{array}{l}\text { Low } \\
\text { achieving }\end{array}$ & 1 & - & 1 & 1 & - & 1 & - & - & - \\
\hline
\end{tabular}

Note. $n=6$ teachers in District $I$ population and 6 teachers in District II population.

asample size in parenthesis.

High performing sixth grade students mastered one stage of writing in both districts (Table 18). Students in District II were reported to exhibit more developed writing abilities than students in District I. Students in District II mastered 
expression of concepts about human values. District I students mastered expression of concepts and expression of concepts about human values.

Table 18

Stage of Mastery of Writing Rerformance Exhibited by Sixth Grade High and Low Performing Students

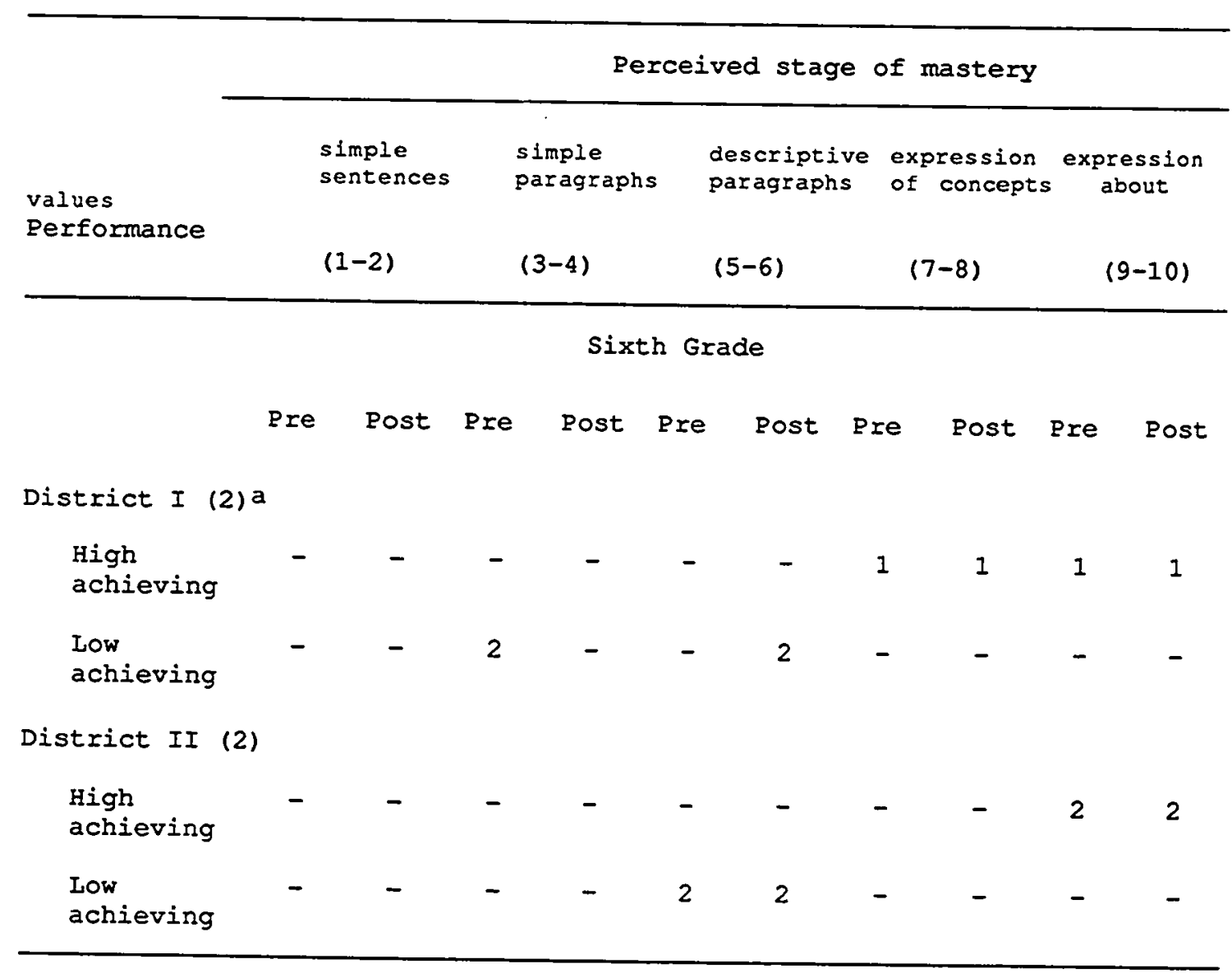

Note. $\mathbf{n}=6$ teachers in District I population and 6 teachers in District II population.

asample size in parenthesis. 
Low performing sixth grade students in District II mastered descriptive paragraphs. Low performing students in District I mastered either simple paragraphs or descriptive paragraphs.

\section{Reading Performance}

Tables 19, 20 and 21 focus on the stages of reading acquisition that teachers reported their students to have mastered on the pre and post interview. Teachers were asked to identify the stage of the reading process that they believed the majority of their high performing students and the majority of their low performing students mastered. Two forms of responses were encouraged: (a) marking a numbered scale, and (b) clarifying their marked response. Each question was read aloud for emphasis. Teachers were asked the following question about the reading performance of their students: At what stage in the reading performance do you believe your advanced students have mastered and what stage have your low students mastered? The discussion of the differences in teacher estimations of students' reading performances follows the sequence of grade levels and high performing students reading progress to low performing students reading progress. First grade teachers in both districts indicated that their high performing students' mastered the reading task as more conceptual and cognitive than simply reading less familiar texts at the end of the study (Table 19). High performing, first grade students in two meaning-centered classrooms and one code-centered classroom began the study reading less familiar 
texts; therefore, progressing through two reading stages rather than progressing through only one reading stage.

Teachers reported that low performing first graders in code-centered classrooms mastered a more advanced stage of reading than the students did in meaning-centered classrooms.

Table 19

Estimated First Grade Reading Performance Exhibited by High and Iow Performing students

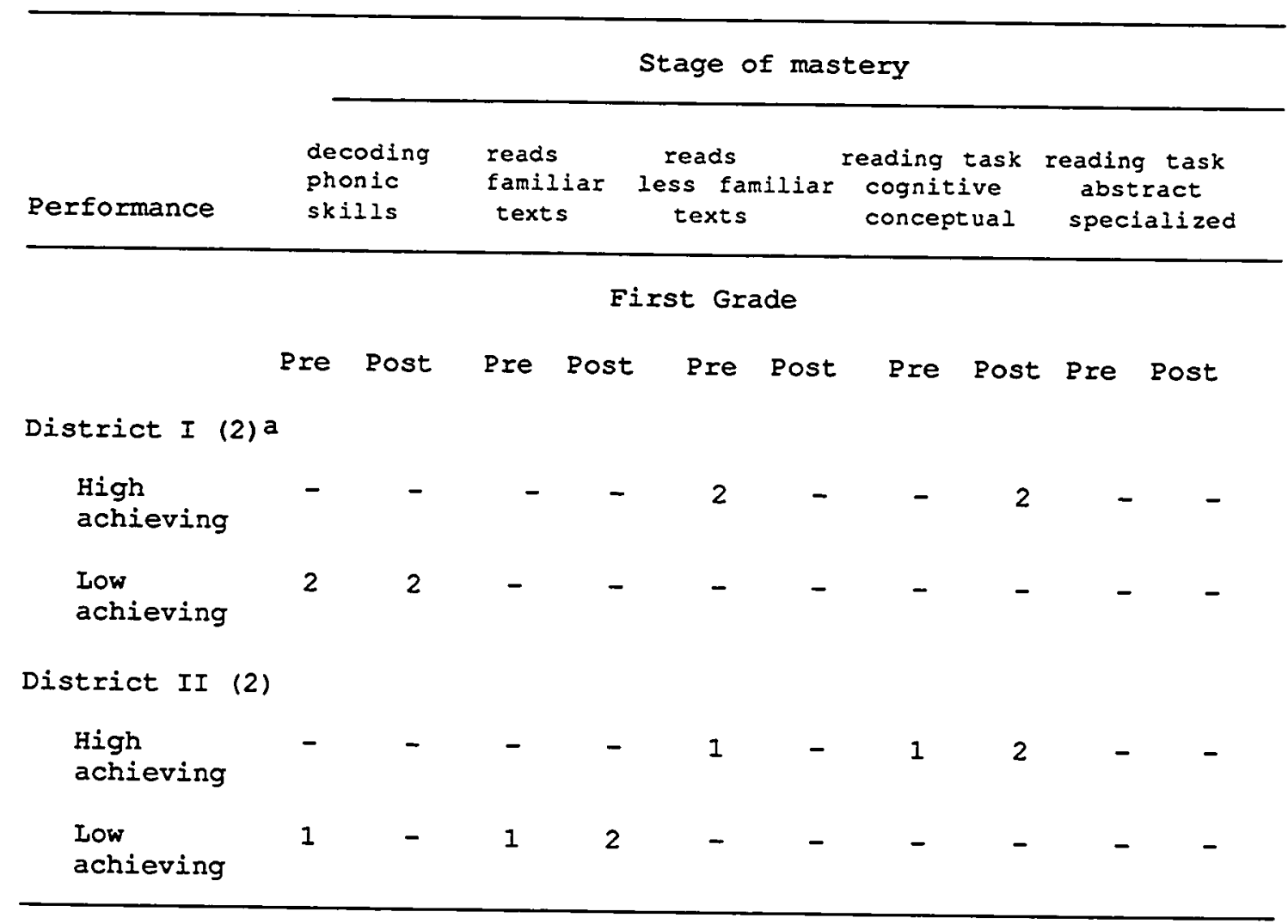

Note. $\mathbf{n}=6$ teachers in District I population and 6 teachers in District II population.

asample size in parenthesis. 
Students from code-centered classrooms mastered decoding skills and the reading of familiar texts; however, low performing students in meaning-centered classrooms mastered the beginning stage of reading, decoding and phonic skills.

Teachers indicated that third grade students in codecentered classrooms exhibited a more advanced reading

Table 20

Estimated Third Grade Beading Performance Exbibited by High and Wow Rerforming students

Stage of mastery

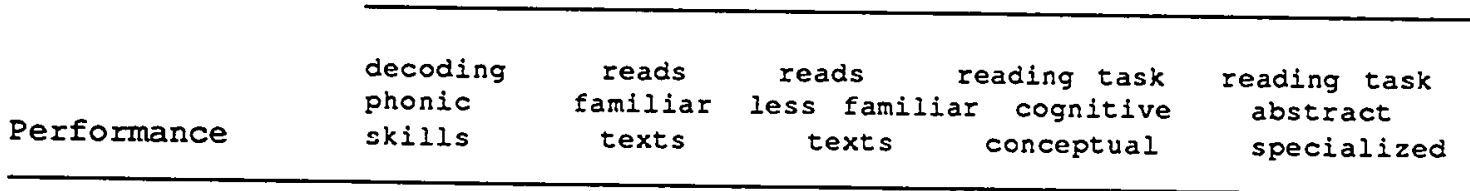

Pre Post Pre Post Pre Post Pre Post Pre Post

District I (2) a
High

achieving

Low

achieving

District II (2)

High

achieving

Low achieving

\section{Third Grade}

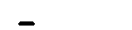

(1)

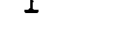

\section{(2)}

Nete. $n=6$ teachers in District I population and 6 teachers in District II population.

asample size in parenthesis. 
performance than students did in meaning-centered classrooms (Table 20). District I students mastered a reading task at the cognitive and conceptual level; however, students in District II mastered a more abstract and specialized reading task.

Table 21

Estimated Sixth Grade Reading Performance Exhibited by High and Iow Rerforming students

\begin{tabular}{|c|c|c|c|c|c|c|c|c|c|c|}
\hline \multirow{4}{*}{ Performance } & \multicolumn{10}{|c|}{ Stage of mastery } \\
\hline & \multicolumn{2}{|c|}{$\begin{array}{l}\text { decoding } \\
\text { phonic } \\
\text { skills }\end{array}$} & \multicolumn{2}{|c|}{$\begin{array}{l}\text { reads } \\
\text { familiar } \\
\text { texts }\end{array}$} & \multicolumn{2}{|c|}{$\begin{array}{l}\text { reads } \\
\text { less familiar } \\
\text { texts }\end{array}$} & \multicolumn{2}{|c|}{$\begin{array}{c}\text { reading task } \\
\text { cognitive } \\
\text { conceptual }\end{array}$} & \multicolumn{2}{|c|}{$\begin{array}{l}\text { reading task } \\
\text { abstract } \\
\text { specialized }\end{array}$} \\
\hline & \multicolumn{10}{|c|}{ Sixth Grade } \\
\hline & Pre & Post & Pre & Post & Pre & Post & Pre & Post & Pre & Post \\
\hline District I (2)a & & & & & & & & & & \\
\hline $\begin{array}{l}\text { High } \\
\text { achieving }\end{array}$ & - & - & - & - & - & - & - & - & 2 & 2 \\
\hline $\begin{array}{l}\text { Low } \\
\text { achieving }\end{array}$ & - & - & 1 & - & 1 & 2 & - & - & - & - \\
\hline District II (2) & & & & & & & & & & \\
\hline $\begin{array}{l}\text { High } \\
\text { achieving }\end{array}$ & - & - & - & - & - & - & - & - & 2 & 2 \\
\hline $\begin{array}{l}\text { Low } \\
\text { achieving }\end{array}$ & - & - & - & - & - & - & 1 & - & 1 & 2 \\
\hline
\end{tabular}

Note. $n=6$ teachers in District I population and 6 teachers in District II population.

asample size in parenthesis. 
One class of third grade, low performing students in District II began the study with a mastery of familiar texts, and in three months they mastered a reading task of less familiar texts; that is, two reading stages. One class of students in District I progressed at the same rate as the one class in District II; however, at the beginning of the study they began with a mastery of decoding skills and in three months mastered the reading of familiar texts.

High performing sixth grade students were reported to have mastered identical reading stages in both districts; that is, a more abstract and specialized stage of reading (Table 21 ). Sixth grade teachers in code-centered classrooms marked low performing students' reading performance at a mastery level two stages higher than teachers in meaning-centered classrooms marked their low performing students. Perceptions of Writing and Beading Performance for Low Achievers

A first grade teacher in District I shared, "Even my little Kate, who we wers considering retaining, wrote four really nice sentences for me."

A third grade teacher in District II noted, "They are more involved with the fluency than they are the mastery. What they are writing is wonderful."

Twelve comments cited specific insights into perceived reading and writing performances of low achieving students resulting from the meaning-centered approaches or code-centered 
approaches to language arts instruction. Each of these twelve comments was reflective of two or more comments of similar nature. Comments were drawn from the additional responses generated from questions 9 and 10 on the pre and post teacher interviews (Appendix C):

1. What stage of an integrated writing ability do you believe your low students mastered?

2. What stage in the reading performance do you believe your low students have mastered?

Comments that provided insight into teacher perceptions of the reading and writing performances of low achievers were as follows :

District $I_{\text {. }}$

1. I have three who really need extra phonics help. They are having double reading.

2. Some of my kids leave my class for 25 minutes of instruction in decoding in Reading Mastery (a systematic integrated skill program).

3. My less advanced kids are just now getting into reading less familiar texts.

4. The new literature is really adding to that (grasping concepts with values). We spend a lot of time discussing the stories and the values inherent in each story.

5. I'm not good enough at cooperative learning to have other students look over and correct it and have it rewritten correctly unless $I$ do it (relating to low kids in class). 
6. We do a lot of oral reading. The material's kind of hard for some of them (Hispanics). They might move along faster if the ratio of Hispanics and Anglos were maybe only five Hispanics out of 30 Anglos.

District II.

7. About 9 or 10 kids go to reading lab. I work total group and then into small groups.

8. Everybody can write something. Now they write more than one word responses. They never used the word "felt" before and they wrote "flet" or "flat" you know, they had the sounds in.

9. Some are still not making letter-sound connection, ending sounds. We still need to back up, drilling with words like fan, man, can. I give them a worksheet. Just to let them practice skills; sometimes they just need some quiet.

10. They can read some familiar text, but they're not transferring it over to unfamiliar material.

11. As far as the concept of a paragraph, I don't know if they've really gotten the idea.

12. We took all kids, regardless of what level and taught them that target and I think they did pass.

Teachers in both districts displayed a perception that they were responsible for teaching their low performing students learning strategies. Their comments indicated that instructional strategies recommended by the prescribed literature program did not provide enough instruction for low performing students to exhibit successful learning strategies. 
Comments 1, 2, and 3, made by first and third grade teachers in

District $I$, indicate that their low performing students need to be given additional skill instruction. Comments 4,5 , and 6 , from third and sixth grade teachers, show that low performing students need additional concept and value discussion, oral reading, and teacher direction with writing abilities.

It is interesting to note that the perceptions of teachers in District II complemented the perceptions of teachers in District I about the learning strategies of low performing students. Comments 7,8 and 9, made by first grade teachers, reflect a need for low performing students to be given additional skill instruction. Comments 10 and 11 note that third grade teachers are concerned that low performing students will not be able to exhibit learning strategies that will transfer to higher levels of reading and writing performances. Comment 12, from a sixth grade teacher, notes that the exhibited learning strategies of sixth grade low performers is reflective of the instructional behaviors specific to the prescribed literature program and specific to the systematic skill program.

Sumary: To what Extent Were Students Able to Exhibit Iearning Strategies Acouired From Being Taught by Teacher Instructional Behaviers Specific to Meaning-centered Strategies and codecentered strategies?

This summary reflects those aspects in the data that give insight into whether or not students are able to exhibit 
learning strategies acquired for reading and writing that prepare students to analyze issues, make decisions, solve problems and communicate effectively relative to their grade level in classroom instruction specific to meaning-centered strategies and code-centered strategies.

High performing third and sixth grade students in meaningcentered classrooms appeared to be able to exhibit reading and writing strategies that shared a mutual relationship. Third grade students were able to exhibit a mastery of cognitive and conceptual reading tasks and a writing mastery of concepts. Sixth grade students exhibited a mastery of abstract and specialized reading tasks and a writing mastery of concepts about the human condition and values.

Third and sixth grade low performing students exhibited similar reading and writing strategies that were mutually influenced by one another: that is, a reading mastery of less familiar texts and a mastery of descriptive paragraphs. Low performing first graders exhibited the connection between a mastery of decoding and phonic skills and a mastery of simple sentences.

High performing first and third grade students and low performing first and sixth grade students in code-centered classrooms appeared to exhibit a mastery of reading strategies more advanced than their writing strategies. High performing first and third grade students in District II exhibited a mastery of advanced reading strategies, cognitive, conceptual, abstract and specialized reading strategies; however, they 
mastered a less advanced range of writing strategies, beginning with simple paragraphs and ending with an expression of concepts.

First grade, and sixth grade low performers in District II exhibited a greater range of mastery with reading and writing strategies: (a) first grade, reading familiar texts and writing simple sentences; (b) sixth grade, mastery of abstract and specialized reading tasks and writing descriptive paragraphs.

High performing sixth grade students exhibited a mastery of reading and writing strategies that mutually influenced each other; a mastery of reading tasks that are abstract and specialized and a mastery of an integrated writing ability to express concepts about human values and conditions.

Code-centered strategies and meaning-centered strategies were used by all twelve teachers; however, teachers in District I emphasized meaning-centered strategies and teachers in District II emphasized code-centered strategies. The extent to which students were able to exhibit reading and writing strategies specific to instructional behaviors related to codecentered classrooms and instructional behaviors related to meaning-centered classrooms were as follows:

Meaning-centered strategies.

1. One high performing first grade class exhibited a mastery of reading abilities more advanced than their writing abilities. 
2. Low performing first grade students exhibited reading and writing abilities that were complementary: simple sentences and decoding skills.

3. High performing first, third and sixth grade students exhibited reading and writing strategies that shared a mutual relationship.

4. Low performing third and sixth grade students exhibited similar reading and writing abilities that were mutually influenced by one another.

code-centered classrooms.

5. High performing first and third grade students exhibited a mastery of reading strategies more advanced than their writing strategies.

6. Low performing third grade students exhibited a mastery of reading ability more advanced than their exhibited writing ability.

7. High performing sixth grade students exhibited a mastery of reading and writing strategies that mutually influenced each other.

8. Low performing first and sixth grade students exhibited a greater range of mastery between reading and writing strategies and reading strategies were more advanced than writing strategies.

Teachers in both districts perceived that a combination of meaning-centered strategies and code-centered strategies provided necessary instruction for low performing students in both districts, and the integration of reading and writing 
instructional strategies had a positive effect on exhibited student performances. A teacher from District II noted, "It seems like the reading helps the writing; the writing helps the reading."

Teachers in both districts perceived that instructional approaches specific to the prescribed meaning-centered literature program did not provide enough instruction for low performing students to be able exhibit successful learning strategies in reading and writing or for students to be able to transfer learned strategies to higher levels of reading and writing performances.

\author{
Research Question Five \\ To What Extent Did Teacher Values and Perceptions \\ Guide Teacher Behavior in a \\ Meaning-Centered Classroom and Code-Centered Classroom?
}

This research question considers the factors, values and perceptions that guide teacher behaviors, lead to individual change and then to organizational change. The new task of implementing the English-Language Arts Framework faces uncertainty until the classroom teachers, guided and supported by the organization, form a perception of the program's success. When the program is socially validated by actual classroom experience and organizational support and as the program continues to be successful then values become embodied 
in the teachers' philosophy. These values can predict observable behavior and will lead to organizational change. A goal of implementing a new language arts program is to facilitate the process of cognitive transformation, identifying assumptions, examining, reexamining, and relearning teacher behaviors congruent with the philosophy of the English-Language Arts Framework. The process of cognitive transformation can be facilitated by interrelating training, modeling, practice and cognitive-conceptual development. An instructional program's success reflects the values, perceptions and behaviors of its teachers.

This research question examines the extent to which teachers' values and perceptions guide their behaviors in a meaning-centered classroom and a code-centered classroom. Questionnaire and interview information focuses on teacher training, perception of organizational support, cognitiveconceptual development, opportunities for modeling, practicing and feedback of instruction, actual classroom experience, perceptions about the number of students who fall below grade level ability in language arts, and the amount of scheduled classroom time for language arts and reading instruction. To analyze this question, nine pieces of data are used originating from the pre and post teacher questionnaires (Appendix D) and the pre and post teacher interviews (Appendix C). Ten tables, 22 through 31, reflect an analysis of the information for this research question: (a) Tables 22, 23, 24 and 25 display the distributions of teacher perceptions of 
organizational support, (b) Table 26 reports time distributions of teacher training and of opportunities for cognitiveconceptual development, (c) Table 27 reflects the number of minutes during a week a teacher spends participating in opportunities for modeling instruction, practicing instruction and receiving feedback on instruction, (d) Table 28 describes the estimated number of students that fall below grade level ability in language arts, and (e) Table 29, 30 and 31 present the number of minutes each day teachers schedule for language arts instruction.

\section{Perceptions of Organizational support}

Table 22, 23, 24 and 25 reflect how much support classroom teachers perceive parents, administration, and peers to be demonstrating for the endorsement of the philosophy of the English-Language Arts Framework in their schools. Teachers were asked to respond to four questions that address support by marking a 5 point numbered scale. The scale was designed to exhibit 5 points with numbers ranging from 15 percent to 100 percent. The greatest range of percentage choices were displayed at the low end, two choices with 15 percent ranges, and the high end, one choice with a 40 percent range. The $85-$ 100 range is not displayed in Table 22, because teachers did not select this range on their questionnaire. Teachers were given the option to mark any percentage that was not displayed. They were reminded that all questions related to the EnglishLanguage Arts Framework philosophy. The first question asked (Appendix D, item number 12): What percentage of your parents 
do you perceive model effective listening, speaking, reading and writing for your students in English?

Table 22 reflects that teachers in both code-centered and meaning-centered classrooms indicated that no more than $80 \%$ or

Table 22

Rarents whe Model Effective Listening, Reading, Speaking, and Writing for Students as Estimated by Teachers

\begin{tabular}{|c|c|c|c|c|c|c|c|c|c|c|}
\hline \multirow[b]{3}{*}{ Grade } & \multicolumn{10}{|c|}{ Frequency of responses } \\
\hline & \multicolumn{5}{|c|}{ District I $(n=6)$} & \multicolumn{5}{|c|}{ District II $(n=6)$} \\
\hline & + & $\begin{array}{c}\text { high } \\
(80-70)\end{array}$ & $(65-55)$ & $(50-35)$ & $\begin{array}{c}\text { low } \\
(30-15)\end{array}$ & + & $\begin{array}{l}\text { high } \\
(80-70)\end{array}$ & $(65-55)$ & $(50-35)$ & $\begin{array}{l}\text { low } \\
(30-15)\end{array}$ \\
\hline Grade & & & & & & & & & & \\
\hline Parents & - & - & - & 2 & - & - & - & 1 & 1 & - \\
\hline Grade & & & & & & & & & & \\
\hline Parents & - & 1 & - & 1 & - & - & - & 1 & - & 1 \\
\hline Grade 6 & & & & & & & & & & \\
\hline Parents & - & - & - & 1 & 1 & - & 1 & - & 1 & - \\
\hline Total & 0 & 1 & 0 & 4 & 1 & 0 & 1 & 2 & 2 & 1 \\
\hline
\end{tabular}

less than 15\% of their parents modeled effective English communication skills for students (teachers did not mark the 85-100 choice, any number between 80 and 100 or any number or choice less than 15). Teachers from both districts were evenly divided in their perceptions between a low percentage of parents who model effective communication and a high percentage 
of parents who model effective communication. Teachers in District II reported that a greater percentage of parents model effective listening, speaking, reading and writing than teachers in District I reported.

The second question (Appendix D, item number 14) of four that addresses support asked: What percentage of teachers, adults, and administrators in your school model effective listening, speaking, reading, and writing for students?

Table 23 reports that teachers perceive a high percentage of fellow teachers, adults and administrators in their schools to model effective listening, speaking, reading and writing for

Table 23

Teachers, Adults and Administraters who Model Effective Listening, Speaking, Reading and Writing for Students as Estimated by Teachers

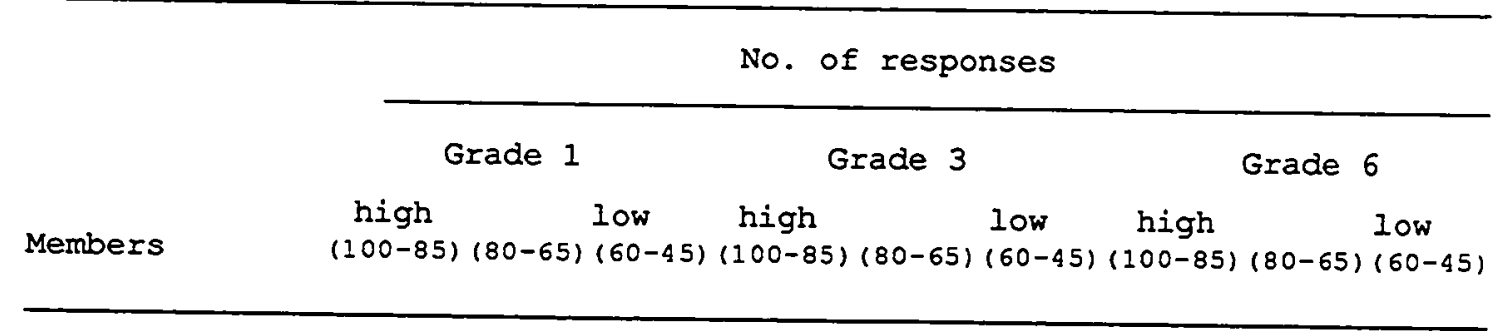

District Ia $^{a}$

$\begin{aligned} & \text { Teachers, adults } \\ & \text { administrators }\end{aligned}$
$\begin{aligned} & \text { District IIb } \\ & \begin{array}{l}\text { Teachers, adults } \\ \text { administrators }\end{array}\end{aligned}$

Note, ${ }^{a}, b_{n}=6$ teachers. 
students. Teachers in District II indicated that $85 \%$ to $100 \%$ of teachers, adults and administrators model effective communication. Teachers in District I reported a greater range by marking $45 \%$ to $100 \%$ of fellow teachers, adults and administrators model effective listening, speaking, reading and writing for students.

The third question (Appendix D, item number 15) of four questions asked: What percentage of teachers in your school teach reading, writing, speaking and listening throughout all subjects?

Table 24 describes that teachers from both districts are equally divided in their perceptions about fellow teachers

Table 24

Teachers whe Teach Reading, Writing, Speaking, and Iistening Throughout Al1 Subjects

\begin{tabular}{|c|c|c|c|c|c|c|c|c|c|}
\hline \multirow[b]{3}{*}{ Teachers } & \multicolumn{9}{|c|}{ No. of responses } \\
\hline & \multicolumn{3}{|c|}{ Grade 1} & \multicolumn{3}{|c|}{ Grade 3} & \multicolumn{3}{|c|}{ Grade 6} \\
\hline & $\begin{array}{c}\text { high } \\
(100-85)\end{array}$ & $(80-65)$ & $\begin{array}{l}\text { low } \\
(60-45)\end{array}$ & $\begin{array}{c}\text { high } \\
(100-85)\end{array}$ & $(80-65)$ & $\begin{array}{l}\text { low } \\
(60-45)\end{array}$ & $\begin{array}{c}\text { high } \\
(100-85)\end{array}$ & $(80-65)$ & $\begin{array}{l}\text { low } \\
(60-45)\end{array}$ \\
\hline \multicolumn{10}{|c|}{ District $I^{a}$} \\
\hline Teachers & 1 & - & 1 & 2 & - & - & 1 & 1 & - \\
\hline \multicolumn{10}{|c|}{ District IIb } \\
\hline Teachers & - & 1 & 1 & - & 2 & - & 2 & - & - \\
\hline
\end{tabular}

Note. $a, b \mathrm{n}=6$ teachers. 
teaching reading, writing, speaking and listening throughout all subjects. Five teachers in District I and District II indicated that $65 \%$ to $100 \%$ of fellow teachers teach reading, writing, speaking and listening throughout all subjects.

The fourth question (Appendix $C$, item number 6) that addresses support asked: On a scale of 1-10, how much administrative support do you have for your English-Language Arts program? Support was defined as more than adequate curriculum materials, school activities, publication resources, student academic acknowledgment, teacher reinforcement, parent involvement and coordination.

Table 25 shows that teachers from both districts perceived

Table 25

Amount of Administrative Suppert for Ianguage Arts Program as Estimated by Teachers

\begin{tabular}{|c|c|c|c|c|c|c|c|c|c|c|}
\hline \multirow[b]{3}{*}{ Grade } & \multicolumn{10}{|c|}{ Numbered scale frequency } \\
\hline & \multicolumn{5}{|c|}{ District I $(n=6)$} & \multicolumn{5}{|c|}{ District II $(a=6)$} \\
\hline & $\begin{array}{c}\text { high } \\
(10-9)\end{array}$ & $(8-7)$ & $(6-5)$ & $(4-3)$ & $\begin{array}{l}\text { low } \\
(2-1)\end{array}$ & $\begin{array}{l}\text { high } \\
(10-9)\end{array}$ & $(8-7)$ & $(6-5)$ & $(4-3)$ & $\begin{array}{l}\text { low } \\
(2-1)\end{array}$ \\
\hline Grade 1 & - & 1 & - & - & 1 & 1 & 1 & - & - & - \\
\hline Grade 3 & 2 & - & - & - & - & 1 & - & 1 & - & - \\
\hline Grade 6 & 1 & 1 & - & - & - & 2 & - & - & - & - \\
\hline Total & 3 & 2 & 0 & 0 & 1 & 4 & 1 & 1 & 0 & 0 \\
\hline
\end{tabular}


that they have a great deal of administrative support for the language arts program as indicated by the scaled responses of ten teachers who marked support between the scaled numbers of 7 and 10. Only one teacher in District I felt that administrative support was low.

The success of the language arts program depends on the continued support of the organization and social validation before values and perceptions concerning the program begin to guide teacher behaviors. Teachers in District II reported more support from parents, teachers, adults and administrators in modeling effective listening, speaking, reading and writing communication than teachers in District $I$.

About half the teachers in District $I$ and all six teachers in District II indicated that fellow teachers and administrators support the language arts program at a high level (Table 23). Teachers in District II perceived that peer and administrative support was at the highest level by marking 85-100; however, only three teachers in District I perceived peer and administrative support at the 85-100 level (Table 23). Teachers in District I indicated more support from fellow teachers than did teachers in District II (Table 24). Teachers in District II marked more administrative support than did teachers in District I (Table 25). It appears that several teachers in this study are still in the process of forming perceptions of the program's success through social validation and organizational support. About half of the teachers in 
District I and about one third of the teachers in District II have not formed a perception of the program's success (the 85100 responses were tallied in Tables 23, 24 and 25 and divided by 18 , the total responses possible, to determine the number of teachers that perceive peer and administrative support). Therefore, values and perceptions of the new language arts philosophy are not guiding teacher behaviors, because the majority of teachers do not perceive social validation and organizational support. epportunities for Cognitive-Conceptual Development

Tables 26 and 27 report the amount of time teachers have spent learning about how to teach an integrated language arts program in graduate classes and the amount of time spent with cognitive-conceptual opportunities specifically designed for the language arts integrated program during the last three years, 1988-1990. Teachers were asked to mark the number of graduate hours beyond the Elementary Teaching Credential earned and the number of teaching credentials held on the pre and post teacher questionnaire (Appendix D, item numbers 3 and 4). During the teacher interview, teachers were asked to estimate the number of hours spent in staff development workshops or conferences related to the English-Language Arts curriculum program (Appendix C, item number 8). Examples were provided for the purpose of activating memories: (a) school based management, (b) curriculum publisher's material presentations, (c) San Diego Area Writing Project, and (d) California Iiterature Program. Table 26 details the number of hours 
teachers estimated that they spent learning about integrated language arts curriculum.

Table 26 indicates that teachers in District II have spent a total of 62 more hours in language arts workshops over the past three years than teachers represented in District I. Teachers in District II have earned a total of 14 more hours of graduate units than teachers represented in District I. It appears that teachers in District II accepted the opportunities offered to participate in professional growth and change in preparation for the English-Language Arts Framework implementation more often than did teachers in District $I$.

Table 26

Teacher Education in Integrated Ianguage Arts Instruction

\begin{tabular}{|c|c|c|c|c|}
\hline \multirow[b]{3}{*}{ Population } & \multicolumn{4}{|c|}{ No. of estimated hours } \\
\hline & \multicolumn{2}{|l|}{ District I $(n=6)$} & \multicolumn{2}{|c|}{ District II $(n=6)$} \\
\hline & Workshops Graduate & units & Workshops & Graduate units \\
\hline Grade 1 & 79 & 18 & 63 & 28 \\
\hline Grade 3 & 66 & 6 & 84 & 16 \\
\hline Grade 6 & 76 & 31 & 136 & 25 \\
\hline Total & 221 & 55 & 283 & 69 \\
\hline
\end{tabular}

Teachers were asked to respond to the following question (Appendix D, item number 17) that addresses the amount of time 
spent with cognitive-conceptual opportunities by marking a 5 point scale: How many minutes during a week do you participate in an observation of instruction in language arts and reading followed by an analysis of the observation and feedback?

Table 27 indicates the number of minutes during a week teachers participated in an observation of instruction in language arts followed by an analysis of the observation and feedback. Table 27 reports that only one sixth grade teacher in District II spent 25 to 40 minutes each week participating in the observation of instruction followed by an analysis of the observation and feedback. All 11 remaining teachers reported that that they spent 20 minutes or less each week

Table 27

Rerceptions Developed by Teacher Population and Instructional observation and Feedback

\begin{tabular}{|c|c|c|c|c|c|c|c|c|}
\hline \multirow[b]{3}{*}{ Population } & \multicolumn{8}{|c|}{ No. of minutes per week } \\
\hline & \multicolumn{4}{|c|}{ District I $(n=6)$} & \multicolumn{4}{|c|}{ District II $(n=6)$} \\
\hline & $(0-20)$ & $(25-40)$ & $(45-60)$ & $(65-80)$ & $(0-20)$ & $(25-40)$ & $(45-60)$ & $(65-80)$ \\
\hline Grade 1 & 2 & - & - & - & 2 & - & - & - \\
\hline Grade 3 & 2 & - & - & - & 2 & - & - & - \\
\hline Grade 6 & 2 & - & - & - & 1 & 1 & - & - \\
\hline Total & 6 & 0 & 0 & 0 & 5 & 1 & 0 & 0 \\
\hline
\end{tabular}


participating in the observation followed by an analysis and feedback of the observation of language arts and reading classes.

The practice of interrelating modeling, practice and cognitive-conceptual development is minimal in both districts. This interrelation tends to have a great effect on teacher practices because this process of learning, reexamining, changing and relearning leads to changes in values, behaviors, basic assumptions, commitment and change. When teachers work together, share ideas, discuss and analyze successes and problems a common language will emerge. The successful implementation of an intervention model requires careful cognitive training and practice rather than exposure through talking. Knowing about the program does not produce changes in perceptions and values. It appears that teacher values and perceptions concerning the philosophy of the English-Ianguage Arts Framework are not guiding the behaviors of six teachers in District $I$ and five teachers in District II. Perceptions of Student's Grade Level Ability

"Teachers have these scary dreams or these nightmares, that they'll (students) come back to school and won't know anything," commented a third grade teacher in District II. "This fear that the parent is going to...say, 'How come you didn't teach my child?," " stated a third grade teachers in District $I$. 
"After the holidays, they (students) always look more tolerant; they always look more grown up; they always look more capable; they come back ready to go, "explained a first grade teacher in District II.

Teacher instructional behaviors are guided by their perceptions of their students: abilities. Teachers were asked to respond to the question on the pre and post questionnaire (Appendix D, item number 11) by marking a 5 point scale. The estimated percentages on the pre and post questionnaire reflected the same numbers. The question asked was: What percentage of students in your language arts class would you identify who fall below grade level ability in language arts and reading?

In Table 28, teachers from both districts estimated that between $15 \%$ and $50 \%$ of their students fall below grade level ability in language arts and reading: 5 teachers in District I and 6 teachers in District II. One sixth grade class in District I was estimated to have 55 웅 to $65 \%$ of its students below grade level ability in language arts, more than 15 students in a class of 30 . Teachers in both districts perceive that they have as few as $15 \%$ of their students below grade level.

The amount of time throughout one day that teachers assign to various classroom activities is a reflection of teachers' values and perceptions. An integrated language arts program somewhat eliminates a recommended time framework. Additionally, teachers must work around recess and lunch 
schedules and schedule the maximum amount of time for instructional emphasis in each subject of class instruction.

Table 28

Estimation of Percentage of Students whe Eall Below Grade Level Ability in Ianguage Arts

Frequency of estimated percentages

Grade $(100-85)$

$(80-70)$

$(65-55) \quad(50-35)$

$(30-15)$

\begin{tabular}{|c|c|c|c|c|c|c|}
\hline \multirow[b]{2}{*}{ Grade } & \multirow[b]{2}{*}{1} & \multicolumn{5}{|c|}{ District I $(n=6)$} \\
\hline & & - & - & - & - & 2 \\
\hline Grade & 3 & - & - & - & 1 & 1 \\
\hline \multirow[t]{3}{*}{ Grade } & 6 & - & - & 1 & - & 1 \\
\hline & Total & 0 & 0 & 1 & 1 & 4 \\
\hline & & \multicolumn{5}{|c|}{ District II $(a=6)$} \\
\hline Grade & 1 & - & - & - & 1 & 1 \\
\hline Grade & 3 & - & - & - & 2 & - \\
\hline Grade & 6 & - & - & - & - & 2 \\
\hline & Total & 0 & 0 & 0 & 3 & 3 \\
\hline
\end{tabular}

Teachers were asked to answer four questions by marking a 5 point numbered scale of minutes on the post questionnaire (Appendix D, item numbers $5,6,7$ and 8 ). The questions were as follows: 
1. How many minutes each day do you have scheduled for language arts instruction which includes reading?

2. How many minutes each day do you schedule for direct instruction of language arts which includes reading?

3. How many minutes each day do you schedule for teaching language skills which includes reading skills?

4. How many minutes each day do you schedule for independent language arts activities which includes reading?

Tables 29, 30 and 31 reflect the scheduled minutes for language arts and reading instruction by grade levels as reported by teachers in code-centered and meaning-centered classrooms.

Table 29 indicates that first grade teachers did not schedule language arts and reading instruction for less than 20 minutes or more than two hours each day in either district. There appears to be a wide variety of times scheduled for language arts instruction among teachers in the same district and between districts. First grade teachers represented in District II scheduled more total minutes each day for language arts and reading instruction than did teachers in District I. Most of the minutes appear to be scheduled for independent activities which includes reading activities. Teachers in District $I$ indicated that they scheduled more minutes for teaching skills and direct instruction than did teachers in District II.

Third grade teachers in District II (Table 30) also reported that they scheduled more total minutes for language 
arts and reading instruction than did District $I$. They scheduled more time for direct instruction than did teachers in District I. However, teachers in District I scheduled more minutes for independent activities.

Table 29

Scheduled Minutes for First Grade Language Arts Instruction as Reported by Teachers

\begin{tabular}{|c|c|c|c|c|c|}
\hline \multirow[b]{2}{*}{ Activity } & \multicolumn{5}{|c|}{ Frequency of no. of minutes } \\
\hline & $(20-30)$ & $(40-50)$ & $(60-70)$ & $(80-90)$ & $(100-120)$ \\
\hline & \multicolumn{5}{|c|}{ First Grade } \\
\hline \multicolumn{6}{|l|}{ District I (2)a } \\
\hline Total time scheduled & - & - & 1 & - & 1 \\
\hline Direct instruction & 1 & - & - & - & 1 \\
\hline Teaching of skills & 1 & - & - & 1 & - \\
\hline Independent activities & 2 & - & - & - & - \\
\hline \multicolumn{6}{|l|}{ District II (2) } \\
\hline Total time scheduled & - & - & - & - & 2 \\
\hline Direct instruction & 1 & - & 1 & - & - \\
\hline Teaching of skills & 1 & 1 & - & - & - \\
\hline Independent activities & 1 & - & 1 & - & - \\
\hline
\end{tabular}

Note. $n=6$ teachers in District I population and 6 teachers in District II population.

asample size is in parenthesis. 
Table 30

Scheduled Minutes for Third Grade Ianguage Arts Instruction as Reported by Teachers

\begin{tabular}{|c|c|c|c|c|c|}
\hline \multirow[b]{2}{*}{ Activity } & \multicolumn{5}{|c|}{ Frequency of no. of minutes } \\
\hline & $20-30)$ & $(40-50)$ & $(60-70)$ & $(80-90)$ & $(100-120)$ \\
\hline \multicolumn{6}{|c|}{ Third Grade } \\
\hline District I (2)a & & & & & \\
\hline Total time scheduled & - & - & 1 & 1 & - \\
\hline Direct instruction & 1 & 1 & - & - & - \\
\hline Teaching of skills & 2 & - & - & - & - \\
\hline Independent activities & - & 2 & - & - & - \\
\hline \multicolumn{6}{|l|}{ District II (2) } \\
\hline Total time scheduled & - & - & - & 2 & - \\
\hline Direct instruction & 1 & - & $I$ & - & - \\
\hline Teaching of skills & 2 & - & - & - & - \\
\hline Independent activities & 1 & 1 & - & - & - \\
\hline
\end{tabular}

Note. $n=6$ teachers in District I population and 6 teachers in District II population.

asample size is in parenthesis. 
Sixth grade teachers (Table 31 ) in District I indicated that they scheduled more total minutes for language arts

Table 31

Scheduled Minutes for Sixth Grade Lanowage Arts Instruction as Reported_by Teachers

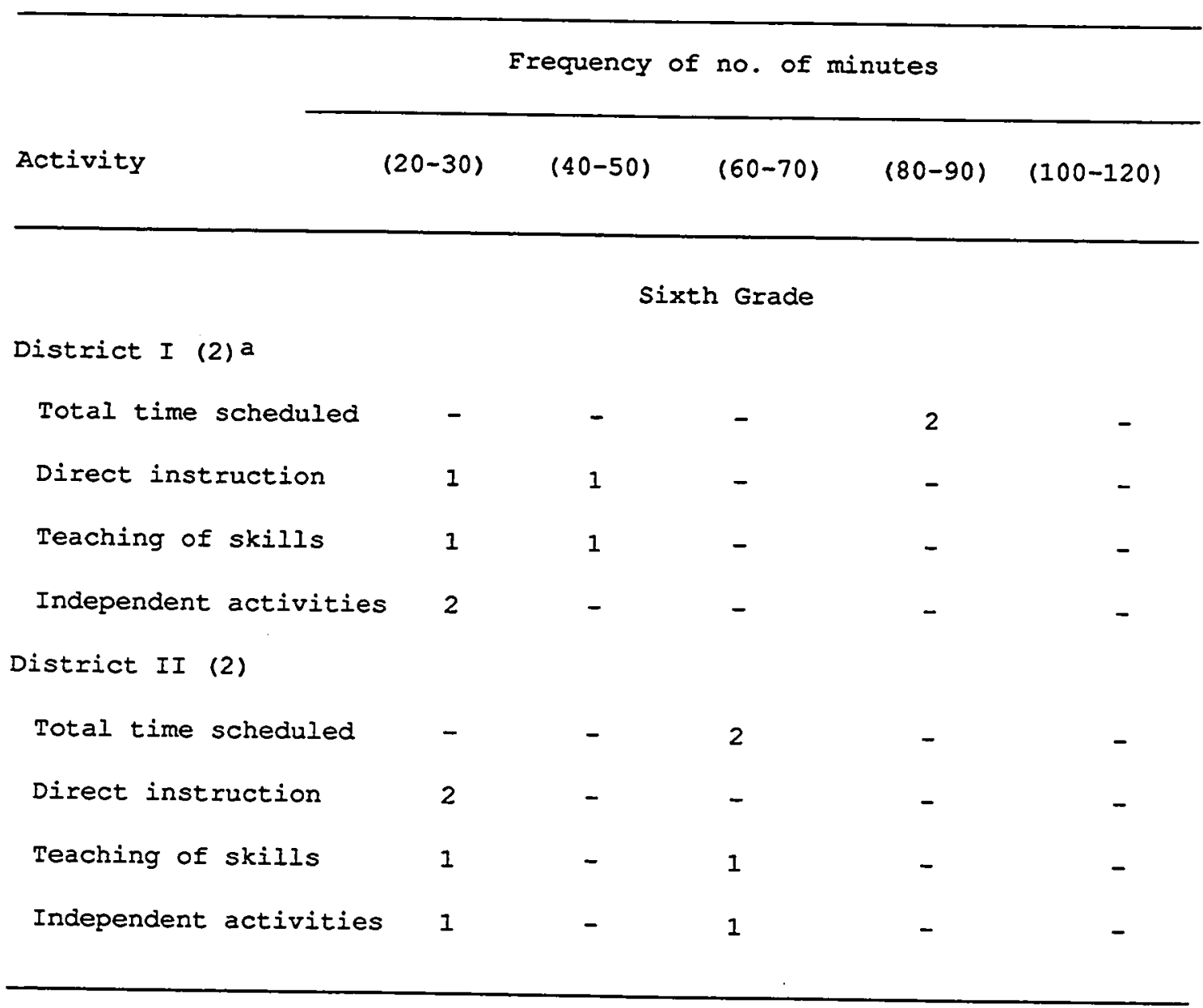

Note. $n=6$ teachers in District I population and 6 teachers in District II population.

asample size in parenthesis. 
instruction than did District II teachers, but teachers in District II scheduled more minutes for the teaching of skills and independent activities.

The English-Language Arts Framework recommends that students should hear good literature read aloud daily, provide many opportunities for students to express themselves, to speak and be heard, provide instruction in phonics in first grade and write daily. Additionally, students should receive feedback on their performances. The amount of time scheduled to complete these recommendations appear to be varied and limited. Furthermore, the scheduled times appear to be the decision of the teachers whose values and perceptions guide their behaviors.

Teachers in District II scheduled more time for language arts instruction and more time for direct instruction in first and third grades and more time for independent activities in first and sixth grades than did teachers in District I. Only three of twelve teachers scheduled less than 80 minutes of instructional time daily for language arts, one first grade teacher in District $I$ and two sixth grade teachers in District II. In fact, the sixth grade teacher in District I who indicated that more than half his/her class exhibited below grade level ability in Table 28 , scheduled 20 minutes of skill instruction, 20 minutes of independent activities and 40 minutes for hearing literature read daily, writing daily, introducing and discussing vocabulary and themes and providing opportunities for students to work in small groups and share 
ideas with each other and provide feedback strategies for students. A 40 minute period of time doesn't seem like enough time for integrated language arts instruction with more than 50 of of the students performing below grade level. Teacher Perceptions of the Strengths and Weaknesses of the Ianguage Arts Curriculum

"I love the literature half of it and how much the kids are exposed to language and writing, but I'm not happy with how it teaches kids how to read. For me it's a crutch. I like to teach them...," commented a third grade teacher in District I. Sixteen comments cited specific insights into the teachers' perceptions about the strengths and weaknesses of the integrated language arts curriculum program that guides instructional behavior in a meaning-centered approach and codecentered approach to language arts instruction. This researcher's intent was to ask teachers to describe the differences in the strengths and weaknesses between an integrated language arts curriculum program exemplified by the prescribed integrated literature series presently used for instruction and an integrated language arts program containing a balance between an integrated literature program and a systematic skill program recommended by the administration or recommended by education, training or experience. The interview question (Appendix C, item number 7) that was asked at the beginning of the study and at the end of the study was the following: How would you describe the differences in the strengths and weaknesses between an integrated English-Language 
Arts curriculum program and an integrated language arts literature program with a systematic skill program component?

Comments that provide insight into the perceived differences between the strengths and weaknesses of the integrated language arts curriculum program that guides instructional behavior in a meaning-centered and code-centered classroom were as follows:

Strengths of orescribed literature orogram

District I.

1. I know they (integrated literature program) skip around, but I prefer that. A lot of times, you could pick up on what they (students) aren't getting and teach to the skill that they need.

2. It (integrated literature program) is kind of as a stepping off place for doing work on phonics, teaching about the main idea, sequencing, and rhyming words.

3. You're actually putting more emphasis on language as a whole. I feel a lot freer to present many different areas of knowledge all within the frame context. I don't have $\mathrm{x}$ number of minutes for writing which has a tendency to kind of split the language arts skills apart rather than draw them together.

4. It's more interesting to prepare. For me it's stimulating. Because of the stimulation, I don't mind spending the extra time to prepare.

District II.

5. The children love the books. When you have the high readers or low readers in the same book, the low ones just come 
to life. You don't have to work to get their interest up. I sort of noticed that I've slacked back a little on the skills. It's easy when you're enjoying it so much. You just have so much fun doing other things.

6. If you mean doing all the testing, mastery teaching, a systematic skills approach as opposed to just bringing up the skill when it arises in the story...personally, I prefer it this way.

7. I can see now at the tail end... ah ha! Here are the skills, now I see why this is working right.

8. The kids seem to pick up on and accelerate faster in their acquisition of skills and in their appreciation of literature and their writing.

9. I feel more comfortable not having to teach certain skills.

Weaknesses of Prescribed Iiterature Program

District I.

10. I feel like unless a program has a skill component, it's not going to be addressing all of the children. I'm bringing in other resources and materials to beef that up and I feel that the kids aren't getting that.

11. They are playing with it (the literature program), learning to appreciate it, learning to enjoy it, but I don't feel it's complete.

12. I'd like to see a skill based component to this program. 
13. It's doing a great job for helping the kids to think more imaginatively, but their writing skills and reading skills, I don't think it helps them understand language or terminology they need when they have to answer state tests. District II.

14. The weakness is the English-Ianguage Arts approach, you will still have to concentrate on the specific skills, because of the nature of the children. My class is high academically, but it (class) still comes low.

15. I prefer the prescribed literature program, but I'm careful to make sure that all those skills are touched on through the day and week.

16. I'm expecting some parents whose children don't quite read, not to be too thrilled about it (prescribed literature program).

Thirteen of a total of 16 teacher comments reflected dual objectives in a language arts program; the appreciation of literature and the acquisition of skills. Three comments from teachers in District I and two comments from teachers in District II that addressed the weaknesses of the literature program indicated that teachers felt that the prescribed language arts program lacked a strong skill component. Three teachers in District $I$ and five teachers in District II commented that the strengths of the prescribed literature program were related to the relationship between the teaching of skills and the teaching of literature. 
Summary: To what extent did teacher values and perceptions guide teacher behavior in a meaning-centered classroom and a code-centered classroom?

This summary deals with those aspects in the data that provide insight into the values and perceptions that teachers have of the integrated language arts curriculum program in the first year of implementing the integrated program. As the integrated program is socially validated by actual classroom experience and organizational support, then values and perceptions become embodied in the teachers' philosophy and in their instructional behaviors which lead to organizational change.

Teacher behaviors are a function of their values and perceptions which predispose an individual to respond in some selective manner. The extent to which teacher values and perceptions guided their behaviors in language arts classroom instruction were the following:

1. Teachers perceived organizational support of the English-Language Arts Framework. Therefore, teachers' values and perceptions guided their behaviors to support organizational change efforts in both districts. Organizational support of the language arts implementation efforts was generally perceived to be at a high level; however, perceptions and values are still being formed of the prescribed program's success through social validation and organizational support. Support was perceived to be greater by teachers in code-centered classrooms. Teachers acknowledged and perceived 
members of the organization, fellow teachers and administrators to be supporting the philosophy of Language Arts Framework. Teachers perceived that members of the organization modeled effective communication skills and provided curriculum materials, student acknowledgement, teacher reinforcement and encouraged parent involvement generally at the high end of a 5 point scale in both districts. However, District II teachers perceived support to be greater than did teachers in District I. First grade teachers in both districts perceived support was less than third and sixth grade teachers. Teachers in District II felt that teachers, adults and administrators modeled effective communication in their organization more than teachers in District I felt about their organization. Parent support was rated to be greater by teachers in District II than by teachers in District I. It appears that the process of forming perceptions of the prescribed program's success through social validation and organizational support is still in motion and on going.

2. The extent to which cognitive-conceptual transformation was facilitated, leading to individual changes in values and perceptions which guide teacher behaviors and thus organizational change, was minimal in both districts. Opportunities for cognitive-conceptual development over the last three years was reported by teachers to be greater in code-centered classrooms than in meaning-centered classrooms. Opportunities for modeling, practicing and feedback of instruction was rated by 11 teachers to be zero to 20 minutes 
each week. Half of the teachers in each district have not formed a perception of the program's success; therefore, it appears that there is minimal effect on values and perceptions concerning the philosophy of the English-Language Arts Framework guiding the behaviors of six teachers in District I and five teachers in District II.

3. The extent to which teacher perceptions about the number of students who fall below grade level ability in classrooms guided teacher behaviors to respond in selective instructional manners was reflective of the values and perceptions teachers have about language arts instruction and low performing students. The extent to which teachers' values and perceptions about language arts predisposed their selection of the amount of instructional time, and the opportunities and experiences they provided for low performing students varied in code-centered and meaning-centered classrooms: The classes with the greatest number of reported low performing students scheduled more time for literature experiences than skill instruction, direct instruction and independent activities. First and third grade teachers in code-centered classrooms scheduled more literature experiences and opportunities for their low performers; sixth grade teachers in meaning-centered classrooms scheduled more literature experiences for their low performers.

The amount of instructional time scheduled for language arts appeared to be the decision of the teachers, whose values and perceptions guide their behaviors. The amount of

Reproduced with permission of the copyright owner. Further reproduction prohibited without permission. 
instructional time scheduled for the teaching of skills and independent activities varied with grade level and district. Teachers in meaning-centered classrooms scheduled more time for direct instruction and skill instruction in first grade than did teachers in code-centered classrooms; first and third grade teachers in meaning-centered classrooms reported a lower percentage of students with low abilities than were reported code-centered classrooms (Table 28). On the other hand, third grade teachers in meaning-centered classrooms scheduled the least amount of time for direct instruction and skill instruction than did the third grade teachers in District II and first grade teachers in both districts (Table 30). Code-centered classrooms scheduled more time for literature instruction in first and third grades than teachers in meaning-centered classrooms (Tables 29 and 30). Therefore, more time was scheduled for literature instruction for the greater percentage of first and third grade students with low abilities.

Sixth grade teachers in code-centered classrooms scheduled more time for skill instruction and independent activities than was scheduled in meaning-centered classrooms: sixth grade teachers in code-centered classrooms reported a lower percentage of students with low abilities than was reported meaning-centered classrooms.

Sixth grade teachers in meaning-centered classrooms scheduled more time for literature instruction than did teachers in code-centered classrooms; teachers in meaning- 
centered classrooms reported a higher percentage of low performing students.

The extent to which teacher values and perceptions guided their behaviors was reflected in their perceptions about organizational support, perceptions developed through cognitive and conceptual efforts, and perceptions about effective teaching practices. The opportunities and experiences that teachers emphasized in their language arts instruction were an indication of their perceptions about teaching practices.

\author{
Research Question Six \\ To What Degree Was the Classroom Teacher Committed \\ to Implementing and Using \\ a Code-Centered Approach or a Meaning-Centered Approach \\ to Teach the English-Language Arts Curriculum? \\ "I would never want to go back to the basal reading. \\ Every day is a different experience. I am enjoying the \\ integrated program," reported a first grade teacher in District
} I.

This research question concentrates on the forces that generate a sense of commitment to a new curriculum intervention, the English-Language Arts Framework. Teacher commitment is interrelated with values, perceptions and behaviors. Research question five explored the extent to which values and perceptions guide teacher behaviors. If teachers' 
see that their behaviors, reflecting the philosophy of the language arts curriculum program, continue to be effective with students, a sense of commitment is generated. A goal of implementing a new language arts program is to facilitate the forces that transform to a sense of commitment. In this study, the forces that lead to a sense of commitment are encased in collegial feedback. Collegial feedback facilitates two types of forces: (a) counterforces, which are open discussion of concerns, new ideas, and issues, open discussion of research and open confrontation with personal basic assumptions; and (b) awareness, which are sharing and analyzing common language, views, feelings, attitudes, successes, problems, perceptions and values.

This research question examines the differences in teacher commitment in a meaning-centered classroom and a code-centered classroom. Questionnaire and interview information focuses on the amount of time teachers participated in collegial feedback and the comments that teachers used to describe the behaviors of their students during language arts instruction. The amount of time a teacher participates in one or more teacher feedback systems will indicate changes in commitment and interpersonal behaviors.

To analyze this question, four pieces of data were used originating from the post teacher questionnaire (Appendix D) and the pre and post teacher interviews (Appendix C). Tables 32, 33 and 34 reflect an analysis of the information for this research question by reporting the number of minutes during one 
week teachers participated in collegial feedback. These tables detail three feedback systems: (a) participation with peers talking about instructional practices used in language arts instruction, (b) finding solutions to teacher identified problems, and (c) mastering specific teaching skills based on models of teaching and supported with staff development. On the teacher post questionnaire, teachers were asked to answer three questions by marking the number of minutes each week they participated with other teachers on a 5 point scale. The following questions were asked (Appendix D, item numbers 16, 18 and 19:

1. How many minutes during a week do you participate with your peers in talking about instructional practices used in language arts classes which includes reading?

2. How many minutes during a week do you participate with others in mastering specific teaching skills based on models of teaching and supported with staff development?

3. How many minutes during a week do you participate in finding solutions to teacher identified problems among your peers?

\section{Teacher Participation in Cellegial Bonding}

In Table 32, the total number of teachers in the first column indicates that seven out of 12 teachers, 58\% of the teachers, may not have participated in collegial activities or may have spent only 20 minutes each week participating with peers. Table 32 reports that first grade teachers in District II participated in two feedback systems 5 minutes to 40 minutes 
more each week than did teachers in District I. First grade teachers talked with one another and discussed problems and solutions. Working together to solve problems and to discuss their language arts instruction expands their awareness of different views, feelings and attitudes which leads to

Table 32

Number of Minutes Committed te Panticipating in collegial Activities by Eirst Grade Teachers

\begin{tabular}{|c|c|c|c|c|c|}
\hline \multirow[b]{2}{*}{ Activities } & \multicolumn{5}{|c|}{ Frequency of no. of minutes per week } \\
\hline & $(0-20)$ & $(25-40)$ & $(45-60)$ & $(65-80)$ & $(85-120)$ \\
\hline & \multicolumn{5}{|c|}{ First Grade Teachers } \\
\hline \multicolumn{6}{|l|}{ District I $(2) a$} \\
\hline Talking with peers & 1 & 1 & - & - & - \\
\hline Finding solutions & 2 & - & - & - & - \\
\hline Mastering teaching skills & 2 & - & - & - & - \\
\hline \multicolumn{6}{|l|}{ District II (2) } \\
\hline Talking with peers & - & - & 1 & 1 & - \\
\hline Finding solutions & - & - & - & 2 & - \\
\hline \multirow[t]{2}{*}{ Mastering teaching skills } & 2 & - & - & - & - \\
\hline & 7 & 1 & 1 & 3 & 0 \\
\hline
\end{tabular}

Note, aThe number in parenthesis represents the number of teachers in sample population. 
interpersonal development, to effective teaching, to commitment and to organizational change. These first grade teachers in code-centered classrooms appear to believe that by working together in a collaborative way they could bring about higher levels of student performance during the implementation of a new language arts program.

Table 33

Number of Minutes Comnitted to Participating in Collegial Activities by Third Grade Teachers

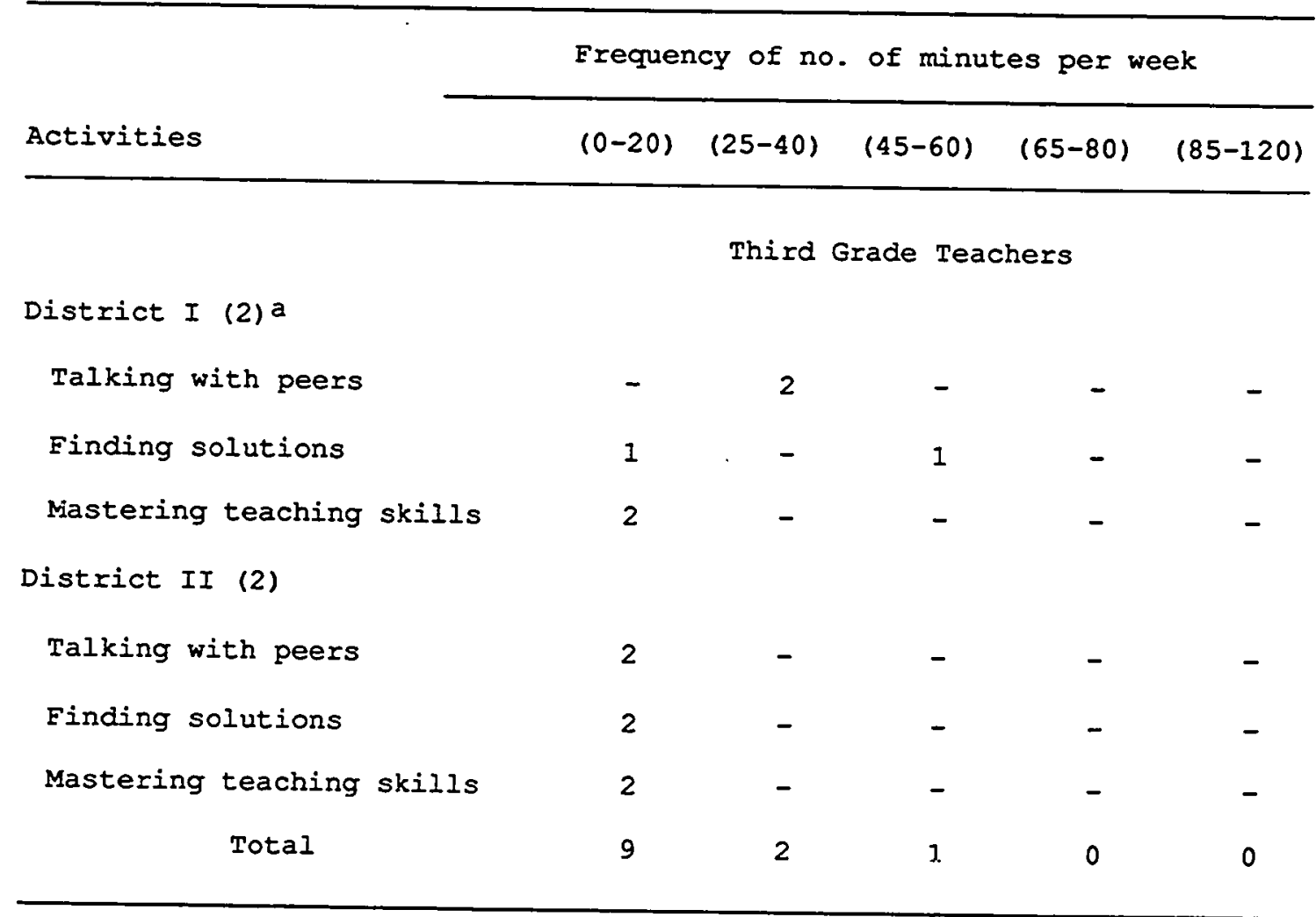

Note. aThe number in parenthesis represents the number of teachers in sample population. 
In Table 33, the total number of nine teachers in the first column (0-20) indicates that nine out of 12 teachers, 75\% of the teachers, may not have participated in collegial activities or may have spent only 20 minutes each week participating with peers. Table 33 notes that both third grade teachers in District I participated in one feedback system 5 to 40 minutes each week more than teachers in District II. It appears that the two third grade teachers talked together about language arts instruction; however, only one teacher shared problems and found solutions with another teacher not in the study. Since one third grade teacher in the study participated in cooperative learning and bonding, it is expected that high levels of student performance will occur in at least one third grade class.

Table 34 indicates that sixth grade teachers in both districts participated in collegial activities about the same amount of time each week; the total number of teachers reflected in columns one, two and three reflect identical numbers, five and one. Sixth grade teachers in both districts participated in three feedback systems from one to three hours each week. All four of these teachers talked with peers about language arts instruction, discussed problems and solutions and worked together to master skills. Cooperation among teachers increases the need to be productive and accountable to one another. This common bonding among teachers helps conceptualize and analyze the language arts intervention model. High levels of student performance are expected to occur in the 
sixth grade code-centered classrooms, because cooperation and bonding among sixth grade teachers help to improve instruction and help teachers master skills.

Table 34

Number of Minutes committed to Participating in Collegial Activities by Sixth Grade Teachers

\begin{tabular}{|c|c|c|c|c|c|}
\hline \multirow[b]{2}{*}{ Activities } & \multicolumn{5}{|c|}{ Frequency of no. of minutes per week } \\
\hline & $(0-20)$ & $(25-40)$ & $(45-60)$ & $(65-80)$ & $(85-120)$ \\
\hline & \multicolumn{5}{|c|}{ Sixth Grade Teachers } \\
\hline \multicolumn{6}{|l|}{ District I (2)a } \\
\hline Talking with peers & 1 & - & 1 & - & - \\
\hline Finding solutions & 1 & - & - & 1 & - \\
\hline Mastering teaching skills & 1 & - & 1 & - & - \\
\hline \multicolumn{6}{|l|}{ District II (2) } \\
\hline Talking with peers & - & 1 & 1 & - & - \\
\hline Finding solutions & 1 & - & 1 & - & - \\
\hline Mastering teaching skills & 1 & - & 1 & - & - \\
\hline Total & 5 & 1 & 5 & 1 & 0 \\
\hline
\end{tabular}

Note. aThe number in parenthesis represents the number of teachers in sample population. 
Expressed Awareness of the Effect of Instruction on student Rerformance

Eight comments that provide insight into teachers' commitment to implementing and teaching the prescribed language arts program were gathered from the responses to the question asking them to describe the strengths and weaknesses of the integrated literature program. Comments were as follows:

District I.

1. I'm thrilled with this program. I'm going through the same things I went through the first year I taught. I'm going with the loop of faith thing, from september to June that they will learn. It's a magical process. It bothers me that I have that percentage that aren't up to grade level but some of them have learning problems.

2. It's a lot more real to use something the kids are actually reading and enjoying. It's a better concept, which is very important.

3. I'm going to a language arts conference in two, three or four weeks. I've never been to one before, so I'm really looking forward to it.

4. This is the way I have felt they should be teaching reading for a number of years.

5. My mind wanders too much and I try to do so much else. I'Il be more prepared for the tangent before it comes up, by reading the material first. 


\section{District II.}

6. I prefer a balanced program, the skill based as well as the literature with the cooperative learning.

7. Well, I don't know. There's not enough about teaching skills in ...this program.

8. I think I like it. The skill program built into it (prescribed series) is not strong as other types of series. That's a difficult question.

Summary: To what degree was the classroem teacher committed to implementing and using a meaning-centered approach or a codecentered approach to teach the English-Ianguage Arts curriculum?.

This summary deals with those aspects in the data that provide insight into the degree of commitment reflected by the classroom teacher to the English-Language Arts curriculum. The degree of commitment is described by the absence or presence of time in collegial participation and teacher participation in a number of feedback systems of more than 20 minutes each week. Additionally, the degree of commitment was validated by the comments teachers made during the pre and post interview (Appendix B) to describe student behaviors during language arts instruction.

The degree to which the classroom teachers are committed to implementing and using code-centered approaches or meaningcentered approaches to teach language arts is described by the presence of the following teacher behaviors: 
1. Participation in collegial bonding. It appears that third and sixth grade teachers represented in the meaningcentered classrooms and first and sixth grade teachers represented the code-centered classrooms are more committed to the implementation of the language arts intervention model, more developed interpersonally and more effective in classroom instruction more than are first grade teachers in District I and third grade teachers in District II.

First and sixth grade teachers in code-centered classrooms were more committed than teachers in meaning-centered classrooms to implementing the new intervention model by talking about instructional practices, discussing problems and finding solutions related to the new language arts model. First and sixth grade teachers in code-centered classrooms spent more time participating in feedback systems each week than did third and sixth grade teachers in meaning-centered classrooms.

Eight teachers, four from each district, were committed enough to gather together and discuss the implementation of the English-Language Arts Framework without the intervention efforts of organizational planned discussion groups. There was no information gathered through data collecting procedures that indicated that these eight teachers received specific and practical feedback on their instruction from a trained facilitator or knowledgeable consultant. The teachers appeared to fit language arts discussions and reflections into their daily routines. These teachers were committed enough to the 
implementation of the English-Language Arts Framework to group themselves for one hour or more of time, during lunch or recess breaks, after class instruction, some time between parent conferences, staff meetings, and organizational

responsibilities to meet among themselves to discuss, reflect and analyze the language arts implementation in their class instruction.

If individuals stick to their habitual ways, find excuses for what they do and never try new approaches, true commitment will be missing. The number of years of teaching experience appeared to have no relation to the degree of teacher commitment in this study. The third grade teachers in District I reported the least years of teaching experience and were more committed than were third grade teachers in District II who had five years more experience.

2. Expressed awareness of the effect of the new language arts philosophy on student performance. Commitment is generated if teachers see that the prescribed language arts curriculum materials implemented with the philosophy of the English-Language Arts Framework affects student performance. In describing the effect of the language arts curriculum on student performances, teachers in meaning-centered classrooms expressed more commitment to the English-Language Arts curriculum than did teachers in code-centered classrooms. However, comments displayed a wide range of degrees of commitment among teachers in both districts. Teacher comments ranged from non committed statements such as "I think I like 


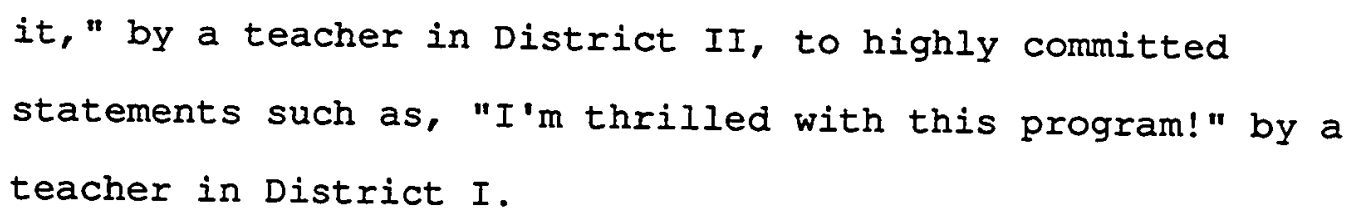

Research Question Seven

To What Degree Does the Organization Support the Changes Introduced by the English-Language Arts Framework?

Active administrative support at all levels of an organization and the degree to which an organization is ready to change are crucial factors to the success of an intervention model exemplified by California's English-Language Arts Framework. This research question focuses on the interrelated forces that support and facilitate the change process necessitated by the introduction of the English-Language Arts Framework in an organization. The forces that are identified in this research study that reflect effective support for changes in an organization are: (a) administrative support, and (b) organizational support. Administrative support focuses on the principal and is defined as: (a) the principal's personal motivation and purpose; and (b) the principal's collaboration with teachers, consultants, and administrators in providing direction and purpose, shaping values, establishing empathic relationships, building strong cultures, and recognizing real needs. Organizational support focuses on the school culture and is determined through: (a) the activities 
within the organization that allow the members of the organization to be open and ready to change (unfreezing, Schein, 1986), the creation of psychological safety, cognitive redefinition, the development of new assumptions and the opportunity for refreezing; and (b) the environment that is created through the developmental stage of the organization, the number of years of principalship at school, the number of years with the present community, the community culture, and the presence of the primary culture creators which is determined by the number of teacher changes in the school. This research question examines the differences between the degree of support that facilitates the change process necessitated by the introduction of the English-Language Arts Framework in District I and District II. Information gathered from principal interviews (Appendix $B$ ), teacher meeting observations (Appendix A) and teacher interviews (Appendix C) examines the degree of administrative support and organizational support.

To analyze this question, 33 pieces of data were used originating from the pre and post principal interviews, the teacher meeting observations and the teacher interviews. Tables 35 through 40 reflect an analysis of the information for this research question: Table 35 displays the confidence distributions of how principals feel about training staff members to implement the language arts curriculum; Table 36 reports the effectiveness of the language arts curriculum on student performance reported by the principal; Table 37 
describes the type of power principals use to make changes in the curriculum; Table 38 presents principals' perceptions of staff relationships; and Tables 39 and 40 examine the dynamics of staff relationships observed in group meetings. Administrative support

Administrative support is reflected in the principal's personal motivation and purpose that provide direction and purpose, and shape values for the organization. The responses to three questions introduced during the principals' interview provide insight into administrative direction, purpose and values for the organization. The first question that was asked in the principal interview was (Appendix B, item number 1): "What are the goals you have identified for your school?" Principals gave the following thirteen responses:

District I.

1. The implementation of the language arts program. Before school started we reviewed the program, materials and lesson plans. A group of teachers worked on the beginning lesson plans for each story in the book at each level. We met periodically to discuss what was working well. We kept notes in a little notebook for each grade level.

2. The continued implementation of the math program.

3. A new instructional model, mastery learning. The idea of having objectives and then teaching to those objectives. It took a couple of years for people to feel comfortable with the idea of mastering an objective. 
4. To identify specific outcomes for each grade level in language arts.

5. To show at least a minimum of one year's growth in the area of language and reading.

6. To look at a magnet school with a language acquisition program emphasizing Spanish and English.

District II.

7. To be accepted as a co-worker with the staff.

6. To increase the amount of writing across the curriculum.

9. To encourage parents to become more involved.

10. To establish a safe and orderly environment.

11. To implement the Language Arts Framework. We have had a lot of staff development on the awareness level. We publish research information each month concerning the language arts instruction.

12. Unstated goal was team building. To create a group who could work together harmoniously and still be dynamic and make change.

13. Three principals stated the same goal: to improve test scores.

For the purpose of this research question discussion concerning the stated goals, it is believed that all goal statements reflected the principal's personal motivation for school improvement and not necessarily district goals or effective school goals noted in statement numbers 9 and 10 . 
Principals in both districts displayed a personal motivation to provide direction and purpose, and to shape values for their organization with performance goal statements and collaboration goal statements. Principals in both districts stated goals for their organization that reflected their motivation to show performance growth, to identify outcomes and to improve test scores. Two statements from principals in each district addressed the purpose of showing performance growth in language arts.

Four of nine statements, 7, 9, 11, and 12, from principals in District II reflected purposes to develop and encourage collective growth and build stronger cultures among members of their organization. Statement one, from District I, reflected the purpose of shaping collaboration among members of their organization.

The second question that was asked in the principal interview was the following (Appendix B, item number 2): "How do you create change in your school?" Principals gave the following responses:

District I.

1. Get people to volunteer, get people excited and get specific people involved. Do a lot of small group meetings to convince and inform about the possible changes. Avoid large groups where you get negative peer pressure. Start talking about the change very enthusiastically. Be involved. Have people try it out and share their successes with others. Start small. Iittle by little. It takes five years to make a 
difference in a school. To make any kind of major change, at least three years.

2. Change is created by identifying a need, looking at that need, bringing many people together to buy into the fact that a need has to be changed and all the people being involved in the decision. Identifying the activity objectivities, making sure the time line and budgets are accountable.

\section{District II.}

3. Creating change is letting them (teachers) know that we create the change ourselves and do it together, not in isolation.

4. It takes a minimum of three years to make some good changes. It takes time to plan the process, get your teams together, to implement the changes, get everybody to know the changes. Change occurs easier once you have ownership. At first the writing was very minimal. Now you can walk down the halls, see displays of writing. Parent participation was one of our goals. That's why I say a minimum of three years. There's a feeling that the parents feel comfortable with you. Having a clear goal, involving your staff so they will buy into the changes you want to make.

"5. I try to be very clear about where I'm going; what the mission is; and what my goals are. I just harp away at it every chance I get. An example is about implementing the Language Arts Framework. I have in my bulletin every week, a little section that I call "research findings." Every single one of them has had to do with research findings that were 
behind the new Language Arts Framework and what the Framework consists of.

Principals valued collaboration among their members of their organization and the need to state goals in their deliberate attempt to make changes. All five principals valued collaboration among members in creating changes in their organization. One principal in each district made statements about change occurring through small group or through team relationships; both principals indicated that it takes three years for team collaboration to make any kind of change.

One principal from each district indicated that they value individual development as well as group development among their organizational members. Implicit in statement eleven, a principal in District II noted that a different member of the staff each month was assigned to collect research information concerning language arts to share with other members of the organization. Implicit in statement one, a principal in District I noted that one staff member was assigned to make a presentation to the group about what instructional practice worked well with his/her students in her language arts class instruction. Both of these activities led to increased personal understanding and awareness.

Four of the five principals made statements about the need to be clear about what changes are expected and the need to continuously talk about the goals and missions concerning the expected changes. In District II, one clear goal was to increase the amount of writing in every classroom. The 
continuous talk about writing, parent involvement in the writing goal and the continuous display of student writing samples in the school halls have created changes in the amount of classroom writing throughout the school.

The third question provides insight into the administrative leadership that supports and facilitates the change process necessary for the successful implementation of the English-ianguage Arts Framework. The third question that was asked in the principal interview was the following (Appendix B, item number 8): "What person or author do you model your management and leadership style after?" The following five responses were given:

\section{District I.}

1. A person I love and admire is Mr. Smith. He helped me through the training program. I've tried to be a principal without sacrificing my principles. I draw from anybody who's effective. A combination of effective people from business and education.

2. Probably the two individuals that I learned most from were Ms. Smith and Ms. Jones who were two people I interned under. One is an incredible organizer, she has a way of envisioning things, making them become reality, a delegator, an incredible motivator, to work, work, work without feeling that the demands were on you. One is very creative, very thorough, organized, takes pride in what she does, wants to do the very best at all times, a real worker bee. 


\section{District II}

3. I don't have any person. I took classes. I developed a style of my own. A lot of people encouraged me.

4. I would be eclectic. I take a very common sense approach. I always search for that male/female model. I've never quite thought too much of leadership styles because it's like trying on a pair of pants; they look fine; they appear to be what you want and you try it on and it doesn't fit.

5. I feel real fortunate to have someone that I really have tried to model my leadership style after. We met together regularly and really helped each other a lot.

This researcher realizes that comments from only one question and only five principals generates limited data for the purpose of drawing inferences about the administrators' personal motivations to provide direction, purpose and shape values in change efforts. Therefore, the following comments only display insights about personal motivations.

Statements from both principals in District I reflect the ability to lead by being led and the critical spirit to be reflective. Both principals value the generative nature of passing down skilis and information to be re-interpreted and re-created in the passing. Statement one by a District I principal indicates that the leadership qualities valued are collaborative relationships, future visions, purposeful, productive and transforming changes.

Statement five from a principal in District II indicates that he/she values the generative nature of passing down skills 
and information to be re-interpreted and re-created in the passing. The generative nature of passing down skills and information shapes and expands the awareness of different views, feelings, reasonings, learnings and attitudes.

Statements three and four from principals in District II suggest that these principals are locked into a common language of leadership styles as opposed to the structure and nature of the transformational leadership process which mobilizes and propels the change process. Both of these principals talked of an influence relationship among organizational members to make changes; however, they appeared to want to discuss leadership style characteristics as suggested by the Gregoric Style Delineator, which is a self-assessment instrument designed by Anthony Gregoric in 1982 and 1985.

Table 35, 36 and 37 illustrate personal administrative support for changes in the organization generated by the implementation of the English-Language Arts Framework. Table 35 displays the confidence distributions of how principals feel about personally training staff members to implement the language arts curriculum in their classroom instruction. Principals were interviewed at the beginning of the research study and at the end of the study. During the interview session, they were given the opportunity to respond in two ways: (a) marking one of the five choices on the numbered scale, and (b) explaining any or all of their responses. Principals were asked to answer the following question (Appendix B, item number 6): "On a scale of 1 to 10, how well 
do you feel that you could personally train your staff on how to implement the English-Language Arts Framework in their classroom instruction?"

Responses to the interview questions indicated that principals representing both districts did not hesitate in talking about their identified goals and missions for their schools. Table 35 reports that principals generally felt competent about guiding their staff in the implementation of the Language Arts Framework; however, principals in District I indicated that they were more knowledgeable about the EnglishLanguage Arts Framework than principals in District II.

Table 35

Administrative competence in Guiding staff in the Implementation of English-Ianguage Ants Framewerk

\begin{tabular}{|c|c|c|c|c|c|c|c|}
\hline \multirow[b]{2}{*}{ Population } & & \multicolumn{6}{|c|}{ Scale of mean total responses } \\
\hline & & \multicolumn{3}{|c|}{ skillfully } & $(6-5)$ & $(4-3)$ & $\begin{array}{c}\text { not } \\
\text { competent } \\
(2-1)\end{array}$ \\
\hline District 1 & $(2)^{a}$ & - & 8.5 & - & - & - & - \\
\hline District 2 & (3) & - & & 7.5 & - & - & - \\
\hline
\end{tabular}

Note, aThe number in parenthesis represents the number of principals in sample.

Table 36 reports how effective principals believe the philosophy of the Language Arts Framework will be on student 
performance. Principals were given the opportunity to respond to the interview question in two ways: (a) marking one of the five choices on the numbered scale, and (b) explaining any or all of their responses. They were asked the following question (Appendix B, item number 7): "On a scale of 1 to 10, how effectively do you believe the philosophy of the Language Arts Framework will be on student performance this year? ...three years from now?"

Table 36

Administrative Perceptions of the Effectiveness of the Language Arts Rhilesophy on Student Rerformance

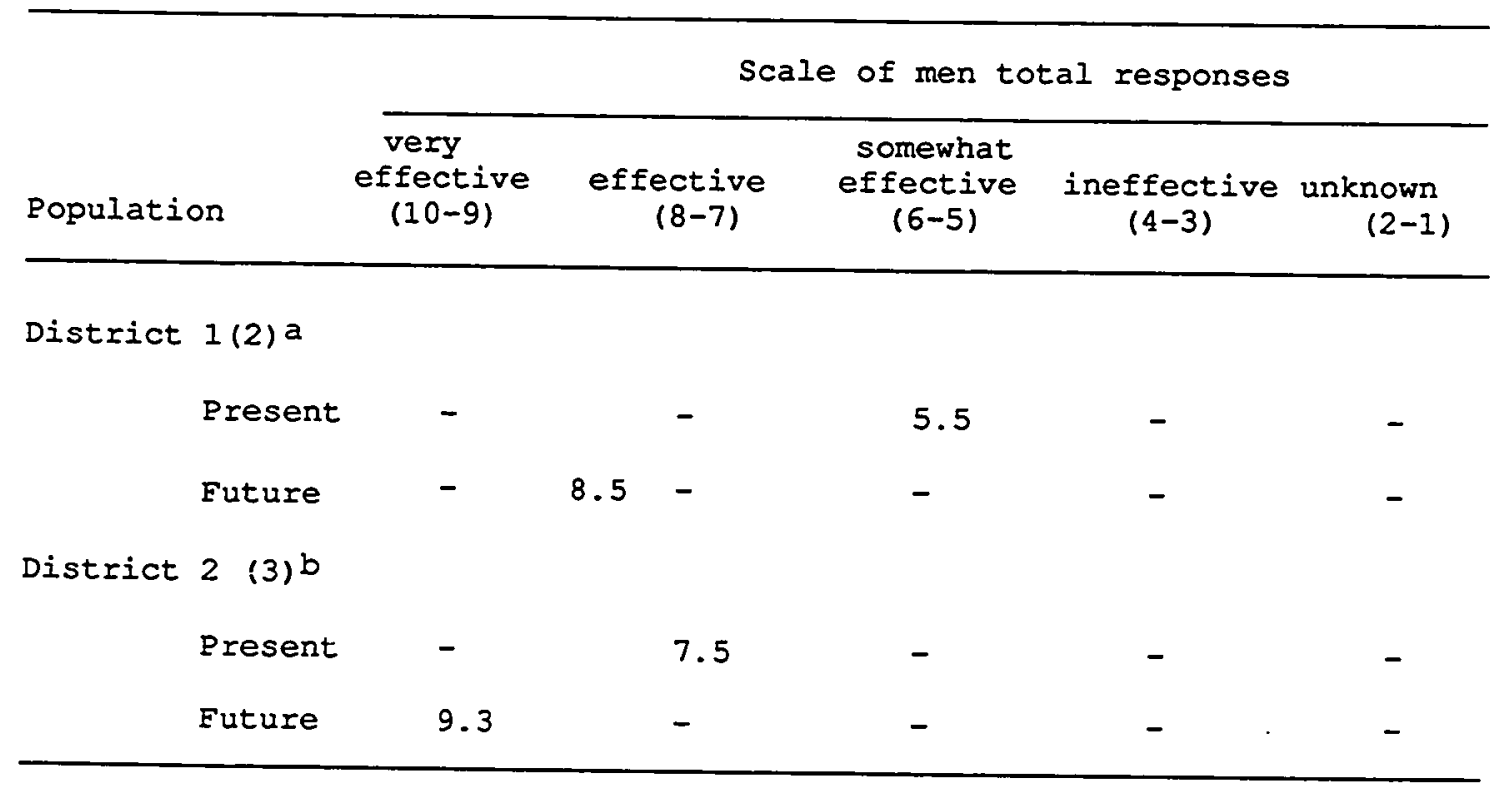

Note. $a, b$ The number in parenthesis represents the number of principals in sample. 
Table 36 reflects that principals believe that the philosophy of the Language Arts Framework will be more effective on student performance three years from now. However, the meaning-centered classroom administrators indicated that the language arts philosophy would be less effective on future student performance than did administrators representing the code-centered classrooms.

Administrators use some form of power to initiate change, provide direction and purpose and shape values for the organization. Principals were asked the following question (Appendix B, item number 3): "How do you describe the type of power you use when you expect change to take place in the curriculum?"

Principals in District I stated, "They'll do it because they like you," and "Personal power is real important." Principals in District II responded, "I try to send personal notes to them, if they work on a committee."

"I don't think that authority stuff works. I think mostly cooperative."

"I use a cooperative type of power. Some expertise would be my fall back position."

Table 37 describes the type of power principals chose to use first and then second when they wanted to make changes in the curriculum. During the interview session, they were given the opportunity to respond in three ways: (a) marking one of the five choices displayed, (b) explaining any or all of their responses, and (c) adding choices that were not displayed. 
All five principals used a combination of each of the suggested forms of power. Expertise was the first choice of a power type selected by all respondents. Personal power was a favorite with administrators in District $I$ and cooperative power was a favorite among principals in District II.

Table 37

Rower Approach Used When Changes Are Expected in the curriculum

\begin{tabular}{|c|c|c|c|c|c|}
\hline \multirow[b]{2}{*}{ Order } & & \multicolumn{4}{|c|}{ Scale of responses } \\
\hline & lority & expertise & reward & cooperative & personal \\
\hline \multicolumn{6}{|l|}{ District 1 (2)a } \\
\hline First choice & - & $x$ & - & - & $x$ \\
\hline Second choice & $x$ & $\mathrm{x}$ & $x$ & $x$ & $\mathrm{x}$ \\
\hline \multicolumn{6}{|l|}{ District 2 (3) } \\
\hline First choice & $\mathrm{x}$ & $x$ & $\mathrm{x}$ & $\mathrm{x}$ & - \\
\hline Second choice & - & - & - & - & $x$ \\
\hline
\end{tabular}

Nete. athe number in parenthesis represents the number of principals in sample.

\section{Organizatienal support}

A principal in District II responded, "Rewards? That's a little hokey I think, because it's sort of like it's an exchange, if you do this, I'll do that. We've come a long way since... I think it's mostly cooperative." 
The principal, in collaboration with teachers, consultants, and administrators, establishes empathic relationships, builds strong cultures, and recognizes real needs. The implementation of the Ianguage Arts Framework requires that changes occur in the organization. Therefore, the principal deliberately attempts to produce new and different responses in members of the organization. A question was asked during the interview that reflects the type of control principals use with organizational members. During the recorded interview, principals were given the opportunity to respond to the question asked in three ways: (a) marking one of the five choices displayed, (b) explaining any or all of their responses, and (c) adding choices that were not displayed. They were asked the following question (Appendix B, item number 4): "How do you describe your type of control with your teaching staff, parent groups, board members, and community members?"

All five principals responded to using influencing, bargaining, negotiating and positional as their source of control. Of the five principals' responses, two persons were in agreement with each of the following comments:

1. If you try using your position, you're a sinking duck.

2. Influencing would be the one $I$ would say that $I$ do.

3. My secondary style would be negotiating or bargaining.

4. It's up to the game plan. Negotiating is kind of a give and take. You use positional sometimes when all the 
negotiating in the world won't work. Then you say, you're going to do this because you're going to do it.

Two administrators in District I responded:

1. "I try to influence; I do some bargaining; I don't really negotiate a whole lot."

2. "They (teachers) all play games so you have to figure out what game they're in and then make sure that you don't really lose."

In both districts, teachers were observed meeting together for three purposes: (a) consistently scheduled, structured staff meetings with the administrators in which all teachers were held accountable to attend and specific tasks were to be accomplished; (b) occasional grade level meetings which appeared to be an extension of the staff meetings in District II and District I in which teachers were held accountable to complete assigned tasks; (c) grade level meetings which were requested by the administrators and occasionally attended by the administrators; however, when meetings were not attended by the administrators, it appeared that teachers were not held accountable to complete a specific task or to even gather for a meeting; and (d) informal teacher meetings that fit into daily routines, that is at lunch, after school or before school.

There appeared to be no organized system for an interpersonal development process with an accountability system, that is, an organized system which is designed for individuals within groups. This system would include: (a) consistent meeting times and places; (b) guidance by individual 
tasks, personal goals, missions and visions designed to foster the cultivation of uniqueness and to focus on differences; and (c) guidance by individuals' background assumptions and individual judgments. This interpersonal development process would lead to increased personal understandings and awareness, the creation of psychological safety, cognitive redefinition and the development of new assumptions. Change occurs more quickly within the interpersonal levels than within the group relationship levels.

In this study, it appears that organized group meetings designed to encourage collective growth in common directions, guided by school and district goals, and focusing on similarities provided the only source of interpersonal and group development within which the change process was to occur. With reference to this group meeting framework, principals were asked the following question (Appendix B, item number 5): "On a scale of 1 to 10 , how do you describe the group relationships and the interpersonal relationships among your teaching staff at this time?" Principals were given the opportunity to answer this question by responding in two possible ways on the post interview: (a) marking one of the five choices displayed on a number scale, and (b) explaining any or all of their responses.

Table 38 presents the degree to which principals perceive the group relationships and interpersonal relationships among their teaching staff. Principals in District I and District II described the interpersonal relationships as being less than close, empathic, collaborative and supportive. Principals in 
District I indicated that group relationships were more collaborative than did principals in District II.

Change occurs through small group and intergroup relations. Strong cultures are created and built with collaborative and empathic relationships which support changes. The organizational change process involves forces that allows the members of the organization to be open and ready to change, the creation of psychological safety, cognitive redefinition, the development of new assumptions and the opportunity for refreezing. It appears that the stage of interpersonal and group relationships among members of the organization in both districts may not support the kind of change necessary to affect student performance in the immediate future with the implementation of the new language arts intervention model.

Table 38

Principal Perceptions of Staff Relationships

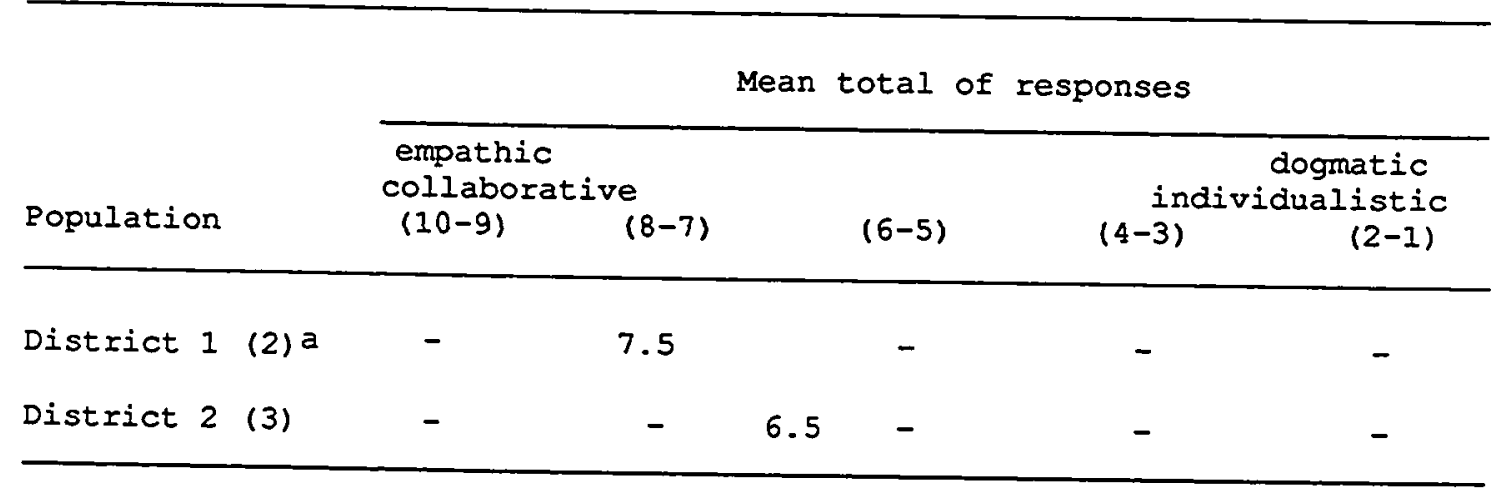

Note, aThe number in parenthesis represents the number of principals in sample. 
Tables 39 and 40 examine the group dynamics of staff relationships observed in group meetings. Information was gathered through a total of 5 hours of observations of teacher meetings, staff meetings and grade level meetings. Observations focused on twenty-three group behaviors that reflected the presence or absence of three criteria of organizational support among staff members: (a) relationship building, (b) sharing, openness and bonding behaviors, and (c) management factors related to time, place, feedback and reinforcement. During the 30 minutes allowed for each group observation, a check mark was used to indicate if the behavior was observed or not observed (Appendix A).

- Table 39 indicates that group behaviors observed in group meetings in both districts focused on the following behaviors in the order listed in the table; making value judgements (100\% and 40\%), clarifying information (100\% and 100\%), acknowledging concerns, formulating understandings and guiding discussions (100\% and 80\%) during most of the observed time (Appendix A, item numbers 1 through 14). These behaviors were observed to occur more often in District I meetings. Relationship building behaviors, value judgments, clarifying, concerns acknowledged, understandings formulated and guided discussion, that focus on similarities among organizational members and psychological safety make change difficult. Psychological safety refers to conforming to the expectations of others and following the common direction of the group expectations. 
Table 39

Observed Relationship-Building Behaviors

\begin{tabular}{|c|c|c|c|c|}
\hline \multirow[b]{2}{*}{ Behaviors } & \multicolumn{4}{|c|}{ of time of observed presence } \\
\hline & $\begin{array}{l}\text { District } \\
\text { Presence }\end{array}$ & $\begin{array}{l}(4)^{a} \\
\text { Total }\end{array}$ & $\begin{array}{l}\text { District II } \\
\text { Presence }\end{array}$ & $\begin{array}{l}(5)^{b} \\
\text { Total }\end{array}$ \\
\hline Relationship Building & & $70 \frac{8}{8}$ & & $60 \%$ \\
\hline Value judgements & $100 \%$ & & 408 & \\
\hline Concerns dispelled & 758 & & $40 \frac{8}{8}$ & \\
\hline Clarifying & $100 \frac{8}{8}$ & & $100 \%$ & \\
\hline Silence & 258 & & $40 \frac{8}{8}$ & \\
\hline Modality acknowledged & $75 \%$ & & $40 \frac{8}{8}$ & \\
\hline Beliefs acknowledged & 508 & & 208 & \\
\hline Concerns acknowledged & $100 \%$ & & 808 & \\
\hline Understandings formulated & 1008 & & $80 \%$ & \\
\hline Guided discussion & 1008 & & $80 \%$ & \\
\hline External knowledge analyzed & 758 & & $60 \frac{9}{3}$ & \\
\hline Personal knowledge & $75 q$ & & 408 & \\
\hline $\begin{array}{l}\text { Open reflection leading to } \\
\text { future changes }\end{array}$ & $50 \frac{8}{8}$ & & 408 & \\
\hline Lack of participation & 0 & & $75 \frac{8}{8}$ & \\
\hline Not prepared & 0 & & 508 & \\
\hline
\end{tabular}

Note, $a, b$ The number in parenthesis represents the total number of observations in the district. 
Group behaviors that recognize counterforces and lead to increased personal understanding and awareness were observed to occur least in both districts; however, they occurred more often in District I than in District II group meetings. In the order listed in Table 39, group behaviors that recognize counterforces are; concerns dispelled, beliefs acknowledged, external knowledge analyzed, personal knowledge and open reflection that may lead to future changes. Group behaviors that recognize counterforces build strong cultures, support change and facilitate the change process. Most of the group members in both organizations were observed to openly respond during the meetings. However, responses appeared to be psychologically safe and related to the task.

Table 40 indicates that bonding and openness were observed more often in group meetings in District I than in District II (Appendix A, item numbers 14 through 21). Group behaviors that value human development, create empathic relationships, acknowledge successes, frustrations, and ideas create a strong culture and facilitate the change process. Organizational members in District I had more of an opportunity to create an environment for bonding together for a common cause, to share an openness about a common cause and to develop interpersonal relationships by their concern for human development and empathic relationships than organizational members in District II. Five organizational members in one school in District I had babies during the four months uf this study. Two additional members were also pregnant. Several group meetings 
Table 40

Observed Bending and Openness of Behaviors

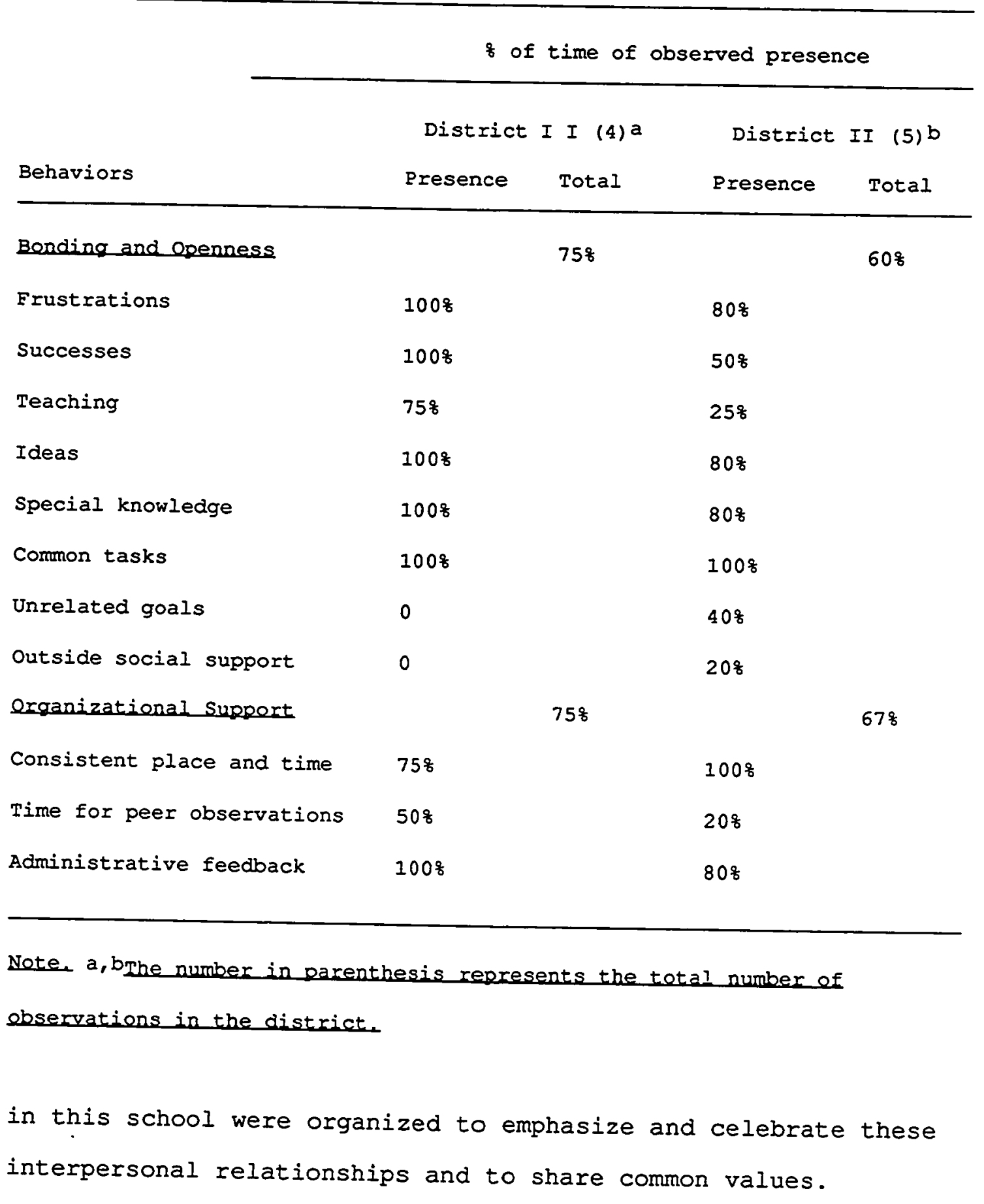

Reproduced with permission of the copyright owner. Further reproduction prohibited without permission. 
The administration supported staff development practices in both districts (Appendix A, item numbers 21, 22, and 23). Although organizational members in District II scheduled consistent times and places for staff meetings, members in District I received more administrative feedback and more time for peer observations.

Six comments were gathered during the teacher interview in response to the question addressing their perceptions of the administrative support for the language arts program (Appendix C, item number 6). Table 36 displays the responses on a numbered scale. Teacher comments on organizational support were as follows:

\section{District I.}

1. The teachers had been promised that there would be an inservice on how to use these materials. That never happened. Not for me. I had to kind of dig through the teacher's manual... and figure it out myself. We had to kind of beg and fight to get enough student workbooks.

2. A lot at the beginning of the year and now...it's failen. It's (organizational support) not that great. District II.

3. I don't see a lot of student academic acknowledgement or parent involvement coordination.

4. We haven't had a whole lot of support other than the publishers telling us how, and we really haven't had school activities. I'm sort of on my own, it seems. 
5. Eight responses from teachers in both districts expressed positive organizational support with the following comments: (a) One hundred percent!, (b) Very high!, (c) Definitely supportive!, (c) Very good!, (d) A real lot of support!, (e) Good support!, and (f) No problem!

Two teachers from each district expressed disappointment in the support they received from the administration. The remaining eight teachers indicated that they had enough organizational support in implementing the language arts program.

The Developmental stage of the organization

A first year principal cited expressions from his/her teachers, "That's not the way we did it last year!"

The degree to which an organization is ready to make change and the rate in which, nange can be made, depends on the interrelated factors of collaboration among the participants, administrators, teachers, parents and community members. Feelings about the principal, viewed among members of the organization as the leader, are projected onto the culture. This researcher linked the strength of collaborative relationships with the number of years the principal served as principal with the school and community culture represented in the study.

During the principal interview each principal was asked to provide the number of years they have been administrator at the school represented in the study. In District I, the minimum number of years at one school was four years and the maximum at 
the other school was eight years. In District II, the minimum number of years was one year and the maximum was four years (Table 3).

The following comments made during the principal interviews, acknowledge perceptions about the school and community cultures represented in the study. District I.

1. "You have to be a sales person for your community. Let people know that the school is open to them." (The principal has been with the school community for four years.)

District II.

2. "Parent involvement is really slow, slow. We have regular education meetings, the type that they want. One positive thing is that we have had nutrition meetings for them." (The principal has been with the school community for four years.)

3. "I treat them (parents) like I would like to be treated. Personal; it's more personal than anything. A couple of people (staff members) had to go in that direction. They had this allegiance to other people on the staff. "You're not going to change us; you can't make me do it!" We have a group of people who are happy to be at this school. (The principal has been with school community for one year.)

4. The group (staff members) is working together better than any group I've worked with. Everyone feels safe to say what they want to say. (The principal has been with school community for one year.) 
The organizations represented in District I have had a minimum of four years to create and develop collaborative relationships among organizational members. The more advanced stages of organizational cohesiveness and cultural development noted among participants in District I support and affect the success of the proposed changes in the language arts curriculum more than the beginning stages of collegiality noted in two schools in District II.

\section{Summary: To what degree does the organization support the changes introduced by the English-Ianguage Arts Framework? \\ This summary reflects those aspects in the data that provide insight into whether or not there was support for the changes introduced by the English-Ianguage Arts Framework by the organization. The degree that the organization supported the changes is reflected in the administrator's personal leadership behaviors and the organizational culture and collaborative relationships. The educational organization in both districts supported the changes in the language arts curriculum by the following patterns:}

1. Principals supported the changes by stating goals that indicated that the organization was designed to achieve a purpose. The stated goals of accountability and staff development indicated that the function of the organization was educative. Principals in both districts stated goals for their organization that reflected their motivation to show accountability for the effectiveness of the language arts 
curriculum on student performance by identifying outcomes, expecting mastery learning and improving test scores.

2. Principals supported the changes by deliberately attempting to produce new and different responses in members of their organization with a combination of power forms. All five principals used a combination of three forms of power: (a) expertise was the first choice of a power type selected by aiI respondents, (b) personal power was a favorite with administrators in District I, and (c) cooperative power was a favorite among principals in District II.

3. Principals supported changes by shaping and building the values to support the changes with a combination of control sources. All five principals used influencing, bargaining, negotiating and positional as their sources of control in their respective order. Positional power was used as a final resort if influencing, then bargaining, then negotiating didn't get the desired results.

Iimited suppert

4. Principals in both districts supported the changes introduced by the Language Arts Framework by their stated goals for creating and building collaborative relationships that affect changes. However, the awareness of affecting the change process through collaborative relationships appeared to be limited by all principals in both districts. A common language expressing ideas about changes through staff development were limited to cooperative and collective growth in a common direction guided by school and district goals. A 
conceptualization for creating and building relationships that affect changes by developing interpersonal relationships that address human life cycle development, individual differences, values, attitudes and perceptions, and guided by the individual's judgments in the context of a critical dimension was not observed through interviews or questionnaires.

5. Principals' motivational support for the changes was observed to be less than dynamic. Administrative motivational spirit for changes introduced by the Language Arts Framework was calm and disowning. The time perception necessary for real change to occur was estimated to be three to five years by principals in both districts. The educational crisis initiated by the concerns for student performances generated the development of the English-Language Arts Framework. However, a dynamic motivation to engage members of the organization in the changes that are designed to focus on and address this crisis within a three to five year estimated limit was not observed in either district.

6. Administrators supported and promoted the changes introduced by the framework by their articulated values addressing the leadership process. Collaborative relationships, future visions, purposeful, productive and transforming changes appeared to be articulated more often by principals in District I than principals in District II. Statements from both principals in District I reflected the ability to lead by being led and the critical spirit to be reflective. However, this influence relationship in a context 
of reflection, interpreting and understanding others was not observed. Both principals in District $I$ and one principal in District II valued the generative nature of passing down skills and information to be re-interpreted and re-created in the passing. Principals in District II expressed a common language of leadership as traits or styles as opposed to the structure and nature of the transformational leadership process which mobilizes and propels the change process.

7. Principals supported the changes by being knowledgeable about the English-Language Arts Framework philosophy and the changes required to take place in the curriculum. Principals in District I indicated that they were more knowledgeable about the philosophy of the Language Arts Framework than did principals in District II; however, District I principals believed that the language arts philosophy would be less effective on student performance in the future.

8. Organizations supported the changes introduced by the Ianguage Arts Framework by creating and building cultures. However, organizational cultures were not observed to be strong enough to support, facilitate and mobilize a dynamic change process. One organization in District $I$, by the nature of human development, was observed to have the most developed school culture. Both organizations in District I reflected stronger cultures than organizations in District II.

9. The administration supported staff development practices that require an assigned place for the change process to occur, but did not encourage and/or support the 
change process in both districts. Although organizational members in District II scheduled consistent times and places for staff meetings, members in District I received more administrative feedback and more time for peer instructional observations.

10. The developmental stage of the organizations in District I supported and affected the success of the changes introduced by the Language Arts Framework more than did the beginning stages of collegiality noted in two schools in District II.

Research Question Eight

How Do The Differences In Materials, Teacher Behaviors, And Organizational Processes Between Classrooms Using A Meaning-Centered Approach And A Code-Centered Approach In Language Arts Affect Student Performance?

This research question acknowledges the interrelated data gathered to answer research questions one through seven and examines how materials, teacher behaviors, and organizational processes affect student performance. Student performance is defined as the extent to which students demonstrate the following as estimated by the teachers: (a) the ability to earn a passing score on the district writing proficiency examination; (b) the average number of selected recreational books students read during one year; (c) the willingness to 
prepare out of class assignments, homework; and (d) the level of success on criterion testing efforts. Student performance is also defined as the level of success to which students achieve in the areas of language arts and reading on a standardized test.

To analyze this question, eight pieces of data were used originating from the pre and post teacher interview, post teacher questionnaire, and district, school, class and individual standardized test scores.

Fourteen tabies, 41 through 54, examine an analysis of the information for this research question: (a) Table 41 displays the estimated percentage distributions of students' writing ability; (b) Table 42 presents the estimated average number of books read by students during the year; (c) Table 43 describes the students' interest in homework assignments; (c) Table 44 deals with the estimated number of students who pass the district writing proficiency examination, (d) Table 45 details the ethnicity and sex of random selected students for first, third and sixth grade levels, (e) Table 46 reports the reading and language arts mean NCE scores, normal curve equivalents, (defined in the following paragraph) for first grade individual students, (f) Table 47 shows the reading and language arts mean NCE school scores for first grade, (g) Table 48 notes the language arts and reading mean NCE district scores for the first grade, (h) Table 49 reports the reading and language arts mean NCE scores for third grade individual students, (i) Table 50 presents the reading and language arts 
mean NCE school scores for third grade, (j) Table 51 shows the language arts and reading mean NCE district scores for the third grade, (k) Table 52 details the reading and language arts mean NCE scores for sixth grade individual students, (1) Table 53 records the reading and language arts mean NCE school scores for sixth grade, (m) Table 54 notes the language arts and reading mean NCE district scores for the sixth grade.

The test scores that are reported in Tables 46 through 54 are the NCE scores, normal curve equivalents. NCE scores are based on an equal-interval scale. The normal curve is represented on an equal-interval scale of 1 through 99 with a mean of 50 and a standard deviation of approximately 21 . The continuous nature of the scale of NCE scores enables meaningful comparisons between different achievement test batteries and between different forms or levels within the same test battery. That is, a difference between two scores at one part of the scale represents the same difference in ability as that represented by the same scaled score at another part of the scale.

NCE scores reported for total content areas and content clusters are defined as follows:

1. The total reading score is a combined score consisting of vocabulary and reading comprehension scores. Reading comprehension clusters are literal, inferential, and critical analysis, and sentences.

2. The total language score is a combined score consisting of language mechanics and language expression. The 
content clusters are language, listening comprehension, punctuation and capitalization, usage and written expression.

3. Word recognition skills are clustered as visual and sound recognition skills as in phonemes and graphemes, consonants, vowels and word part clues. Estimated Ability on a Writing Proficiency Examination

Teachers were asked to estimate the writing ability of their students in their language arts class by marking a percentage for each of the five choices offered on a numbered scale on the teacher questionnaire (Appendix D, item number 22). A response space was provided for additional comments after the following question: Estimate the percentage of students in your language arts class who would earn each score ( 1 is low and 6 is high) on the district writing proficiency examination. The scale numbers 4,5 , and 6 represented a passing grade on a holistically scored writing sample.

Table 41 reflects the mean percentage of students in each grade level who would pass the district writing examination as estimated by their teachers. Teachers in District II clearly estimated that a greater percentage of students would pass the district writing examination than did teachers in District $I$.

The data were reviewed to determine what the differences were between teacher behaviors in District I and District II that may have effected estimated student writing performances. Table 55 summarizes the teacher behaviors in District II that were performed more frequently than were the teacher behaviors in District I. First and third grade teachers in District II 
assessed writing performances more often than did teachers in District I (Tables 9, 10, and 11). Students in District II received more positive reinforcement than did students in District I (Table 8). Teachers in District II reported higher expectations of student performances than did teachers in District I (Table 13). Students in District II were observed to write more often during language arts instruction (Table 14). First and sixth grade teachers in District II scheduled more time for independent activities than did teachers in District $I$. Sixth grade teachers in District II scheduled more skill instruction than did the sixth grade teachers in District I (Tables 29, 30 and 31).

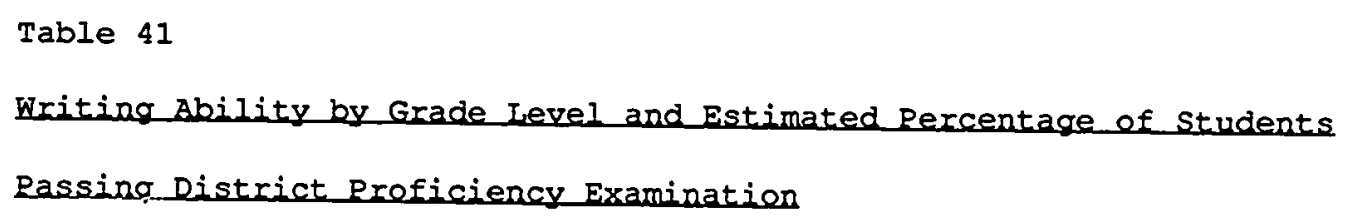

\begin{tabular}{|c|c|c|}
\hline \multirow[b]{2}{*}{ Grade } & \multicolumn{2}{|c|}{ Estimated mean $\frac{\gamma}{\gamma}$} \\
\hline & $\begin{array}{l}\text { District I }(n=6) \\
\text { Percentage Passing }\end{array}$ & $\begin{array}{l}\text { District II }(D=6) \\
\text { Percentage Passing }\end{array}$ \\
\hline Grade I & 32.5 & 41.5 \\
\hline Grade 3 & 26.0 & 37.5 \\
\hline Grade 6 & 35.5 & 93.5 \\
\hline
\end{tabular}


Students in District II participated in cooperative learning more often than did students in District I (Table 6). Cooperative learning experiences provide students with the opportunities to develop and expand creative language that can be transferred to writing and reading.

It appears that the greatest difference in writing abilities was the sixth grade teacher's estimation of their students' ability in District II. Sixth grade teachers in District II scheduled more time for skill instruction, assessed writing more often, scheduled more time for independent activities and provided cooperative learning experiences for their students more often than did sixth grade teachers in District I.

Table 15 reports that teachers in District II indicated that writing instruction was less effective than teachers in District $I$. However, three teachers in District I reported that they didn't use writing instruction. It appears that teachers in District II did not find the systematic teaching of the writing process to be effective. Systematic writing instruction follows the process model that includes these steps; prewriting, drafting, revising, editing and publishing. It appears that teachers in District II who did not find the systematic teaching of the writing process to be effective, simply offered writing opportunities for students and assessed the student products. Therefore, students must have developed naturally into being able to pass the district writing competency test. The alternative explanation is that teachers 
did not know they were systematically teaching the writing process.

Estimated Number of Student Selected Recreational Books

"I don't know if they read all of them, but they said that they did for our Book Club," stated a first grade teacher in District $I$.

The following remarks were by first grade teachers in District II. "This number would be much higher if you include books read to them by parents as part of our program. Many have passed the 100 mark in this."

"I have my own collection of books in the classroom. For many students, reading is done in school."

Teachers were asked to estimate the average number of books that students chose to read during the year on the post teacher questionnaire by marking a numbered scale (Appendix $D$, item number 20). A response space was provided for additional comments and/or for the addition of a number that represented a greater number of books than was offered on the scale. The 5 point scale reflected a number of books ranging from zero books to 27 books.

Table 42 reviews the mean number of books selected and read by students during the school year at each grade level. It appears that more first and third grade students in District I chose to read more often than did students in District II. In District II, the movement from familiar texts in first grade to a reading task more cognitive and conceptual in third grade (Tables 19 and 20) appeared to decrease students' interest in 
Table 42

Estimated Number of Recreational Books Selected and Read by Students

\begin{tabular}{|c|c|c|c|c|c|c|c|c|c|c|}
\hline \multirow{3}{*}{$\begin{array}{l}\text { Grade } \\
\text { Grade }\end{array}$} & \multicolumn{10}{|c|}{ Mean number of books } \\
\hline & $(0-5)$ & \multicolumn{4}{|c|}{ District I $(n-6)$} & \multicolumn{5}{|c|}{$\begin{array}{c}\text { District II }(n-6) \\
(0-5)(6-10)(11-15)(16-21)(22-27)\end{array}$} \\
\hline & - & - & - & - & 24.5 & - & - & 13.5 & - & - \\
\hline Grade 3 & - & - & - & 18.5 & - & 1.5 & - & - & - & - \\
\hline Grade 6 & - & - & 13.5 & - & - & - & - & - & 18.5 & - \\
\hline
\end{tabular}

reading recreational books (Table 42). This transition from reading familiar texts in the first grade to a reading task more cognitive and conceptual in the third grade appeared to be slow and/or difficult. This researcher suggests five possible reasons for this reading transition from first to third grade: (a) there was a decrease in understanding and intellectual growth, (b) there were limited reading opportunities for students as noted by the first grade teacher's remark, "...reading is done in school.", (c) independent reading was not an activity of choice and pleasure, (d) there were not enough instructional opportunities to affect information processing, and (e) there was not an interest in learning through reading.

Fewer books were read by sixth grade students than by first and third graders in District I (Table 42). The movement 
Fewer books were read by sixth grade students than by first and third graders in District I (Table 42). The movement from familiar texts and formula books with predictable plots in first grade to more complex stories in sixth grade appeared to cause a decrease in the numbers of books read. However, the reading of more than one complex book each month (13.5 books divided by nine months of the school year) by a sixth grader is impressive and does reflect a degree of confidence in approaching reading tasks.

The mean number of books with complex plots read by sixth grade students in District II appeared to be more than the mean number of books read by sixth grade students in District I (Table 42). Students in District II read a little more than two books during each month of school (18.5 books divided by nine months of school). Apparently, these students were interested in exploring new reading experiences, in increasing their understanding and intellectual growth and in participating in an activity of choice and pleasure. They were motivated enough to find the time, find the place, and find the books to read.

Estimated Willingness to Prepare out of class Assignments

The answers to this question may not report an accurate degree of the students' interest and willingness to prepare out of class assignments due to the many out of school environmental factors. However, the intention was to review differences in the new language arts program that may generate outside interest and allow permanent learning in speaking, 
reading and writing activities. Teachers were asked to mark a 5 point scale in response to the following question: What percentage of students complete their language arts homework assignments on time? A response space was provided for additional comments (Appendix D, item number 21).

Table 43 presents the percentage of students in each grade level who finished their homework on time as estimated by classroom teachers. First and third grade teachers in both districts estimated that the same percentage of students complete homework assignments on time. Sixth grade students in

Table 43

Estimated Number of students who complete Homework Assignments on Time

Mean percentage of studentsa

District I $(n-6) \quad$ District II $(n-6)$

Grade $\quad(0-20)(25-40)(45-60)(65-80)(85-100) \quad(0-20)(25-40)(45-60)(65-80)(85-100)$

\begin{tabular}{llllllllll} 
Grade 1 & - & - & -62.5 & - & - & - & -62.5 & - \\
Grade 3 & - & - & - & 82.5 & - & - & - & - & 82.5 \\
Grade 6 & - & - & - & 72.5 & - & - & - & - & - \\
\hline
\end{tabular}

Nete, apercentage of students is estimated by the classroom teacher.

District II completed their homework more often than did students in District I. More than $92 \%$ of sixth grade students 
in District II took the opportunity to independently practice the lesson that he or she mastered in class and to make the learning permanent. They were motivated and willing to grapple with understandings of the subject and communicate their thoughts. These students received a greater amount of classroom positive reinforcement (Table 8), student feedback (Table 11), skill instruction (Table 31), and non directive teaching (Table 15) than did those in other grade levels in District I or District II. Estimated Success on criterion Testing Efforts

Table 44 details one performance indicator that require students to use their acquired learning strategies. Criterion testing identifies a well-defined end point to the assignment or to the instructional objectives. Students and teachers have clear performance goals in reading, writing, listening and speaking. Teachers were asked to estimate the percentage of students who achieve average or better performance on their criterion testing efforts the first time. Teachers were asked to answer the following question by marking one of five choices offered on a numbered scale (Appendix D, item number 13): What percentage of students in your language arts class achieve average or better performance on the criterion testing efforts the first time?

The number scale did not offer a 0-14 choice, because this researcher believed that more than $14 \%$ of a class would pass a criterion test after being taught the lessons that related to the test by an effective classroom teacher. However, a space 
was provided for teacher comments in the event that less than $15 \%$ of a class passed a test or in the event of additional possibilities. Criterion tests are graded as a pass or fail; therefore, teachers were asked to estimate the percentages in student groups. The missing $5 \%$ between each choice represents a little more than one child in a class of 28 students. None of the twelve teachers estimated that less than $15 \%$ of the students achieve average or better on the criterion testing or marked additional choices.

The discussion of Table 44 looks first at the major differences in student performance between districts and second at the grade level differences. Grade level discussions include the differences in teacher behaviors, student performances and population characteristics within the grade level, and discussions follow the first, third and sixth grade level sequence. Table 44 takes into consideration the mean percentage of students in each grade level whose efforts were successful the first time on criterion tests. Third and sixth grade teachers estimated that a greater percentage of students pass their criterion tests the first time in the code-centered classrooms than in meaning-centered classrooms.

First grade teachers in both districts estimated that between $15 \%$ and $65 \%$ of the first graders passed their criterion tests the first time. Table 1 reports that there were more multi-ethnic, low socio-economic, low achievement and learning handicapped first grade students in District II than were in District I. 
Teachers estimated that third grade students in District II scored higher on their criterion testing efforts than did students in District I. The mean percent of low achievers was equal in both districts. District II had a higher percentage of multi-ethnic and low socio-economic students than District I (Table 1). Students in District II participated in more skill instruction (Table 14), and performed at a more advanced level

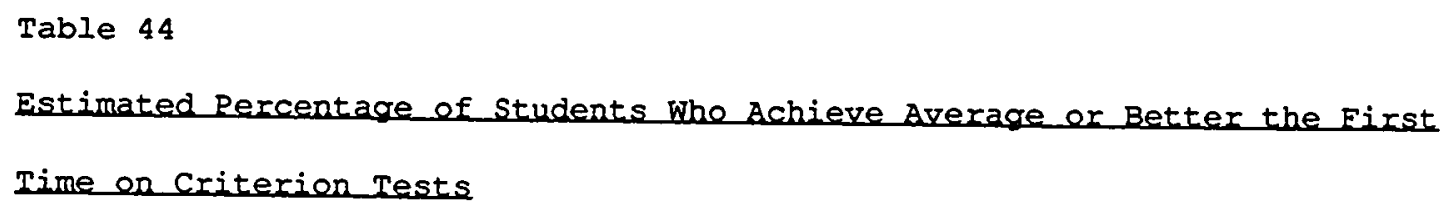

\begin{tabular}{|c|c|c|c|c|c|}
\hline Grade & \multirow[t]{2}{*}{$(100-85)$} & \multirow[t]{2}{*}{$(80-70)$} & $(65-55)$ & \multirow[t]{2}{*}{$(50-35)$} & \multirow[t]{2}{*}{$(30-15)$} \\
\hline & & & $I \quad n=6$ & & \\
\hline Grade 1 & - & - & 1 & - & 1 \\
\hline Grade 3 & - & 1 & - & - & 1 \\
\hline Grade 6 & - & - & 1 & $I$ & - \\
\hline Total & 0 & 1 & 2 & 1 & 2 \\
\hline & & Distr & II $\quad(n=$ & & \\
\hline Grade I & - & - & 1 & - & 1 \\
\hline Grade 3 & - & 1 & 1 & - & - \\
\hline Grade 6 & 1 & 1 & - & - & - \\
\hline Total & 1 & 2 & 2 & 0 & 1 \\
\hline
\end{tabular}


of reading tasks (Table 20) than did students in District I; however, the student performance in writing and the amount of writing done in class was equal to District $I$. Students in District I read more independent books (Table 42) than did students in District II. It appears that third grade students in District II mastered writing skills and reading skills at a more advanced level than students in District I (Tables 17 and 20); however, they appeared to not be as motivated to read books or find reading as pleasurable as students in District I (Table 42). It appears that third grade students in District II benefited the most from proficiency driven instruction than from a literature driven curriculum. Their problems appear to be specific to the transition of reading and writing skills from earlier grades.

Sixth grade classrooms in District I contained a greater percent of low achieving students than did District II. District II classrooms had a greater percentage of multi-ethnic and low socio-economic students than did District I (Table 1). Between $70 \%$ and $100 \%$ of the sixth graders in District II passed their test the first time. The percentage of sixth grade students in District II who passed their tests the first time was greater than in other classrooms in both districts. It appears that these sixth grade students who read more independent books (Table 42), wrote more often in class (Table 14), passed their writing performance tests (Table 41), participated in more advanced cognitive conceptual developmental activities (Table 21), and who spent more time 
learning skills (Table 31) scored higher the first time on their criterion testing efforts than did other students in the study. Testing often shapes instruction; therefore, it appears that instruction aimed at a balance between skill development and integrated literature development, affected sixth grade student performance more than the integrated literature development alone.

Estimated Effectiveness of Language Arts on Student Performance

"I'm dealing with a cultural situation. They're still learning English words, much less using full sentences, so it (language arts curriculum program) helps them a great deal to acquisition more English, but as far as putting the grammar...we're just slow going on with that," responded a sixth grade teacher in District $I$.

A sixth grade teacher in District I noted, "I think the Iiterature is fabulous, but I think it lacks a little bit in organization as far as skills go."

During the pre and post interview, teachers were asked to respond to a question concerning their perceptions of the effectiveness of the philosophy behind the English-Language Arts Framework on student performance in two ways: (a) selecting an answer on a numbered effectiveness scale, and (b) commenting on their response (Appendix $c$, item number 1). They responded to the following question: To what degree does the learning progress of your students using the new EnglishLanguage Arts curriculum program meet or not meet your expectations? 
At the end of the study, four of six teachers in District I marked that the progress of their students met their expectations effectively, and four of six teachers in District II marked that student progress met their expectations very effectively. First grade teachers made the greatest change in their perceptions. On the pre interview, of the total four first grade teachers in District I and II, three teachers indicated that student progress met their expectations somewhat effectively; however, on the post interview only one first grade teacher marked somewhat effective. Two, of the original four teachers, marked effective and one marked very effective. On the pre and post interview, the progress of students met the expectations of third and sixth grade teachers in District I effectively; two teachers marked very effectively and two marked effectively, an even split. Third and sixth grade teachers in District II began the study with perceptions that the progress of their students were meeting their expectations effectively. At the end of the study, teachers reflected a 3 to 1 split; three teachers perceived that student progress was meeting their expectations very effectively and one teacher effectively. It appears that teachers' expectations of the learning progress of their students using the prescribed language arts program were met effectively and very effectively. 


\section{Student Performance in Ianguage Arts Reflected from}

\section{Standardized Test Scores}

District I and District II administrated norm referenced tests in the spring of 1989 and 1990 to students in grades one through six. Norm referenced tests refer to the developmental process of standardizing a test. A student population of thousands representing different grade levels, socio-economic status, geographic locations, and ethnic origins are tested in the spring and fall to form a "norming population." The standardized test that District I used was normed by a population of 200,000 students, $K-12$, in the spring and fall of the 1984 to 1985 school year. District II used a standardized test that was normed in the fall of 1981 with a population of 250,000 students, $\mathrm{K}-12$. Both norm referenced tests represent a traditional approach to assessing student achievement as compared to the more current integrative testing that reflects the application of skills and the writing, speaking and listening performance assessments. That is, both normed tests focus on objectives that were written to reflect the content of the reading and language programs in common use throughout the country between 1980 to 1985 .

Each normed referenced test includes several recommended levels with forms that align to specific grade levels. Both District I and II used the publisher's recommended level and form for the appropriate grade level. However, District I uses an alternate form of the test for each grade level, each year, while District II uses the same form and same level of test 
each year. The results of these group tests provide standardized data to use for decision-making. These indirect measures provide broad indicators of students conceptual understanding and verbal skills. These measures have statistical validity, therefore the data are useful in making reasonable and useful judgments about student performance in the area of reading and language skills. For the purpose of this research study, these measures will be used to discuss the differences in trends in language arts and reading performance over the last two years.

Ethnicity, Grade Level and Sex of Random Student Ropulation

Standardized test scores were collected from twenty random students in each grade level. After the cumulative records of appropriate grade levels, first, third and sixth, were gathered, the first criterion of selection was the sex. There were 13 to 15 boys and girls in each class. After dividing the cumulative folders of boys and girls into separate groups, every third student was selected. If the student record possessed complete test results from the previous year and the present year, from the same school and from the same test battery, test scores were recorded. Finally, the student's ethnicity was recorded. In one sixth grade class in District II, there were not enough boys who had complete test results to complete a list of 10 boys; therefore, the test scores were pulled and recorded only from boys in the second sixth grade class in this study in District II. 
The test results from students in the random sample indicated that they were English language proficient enough to take the test. If the bilingual, multi-ethnic students were not English proficient they did not have test results from the testing battery selected for this study. Table 45 describes the random student population.

Table 45 reports a greater number of multi-ethnic students in the student sample in District I than in District II: 40 students in District I and 24 students in District II.

However, Table 1 described the mean total percent of the multiethnic student population in District II classrooms to contain almost twice as many multi-ethnic students as in District I classrooms: $82 \%$ in District II and $43 \%$ in District I. It appears that multi-ethnic students in District II are more transitional than students in District $I$ by process of the following logic: The total sample in District I was 168 students with a mean total of $43 \%$ multi-ethnic students, and the total sample was 154 students in District. II with a mean total of $82 \%$ multi-ethnic (Table 1). In District II, the random sampling procedures began with a sample population containing less students and a greater percentage of multiethnic students in the classrooms than were in District I classrooms. The random sampling procedures selected students who were in the same district for at least two years taking the same standardized test. The final sample student population contained only 15 \% of the the total 154 student population in District II and $24 \%$ of the total 168 students in District I (in 
Table 45

Selected Random Sample of the Population of Students by Ethnicity, Grade Level, and Sex

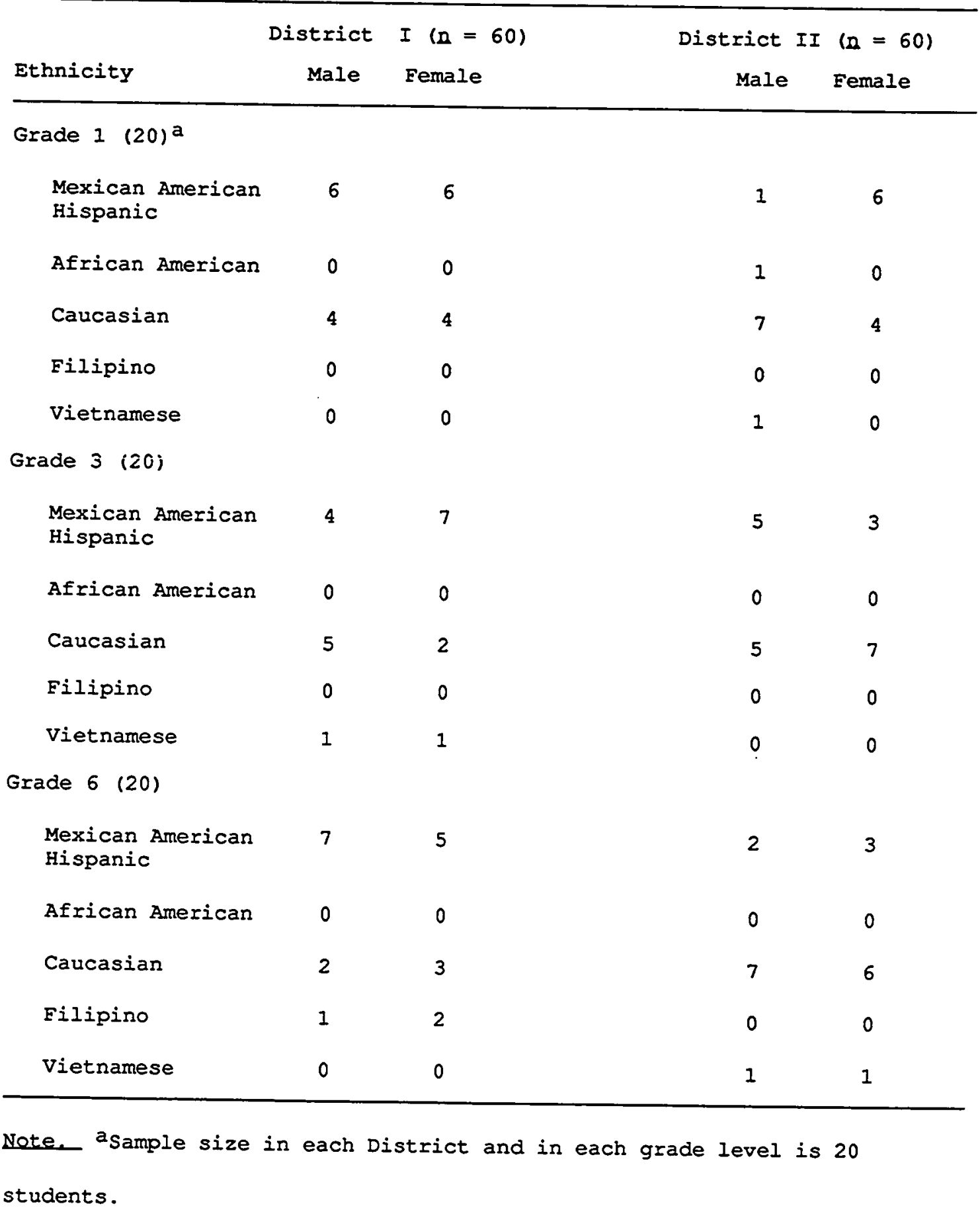


District II, the total of 24 multi-ethnic students in Table 45 divided by the total of 154 students in Table 1). Therefore, it appears that more multi-ethnic students in District II did not attend the same school for two years than did multi-ethnic students in District $I$.

\section{Eirst grade standardized test scores.}

To determine the differences in student performances on standardized tests, the 1990 student sample populations are related to the 1989 and 1990 school and district mean NCE scores in Tables 46,47 and 48 . Discussion of the differences in student performances begins with relating District I student sample NCE scores to District II student sample NCE scores, then student sample performances are related to NCE district scores, then NCE scores are related to the differences between districts, next student sample performances are related to school NCE scores and finally school NCE scores are related to school NCE scores within the same district. However, only the student sample NCE scores from District II describe classrooms using a code-centered approach and the prescribed literature program. Not all classrooms in District II in 1990 implemented the prescribed literature series. In District II, the school and district 1990 mean NCE scores include classrooms using a code-centered approach with the old basal readers which reflects an even greater emphasis on skills.

District I student scores and District II student scores.

Table 46 reports the 1990 mean NCE scores for the sample population of first graders in both districts. District I mean 
Table 46

Eirst Grade Standardized Test Sceres in Ianguage Arts and Reading for Sample Ropulation

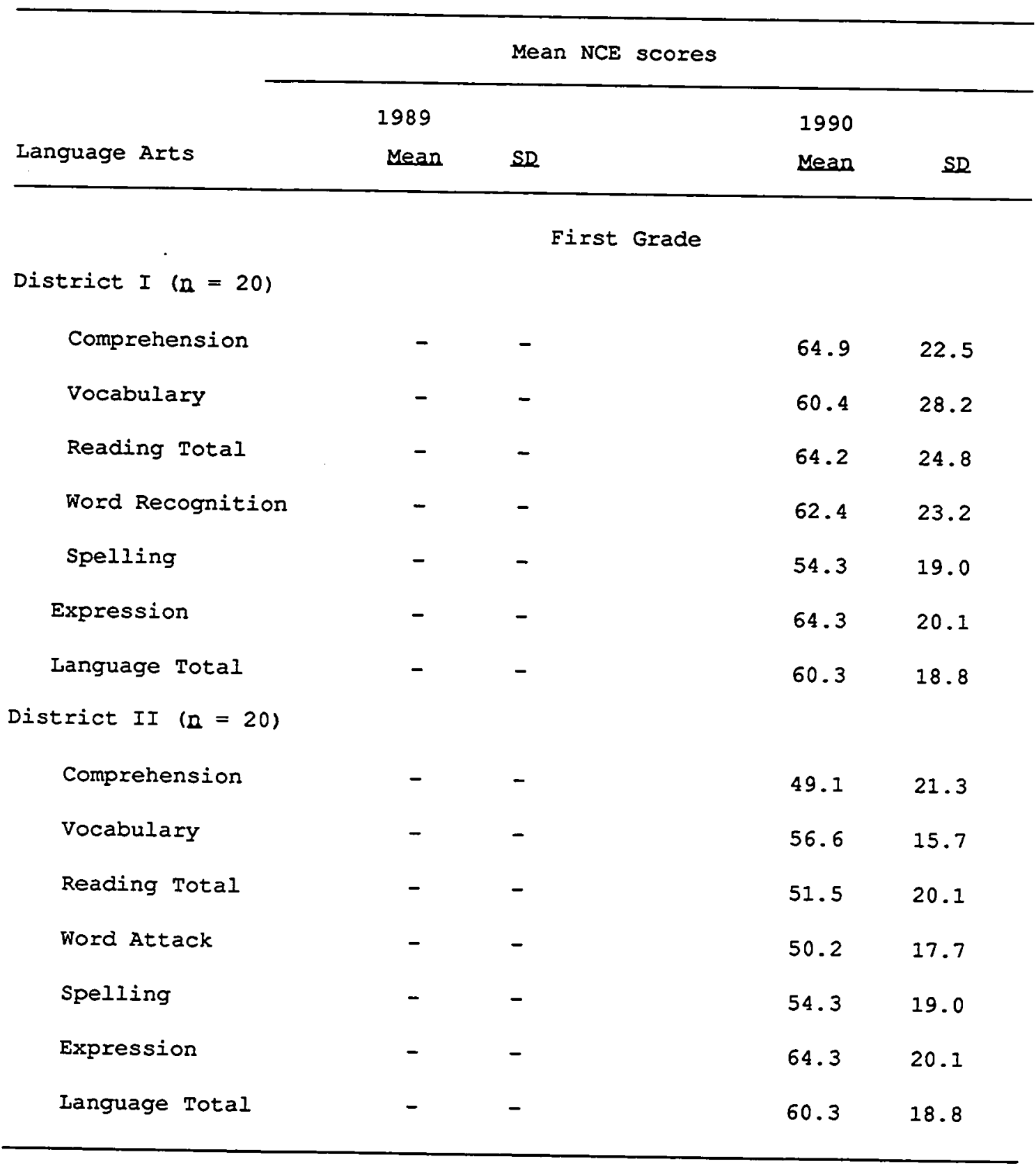

Note, The dash indicates that data are unavailable, therefore the cells cannot be filled. 
NCE scores in comprehension, vocabulary and word recognition were higher than were the NCE scores in District II; 15 points in comprehension, 3 points in vocabulary and 12 points in word recognition. NCE mean scores in spelling mechanics and total language were the same in both districts. It appears that first grade sample students in both districts performed equally in total language skills (mechanics and expression) and spelling skills, but reflected a 12 point difference in total reading skills (vocabulary and comprehension) and word recognition skills.

District 1989 scores and student 1990 scores.

Discussion of the differences between the 1990 student sample NCE scores (Table 46) and the 1989 and 1990 district NCE scores (Table 47) begins with 1989 district NCE scores and follows with 1990 district NCE scores. Relating the 1989 district mean NCE scores to the first grade 1990 sample populations (Table 46), District II sample populations showed a 2 point to 15 point gain in all language arts subject areas; 2 point gain in comprehension, 8 point gain in vocabulary and 15 point gain in mechanics. District I sample populations showed a 3 point gain in comprehension, 5 point gain in word recognition and 4 point gain in expression; however, there was a 3 point drop in vocabulary and a 5 point drop in spelling. It appears that District II sample students reflected greater gains in vocabulary and mechanics than did students in District I; 8 points (District II) to 3 points 
(District I) in vocabulary and 15 points (District II) to 4 points in mechanics (District I).

District 1990 scores and student 1990 scores.

Examining the 1990 district mean NCE scores and the 1990 student sample scores (Tables 46 and 47), it appears that the student sample scores reflected higher scores than the 1990 NCE scores in both districts in reading and language areas; spelling was the exception. Student sample scores in District I were higher than District I scores in comprehension, vocabulary, word recognition and expression. The greatest difference was a 6 point difference in comprehension and a 5 point difference in mechanics. There was a 2 point drop in spelling among the sample population scores and the district scores.

Relating the mean NCE 1990 District II scores and the student sample scores, it appears that District II scores followed a similar pattern to District I scores. That is, the student sample scores were higher than the district scores in vocabulary, word recognition (word attack) and comprehension. The greatest difference was a 12 point difference in vocabulary, 7 point difference in word recognition (word attack) and a 6 point difference in comprehension. School 1989 and 1990 scores and student 1990 scores. Table 48 reports the NCE school scores for the first grade classes. The first grade student sample NCE scores were higher than the 1989 and 1990 school scores in reading and language 
Table 47

District Standardized Test scores for First Grade in Lanouage Arts and Reading

Mean NCE scores

1989
District I D District II D District I D District II D

Language Arts

First Grade

\begin{tabular}{llllllllll} 
Comprehension & 61.7 & 510 & 47.0 & 602 & 59.3 & 453 & 43.0 & 561 \\
Vocabulary & 62.9 & 504 & 49.0 & 604 & 58.5 & 435 & 45.0 & 561 \\
Reading Total & 61.8 & 503 & 47.0 & 602 & 59.1 & 432 & 43.0 & 561 \\
Recognitiona & 56.9 & 508 & 47.0 & 604 & 55.3 & 447 & 43.0 & 561 \\
Spellingb & 58.6 & 508 & - & - & 56.2 & 454 & - & - \\
Expression & 60.0 & 510 & 49.0 & 602 & 58.1 & 453 & 48.0 & 561 \\
Ianguage Totalc & 59.5 & 507 & - & - & 57.4 & 450 & - & - \\
\hline
\end{tabular}

Note. The dash indicates that there were no data available.

$a_{\text {Word }}$ recognition in District I tests assesses similar skills as word attack in District II tests.

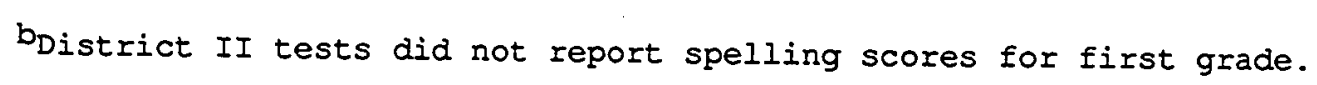

$C_{\text {District }}$ I test scores report only two language scores; language and total language. To avoid using language and total language in this table, expression was used to represent language. District II tests report three scores; expression, mechanics and total language. However, total language scores are not reported for test levels that do not include these two tests.

Reproduced with permission of the copyright owner. Further reproduction prohibited without permission. 
arts subjects in both districts. The performance of first grade students who participated in this study appears to be more successful on standardized tests than was the performance of students who were not part of this study.

District 1989 scores and district 1990 scores.

Table 47 reports the 1989 and 1990 first grade district mean NCE scores. The first grade standardized test scores in District I were higher than the scores in District II for both the 1989 and 1990 school years. District I mean NCE scores were 11 to 15 points higher in 1989 and 10 to 16 points higher in 1990 than the mean NCE scores in District II in all language arts subject areas. However, the mean $1990 \mathrm{NCE}$ scores in both districts dropped from the 1989 mean NCE scores; District I dropped 2 to 4 points in all language arts subject areas and District II dropped 1 to 4 points in all subject areas; both districts dropped 3 to 4 points in comprehension and 4 points in vocabulary.

Schoel 1989 and scheol 1990 scores.

Table 48 reports the 1989 and 1990 mean NCE school scores for the first grade classes represenced in two schools in District $I$ and II. District I 1989 and 1990 mean NCE scores present two different trends in language arts scores between the schools. At the end of 1989, District I School 2 reflected language arts and reading $\mathrm{NCE}$ scores that were eight to 10 points higher than School 1; however, at the end of 1990 school 1 reflected NCE scores 3 to 10 points higher than school 2. It appears that between 1989 and 1990, School 1 gained 3 to 8 
Table 48

School Ianguage Arts Standardized Test scores for First Grade

Mean NCE scores

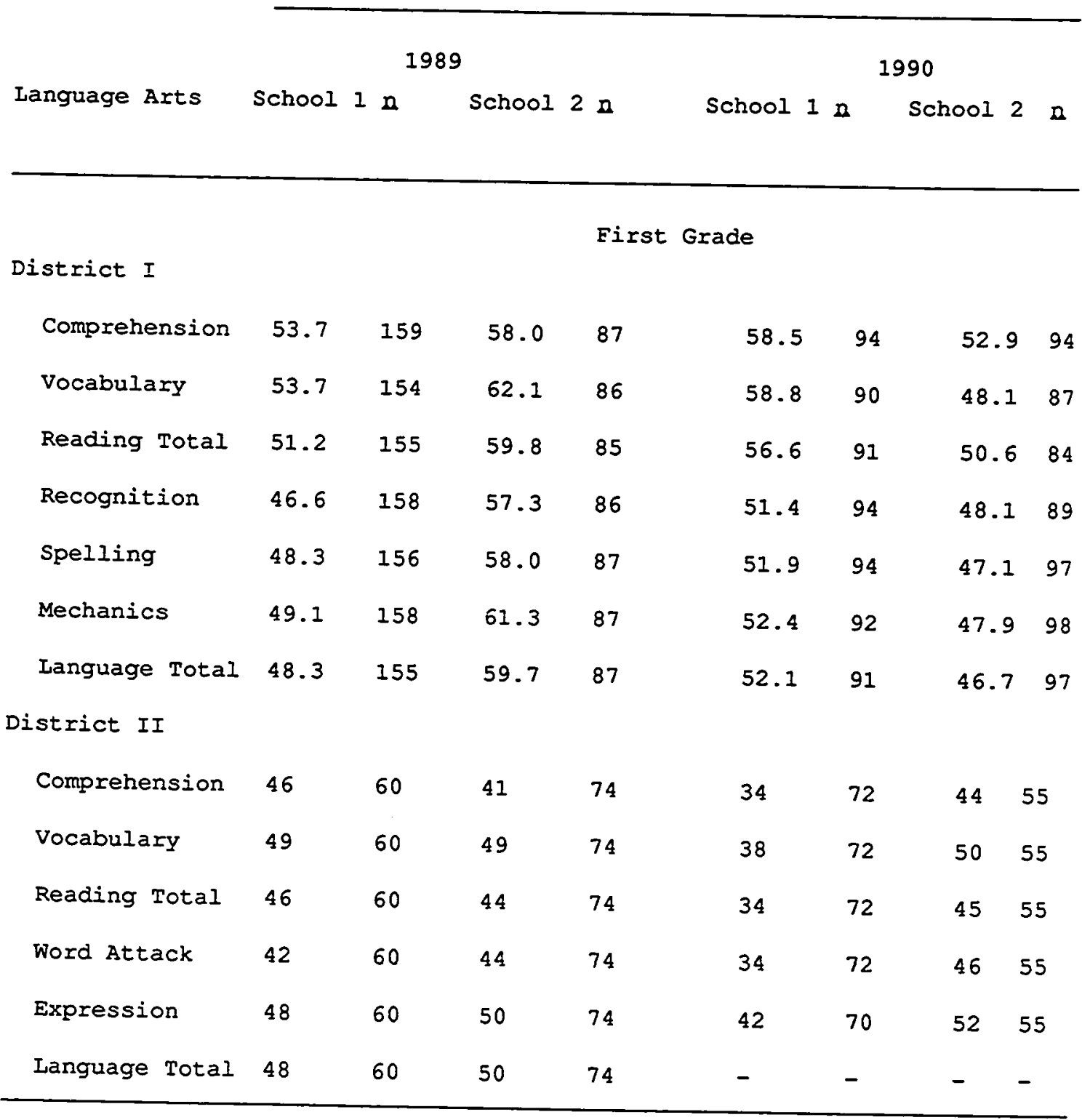

Note. The dash indicates that there were no data available. Total language scores are not reported for test levels that do not include expression and mechanics scores in District II. 
points in language arts areas; the greatest gain was 8 points in vocabulary. School 2 dropped 5 to 14 points in language arts; the greatest drop was 14 points in vocabulary. Both schools implemented the prescribed language arts program in 1989-1990 school year. While it appears that the implementation of the language arts curriculum affected student performance in language arts in School 1 more than the implementation affected student performance in School 2, it should be noted that school 2 maintained approximately the same number of first graders in 1990 while school 1 lost approximately 65 first graders in 1990. Thus, only one classroom in school 1 participated in this study.

The District II 1989 and 1990 mean NCE scores indicate that the two schools ended the 1989 school year with very similar scores in language arts and reading; School 1 displayed a comprehension score 5 points higher than Schocl 2 . However, at the end of 1990, School 1 reported scores 6 to 12 points down from 1989 in language arts subjects; comprehension and vocabulary was down 11 points from 1989. School 2 reported 1990 scores 1 to 3 points higher than 1989 scores in language arts subjects. A reminder concerning the language arts curriculum is that classrooms in District II continued to use a code-centered approach with the basal readers while other classrooms used a code-centered approach with the new prescribed curriculum program. Therefore, the school NCE scores reflect a code-centered approach with the old basal reading program and the new prescribed literature program. 
First grade standardized test scores at the end of 1989 reflected a 0 to 17 point difference in scores between districts; School 1 in District I and II showed the same language arts totals of 48 while school 2 in District I and II showed a 17 point difference in comprehension. At the end of 1990, first grade test scores reflected a 0 to 25 point difference; School 1 District I and School 2 District II showed the same language arts total scores of 52 while school 1 in District I and II showed a 25 point difference in comprehension. It appears that comprehension and vocabulary scores reflect a greater range of school test scores between districts than do the language arts school test scores.

Third grade standardized test scores.

The 1989 and 1990 student performances on standardized tests are related to the 1989 and 1990 district and school mear NCE scores in Tables 49, 50 and 51. Discussion of the differences in student performances begins with relating District I student sample NCE scores to District II student sample NCE scores, then student sample performances are related to NCE district scores, then NCE scores are related to the differences between districts, next student sample performances are related to school NCE scores and finally school NCE scores are related to school NCE scores within the same district. District I student scores and District II student scores.

Table 49 reports the 1989 and the 1990 mean NCE scores for third grade random sample students in both districts. At the 
end of the 1989 school year, third grade student sample scores

Table 49

Third Grade Standardized Test Scores in Lanouage Arts and Reading for Sample Population

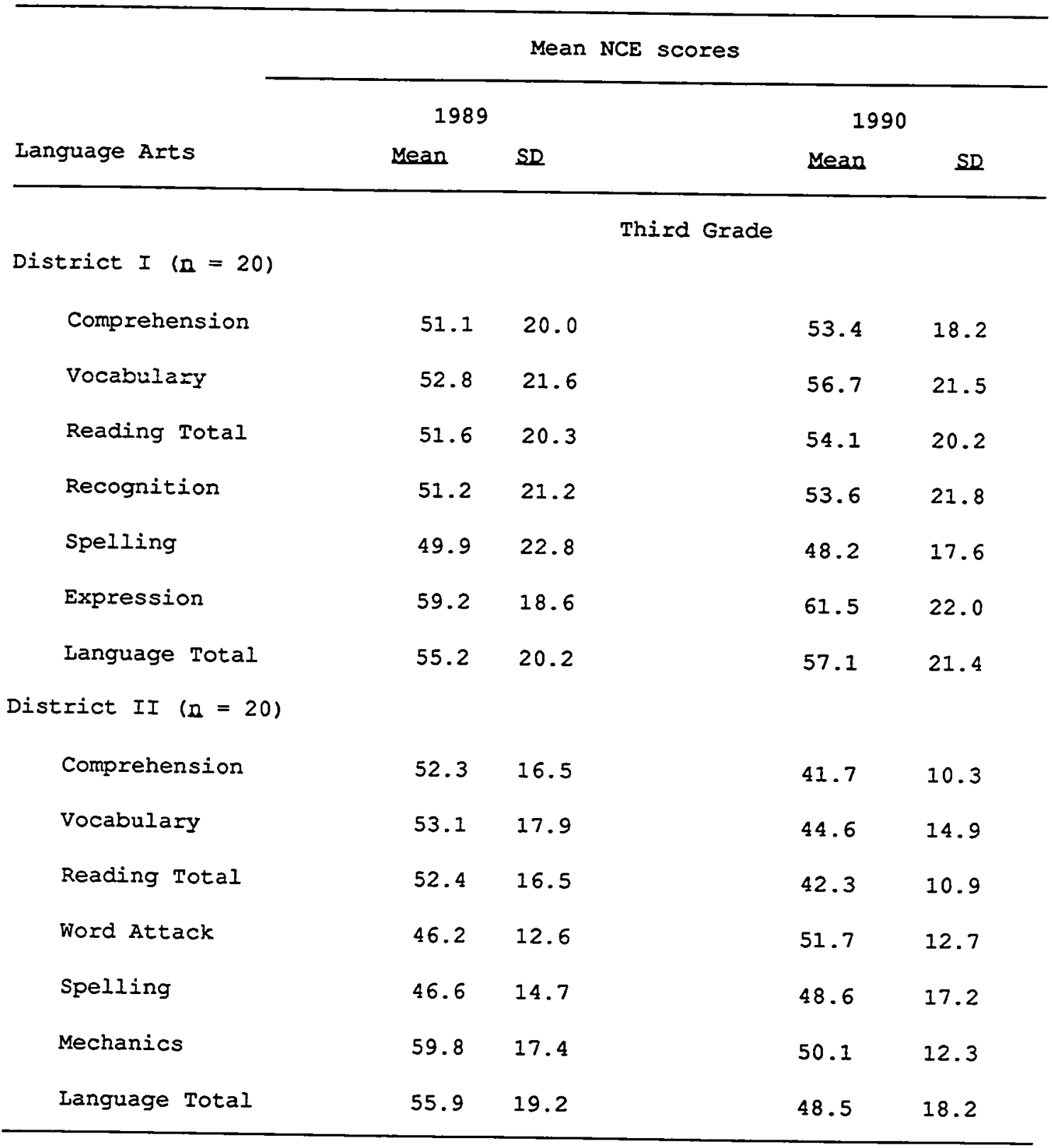


were similar in reading and language arts. The NCE scores reflected a zero to 5 point difference in reading and language arts between both districts; the mean vocabulary score in District I was 5 points higher than the mean vocabulary score in District II while the reading total and vocabulary reflected the same mean NCE score.

At the end of 1990, District I sample student NCE scores reflected a 2 to 4 point gain from 1989 scores in reading and language arts with the exception of spelling; spelling dropped 2 points. On the other hand, District II sample student 1990 NCE scores reported a 6 to 10 point drop from 1989 NCE scores; 10 point drop in comprehension, 6 point drop in vocabulary, and a 10 point drop in mechanics. The only gains in District II mean NCE student scores were a 2 point gain in spelling and a 6 point gain in word attack skills from the 1989 mean NCE student sample scores.

District 1990 scores and student 1990 scores.

Examining the 1989 and 1990 District I mean NCE scores and the District I 1990 student sample NCE scores (Tables 49 and 50), it appears that 1989 NCE district scores were higher than 1990 student scores in comprehension ( 3 points), spelling (4 points), and expression (2 points). The 1990 NCE student scores showed a 4 point gain in vocabulary, and a 2 point gain in word recognition from the 1989 district NCE scores. District I $1990 \mathrm{NCE}$ scores reflected higher scores in reading and language arts than the 1990 student sample NCE scores; 6 points in reading total and 5 points in language arts. 
Focusing on the 1989 District II NCE scores (Table 50) and the 1990 student sample NCE scores (Table 49), it appears that the 1990 student sample scores were 3 points higher in word attack skills and spelling and a 4 points higher in mechanics from the 1989 district NCE scores. In District II, the 1989 district vocabulary score and 1990 student sample NCE vocabulary score reflected identical scores; 45 was the mean

Table 50

District Standardized Test Scores for Third Grade in Language Arts and Reading

Mean NCE scores

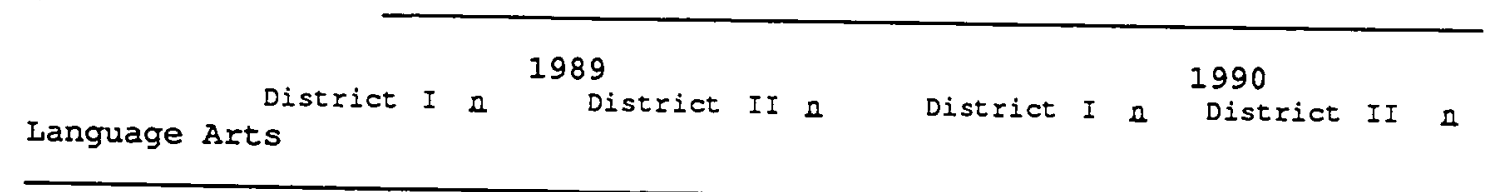

Third Grade

\begin{tabular}{lllllllll} 
Comprehension & 55.7 & 452 & 44.0 & 593 & 58.8 & 448 & 45.0 & 560 \\
Vocabulary & 53.0 & 453 & 45.0 & 593 & 60.9 & 447 & 46.0 & 560 \\
Reading Total & 54.4 & 452 & 45.0 & 592 & 60.3 & 445 & 46.0 & 560 \\
Word Attack & 51.6 & 453 & 49.0 & 593 & 60.3 & 447 & 50.0 & 560 \\
Spelling & 53.2 & 450 & 46.0 & 594 & 55.7 & 448 & 49.0 & 560 \\
Expression & 64.4 & 448 & 46.0 & 592 & 65.6 & 448 & 49.0 & 560 \\
Language Total & 61.3 & 447 & 47.0 & 592 & 62.6 & 447 & 49.0 & 560 \\
\hline
\end{tabular}

Note. Expression was used to represent language scores in District I and mechanics scores in District II. 
NCE score for both the district and the student scores. District II 1990 mean scores were higher in comprehension ( 3 points), vocabulary ( 1 point), and reading total ( 4 points) than were the 1990 student NCE scores. The 1989 and 1990 district scores reflected both a basal and a literature curriculum with a code-centered approach while the student sample scores reflected a literature curriculum with a codecentered approach.

Scheel 1990 scores and student 1990 scores.

The 1990 student sample NCE scores reflected different trends to the school NCE scores in District I and District II (Tables 49 and 51). In District I, the student sample scores were higher than the school scores by one to 3 points; 1 point higher in comprehension and word recognition, 3 points in vocabulary and 2 points in mechanics. The only school score that was higher than the student sample score was spelling (2 points).

In District II, the school scores were generally higher than the student sample NCE scores. School 1 NCE scores were higher in comprehension (2 points) total reading, spelling, and mechanics (1 point) than the student scores. School 2 NCE scores were higher only in comprehension and reading total (2 points) than the student scores. However, student sample scores were higher in word attack ( 5 points), spelling (4 points), and mechanics ( 5 points). It appears that the District II student sample scores in school 2 reflected greater 
gains in word attack, spelling and mechanics than did School 1 NCE scores and District I student scores.

District 1989 sceres and district 1990 scores.

The 1990 NCE scores in District I and District II reported gains in reading and language arts areas from the 1989 district scores (Table 50). However, District I showed greater gains in comprehension ( 3 points), vocabulary ( 7 points), word attack ( 8 points), and reading total ( 5 points) than did District II from the 1989 scores; District II reflected a 1 point gain in comprehension, vocabulary, word attack and reading total. Spelling ( 3 points), expression ( 3 points) and language total (2 points) 1990 NCE scores reflected identical gains in both districts. It appears that there were considerable gains in comprehension, vocabulary and word attack skills in third grade with the implementation of the new language arts curriculum in District $I$.

Schoel 1989 scores and scheol 1990 sceres.

Table 51 reports the mean NCE school scores for the third grade classes represented in this study in District I and II. Both third grade classes were within one school in District I while each of the two third grade classes was represented in a different school in District II. The 1990 school scores in District $I$ appeared to show greater gains in reading and language arts scores than did District II school scores from the $1989 \mathrm{NCE}$ scores. In District I, the school $1990 \mathrm{NCE}$ scores reflected gains in all reading and language arts areas from the 1989 school scores. The most notable gains were 6 points in 
Table 51

Schoel Ianguage Arts Standardized Test Scores for Third Grade

\begin{tabular}{|c|c|c|c|c|c|c|c|c|}
\hline \multirow[b]{3}{*}{ Language Arts } & \multicolumn{8}{|c|}{ Mean NCE scores } \\
\hline & \multicolumn{4}{|c|}{1989} & \multicolumn{4}{|c|}{1990} \\
\hline & School 1 & 12 & School 2 & n & School 1 & $n$ & School 2 & $2 n$ \\
\hline \multicolumn{9}{|c|}{ Third Grade } \\
\hline \multicolumn{9}{|l|}{ District I } \\
\hline Comprehension & 49.2 & 69 & & & 52.4 & 77 & & \\
\hline Vocabulary & 48.9 & 69 & & & 54.8 & 77 & & \\
\hline Reading Total & 48.4 & 69 & & & 52.7 & 76 & & \\
\hline Recognition & 47.5 & 69 & & & 52.5 & 77 & & \\
\hline Spelling & 46.8 & 69 & & & 49.9 & 77 & & \\
\hline Mechanics & 59.3 & 69 & & & 60.3 & 78 & & \\
\hline Language Total & 54.5 & 69 & & & 56.5 & 77 & & \\
\hline \multicolumn{9}{|l|}{ District II } \\
\hline Comprehension & 46 & 58 & 45 & 53 & 44 & 66 & 44 & 56 \\
\hline Vocabulary & 45 & 58 & 47 & 53 & 45 & 66 & 45 & 56 \\
\hline Reading Total & 46 & 58 & 46 & 53 & 44 & 66 & 45 & 56 \\
\hline Word Attack & 50 & 58 & 50 & 53 & 50 & 66 & 47 & 56 \\
\hline Spelling & 46 & 58 & 41 & 53 & 50 & 65 & 44 & 56 \\
\hline Mechanics & 49 & 58 & 48 & 53 & 51 & 64 & 45 & 56 \\
\hline Language Total & 49 & 58 & 47 & 53 & 49 & 64 & 46 & 56 \\
\hline
\end{tabular}


vocabulary and 5 points in word recognition and reading total scores. The smallest gains were reflected in mechanics ( 1 point), spelling and comprehension ( 3 points).

District II school scores reflected small differences in the school scores from 1989 to 1990 in the two schools. Both schools displayed a drop in 1990 comprehension scores and reading total scores; School 1 (2 points) and School 2 (I point). The only gains in the 1990 school scores were in spelling--School 1 showed a 4 point gain and school 2 showed a 3 point gain--and a 2 point gain in mechanics.

Sixth grade standardized test sceres.

Sixth grade student sample test scores are related to the 1989 and 1990 school and district mean NCE scores in Tables 52, 53 and 54. Discussion of the differences in student performances begins with relating District I student sample NCE scores to District II student sample NCE scores, then student sample performances are related to NCE district scores, next student sample performances are related to school NCE scores, then NCE scores are related to the differences between districts, and finally school NCE scores are related to school NCE scores within the same district.

District I student scores and District II student scores.

Table 52 reports the 1989 and the 1990 mean NCE scores for sixth grade random sample students in both districts. The greatest gains from the 1989 student scores to the 1990 student scores were in comprehension; a 5 point gain in District I and 
Table 52

Sixth Grade Standardized Test Scores in Ianguage arts and Reading for Sample Population

Mean NCE scores

\begin{tabular}{lcccc}
\cline { 2 - 4 } & & & & \\
& 1989 & & 1990 & \\
Language Arts & Mean & SD & Mean & SD \\
\hline
\end{tabular}

Sixth Grade

District I $(n=20)$

Comprehension

Vocabulary

Reading Total

Spelling

Expression

Language Total

District II $(n=20)$

ComErehension

Vocabulary

Reading Total

Spelling

Mechanics

Language Total
$51.4 \quad 25.4$

$51.6 \quad 24.7$

$51.2 \quad 26.6$

$51.3 \cdot 20.4$

$56.4 \quad 25.7$

$52.6 \quad 22.6$

$52.3 \quad 17.5$

$56.8 \quad 22.7$

$55.7 \quad 20.6$

$49.1 \quad 20.7$

$53.2 \quad 25.2$

$53.5 \quad 23.3$
$56.2 \quad 23.2$

$48.6 \quad 21.0$

$54.0 \quad 22.0$

$\begin{array}{ll}52.7 & 23.7\end{array}$

$56.1 \quad 17.8$

$53.5 \quad 17.5$

$58.3 \quad 22.9$

$56.7 \quad 23.6$

$58.6 \quad 25.1$

$46.5 \quad 18.6$

$55.9 \quad 19.2$

$57.2 \quad 20.0$

Note. Expression was used to represent language scores in District I and mechanics scores in District II. 
a 6 point gain in District II. The 1989 mean NCE scores report that students in District II ended the year with higher scores in comprehension ( 1 point), vocabulary ( 5 points) and language total ( 1 point) than sample students in District I. The 1990 mean NCE scores indicate that students in District II maintained their higher mean scores in comprehension (2 points), vocabulary ( 7 points) and language total ( 3 points) than did student scores in District $I$. However, students in District II reflected no change in vocabulary NCE scores from 1989 to 1990, while students in District I reported a 3 point drop in vocabulary scores from 1989 scores. Sample student 1990 spelling scores reflected a 2 point drop from the 1989 scores in District II while student scores in District I showed a 2 point gain in spelling.

District $I$, student scores reflected no change in the mechanics score from 1989 to 1990 while District II student scores reported a 3 point gain in mechanics. District $I$, student scores showed greater gains in comprehension (5 points) and spelling (2 points) in 1990 than did the student scores in District II.

District 1989 scores and student 1990 scores.

Table 53 details the 1989 and 1990 district scores. At the end of 1989, District II sample student NCE scores reported lower scores in all of the reading and language arts scores than District I scores; however, student scores were higher in vocabulary (1I points), reading total ( 7 points), spelling (2 points) and language total (1 point) than the District II NCE 
Table 53

District Ianguage Arts Standardized Test Sceres for sixth Grade

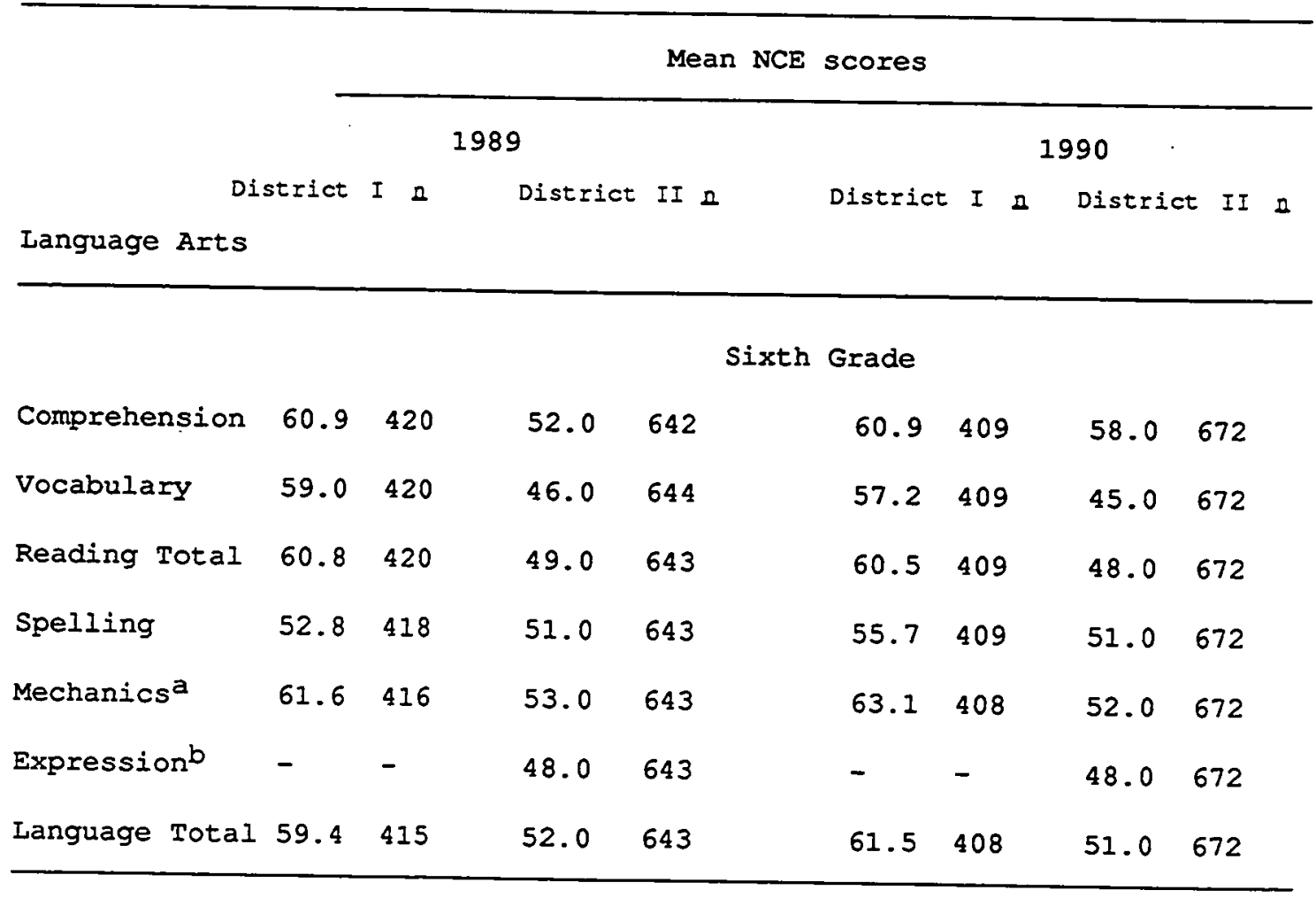

Note. The dash represents data that were unavailable.

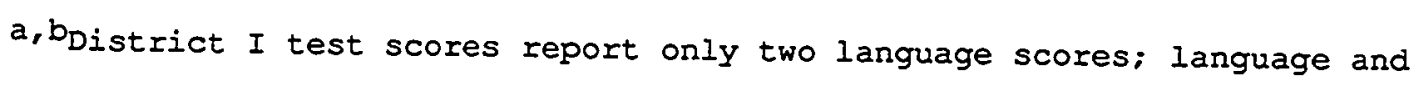
total language. To avoid using language and total language in this table, mechanics was used to represent language scores. District II reports three scores; mechanics, expression and total language.

scores. At the end of 1990, District II student NCE scores continued to show lower scores in comprehension and language arts scores (vocabulary scores were the same) than were District I scores, but student scores were higher in vocabulary (12 points), reading total ( 11 points), mechanics (4 points), 
and language total ( 6 points) than were the District II scores. The 1990 district spelling score was 4 points higher than the student 1990 NCE scores.

At the end of 1989 and 1990, District I sample student NCE scores reported lower scores in all of the reading and language arts scores than the 1989 and 1990 District I scores. The range of differences were similar between the two years; District I scores were 5 (1989) to 4 (1990) points higher in comprehension, 6 points higher in vocabulary, 3 points higher in spelling and 6 (1989) to 8 (1990) points higher in language total than student NCE scores. It appears that the implementation of the prescribed literature program did not have a considerable effect on district standardized test scores in District I ( 3 to 8 points difference). However, the implementation of the prescribed literature program with the continued skill approach (Target Teach) appeared to show a distinctive difference between student sample performance and district scores in District II (4 to 12 point difference).

Scheol 1989 and 1990 scores and student 1990 scores.

Focusing on student sample scores (Table 52) and school scores (Table 54), District I student sample NCE scores at the end of 1989 were higher in reading total (5 points) and language total ( 6 points) than school 1989 scores. At the end of 1990, student scores showed only 1 point higher in reading total and no gain in language total than school scores. District I school scores reflected greater gains in reading rotal and language total ( 7 points) than student sample score 
Table 54

Scheel Ianguage Arts Standardized Test Sceres for Sixtb Grade

\begin{tabular}{|c|c|c|c|c|c|c|c|c|}
\hline \multirow[b]{3}{*}{ Language Arts } & \multicolumn{8}{|c|}{ Mean NCE scores } \\
\hline & \multicolumn{4}{|c|}{1989} & \multicolumn{4}{|c|}{1990} \\
\hline & School & 12 & School & $2 n$ & School 1 & n & School 2 & 2 \\
\hline & \multicolumn{8}{|c|}{ Sixth Grade } \\
\hline \multicolumn{9}{|l|}{ District I } \\
\hline Comprehension & 46.2 & 103 & & & 54.5 & 104 & & \\
\hline Vocabulary & 44.4 & 103 & & & 46.3 & 104 & & \\
\hline Reading Total & 45.5 & 103 & & & 52.5 & 104 & & \\
\hline Spelling & 44.2 & 103 & & & 50.2 & 104 & & \\
\hline Mechanics & 49.6 & 101 & & & 56.1 & 103 & & \\
\hline Language Total & 47.4 & 101 & & & 54.3 & 103 & & \\
\hline \multicolumn{9}{|l|}{ District II } \\
\hline Comprehension & 56 & 41 & 54 & 41 & 59 & 66 & 49 & 59 \\
\hline Vocabulary & 51 & 41 & 51 & 41 & 52 & 66 & 45 & 59 \\
\hline Reading Total & 54 & 41 & 53 & 41 & 56 & 66 & 47 & 59 \\
\hline Mechanics & 58 & 41 & 58 & 40 & 54 & 66 & 56 & 59 \\
\hline Expression & 54 & 41 & 49 & 40 & 52 & 66 & 48 & 59 \\
\hline Language Total & 58 & 41 & 56 & 40 & 55 & 66 & 54 & 59 \\
\hline
\end{tabular}

gains in reading and language total. It appears that the student sample should have made greater gains in their 1990 standardized test scores in reading and language arts. 
At the end of 1989, District II student sample scores were only 2 to 3 points higher in reading total and 2 to 4 points down in language total than school NCE scores. In 1990, student sample NCE scores reflected higher reading totals than School 1 (3 points) and school 2 (12 points) and higher language totals than school 1 (2 points) and School 2 ( 3 points). It appears that student sample NCE scores reflected significance gains in reading total as compared to school 2 scores and in the language totals as compared to School 1 (6 points) and School 2 (5 points).

District 1989 scores and district 1990 scores.

District scores for 1989 and 1990 in reading and language arts are reflected in Table 53. At the end of 1990, District I showed slightly greater gains in language total ( 3 points) and spelling ( 3 points) than the 1989 district NCE scores. There appeared to be no change in reading total and comprehension scores and there was a 2 point drop in vocabulary after the first year implementation of the language arts curriculum.

District II reflected a 1 point drop in reading total, language total and vocabulary from 1989 district scores to 1990 district scores. Comprehension was the only score to show a marked gain ( 6 points) between 1989 and 1990 in a district that implemented the literature curriculum in only a few sixth grade classes and continued to use the code-centered approach. Actually, District II NCE scores reflected greater gains in comprehension than did District I scores. 


\section{Scheol 1989 scores and scheol 1990 scores.}

Table 54 reports the mean NCE school scores for the 1989 and 1990 sixth grade classes. Two classes in District I were represented in one school, school 1, while two classes in District II were represented in two schools, School 1 and School 2. At the end of 1989, the two schools in District II reflected similar school scores in reading and language arts areas; 1 point difference in the reading total and 2 points difference in the language total (mechanics reflected a 5 point difference). At the end of 1990, District II school scores reported different trends between the schools. School 1 reflected a 2 point gain in reading total while school 2 rerlected a 6 point drop in reading total; a 5 point drop in comprehension and a 6 point drop in vocabulary. Both schools dropped in mechanics ( 4 and 2 points), expression (2 and 1 point) and language totals ( 3 and 2 points).

At the end of 1990, District I school scores reflected prominent gains in comprehension ( 9 points), reading total ( 7 points), spelling ( 6 points), mechanics ( 6 points), and language total ( 7 points). Spelling school scores showed only a 2 point gain from the 1989 school scores.

At the end of 1989, District I sixth grade school scores were 11 and 13 points lower in reading totals and 9 points lower in language totals than school scores in District II. However, at the the end of 1990, District 1 school scores reflected greater gains in reading totals ( 7 point gain) and language total ( 7 point gain) than did the school scores in 
District II. In District II, School 1 showed a 2 point gain in reading total and a 3 point drop in language total and school 2 showed a 6 point drop in reading total and a 2 point drop in language total. It appears that the implementation of the language arts curriculum in District I caused greater gains in student performance on standardized tests than was observed in District II. By observing the gains made in the school scores in District I with the implementation of the language arts curriculum, it appears that the implementation of the language arts curriculum in all sixth grade classes in District II would have effected greater gains than school scores in District I.

Summary: How de the differences in materials, teacher behaviors and organizational processes between classrooms using a meaning-centered aporoach and a code-centered aporoach in language arts affect student performance?

This summary reflects those aspects in the data that provide insight into the differences in materials, teachers behaviors and organizational processes among grade levels and between districts that affect student performance. A discussion of the similarities and differences in student performance on standardized tests between districts follows grade level sequence.

Table 55 summarizes the teacher behaviors in District I and District II that were performed more frequently in one district than in the other. The table focuses on the teacher behaviors emphasized in this study; adherence to prescribed 
curriculum materials, management, instructional techniques, values and perceptions and commitment (Tables 4 through 11, 13, 14, and 16 through 35). Teacher behaviors that were found to be performed the same among first, third and sixth grade teachers and between districts were not reported in Table 55; that is, behaviors related to discipline, recognition of cultures, and multimodal applications. Furtinermore, observed teacher behaviors are reported in this summary, and not the contradictory data collected from information and reflected in Tables 12 and 15: (a) Cooperative learning was observed to occur more often in code-centered classes (District II) than in meaning-centered classes (District I), however, Table 12 indicates that teachers in District II marked cooperative learning as less effective than did the teachers in District I; and (b) writing instruction was observed to occur more often in code-centered classes (District II) than in meaning-centered classes (District I), however, Table 15 reports that three teachers in District II indicated that they didn't use writing instruction while only one teacher in District I indicated that writing instruction was not used.

The summary table reports by grade level which made it necessary for this researcher to refer to the original observations and questionnaires for confirmation of summary material for Table 55, since Table 6 reports by district and not by grade level. A summary discussion of student performances--homework, criterion testing, recreational reading and estimated writing and reading performances--that identifies 
the more advanced student performances between the districts follows the summary table. The summary discussion refers to the differences in teachers' adherence to prescribed curriculum materials (Table 4), education in integrated language arts instruction and teaching experience (Tables 2 and 26), lesson presentation (Table 14) and orgänizational processes between districts (Tables 35 through 40 ).

District I: Meaning-centered classrooms.

Table 55 summarizes the teacher behaviors in District I that were performed more frequently than the teacher behaviors in District II. It appears that teachers taught more direct instruction and skill instruction in first grade and less in third grade and sixth grade with a corresponding decrease in the percentage of third and sixth grade students who read for pleasure (Tables 29 through 31 and 42). This phenomenon may suggest that the third graders, who participated in direct, skill instruction over the past two years (discussed in Chapter 1) and during the year of this study, used their abilities to decode, were able to decode complex books independently and were motivated through the new language arts instruction to read more recreational books and found reading pleasurable. The only teacher estimation of student performances that exceeded the teacher estimations of student performances in District II was the number of recreational books that were read by first and third grade students in District I (Table 42).

The data were reviewed to determine what teacher behaviors in District I caused such a difference in students' interest 
Table 55

Checklist of Teacher Centered Behaviors Performed More Frequently in

Either code-centered Classrooms or Meaniü-Centered classrooms

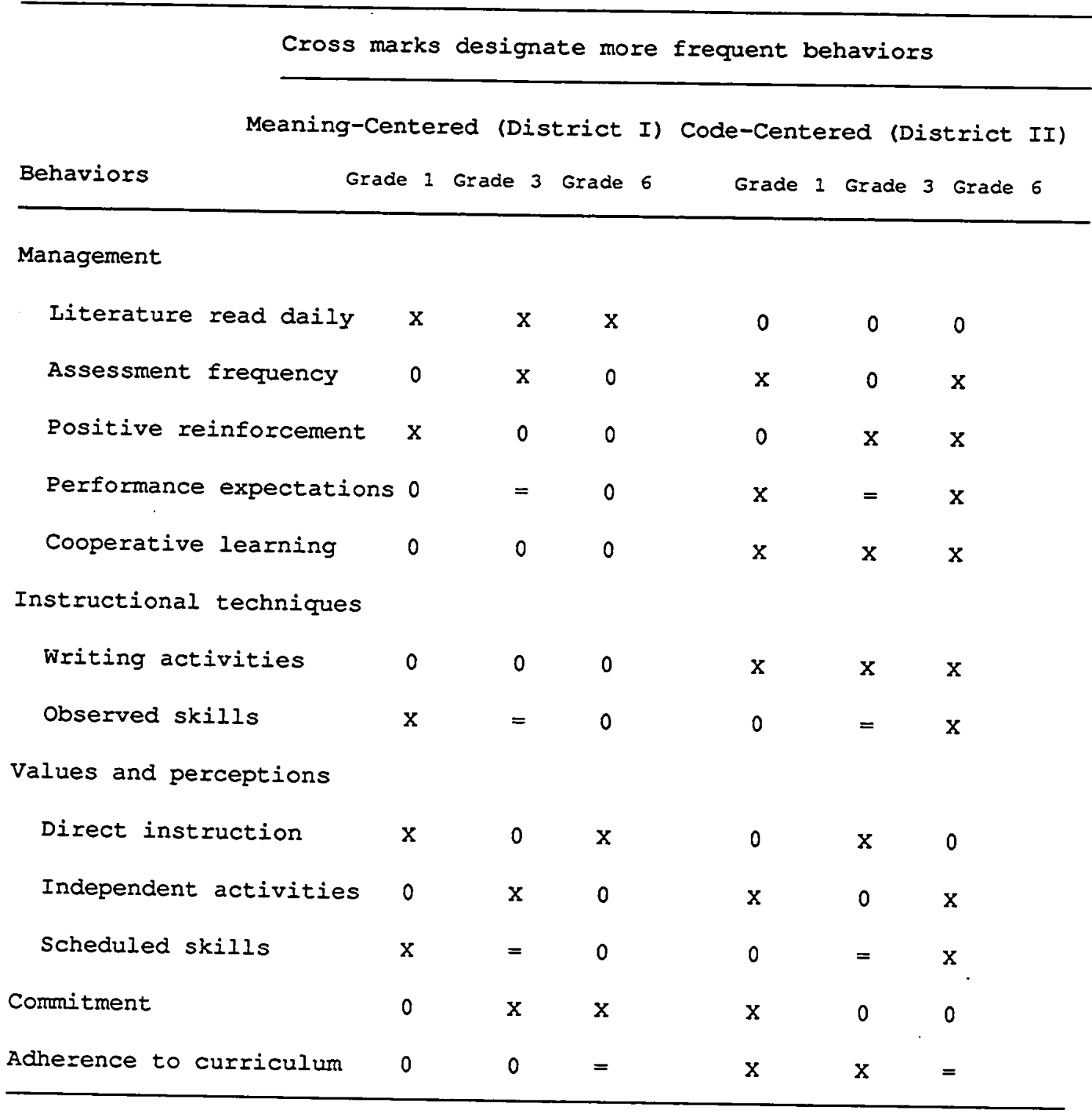

Note. Equal marks symbolize that there was no difference in the frequency of the behaviors. 
and motivation to read books in first and third grades. The only teacher behavior that was performed in both grade levels was the daily reading of literature. The daily reading of literature was performed more often in meaning-centered classrooms than was performed in code-centered classrooms (Table 14). The number of minutes committed to participating in collegial activities by third grade teachers in District I appeared to be greater than the minutes committed by teachers in District II (Table 33). Organizational support, reflected as bonding, openness and relationship building, appeared to be present more often among teachers in District I than was present among teachers in District II (Tables 39 and 40). District II: code-centered classrooms.

Table 55 also summarizes the teacher behaviors in District II that were performed more frequently than were the teacher behaviors in District $I$. It appears that the greatest differences in teaching behaviors between grade levels in District II and between districts were in the sixth grade classes. Teachers in the sixth grade classes performed the listed teacher behaviors more frequently than did teachers in first and third grade classes in District II and first, third and sixth grade teachers in District $I$.

The percentage of students passing the district writing proficiency examination of first, third and sixth grade students (Table 41), the number of recreational books read by sixth grade students (Table 42 ), and the number of completed homework assignments by sixth grade students (Table 43) were 
estimated by teachers to be greater in District II than were in District $I$. Third and sixth grade students' first time performances on criterion testing (Table 44) were estimated by teachers to be more successful than were the performances of students in District $I$.

Teachers in District II participated in learning about language arts instruction (Table 26), followed the prescribed language arts materials closely (Table 4), and provided opportunities for information processing (Table 14) more often than did teachers in District $I$. The number of minutes committed to participating in collegial activities by first and sixth grade teachers in District II appeared to be greater than the minutes committed by teachers in District I (Tables 32 and 34). First and third grade teachers in District II had more teaching experience than did first and third grade teachers in District I (Table.2).

The following discussion of student performances on standardized tests follows the first, third and sixth grade level sequence, reviews and summarizes the similarities and differences among student sample scores, district scores, and school scores, and between districts during the 1989 and 1990 testing years.

Eirst Grade Performance on Standardized Tests

Tables 46,47 and 48 reported the first grade 1989 and the 1990 mean NCE scores in reading and language arts subject areas. The discussions presented with Tables 46 through 48 are summarized to reflect the following similarities and 
differences in the student sample scores, district scores and school scores between District I and District II:

Similarities in District I and District II in first grade.

1. Student sample 1990 NCE scores were the same in spelling, mechanics and language total mean scores in both districts.

2. Student sample 1990 NCE scores were higher than their 1990 district NCE scores in reading and language arts subject areas.

3. Student sample 1990 NCE scores were higher than each of their school 1990 NCE scores in reading and language arts subject areas.

4. District $1990 \mathrm{NCE}$ scores dropped 2 to 4 points from their 1989 district NCE scores in reading and language arts subject areas.

5. School $1990 \mathrm{NCE}$ scores reported that in each district one school dropped in all reading and language arts subjects from 1989 scores, and one school gained in all reading and language arts subjects from 1989 scores: School 2 scores dropped in District $I$, and School 1 scores dropped in District II.

Differences between District I and District II in first grade.

6. Comparing 1990 student sample NCE scores with 1989 and 1990 district scores, student sample scores in District II reflected greater growth in vocabulary, reading total and expression than did student sample scores in District I: 
District II student sample mean score in vocabulary was 8 points higher than was the 1989 district score and 11 points higher than was the 1990 district score; reading total mean score was 10 points higher than was the 1989 district score and 9 points higher than was the 1990 district score; and expression mean score was 15 points higher than was the 1989 district score and 16 points higher than was the 1990 district score. District I student sample vocabulary mean score was 3 points less than was the 1989 district score and 1 point higher than was the 1990 district score, reading total score was only 2 points higher than was the 1989 district score and 5 points higher than was the 1990 district score, and expression mean score was 4 points higher than was the 1989 district score and 5 points higher than was the 1990 district score.

7. Student sample $1990 \mathrm{NCE}$ vocabulary and spelling scores in District I, related to the 1989 district NCE scores, were 3 points less in vocabulary and 4 points less in spelling than were the 1989 district vocabulary and spelling mean scores. However, District II student sample mean vocabulary score was 8 points higher than was the 1989 district vocabulary mean score. There was no difference in District II student sample mean spelling score and 1989 district spelling mean score.

8. Student sample 1990 mean scores in District I were higher in comprehension ( 6 points), vocabulary ( 3 points), word recognition ( 12 points) and reading total (10 points) than were District II 1990 student sample scores in the same subject 
areas; comprehension, vocabulary, word recognition and reading total.

9. At the end of 1989, District I district scores were higher in comprehension, vocabulary ( 14 points), reading total (22 points), word recognition (13 points) and expression (11 points) than were the 1989 District II district scores. At the end of 1990, District I district scores remained higher in comprehension ( 16 points) vocabulary (14 points), reading total (16 points), word recognition (12 points) and expression (10 points) than were the 1990 District II district scores.

10. Comparing District I 1990 school mean scores in both schools to District II 1990 school mean scores in both schools, District I 1990 school scores were higher in comprehension (minimum 8 points higher), reading total (minimum 6 points higher), and word recognition (minimum 2 points) than were school scores in comprehension, reading total, and word recognition in District II.

11. Comparing 1990 school mean scores of both schools within District I to 1989 mean scores and comparing 1990 school mean scores of both schools within District II to 1989 mean scores, school 1990 mean scores reflected considerable drops from the 1989 school mean scores in comprehension and vocabulary in one school in each district. In District II, School 1 comprehension mean score dropped 12 points from 1989 school score, and in District I, School 2 vocabulary score dropped 13 points from 1989 school score. 
The summary of the five similarities (1-5) and the six differences $(6-11)$ in the standardized testing of the first grade students reflected similarities and differences in student performances between code-centered classrooms and meaning-centered classrooms. There appeared to be little difference in student sample performance in spelling, mechanics and language total mean scores in classrooms using a meaningcentered approach or a code-centered approach (number 1). However, there appeared to be a notable difference in comprehension (16 points) and reading total (12 points) mean scores between District I and District II (number 6). The student sample population in meaning-centered classrooms (District I) reflected higher mean scores in comprehension and reading total than did the student sample population in codecentered classrooms (District II).

Comparing 1990 district mean scores to the 1989 district mean scores, there appeared to be a decline in the performance of first grade students in code-centered and meaning-centered classrooms in comprehension, vocabulary, word recognition, spelling, expression and mechanics (number 4). It appears that the implementation of the new language arts curriculum made little difference in the performance of first grade students in District I and District II (number 9).

Comparing student sample 1990 mean scores to 1990 school and district scores in both districts, the 40 student sample mean scores were higher than school mean scores and district mean scores in both districts (numbers 2 and 3). Furthermore, 
in District II, with the implementation of the new language arts curriculum and the continued skill centered instruction, student sample scores in first grade code-centered classrooms appeared to make more notable gains in spelling, expression and language total than did the student sample mean scores in District I (spelling and language total mean scores are not reflected in the district mean scores in Table 47). In District II, district 1990 mean scores in reading total (16 points lower), word recognition (12 points lower) and expression ( 10 points lower) were 10 to 16 points lower than district mean scores in District I. However, District II 1990 student sample scores reflected identical mean scores in spelling, expression and language total as did student sample scores in District I (numbers 1 and 6).

cenclusion.

First grade students in meaning-centered classrooms (District I) appeared to perform more successfully on standardized testing efforts in comprehension, vocabulary and word recognition, and on reading the greatest number of recreational books (Table 42) than did students in codecentered classrooms. Teachers in meaning-centered classrooms provided opportunities for the daily reading of literature, direct instruction, skill instruction and practiced positive reinforcement more often than did teachers in code-centered classrooms (Table 55).

First grade students in meaning-centered classrooms and code-centered classrooms performed equally as well on 
standardized testing efforts in spelling and language mechanics, on completing homework on time (Table 43) and on passing criterion tests (Table 44).

First grade sample students in code-centered classrooms (District II) appeared to make greater gains in spelling, expression and language total mean scores than did the student sample mean scores in District I. A greater percentage of students passed the district writing examination in codecentered classrooms than did students in meaning-centered classrooms (Table 41). Teachers in code-centered classrooms provided opportunities for cooperative learning, assessed student progress, expected all students to learn, practiced writing activities daily, and provided opportunities for independent activities more often than did teachers in meaningcentered classrooms (Table 55). Teachers were more committed to the new language arts curriculum than were the meaningcentered classroom teachers, and code-centered classroom teachers followed the prescribed curriculum program closer than did the first grade teachers in the meaning-centered classrooms (Table 4).

Third Grade Performance on Standardized Tests

Tables 49, 50 and 51 reported the third grade 1989 and the 1990 mean NCE scores in reading and language arts subject areas. The discussions presented with Tables 49 through 51 are summarized to reflect the following similarities and differences in the student sample scores, district scores and school scores between District I and District II: 
Similarities in District I and District II in third grade,

1. Student sample 1989 NCE scores in both districts reported similar scores in vocabulary (53) and reading total (52) while comprehension, mechanics, language total (1 point difference), spelling ( 3 points difference) and word recognition ( 4 points difference) reflected a 1 to 4 points difference between District I and District II student sample scores. However, word recognition was the only subject area that reflected a gain in the 1990 mean NCE scores in both districts; a 4 point gain in District $I$ and a 6 point gain in District II.

2. Comparing 1989 district NCE scores to 1990 district NCE scores, 1990 mean scores in both districts reflected a gain in all reading and language arts subject areas from 1989 district mean scores.

Differences between District I and District II in third grade.

3. Student sample $1990 \mathrm{NCE}$ scores in District I reported a gain in comprehension (2 points), vocabulary ( 5 points), reading total (2 points), word recognition (3 points), mechanics ( 3 points) and language total (2 points) from 1989 NCE scores. The only drop in student sample 1990 mean scores was in spelling ( 2 points) in District $I$. However, student sample 1990 mean scores in District II reflected a considerable drop in comprehension ( 10 points), vocabulary (8 points), reading total (10 points), mechanics (10 points), and language total ( 7 points) from 1989 NCE scores. The only gains in 1990 
student sample mean scores were in word attack ( 6 points) and spelling ( 2 points) from the 1989 NCE scores in District II.

4. Comparing 1990 third grade student sample mean scores to 1989 and 1990 district third grade NCE scores in District I, the standardized testing performances of third grade sample students were weaker than third grade students at the end of the 1989 school year, reflected in 1989 district mean scores, in spelling, language and comprehension. The trend in weak language total and comprehension mean scores continued at the end of 1990 with the third grade student sample mean scores reflecting additional weaknesses in vocabulary, reading total and word attack subject areas as compared to the 1990 district mean scores. Student sample 1990 mean scores in District I were lower than the 1989 district mean scores in comprehension ( 3 points), spelling ( 5 points), expression ( 2 points) and language total ( 4 points), and lower than the 1990 district NCE scores in comprehension ( 6 points), vocabulary ( 4 points), reading total ( 6 points), word attack ( 6 points), spelling ( 7 points), expression ( 4 points) and language total (6 points). Comparing 1990 third grade student sample mean scores to 1989 and 1990 district third grade NCE scores in District II, the standardized testing performances of third grade sample students were weaker than third grade students at the end of the 1989 school year, reflected in 1989 district mean scores, in comprehension and reading total. The trend in weak reading total and comprehension mean scores continued at the end of 1990 with additional weaknesses in vocabulary and expression 
reflected in 1990 district mean scores. Student sample NCE scores in District II were lower than the 1989 district NCE scores in comprehension (2 points) and reading total (3 points) and lower than the 1990 district NCE scores in comprehension (3 points), vocabulary ( 1 point), reading total ( 4 points) and expression ( 1 point).

5. In comparing 1989 district NCE scores to 1990 district NCE scores, District I reflected greater gains in 1990 district mean scores than did District II from 1989 district mean scores (Table 50). District I showed a 6 point gain in reading total and a 2 point gain in language total while District II showed a 1 point gain in reading total and a 2 point gain in language total.

6. Comparing 1989 school NCE scores to 1990 school NCE scores, District I 1990 school scores reflected greater gains in reading total mean scores than in language total mean scores from the 1989 school scores; comprehension (3 points), vocabulary, reading total, word recognition (5 points), spelling ( 3 points), mechanics ( 1 point), and language total (2 points). District II 1990 school scores reflected only gains in spelling ( 3 and 4 points) and mechanics ( 2 points) from the 1989 school scores. The remaining reading and language arts subjects in District II school scores either dropped 1 to 3 points or remained the same from the 1989 school scores (Table 51).

The summary of the two similarities $(1-2)$ and the four differences $(3-6)$ in the standardized testing of the third 
grade students reflected similarities and differences in student performances between code-centered classrooms and meaning-centered classrooms. At the end of 1989, third grade student sample NCE mean scores reflected similar reading total and language total mean scores (number 1). However, at the end of 1990, student sample mean scores in District II (codecentered classrooms) dropped 10 points in reading total and 7 points in language total mean scores while student sample scores in District I (meaning-centered classrooms) reflected a 2 point gain in reading total and language total mean scores (number 3).

Comparing 1989 and 1990 school NCE scores and district NCE scores, it appears that third grade students in meaningcentered classrooms (District I) showed greater growth in 1990 mean scores in reading total, vocabulary and comprehension than in language total, expression, and mechanics from 1989 school and district mean scores (numbers 4,5 and 6). Furthermore, students in meaning-centered classrooms (District I) showed greater growth in 1990 district and school mean scores in reading total, vocabulary and comprehension than did students in code-centered classrooms (District II).

conclusion.

At the end of 1989, third grade sample students showed very similar reading and language mean NCE scores in both districts. However, at the end of 1990, third grade sample students in meaning-centered classrooms (District I) reflected higher scores on standardized testing efforts in comprehension, 
vocabulary and reading total (Table 49), and on reading the greatest number of books (Table 42) than did students in codecentered classrooms (District II). Teachers in meaningcentered classrooms provided opportunities for the daily reading of literature, assessed student progress, and provided opportunities for independent activities more often than did teachers in code-centered classrooms (Table 55). Teachers were more committed to the new language arts curriculum than were teachers in the code-centered classrooms.

Third grade students in meaning-centered classrooms and code-centered classrooms performed equally as well on standardized testing efforts in spelling and word atcack skills and on completing homework on time (Table 43). Third grade teachers in both districts expected students to learn and scheduled the same amount of time for skill instruction (Table 55).

Third grade sample students in code-centered classrooms reflected similar $1989 \mathrm{NCE}$ scores in reading and language to sample students in meaning-centered classrooms; however, at the end of 1990, sample students in code-centered classrooms reflected a considerable drop in reading and language mean scores. A greater percentage of students passed the district writing examination (Table 41) and performed well on criterion testing efforts (Table 44) than did students in meaningcentered classrooms. Teachers in code-centered classrooms provided opportunities for cooperative learning, positive reinforcement, practiced daily writing activities, and 
practiced direct instruction more often than did teachers in meaning-centered classrooms (Table 55). Code-centered classroom teachers followed the prescribed curriculum program closer than did the first grade teachers in the meaningcentered classrooms (Table 4).

Sixth Grade Performance on Standardized Tests

Tables 52, 53 and 54 reported the sixth grade 1989 and the 1990 mean NCE scores in reading and language arts subject areas. The discussions presented with Tables 52 through 54 are summarized to reflect the following similarities and differences in the student sample scores, district scores and school scores between District I and District II:

Similarities in District I and District II in sixth grade.

1. Student sample 1990 NCE scores showed a marked gain in comprehension ( 5 points in District $I$ and 6 points in District II), a 3 point gain in reading total and a gain in language total (only 1 point in District $I$ and 3 points in District II) from the 1989 student sample mean scores in both districts.

2. Comparing 1990 student sample NCE scores to 1990 school NCE scores, student sample mean scores reported higher scores in vocabulary $(3$ points in District $I$ and 5 and 12 points in District II) and reading total (only 1 point in District $I$ and 3 and 12 points in District II) than the school mean scores in both districts.

3. Comparing 1989 district NCE scores to 1990 district NCE scores, 1990 district mean scores reflected a slight drop 
in vocabulary ( 2 points in District $I$ and 1 point in District II) from the 1989 district mean scores in both districts. Differences between District I and District II in sixth grade.

4. Comparing 1989 and 1990 student sample NCE scores in District II to 1989 and 1990 student sample NCE scores in District $I$, at the end of 1989, student sample scores in District II were higher in comprehension ( 1 point), vocabulary ( 5 points) and reading total (5 points) than the 1989 student sample mean scores in District $I$. At the end of 1990 , student sample mean scores in District II continued to be higher in comprehension ( 2 points), vocabulary ( 8 points) and reading total ( 5 points) than the student sample mean scores in District I.

5. Comparing 1989 and 1990 student sample NCE scores in District II to 1989 and 1990 student sample NCE scores in District $I$, at the end of 1990, District II student sample scores reflected the same mean score in mechanics as the student sample score in District I (56.0), and only a 2 point difference in the language total score from the 1990 student sample scores in District $I$. District II student sample mean scores reflected a 3 point gain in mechanics and language total from their 1989 student scores. However, District I student sample mean scores showed no gain in expression and only a 1 point gain in language total from their 1989 student sample mean scores. 
6. Comparing 1990 student sample NCE scores to 1990 district NCE scores, District II student sample mean scores were considerably higher in vocabulary (12 points) and reading total (11 points) and 6 points higher in language total than the 1990 district mean scores. District I student sample mean scores were lower in comprehension (5 points), vocabulary (8 points), reading total ( 7 points) and language total ( 8 points) than the district 1990 mean scores.

7. Comparing 1990 district scores to 1989 district scores, at the end of 1990, District II district mean scores reflected a 6 point gain in comprehension, and a 1 point drop in vocabulary, reading total and language total from the 1989 district mean scores while District I district scores showed no gain in comprehension or reading total and a 2 point drop in vocabulary and a 3 point gain in language total from the 1989 district mean scores.

8. Comparing 1990 school NCE scores to 1989 school NCE scores, at the end of 1990, District I school mean scores reflected notable gains in comprehension ( 9 points), reading total ( 7 points), spelling ( 6 points), mechanics, (six points) and language total (7 points) from the 1989 school mean scores; vocabulary scores reflected only a 2 point gain from the 1989 scores. However, District II school mean scores reflected lower mean scores in language total (dropped 2 to 3 points) and vocabulary ( 1 point and 12 points) from the 1989 mean school scores. Reading total and comprehension gained 2 to 3 points 
in School 1 and dropped 4 to 6 points in School 2 from the 1989 schoc? scores in District II.

The summary of the three similarities (1-3) and the five differences $(4-8)$ in the standardized testing of the sixth grade students reflected similarities and differences in student performances between code-centered classrooms and meaning-centered classrooms.

At the end of 1989 and 1990, student sample NCE scores in District II reflected higher scores in comprehension, vocabulary, reading total and language total than did students in District I. Student scores (student sample mean scores, District I school scores, and District II district scores) in both code-centered and meaning-centered classrooms reflected a notable performance in comprehension on the 1990 standardized testing (numbers 1,4 and 7 ). However, vocabulary scores appeared to show little growth between 1989 standardized testing and 1990 standardized testing in both districts among student sample population, school scores and district scores (numbers 3,7 and 8 ).

Comparing student sample NCE scores with district NCE scores and with school NCE scores and at the end of 1990 (Tables 52, 53 and 54), the performance of sample students in code-centered classrooms was more successful in comprehension, vocabulary, mechanics and language total than was the performance of the sample students in meaning-centered classrooms (numbers 1,6 and 7). Furthermore, schools in District II (Table 54) using a combination of basal readers, 
literature curriculum and code-centered approaches reflected notable weaknesses in reading total scores and language total scores in 1990 from the $1989 \mathrm{NCE}$ scores (number 8). conclusion.

At the end of 1989, sixth grade sample students in codecentered classrooms reflected higher mean scores in reading total ( 5 points) and language total (only 1 point) than did sample students in meaning-centered classrooms. At the end of 1990, sixth grade sample students in code-centered classrooms appeared to be more successful in reading total ( 5 points) and language arts ( 3 points) than did students in meaning-centered classrooms. Furthermore, teachers in code-centered classrooms appeared to practice more of the teacher behaviors identified in this study than did teachers in code-centered classrooms. The student sample population in code-centered classrooms appeared to be more successful on standardized testing efforts in comprehension, vocabulary, reading total, mechanics and language total subject areas (Table 52), on proficiency writing examinations (Table 41 ), on reading the greatest number of books (Table 42), on completing homework on time (Table 43), and on passing the criterion testing (Table 44) than did the student sample population in meaning-centered classrooms. Teachers in code-centered classrooms provided opportunities for cooperative learning, daily writing activities, frequent assessment of student progress, skill instruction, independent activities and the teachers expected all students to learn 
(Table 55) more often did the teachers in meaning-centered classrooms.

Sixth grade sample students in meaning-centered classrooms appeared to show a greater gain in their reading than in their language on standardized testing efforts. Teachers appeared to be more committed to the language arts curriculum than did teachers in the code-centered classrooms. Compared to District II school scores, the most distinctive success in District I was the sixth grade performance in reading and language subject areas reflected in the school NCE scores (Table 54) Summary of chapter Four

In this chapter, the data collected from the examination instruments, interviews, questionnaires and observations were organized and analyzed according to the eight research questions stated in Chapter I to determine how a meaningcentered approach versus a code-centered approach to the teaching of language arts affects student performance. The purpose of the implementation of the English-Language Arts Framework was to cause a change in student performance in language arts and address the educational crisis. In this study, student performance was determined by their performance on a standardized test of objectives that were formulated five to ten years ago and on four teacher estimations of student performance recommended by the English-Language Arts Framework. In the 1989-1990 school year, it appears that students' success, as estimated by teachers, on classroom assessments-writing, criterion testing, homework, recreational reading-- 
reflected their success on standardized testing which reflected objectives that were formulated and normed in the 1980-1985 years.

Students appeared to reflect more notable gains on teacher estimates of classroom performances and their testing performance in classrooms whose teachers provided a balance of opportunities that emphasized both a code-centered (District II) approach--systematic skill instruction and teacher directed--and a meaning-centered (District I) approach-intensive reading, writing, speaking, and listening and student directed. Of the eleven teacher behaviors identified for examination in this study, only three of the eleven teacher behaviors were commonly practiced among teachers whose students appeared to perform successfully on both classroom assessments-recreational reading and homework--and standardized testing in the subject areas of comprehension, vocabulary, and reading total: (a) the daily reading of literature, (b) systematic skill instruction, and (c) a limited adherence to the prescribed curriculum materials. Only three of the eleven teacher behaviors were commonly practiced among teachers whose students appeared to perform successfully on classroom assessments--writing ability and criterion testing--and standardized testing in the subject areas of expression and language total: (a) daily writing activities, (b) cooperative learning activities, (c) positive reinforcement, and (d) expectations of student learning. Teachers in District I appeared to emphasize the daily reading of literature and 
teachers in District II appeared to emphasize daily writing instruction. The daily reading of literature and skill instruction appeared to affect the following student performances: (a) amount of recreational reading, and (b) gains in comprehension, vocabulary, and word recognition subject areas on standardized tests. Daily writing, and adherence to the prescribed curriculum appeared to affect; (a) student writing performance, (b) criterion testing performance, and (c) gains in language on standardized tests. Student success in spelling performance on standardized testing appeared to follow their successful writing experiences in first and third grade. Considerable gains in language performance on standardized testing did not appear in third or sixth grade classrooms as did marked gains appear in reading total performances in third and sixth grade classrooms. On standardized testing in first grade, there appeared to be notable gains in comprehension, vocabulary and word recognition in District I and notable gains in language total scores in District II.

The organizations in both districts supported the changes necessitated by the implementation of the English-Ianguage Arts Framework within their existing environments. Principals stated goals, attempted to produce new and different responses in members of the organization and to shape and build values to support the changes in the language arts curriculum. However, organizational awareness of affecting change through collaborative relationships in a context of reflection, 
interpreting and understanding which mobilizes and propels the change process was limited. Within the framework of this study, organizational culture was not observed to be strong enough to support, facilitate and mobilize a dynamic change process.

Chapter 5 will provide a synopsis of each research question as well as an integration of the findings from the eight research questions. Implications of these findings will be discussed. Recommendations aimed at strengthening language arts instruction to affect student performance will be addressed. Finally, suggestions for further research and study will examine how this research could be extended. 
CHAPTER V

SUMMARY, INTEGRATION AND SYNTHESIS, IMPIICATIONS,
RECOMMENDATIONS, AND SUGGESTIONS FOR FURTHER RESEARCH

Introduction

The purpose of this study was to determine how a meaning-centered approach versus a code-centered approach to the teaching of language arts affects student performance in a regular education classroom containing low achieving, low socio-economic, multi-ethnic and learning handicapped students. To accomplish this purpose this research focused on three interrelated dimensions of organizational change which are linked to student performance: curriculum materials, teacher behaviors and organizational change processes.

Classrooms using a meaning-centered approach were represented in District $I$, and classrooms using a codecentered approach were represented in District II. The curriculum mission directed to all schools and teachers in District I was to implement the prescribed literature series which reflects the philosophy of the California EnglishIanguage Arts Framework in classroom instruction. The curriculum mission directed to all schools and teachers in 
District II was to implement the prescribed literature series, reflecting the new language arts philosophy, and to continue using the systematic skill assessment program in classroom instruction. This study examined the differences within and between organizations and among teachers and administrators who followed their mission and implemented the prescribed literature series, and the effects of this implementation on student performance.

Data originated from the following six sources: (a) pre and post structured interviews of teachers and principals; (b) observations of teacher meetings; (c) pre and post questionnaires of teachers; (d) classroom observations of teachers teaching language arts; (e) examination of pre and post standardized test scores in the subject areas of reading and language arts at grade levels one, three and six using school mean scores and district mean scores; and (f) pre and post standardized test scores of individual students in grades three and six and post standardized test scores of individual students in grade one from classrooms identified for the study in two districts. The three interrelated reform dimensions, referred to in Chapter I in the section titled Purpose of the Study, precipitated eight specific research questions. The three interrelated dimensions and eight questions guided the examination of both qualitative and quantitative data. 


\section{Research Questions}

\section{Curriculum materials.}

Dimension I which examined the differences between classrooms using meaning-centered and code-centered published language arts curriculum materials prompted research question numbered one:

I. To what degree were the published code-centered and meaning-centered language arts curriculum materials presentation recommendations followed by the classroom teacher?

Teacher centered behaviors.

Dimension II which examined the differences between teacher centered behaviors used in a meaning-centered classroom and a code-centered classroom prompted the following research questions numbered two, three, four, five and six:

2. What teacher behaviors related to the instructional management factors--control, curriculum, and societal--were performed in a code-centered and meaning-centered CaliforniaEnglish classroom?

3. What were the differences between instructional techniques used in a code-centered classroom and a meaningcentered classroom?

4. To what extent were students able to exhibit learning strategies acquired from being taught by teacher instructional behaviors specific to code-centered strategies and meaning-centered strategies? 
5. To what extent did teacher values and perceptions guide teacher behavior in a code-centered classroom and/or a meaning-centered classroom?

6. To what degree was the classroom teacher committed to implementing and using a code-centered approach or a meaning-centered approach to teach the California-English curriculum?

Organizational processes.

Dimension III which examined the differences between the effects that organizational processes have on teacher centered behaviors and on the intervention of the California English-Ianguage Arts Framework in code-centered and meaningcentered classrooms prompted research question numbered seven:

7. To what degree did the organization support the changes introduced by the California-English Language Arts Framework?

Student performance.

The final research question number eight interrelated the three reform dimensions, the preceding seven questions and student performance.

8. How did the differences in materials, teacher behaviors and organizational processes between classrooms using a meaning-centered approach and a code-centered approach in language arts affect student performance?

In the first section of this chapter there is a summary of the data on meaning-centered and code-centered approaches 
collected by this researcher during five months of the 19891990 school year implementation of the California-English Language Arts Framework. A synopsis of the findings from each of the eight research questions is presented.

The next section integrates and synthesizes the major findings from the eight research question summaries.

Upon conclusion of this synthesis, there are three sections:

1. Implications of the findings as they relate to student performance.

2. Recommendations aimed at implementing major changes in language arts curriculum that affect student performance.

3. Suggestions for further research to extend or expand this research.

Summary of the Research

Summary of ouestion one: To what degree were the oublished code-centered and meaning-centered language arts curriculum materials presentation recommendations followed by the classroom teacher?

Teachers in both districts found the new curriculum materials to be somewhat difficult to manage and to understand. However, they tended to confront the difficulties and become courageously involved in the lessons. They carried instructional practices used with past curriculum materials, known to be effective with students, 
into the delivery of the new program. Regardless of the philosophy, format, or methods of the new curriculum materials designed to reflect the philosophy of the California English-Language Arts Framework, teachers continued to use past instructional practices, although some of these practices were quite contrary to the Framework's philosophy. Teacher comments and observations appeared to indicate that the instructional format of the prescribed curriculum materials required that the teachers use a discovery process to determine the skill instruction design. It was rot unitil the end of the school year that teachers were aware that the prescribed program presented a sequence of skill development.

While the new aspects of the literature program were ambitiously addressed by the teachers, they were not certain of the effectiveness of the new curriculum program on student performance. Teachers with the least teaching experience followed the program more closely than those teachers with more teaching experience. Comments of the newer teachers indicated that they were full of hope that the new literature approach would bring about student improvement. It appears that the more experienced teachers were not willing to swap instruction they had learned through experience to be effective with students for a new philosophy encased in novel curriculum materials. All twelve teachers enthusiastically followed the prescribed program requirements; however, they were not willing to gauge its effectiveness with the 
students, and they were not willing to allow the prescribed program recommendations to dictate the sole classroom instruction for their students.

Summary of Ouestion Two: What teacher behaviors related to the instructional management factors-centrol, curriculum, and societal-were performed in a code-centered and meaningcentered language arts classroom?

Teacher behaviors related to the instructional management control factors reflected similarities and differences between districts. In a positive environment more learning results. Teachers in both districts managed the classroom environment similarly. The arrangement of furniture, the posted goals, objectives and rules, display of student work and teacher preparation were observed to be satisfactory or even exemplary in both districts.

Teachers in District I with more classroom experience exhibited habits that attended to positive interactions with students more often than did teachers with less experience. Teachers in District II attended to positive and supportive interactions that addressed the self-concept of students more often than did the teachers in District I. Participating in positive and supportive interactions with teachers, students in District II received opportunities to follow a more positive model of interactions more often than did students in District $I$. 
Regardless of the particular program of instruction, stories, art activities, writing or materials in use, there seemed to be very few differences in the students. responsiveness to their independent language arts activities in either meaning-centered or code-centered classrooms. Student engagement in activities appeared to depend on the support and expectations created by the classroom teacher. The monitoring of students' success rate did not occur consistently during independent activities in both districts. However, teachers in code-centered (District II) classrooms seemed to give corrective feedback concerning students' success more often than did the teachers in District I. During independent activities, four to five students in each classroom appeared to require more corrective feedback-teacher support and encouragement--than did the remaining students in the classroom.

The instructional management practice of offering opportunities for students to participate in sharing ideas was performed at a high level and as often by teachers in both districts. The practice of sharing ideas was not performed during every language arts lesson observed. However, during each allotted time for sharing ideas, three to four students in each classroom were consistently observed to avoid participation in responding to directed sharing, but they were enthusiastic about communicating with partners or buddies. 
The practice of offering opportunities for students to participate in cooperative learning groups was observed to occur more often in District II than in District I. District II practiced cooperative learning at all grade levels; however, cooperative learning groups were not often observed. Cooperative learning groups were rarely observed during language arts instruction in District $I$.

Teacher behaviors in both districts addressed individual differences in learning through a balance of multimodal lesson presentations. Teachers were observed to offer a range of auditory, visual and kinesthetic strategies to engage students in the learning process. The majority of these strategies seemed to be suggested by the recommendations of the prescribed literature curriculum. Opportunities for students to recognize minority languages and other cultures through language arts activities, literature selections and assignments were rarely observed in classrooms in either district. The student population characteristics in classrooms in both districts created an educational need to recognize minority languages and other cultures. The least number of multi-ethnic students in classes in District I was $32 \%$ of the sample population and greatest number was $51 \%$ of sample population. The least number of multi-ethnic students in classes in District II was $78 \%$ of the sample population and the greatest number was $86 \%$ of the sample population. Opportunities for cooperative learning, sharing ideas and frequent literature 
references to cultural differences that reinforce selfesteem, friendship and language acquisition were rarely observed.

Frequent informal assessment strategies--oral presentations and portfolio consultations--and formal performance assessment strategies--written essay tests and criterion referenced tests--of students' academic performances reinforce students' efforts and provide instructional direction for the teacher. First grade teachers in District II reported using a greater variety of assessment strategies more often than did teachers in District I. Teachers in District II appeared to emphasize students' making meaning by informally assessing the writing progress of their students almost daily. They also emphasized a mastery of objectives--criterion tests, progress on skills, letter grades and written essay tests--and a direction for instruction toward objectives more often than did the teachers in District $I$.

Third grade teachers in District I reported using assessment strategies more frequently than did the teachers in District II; however, teachers in District II used informal assessment strategies more often than did teachers in District $I$. The frequency of formal performance assessment strategies was balanced between both districts except for the major difference in the frequent use of letter grades by teachers in District I; however, there seemed to be 
a limited emphasis on student mastery of objectives in both districts.

Sixth grade teachers in both districts emphasized a mastery of objectives and a direction for their instruction toward objectives through their almost daily use of formal assessment strategies. However, teachers in code-centered (District II) classrooms apparently used a balance between formal and informal performance assessment strategies. Teachers in District II informally assessed writing and speaking performances more often than did teachers in District I. Sixth grade teachers in District II emphasized a mastery of objectives and students' meaning through writing and speaking opportunities. Students were encouraged to create, develop and formulate meaning of their own understanding through writing and speaking activities. Cooperative learning groups participated in a discussion of the writing assignment with constant teacher feedback. Students participated in individual consultations with their teacher and finally, the written meaning and individual understanding was presented to members of the class in the form of an oral presentation. Teachers in District II emphasized a balance between a mastery of objectives and strategies that encouraged students' meaning and understanding through writing and speaking activities while teachers in District I appeared to use assessment strategies that emphasized a mastery of objectives more than students' meaning and understanding. 
A noticeable discrepancy occurred between the three instructional management approaches--assertive discipline, classroom management and cooperative learning--teachers listed as effective in classroom instruction and the observed teacher behaviors related to the instructional management approaches. All twelve teachers were observed using various elements of assertive discipline and related classroom management practices; however, two teachers in District I and three teachers in District II indicated that they didn't use classroom management practices, and only two teachers in District II and four teachers in District I indicated that assertive discipline was effective. A similar discrepancy occurred with cooperative learning. Cooperative learning was observed more often in classrooms in District II than in classrooms in District $I$; however, all six teachers in District II indicated that cooperative learning was somewhat effective, ineffective or not used. Teachers in District I indicated that cooperative learning was very effective, effective or somewhat effective in classroom instruction; however, cooperative learning practices were observed during only three of the 30 language arts observations. This discrepancy between teachers' responses and classroom observations implies that teachers in District II continued using an instructional management approach that they found to be only somewhat effective or ineffective with student performance, while teachers in District I did not practice an instructional management approach that they found to be 
effective with student performance. Since teacher comments reflected their interests in the successful progress of their students' performance, a more reasonable implication suggests that teachers were not familiar with or aware of the nomenclatures assigned to the instructicnal management approaches they were using in their classroom instruction. Furthermore, if teachers are not aware of the nomenclature or "language" of their teaching behaviors, how will they know what aspect of an approach leads to what student performance and why that approach affects student performance?

During the interviews, teachers in both districts indicated that they maintained high performance expectations for their students. However, when asked to what degree they maintained high expectations, five teachers in District II maintained higher expectations for their students than did five teachers in District I. Teachers in District II espoused high expectations for their students with conviction and intensity, and they marked higher degrees of expectations than did the teachers in District II.

Summary of Question Three: What were the differences between instructional techniques used in a code-centered classroom and a meaning-centered classroom?

Teachers in both districts rarely integrated past knowledge about the transference of understandings, the performance of tasks effectively, and the mastery of learning goals into the literature focus on reading, writing, speaking 
and listening. Past knowledge about the transference of information from teacher to student within the context of minimal performance anxiety for the student was limited to the first six stages of an effective sequenced lesson by teachers in both districts: motivation, review, goals and objectives, explanation, modeling and structured practice. Teachers in code-centered classrooms practiced motivation, review, objective and modeling stages more often than did the teachers in the meaning-centered classrooms.

The explanation stage was practiced more often than was other structured lesson stages by teachers from both meaningcentered and code-centered classrooms; however, teachers in meaning-centered classrooms performed the explanation stage during all 30 observations. In meaning-centered classrooms, students were given the opportunity to practice correct performance during structured practice more often than were the students in code-centered classrooms.

The use of a systematic skill program, a phonic program or semantic and structural analogy strategies was limited in classrooms in both districts. However, teachers in codecentered classrooms were observed using a systematic skill program slightly more often than were teachers in meaningcentered classrooms. First grade teachers in meaningcentered classrooms and sixth grade teachers in code-centered classrooms scheduled more time for skill instruction than did the remaining eight teachers. 
The California English-Language Arts Framework suggests that good literature be read aloud daily and writing be practiced daily. Exemplary writing activities were limited in both meaning-centered and code-centered classrooms during the observations of language arts instruction; yet, from observations and the number of daily writing assessments reported, teachers in code-centered classrooms seemed to provide opportunities for their students to write more often than did teachers in meaning-centered classrooms. Iiterature was read daily more often in meaning-centered (District I) classrooms than in code-centered classrooms (District II).

The same noticeable discrepancy that occurred between the perceived effectiveness of instructional management approaches and the observed teacher behaviors occurred between the perceived effectiveness of instructional techniques used and the teacher behaviors that were observed. Several teachers indicated that instructional techniques were not used in their classroom instruction; however the teachers were observed using the techniques. The indication is that some teachers were not aware of the nomenclatures given to the instructional techniques they were using in their classrooms.

Assuming that many teachers were knowledgeable about the instructional techniques they used in the classrooms, the most effective instructional techniques marked by teachers in meaning-centered classrooms were writing instruction, mastery learning, direct instruction, key elements of teaching and 
language experience approach. Mastery learning was marked to be most effective by teachers in code-centered classrooms. Teachers' perceptions of the success of the prescribed curriculum program was formed by their observed performances of their students. Comments from teachers in both districts reflected a concern for the loss of instructional time to actually teach students' skills. Comments further indicated that students were developing good attitudes about reading and learning; however, several teachers were concerned that all their students were not learning the necessary skills to be successful in reading and language that were usually taught in a structured program. Comments from teachers in meaning-centered classrooms reflected on the improved attitudes and self-concepts of students toward reading and writing activities. Teacher comments also reflected concern for the performance of students' with language difficulties and students without the background experiences to respond and discuss the literature read to them.

Comments from teachers in code-centered classrooms reflected concerns about the progress of student performance using the literature approach as often as teachers in meaning-centered classrooms. Teacher comments indicated a concern for the lack of structure, quiet time and skill instruction implied by the prescribed literature approach. They also noted the improved attitude toward reading and writing of students who were not performing as expected. Teacher comments indicated that their perceptions of the 
success of the prescribed literature program is contingent upon the remarkable improvement of students' positive attitudes toward reading and writing and their self-concepts. Teacher comments reflected confusion and uncertainty as to how successful the prescribed program would be on students' reading and writing performances.

Summary of ouestion Four: To what extent were students able to exhibit learning strategies acquired from being taught by teacher instructional behaviors specific to code-centered strategies and meaning-centered strategies?

This question examines the differences between exhibited learning strategies from high and low performing students as they relate to writing and reading. Students in codecentered classrooms were observed writing more often during language arts instruction than were students in meaningcentered classrooms. Students were observed participating in systematic skill instruction in classrooms in both districts; first grades in District I, sixth grades in District II and in both districts in the third grades. Iiterature was read aloud more often to students in meaning-centered classrooms than to students in code-centered classrooms. All four first grade teachers reported that their low performing students had mastered the writing of simple sentences at the end of first grade. All four third grade teachers indicated that their low performing students had mastered simple paragraphs and/or descriptive paragraphs at the end of third grade. AII 
four sixth grade teachers noted that their low performing students had mastered descriptive paragraphs by the end of sixth grade.

According to the first grade teachers in code-centered classrooms, their low performing students were able to read familiar texts at the end of first grade; however, first grade teachers in meaning-centered classrooms showed that their low performing students were only able to decode words by the end of first grade. Third grade teachers in codecentered classrooms related that their low performers had mastered the ability to read less familiar texts by the end of third grade. Teachers in meaning-centered classrooms recorded that their low performing students had mastered familiar texts and less familiar texts by the end of the year. A great difference between sixth grade code-centered and meaning-centered classrooms was the reported reading performance of low performing students. Teachers in meaningcentered classrooms indicated their students had mastered the task of reading less familiar texts by the end of sixth grade. Teachers in code-centered classrooms noted that their sixth grade students had mastered a reading task with abstract and specialized vocabulary that required cognitive performance and was conceptually complex.

High performing first grade students in code-centered (District II) classrooms apparently developed writing skills at a faster pace than did students in meaning-centered (District I) classrooms; that is, students began with simple 
sentences, then mastered simple paragraphs and finally descriptive paragraphs by the end of first grade. According to all four third grade teachers, their high performing students had mastered the ability to express concepts in their writing. Sixth grade teachers in code-centered classrooms described the mastered writing ability of their students as the ability to express concepts about human values and conditions. Sixth grade teachers in meaningcentered classrooms related that half of their students had mastered expression of concepts and half of their students had mastered expression of concepts about human values and conditions.

First grade teachers in District I proclaimed that their high performing students had mastered the reading of less familiar texts that was both cognitive and conceptual in nature, while students in District II had mastered a reading task more advanced by the end of first grade. The mastered reading task of high performing third graders in codecentered classrooms was described as a reading task that was cognitive and conceptual with abstract and specialized vocabulary, while third graders in meaning-centered classrooms were reported to have mastered a reading task that was only cognitive and conceptual. Sixth grade teachers indicated that all sixth grade high performing students mastered a reading task that required cognitive and conceptual thought processes and the understanding of abstract and specialized vocabulary. 
At the end of 1990, low performing students exhibited similar writing abilities in both districts. However, teachers in code-centered classrooms estimated that their first, third and sixth grade low performing students exhibited reading abilities more advanced than were students' abilities in meaning-centered classrooms.

The writing performance of high performing first grade students in District II progressed at a faster pace than did students in District I. At the end of 1990, sixth grade students in District II exhibited writing strategies more advanced than did students in District $I$. Third grade students demonstrated similar writing strategies in both districts. First and third grade students in District II displayed more advanced reading strategies than did students in Districc I. Sixth graders exhibited similar reading strategies in both districts.

Teachers from both meaning-centered (District I) and code-centered (District II) classrooms indicated that the prescribed literature program did not provide enough skill instruction for low performing students to exhibit successful learning strategies or to be able to transfer strategies to higher levels of reading and writing performances.

Summary of Question Five: To what extent did teacher values and perceptions guide teacher behavior in a code-centered classroom and/or a meaning-centered classroom? 
According to teachers' responses on questionnaires (Research Question Five), organizational support of the language arts implementation efforts was generally perceived to be at a high level in both districts. However, teachers in code-centered classrooms perceived language arts support by parents, administrators and peer teachers to be greater than did teachers in meaning-centered classrooms. Perceptions and values about the success of the prescribed program have not been formed by teachers in either district.

The extent to which opportunities were offered to facilitate the development of the cognitive-conceptual transformation was minimal in both districts. Therefore, without this cognitive-conceptual development teacher behaviors were rarely guided by their values and perceptions concerning the philosophy of the California English-Language Arts Framework.

The extent to which teacher's values and perceptions about language arts predisposed their selection of the amount of instructional time, opportunities and experiences they provided for low performing students varied with the number of estimated low performers in the class, the grade level and the district. The general trend among teachers in both districts was to schedule more time for literature opportunities if a high percentage of low performing students was estimated to be in their classrooms. Teachers who reported a lower percentage of low performing students in their classrooms, scheduled more time for skill instruction, 
teacher directed instruction and independent activities. However, as was reported in questions three and four, comments from teachers in both code-centered and meaningcentered classrooms indicated that the prescribed literature program did not provide enough skill instruction for their low performing students to perform successfully or improve their performance. It appears that the trend among teachers, with estimated high percentages of low performers in their classrooms, was to schedule more time for the literature experiences presented in the prescribed curriculum and less time for skill instruction. But they didn't perceive that the literature experiences offered in the program provided enough opportunities for their low performing students to improve their performance.

Summary of Question Six: To what degree was the classroom teacher committed to implementing and using a code-centered approach or a meaning-centered aporoach to teach the language arts curriculum?

A total of eight of the twelve teachers, four teachers from each district, seemed to be more committed to the implementation of the language arts intervention model, more developed interpersonally and more effective in classroom instruction than were the remaining four teachers. The number of years of teaching experience appeared to have no relation to the degree of teacher commitment in this study. Teachers in meaning-centered classrooms expressed more 
commitment to the California English-Language Arts Framework curriculum than did the teachers in code-centered classrooms. However, their comments displayed a wide range of degrees of commitment among teachers in both districts.

\section{Summary of ouestion Seven: To what degree did the erganization support the changes introduced by the English- Ianguage Arts Framework?}

The educational organization in both districts supported the changes in the language arts curriculum with effective leadership. Principals stated goals for accountability and staff development, indicating that the organization was designed to achieve an educative purpose. Their goals reflected a motivation for formal testing to reflect the purposes of the language arts curriculum by identifying outcomes and objectives in language arts curriculum and teaching to a mastery of objectives. The improvement of scores with standardized testing procedures was still very much a part of their stated goals.

Principals supported changes in the language arts curriculum by deliberately attempting to produce new and different responses in members of their organization with a combination of three power forms: expertise, personal power and cooperative power. Principals used a combination of four control sources to shape and build values that support the changes in the language arts curriculum; influencing, bargaining, negotiating and positional. 
The educational organization in both districts supported the changes in the language arts curriculum; however, the degree of support was observed to be less than was its potential support in both districts. The awareness of affecting the change process through collaborative relationships seemed to be limited. Principals stated goals of creating and building collaborative relationships that affect changes. However, the conceptualization of an actual developmental design that would affect the change process through collaborative relationships seemed to be missing erong all principals in both districts. Building and creating relationships through interpersonal relationships that address human life cycle development, individual differences, values, attitudes and perceptions, and guided by the individual's judgments in the context of a critical and reflective dimension that affect change were not discussed or observed.

Staff development practices in District $I$ and District II did not appear to encourage and/or support the change process. Information about the California English-Language Arts Framework was presented, discussed and background information was provided for teachers; however, the process to affect change apparently stcpped at that point. The data collected from the instrument used in this study to determine the degree of support of the organization through the presence of relationship building behaviors and bonding and openness behaviors indicated that relationships were not 
bonded enough to affect notable changes in teacher behaviors or student performances in either district (Tables 39 and 40). As indicated in Table 40, teachers in District I appeared to be more bonded than did teachers in District II. The principal of one organization in District I indicated that small groups of teachers worked closely together at the beginning of the year developing language arts lesson pians for their first and third grade students. Additionally, the same group of teachers bonded closer together during the school year through motherhood events. These same teachers were observed to receive more administrative feedback and more time for peer instructional observations than teachers did in District II. However, pre and post questionnaires reflected few changes in responses, observations reflected few changes in individual teacher behaviors, only four of the eleven instructional techniques observed were common among the three teachers, and students in their classrooms reflected similar performances on formal and informal performance assessments. There were no opportunities for demonstration, practice, correction, teaching, feedback, or sharing in a collegial fashion. Therefore, it appears that openness and bonding behaviors observed in staff meetings, occasional working committees and social events do not influence change in teacher behaviors or student performances.

Administrators supported and promoted the changes introduced by the framework within their understandings and 
year time line. Perhaps leaders found it difficult to display a motivational spirit for any new change while the present operating procedures required so much energy and time. The educational crisis that initiated the changes in the language arts curriculum did not appear to be transferred to a focus of engaging members of the organization in the changes.

Only one school in District I seemed to reflect a somewhat charged spirit supporting the language arts curriculum changes. It was the principal of this school who said that her mentor had a way of envisioning things, making them reality and motivating people to work, work, work without feeling that demands were on them. This school seemed to generate the greatest amount of supporting motivational spirit. This organization was observed to reflect the most developed school culture from among the three organizations in District II and the remaining organization in District $I$. This organization in District I appeared to have a culture strong enough to support, facilitate and mobilize a dynamic change process. Furthermore, the developmental stage of this organization in District I was more advanced than were the organizations in District II. 
Summary of Question Eight: How did the differences in materials, teacher behaviors and organizational orocesses between classrooms using a meaning-centered aporoach and a code-centered approach in language arts affect student performance?

This research question acknowledges the interrelated nature of materials, teacher behaviors and organizational processes on student performance. The summary to this question is organized by grade level from a micro perspective to macro perspective; that is from student sample population, to class population and finally to district population. Student performance is defined by informal assessments--the ability to pass writing proficiency examinations, the number of selected recreational books read and the willingness to complete homework on time--and formal performance assessments, the successful performance on criterion testing efforts, and achievement assessments, the level of success achieved on a standardized test in reading and language arts.

Teacher estimations of student performance defined by classroom formal and informal assessments may be considered too inferential for summarizing the influences of language arts instruction on student performance. However, this study described what actually occured. in classrooms during the implementation of the English-Language Arts Framework. The California State Department of Education (1987) suggested that "alternatives to objective testing provide more formative data" (p. 34). According to the California state 
Department of Education, "Teachers, students, and parents are offered a more accurate picture of students' facility with English-language arts by using a variety of assessment strategies ..." (p. 34). Decisions concerning student performance in the classroom are guided daily by teachers' values, perceptions, attitudes and judgments. Therefore, teachers' estimations of students' progress and academic performances are considered meaningful for the purposes of this descriptive study.

Mean NCE scores of the student sample population may be misleading for summarizing the effects of language arts instruction on low performing students. These mean scores may have been influenced by very high scores of students in the sample. Therefore, student performance on standardized tests is related to the classroom teacher's estimation of students' reading and writing performance. The standardized test scores in the subject areas of language arts and reading are viewed and discussed as three interrelated basic components :

1. Comprehension. Comprehension is to get meaning from and putting meaning into what students read; either a passage, a text or a story.

2. Language. Language is defined as the ability to demonstrate a knowledge of spelling, mechanics, expression, word attack and word recognition skills.

3. Vocabulary. Vocabulary is defined as the ability to demonstrate the knowledge of word meanings. Demonstrating a 
knowledge of word meanings also implies that the student can use the meaning, context, and orthographic processors (Adams, 1990). Student performance is further interrelated with a summary of materials, teacher behaviors and organizational processes which appear to be attributed to student performance.

Eirst girade.

This discussion of how the differences in teacher behaviors, organizational processes and materials affected student performance is confined to the classrooms identified in this study using the prescribed curriculum program, since some first grade classrooms in District II continued to use the basal reading program. Teachers in code-centered classrooms (District II) performed the following instructional behaviors more often than did teachers in meaning-centered classrooms (District I): (a) frequent assessment of student performance, (b) high student expectations, (c) cooperative learning opportunities, (d) daily writing activities, (e) independent activities, and (f) the prescribed literature program recommendations were followed closely. Teachers in code-centered (District II) classrooms scheduled 30 more minutes of language arts instruction than did teachers in meaning-centered (District I) classrooms. They seemed to be more committed and had more teaching experience than did first grade teachers in the meaning-centered classrooms. Organizational processes 
generally supported the implementation of the language arts curriculum.

Teacher behaviors, materials and organizational processes in District II appeared to affect student performances in the following four ways:

1. Students' standardized testing scores reflected notable strengths in expression and language total scores and weaknesses in comprehension and vocabulary scores.

2. Students performed successfully on district writing proficiency examinations, criterion testing and completion of homework assignments, but did not read as many recreational books as students in District $I$.

3. High performing students made greater progress in their reading and writing performances than did students in District. I (as estimated by teachers). Iow performing students made greater progress in their reading performance than did students in District $I$. Students were equally successful in their writing performance as were students in District I.

4. Students were enthusiastic and motivated about reading and writing activities.

Teachers in meaning-centered classrooms (District I) performed the following instructional behaviors more often than did teachers in code-centered (District II) classrooms: (a) literature was read daily, (b) a systematic skill program was taught, (c) a direct instruction approach was used, (d) the prescribed curriculum program was not followed closely, 
and (e) there were more positive than negative interactions between students and teachers. There were more multi-ethnic students represented in the student sample population in meaning-centered classrooms than were in code-centered classrooms (Table 45).

Teacher behaviors, materials and organizational processes in District I appeared to affect student performances in the following five ways:

1. Students' standardized test scores reflected considerable strengths in comprehension, vocabulary and word recognition. Scores in expression and language total were identical to student scores in District II.

2. Students read a greater number of recreational books than did students iñ District II and performed equally as well as students did in District II on criterion testing and homework expectations.

3. Students were enthusiastic and motivated about reading and writing activities.

4. Low performing students' writing performance progressed to the same stage as did low performing students in District II, simple sentences.

5. There was a greater difference between high performing students' reading and writing performances and low performing students reading and writing performances in meaning-centered (District I) classrooms than were the differences between students' performances in code-centered (District II) classrooms. 
Apparently, there were distinctive differences between the estimated reading and writing performances exhibited by low performing students and high performing students and the standardized testing results of the student sample populations as early as first grade. However, there were distinctive similarities among the estimated successes on assessments--recreational reading, homework, criterion tests and writing proficiency tests--and success on standardized testing subject areas: (a) Students who read the most recreational books seemed to perform well in comprehension, vocabulary and reading total, and (b) students who performed well on writing proficiency examinations appeared to perform well in language total, expression and mechanics.

Third grade.

Teachers in code-centered (District II) classrooms performed the following instructional behaviors more often than did teachers in meaning-centered (District I) classrooms: (a) provided cooperative learning opportunities, (b) engaged in positive reinforcement, (c) practiced daily writing activities, (d) practiced direct instruction behaviors, and (e) followed the prescribed literature program recommendations very close. Teachers reported to have more teaching experience than did third grade teachers in the meaning-centered classrooms. Teachers in code-centered classrooms scheduled 10 minutes more total language arts instructional time than did teachers in meaning-centered classrooms. 
Teacher behaviors, materials and organizational processes in District II appeared to affect student performances in the following four ways:

1. Students were able to pass the district's writing proficiency examination and perform successfully on criterion testing efforts the first time. Students read few recreational books. They did complete homework assignments as often as students in District I. Students who performed well on writing proficiency examinations and criterion testing (as estimated by teachers) did perform well on only one subject area on the standardized tests, spelling.

2. High performing students and low performing students made greater progress in their reading performances than did students in District I (as estimated by teachers).

3. The writing performance of high and low performing students progressed to the same stage as the writing performance of students in District $I$.

4. Students reflected similar scores in spelling and word attack subject areas on their standardized testing in both districts. Students' standardized test scores reflected a notable drop in comprehension, vocabulary, mechanics and language total subject areas.

Teachers in meaning-centered (District I) classrooms performed the following instructional behaviors more often than did teachers in code-centered (District II) classrooms: (a) literature was read daily, (b) a systematic skill program was taught, (c) student progress was assessed daily, and (c) 
independent activities were scheduled for students. There were a greater percentage of multi-ethnic students in the sample population than were in the sample population in codecentered classrooms (Table 45).

Teacher behaviors, materials and organizational processes in District I appeared to affect student performances in the following three ways:

1. Students read a great number of recreational books.

2. Students performed well on standardized test scores in comprehension, vocabulary, word recognition and expression and language total subject areas.

3. Students completed homework assignments as often as students did in District II.

There appeared to be distinctive differences between the estimated reading performances exhibited by low performing students and high performing students and the standardized testing results of the student sample populations. The only similarity among the estimated successes on performance assessments--recreational reading, homework, criterion tests and writing proficiency tests--and success on standardized (achievement) testing subject areas was that students who read the most recreational books, seemed to perform well in comprehension, vocabulary and reading total subject areas. Organizational processes generally supported the implementation of the language arts curriculum in both districts. 


\section{Sixth grade.}

Teachers in code-centered (District II) classrooms used the following effective instructional behaviors more often than did sixth grade teachers in meaning-centered classrooms: (a) provided cooperative learning opportunities, (b) engaged in positive reinforcement, (c) maintained high expectations, (d) used frequent formal and informal performance assessment strategies, (e) practiced daily writing activities, (f) practiced skill instruction, and ( $g$ ) provided opportunities for independent activities. Teachers scheduled 10 minutes more of total time for language arts instruction than did teachers in meaning-centered classrooms.

Teacher behaviors, materials and organizational processes in District II appeared to affect student performances in the following three ways:

1. Students were able to pass the district's writing proficiency examination, perform successfully on criterion testing efforts, read a great number of recreational books and completed homework assignments.

2. Students reflected higher scores in comprehension, vocabulary, total reading, and total language than did students in District $I$. Spelling was the weakest subject area.

3. The writing performance of high performing students progressed to the most complex stage identified in this study. Low performing and high performing students progressed to the same advanced reading stage. 
Teachers in meaning-centered (District I) classrooms scheduled more time for direct teacher instruction, seemed to be more committed to the language arts philosophy and had more years of teaching experience than did teachers in codecentered (District II) classrooms. Teachers in code-centered and meaning-centered classrooms followed the prescribed curriculum recommendations about equally.

1. Students did reflect growth in comprehension and spelling on standardized testing. However, there was a drop in vocabulary scores.

2. High performing students in both districts progressed to the most complex stage of reading identified in this study (estimated by teachers).

3. Low performing students in both districts mastered descriptive paragraphs.

There were almost twice as many multi-ethnic students in the student sample population in the meaning-centered (District I) classrooms as in the code-centered classrooms (Table 45). However, there were more multi-ethnic students and low performing sixth grade students in the code-centered (District II) classrooms (Table 1).

There appeared to be distinctive differences between the estimated reading performances exhibited by high performing students and the writing performances exhibited by low performing students and the standardized testing results of the student sample populations. There were similarities among the estimated successes on assessments--recreational 
reading, homework, criterion tests and writing proficiency tests--and success on standardized testing subject areas in comprehension, vocabulary, reading total and language total subject areas. Organizational processes generally supported the implementation of the language arts curriculum in both districts.

\author{
Differences Between Code-Centered and \\ Meaning-Centered Classrooms In the First Year Implementation \\ of the English-Language Arts Framework: \\ Integration and Synthesis
}

\begin{abstract}
This research study looked at the implementation in two districts of a statewide effort to change the language arts philosophy in the elementary curriculum and to improve student performance in reading and language arts. The California English-Language Arts Framework discussed the emphases and goals of the educational reform movement, essential elements of instructional programs, effective instruction, exemplary instructional practices, assessment of student performance and the necessary resources to implement the language arts program. Each school district selected curriculum materials and implemented the program according to its particular agenda. A macro view of the similarities and differences in the language arts implementation in code-
\end{abstract}


centered and meaning-centered classrooms that affected student performance reflects the following observations: Influence of Prescribed curriculum Materials on classroom Instruction

1. The prescribed curriculum materials seemed to generate motivation, excitement and interest in classroom instruction among teachers and students in both districts. The curriculum materials offered opportunities for students to discover learning on their own and with others.

2. Teachers willingly followed the recommendations of the curriculum materials, regardless of the difficulty experienced with the prescribed materials in both districts. However, several less experienced teachers in language arts apparently followed the program recommendations more closely than did the teachers with more experience. Teachers continued to supplement the prescribed materials with materials they had found to be effective with student performance.

3. Teachers' initial commitment to the language arts philosophy appeared to remain stabilized, neither more committed nor less committed at the end of the school year in both districts. Their degree of commitment seemed to depend upon the standardized test results of their students' achievement. Teacher Behaviers Related to Instructional Management

4. There appeared to be many variations in the management of effective instructional time. Within 45 
minutes of observed language arts instruction, there appeared to be no uniformity among the teachers in both districts in the percentage of instructionai time teachers used for modeling tasks, student time-on-task activities, lesson explanation, literature reading and writing activities. Teacher Behaviers Related to Instructional Techniones

5. There seemed to be a set of instructional practices that affected student performances among first, third and sixth grade classrooms. First and third grade students in meaning-centered classrooms and sixth grade students in codecentered classrooms who received instruction in both a systematic skill program and an integrated literature program, who read and heard literature daily and who participated in writing activities daily performed successfully in comprehension, vocabulary, word attack and word recognition subject areas on standardized tests. They liked to read literature independently and completed homework as expected.

6. Many teachers appeared to use instructional practices they knew to be effective from experiences or educational opportunities regardless of the suggestions of the new language arts philosophy. Multi-ethnic and lowincome students who were members of one sixth grade class in a code-centered classroom performed well on both formal and informal performance assessments. Their teacher was observed to balance the language arts program with code-centered and meaning-centered opportunities and to use a large number of 
effective teaching strategies with the greatest percentage of multi-ethnic and low income students in this study. Teacher Behaviors Related to Perceptions and Values

7. Teachers structured the classroom environment to support the emergent literacy perspective supported by the California English-Language Arts Framework. Teachers seemed to restructure the environment with instructional management practices and instructional techniques so that literacy experiences could occur. However, they appeared to define their role as a teacher as promoting more teacher directed activities than promoting more student directed opportunities.

Effects of the Ianguage Arts curriculum on student Performance

8. High estimations of reading and writing competencies and success on criterion referenced tests did not appear to agree with student performances on standardized tests in the subject areas of reading comprehension, vocabulary and language mechanics in first grade and third grade in District II. The writing competency estimations did agree with sixth grade student performances on standardized tests in District II.

9. Within the framework of this study, language arts instruction as presented in first and third grade classrooms in District I and sixth grade classrooms in District II appeared to be used successfully with the majority of student population. The percentage of multi-ethnic, low socio- 
economic, low achievement, and learning handicapped students in the first, third and sixth grade code-centered and meaning-centered classrooms did not seem to make a difference in overall student performances.

10. First and third grade student sample spelling and expression NCE test scores, were very similar in code-centered and meaning-centered classrooms. Students in both classrooms using code-centered or meaning-centered approaches participated in writing activities and reading literature.

11. Low performing first grade students who participated in both a systematic phonic instructional program and the literature based curriculum appeared to perform at a higher level on standardized tests than did students who did not participate in both a systematic phonic program and the literature curriculum. However, the progress of reading and writing abilities of low-performing students cannot be determined from looking at the standardized test mean scores for three reasons: (a) high performers skew the mean scores, (b) standardized tests used in this study did not test writing proficiency, and (c) stindardized tests provide an achievement score at the end of the year--they are not designed nor normed to gauge the ongoing progress of students. Furthermore, teacher estimations of the abilities of their low performing students indicated a very slow growth rate in first grade writing and reading abilities compared to the growth rate of high performing students in both districts. However, high and low performing students in 
meaning-centered classrooms who received both systematic phonological instruction and Iiterature instruction scored 10 points higher in comprehension and vocabulary on standardized tests, and they read more recreational books than did students in District II who did not receive systematic skill instruction.

12. In the first, third and sixth grades, high performing students made greater gains in reading and writing in the early grades than in the later grades. Low performing students made greater gains in writing in the third grade and greater gains in reading in third and sixth grades.

13. Classrooms which were observed to be using both a systematic skill program and inventive speling seemed to reflect the greatest improvement in the subject of speling on the standardized tests in both districts. Inventive spelling was encouraged at all three grade levels in the study in both districts. The school, district and student sample NCE mean spelling test scores seemed to reflect only a two to three point change from 1989 to 1990. However, the most distinctive improvement was the seven point increase from first grade 1989 school scores and 1990 student sample scores in meaning-centered classrooms. These classrooms were observed using a systematic skill approach with their low performers and also encouraging inventive spelling.

14. At the end of the first year of the implementation of the California English-Language Arts Framework, first grade 1990 standardized test scores in both districts 
appeared to drop from 1989 scores; however, the student sample scores from this study in classrooms using a balanced program of systematic skill instruction and literature instruction seemed to receive higher test scores in comprehension and vocabulary.

erganizational support of change Process

15. Principals appeared to support the change process within the context of their experiences and understandings: that is, they stated goals related to educational directions, deliberately attempted to produce new and different responses with power and control forms, articulated their values, and established consistent gathering times and places for their teachers. However, they seemed to lack the power--skills, understanding, energy, time, motivation, beliefs, perceptual procedures or knowledge of collaboration models--to energize the change process. Their energies and efforts appeared to be used to stabilize and manage the existing operations of their environments. The strategies that were suggested and recommended for teachers to use in the The California English-Language Arts Framework to effect student performance could be interpreted as suggestions and recommendations for organizational leaders to effect change in members of their organizations.

16. Openness and bonding behaviors in social situations and in occasional working committees, and staff meeting operations do not seem to influence change of teacher instructional behaviors or the academic performance of the 
students. Openness and bonding behaviors in this study appeared to be bounded within the circumstances in which the bonding occurred. Apparently, bonding relationships that take place within a framework of specific values, perceptions, and beliefs cannot be transferred to another set of values, perceptions and beliefs. Therefore, the motherhood bonding that took place in District I could not be transferred to beliefs, values and perceptions concerning effective teaching behaviors. It is the opinion of this researcher that the motherhood bonding could have been transitioned to classroom instructional bonding through the restructuring of interpersonal staff development processes. conclusion

Organizational members seemed to find difficulty in using the prescribed curriculum materials and relating the materials to the emphases and goals discussed in the Framework. Therefore, interpretations of the Framework's emphases and goals reflected many variations. Several of the variations in interpretations noted in this study are: (a) the emphases, goals and elements of effective instruction discussed in the Framework were assumed to be covered in the prescribed curriculum materials, therefore the recommendations of the prescribed materials were followed closely by the teachers; (b) teachers who were observed to be knowledgeable (Tables 2, 5, and 15) about effective instruction based on research and experience in language arts instruction, appeared to balance the prescribed curriculum 
materials with additional structured and systematic skill instruction; and (c) administrators less familiar with effective instruction discussed in the Framework and/or the research in reading and writing over the past 15 years, or who reflected a special interest in whole language only, tended to interpret the English-Language Arts Framework emphases and goals as the integration of listening, speaking, reading and writing in literature books.

First, third and sixth grade students who received opportunities to participate in a literature program and a systematic skill program, seemed to be able to perform at a higher level on informal and formal performance assessments than did students who only participated in a literature program. The set of instructional practices that appeared to affect first and third grade student performance in comprehension, vocabulary, word attack and word recognition on standardized tests and independent reading was the following: (a) a systematic skill program, (b) an integrated literature program, (c) positive reinforcement, (d) literature read and heard daily, and (e) daily participation in writing activities. This same set of instructional practices seemed to affect sixth grade student performance in comprehension and mechanics on standardized tests and independent reading.

Low performing first grade and sixth grade students who participated in both a systematic phonic instructional program and the literature curriculum, seemed to perform at 
higher levels in reading and language than did students who did not participate in both a systematic phonic program and the literature curriculum. If this study indicates that an emergent literature approach combined with a direct, systematic skill approach to language arts instruction affects student performance considerably, then it seems reasonable to assume that if additional teaching strategies found to be effective through research were also applied to a balanced language arts program, student performance would have an even greater chance to be affected and perhaps at a more rapid rate than is currently observed. Perhaps, two great dangers to effective instruction are the continued practices of allowing individuals to interpret and make value judgments for others and the continued practice of resisting change. Therefore, opportunities to collaboratively discuss and explore research findings contrary to personal experiences, belief systems and sociological influences, and opportunities to address emotional status related to change may lead to a shift in attitudes and motivational energy that effects change. Proposed strategies to counter these dangers are found in team collaboration, cooperation and coaching models. A revised focus on continuous organizational collaboration would enable organizational support of a change process. Within this focus, education would become a shared activity. This engineering issue is possible within the confines of a school year, has been researched, and has been successful in 
businesses (Argyris, 1985, 1987; Costa, 1987; Goodman, 1986; Joyce, et al., 1990; \& Schein, 1986). This shared collaboration suggests that educational change should become the business of educational organizations in the 90 's.

\author{
Implications for the Implementation of \\ English-Language Arts Framework in \\ Code-Centered and Meaning-Centered Classrooms
}

Several ideas that could strengthen the potential for affecting student performance in the implementation process of language arts in code-centered and meaning-centered classrooms emerged from this study. The limitations of this study are recognized-the small sample of students and the unequal percentages of multi-ethnic and low socio-economic students in District II. Some of the findings in this research corroborate portions of the information reviewed in the literature. This section addresses particular dimensions for strengthening the potential for affecting student performance in language arts by emphasizing the following: (a) findings that corroborate the information documented by researchers noted in the bibliography, and (b) aspects which have not had a great deal of documentation from other sources. 


\section{Curriculum Materials}

The new language arts approach appeared to bring energy, excitement and motivation to language arts instruction. However, neither the prescription of a philosophy or the prescribed curriculum materials tailored to that philosophy can guarantee the best outcomes for student performance. The classroom teacher must ultimately interpret the philosophy and materials and deliver instruction to the students. The prescribed curriculum materials did not clearly present an instructional system to guide the classroom teacher. The implication is that the teachers may have been confused as to what instructional strategies emphasized in the prescribed curriculum materials affected student performance. Therefore they were not in a good position to determine student performance problems or provide corrections (Gersten, Woodward, \& Darch, 1986; Adams, 1950). Teachers, unwilling to abandon effective instruational strategies and concerned with the performance of their students, turned to instructional behaviors they had found successful in the past. These instructional behaviors often emphasized codecentered approaches.

During the transitional period of implementing a new instructional philosophy with newly adopted instructional materials, teachers seemed to depend on the curriculum materials to guide their instruction. The newly adopted curriculum materials appeared to guide instruction in the direction of only a few effective teaching strategies. 
Guided practice, independent practice and corrective feedback were only three strategies not addressed in the prescribed materials. Teachers' expectations appeared to be that the design of the prescribed curriculum materials would help make up performance differences in less prepared students and improve student performance. It seems that the teachers who followed the prescribed curriculum program recommendations closely, expected that differences in less prepared students and more advanced students would be shortened by engaging twenty-five students' active attention for 180 hours of listening to literature.

Additionally, to prevent foreseeable concerns about the progress or lack of progress of student performance using the new prescribed curriculum, two safety nets seemed to accompany the implementation of the prescribed curriculum programs: (a) a three to five year waiting period for changes in student performances to make notable gains in reading and language arts (implicit and explicit in principals' responses to interview questions--Research Question Seven), and (b) a recommendation that the emphasis on student accountability be placed on informal assessments-speaking, listening, writing, recreational reading, and homework--and not formal, objective assessments; criterion testing (performance assessment) and standardized testing (achievement assessment). The California state Board of Education (1987) emphasized the use of a variety of informal assessment strategies: "Although objective tests are clearly 
easier to administer, less expensive, or more quicky scored, they can measure only a small portion of what children have learned and understood" (p. 35).

The instructional recommendations of the prescribed literature program followed by the classroom teacher appeared to assume prior background knowledge for many students. The implication is that the lack of background knowledge may explain why three or four students in each classroom consistently avoided participating in sharing ideas with their buddies. These students may not have developed the concepts enabling them to respond to questions about the stories. The different interpretations about a directed topic prompt that was discussed among friends and buddies may have been confusing for some students.

Opportunities for cooperative learning, sharing ideas and frequent literature references to cultural differences that reinforce self-esteem, friendship and language acquisition were rarely observed being offered to students. However, teacher behaviors in both districts addressed individual differences in learning through a balance of multimodal lesson presentations. Teachers were observed to offer a range of auditory, visual and kinesthetic strategies to engage students in the learning process. The majority of the strategies were suggested by the prescribed literature programs and supported by the English-Language Arts Framework. The California State Department of Education (1987) suggested that language arts programs "offer a range 
of these multimodal strategies to engage all the aspects of learning and make language growth possible" (p. 20). The inference is that teachers depend on the curriculum materials to guide their instruction and the prescribed curriculum materials did not appear to guide instruction in the direction of cooperative learning and cultural literature references.

Teacher Behaviors

Teachers in meaning-centered (District I) classrooms were not observed using instructional management approaches that they marked to be effective with student performance in their classroom instruction. The implication is that some teachers were not familiar with the nomenclatures given to the instructional management approaches they were using in their classroom. Furthermore, if teachers were not aware of the instructional techniques they were using, then they could not make student performance corrections, repeat the same behaviors or make these effective instructional techniques part of their teaching behaviors.

The instructional approach, whether code-centered or meaning-centered, and teacher behaviors seemed to contribute separately and distinctively to students' performances. The possibilities of how teachers interpret the English-Ianguage Arts philosophy and the prescribed curriculum materials individually or with others, what is in their minds and hearts and how the directions are implemented in classroom instruction are unlimited (Adams, 1990). The implication is 
that the integration of meaning-centered and code-centered approaches in classroom instruction and the continuous development of teacher behaviors will contribute to the improvement of students' reading, writing, listening and speaking performances at a faster rate. Student Performance

The implementation of the English-Ianguage Arts Framework appeared to bring energy, excitement and motivation to language arts instruction. The interaction of codecentered and meaning-centered instructional approaches grounded in writing activities and opportunities for reading and listening to literature seemed to motivate independent reading and improve standardized test performance in comprehension, word recognition and vocabulary. The integration of the two instructional approaches suggests that language arts performance will improve.

The first and third grade students in meaning-centered classrooms and sixth grade students in code-centered classrooms who participated a balanced program, that is a prescribed literature program and an explicit, systematic skill instruction, appeared to read more independent books and produce better word reading skills and comprehension skills on standardized tests than those code-centered classrooms who did not use an explicit, systematic skill instruction. Therefore, students received skill instruction from two sources: (a) their prescribed literature program; and (b) instruction from additional curriculum, Target Teach 
programs and direct instruction programs. The suggestion is that if the remaining first, third and sixth grade teachers in District I and District II had included a systematic skill instructional program with their prescribed literature program, students would have performed at least as well or better than would have students in classrooms not using both program approaches.

Regardless of the amount time scheduled for presenting opportunities for skill instruction, writing activities and reading literature, the writing skills of low performing first grade students in both code-centered and meaningcentered classrooms progressed slowly. Students were able to master only simple sentences in one year of instruction with the new language arts instructional program (Table 16). However, the writing skills of the high performing students in the meaning-centered classrooms appeared to progress at a greater rate than did writing skills of students in codecentered classrooms. Systematic skill instruction, daily writing activities and daily listening to literature suggests that writing skill performance for high performing students will improve.

The estimated reading progress of low achieving students in code-centered (District II) classrooms seemed to progress faster than did those of students in meaningcentered (District I) classrooms. At first glance, the implication is that daily writing activities and opportunities for listening to literature improved the 
reading performance of low performing students at a faster rate than did low performing students who received direct phonic instruction, listening to literature and writing opportunities. However, reading familiar stories can be accomplished without the orthographic processor (Adams, 1990). Ideally, low performing students in the first years of school are curious and motivated enough to memorize and examine familiar texts over and over again which will lead to reading less familiar tests. The NCE mean comprehension scores reflected a notable difference in the two approaches: first grade students in classrooms using the prescribed literature program, combined with a systematic skill instruction program and providing writing opportunities scored 12 points higher than did students in code-centered classrooms (Table 46). Low-performing students in codecentered (District II) and meaning-centered (District I) classrooms exhibited the same writing skill performance. Apparently, teachers estimations of reading performances of low performing students in code-centered classrooms were contingent upon the observed performances of students examining familiar texts. A second implication is that writing activities seemed directly to link meaning to comprehension, vocabulary and recreational reading for low performing students.

The estimated reading progress of high performing first grade students in code-centered and meaning-centered classrooms appeared to progress at the same rate regardless 
of the instructional approach. High performing students seemed to master the same level of reading and writing stages regardless of the instructional emphasis on code-centered or meaning-centered approaches and regardless of the balance of time spent on hearing literature read daily, writing daily and receiving systematic explicit and implicit decoding instruction. However, students in meaning-centered classrooms who received explicit phonic instruction scored three to 12 points higher in reading--comprehension and vocabulary--on standardized testing, within testing time constraints which implies fluency and speed, in comprehension, word recognition and vocabulary than did students who did not receive explicit phonic instruction. First grade students in meaning-centered classrooms who received both skill instruction and literature experiences read more recreational books than did students in codecentered classrooms. The implication is that the children who read a lot were able to read well.

The same percentage of first grade students in both districts completed homework assignments on time, achieved average or better on criterion testing efforts the first time and reflected identical mean 1990 standardized test scores in spelling, mechanics, expression and total language and only four points difference in vocabulary (Table 46). The population characteristics of first grade students in District II represented a greater number of low socioeconomic, low achievement, multi-ethnic and learning 
handicapped students than did the population characteristics in District I. The suggestion is that the population characteristics did not appear to effect or detour a high performance in word meaning, spelling, mechanics, expression and total language skills.

Third grade students in the code-centered classrooms did write more often and passed criterion referenced tests more often than did students in mearing-centered classrooms; however, students in the meaning-centered classes read more independent books, and received higher scores on the 1990 standardized tests. Sixth grade students in code-centered classrooms wrote more often, passed criterion referenced tests more often, read more independent books, and received higher scores on the 1990 standardized tests than did students in the meaning-centered classrooms. The implications are: (a) first, third and sixth grade students who were given opportunities to write, to participate in a systematic skill program, to hear and read literature daily, to receive positive reinforcement and who read independent literature performed well on both informal--writing proficiencies--and formal assessments; criterion referenced testing and standardized testing; and (b) teacher estimations of students" informal and formal performances are similar to the achievement of students on standardized tests. Instructional principles do not change for older students (Adams, 1990). The 1990 NCE mean vocabulary scores of the student sample, and the district scores in the 
meaning-centered classrooms were lower than were the 1989 NCE mean scores. District I teachers commented that students skipped over words that were difficult for them while reading literature or listening to literature too difficult for their reading skills. However, several students in District I received additional instruction in word definitions. Sixth grade sample students in District II received vocabulary scores 7 points higher than sample students in District I, and their performances were higher on classroom assessments, recreational reading, criterion testing, writing proficiencies, and homework expectations. Sixth grade students in District II participated in a systematic skill instruction program in addition to their prescribed literature program. Perhaps, sixth grade students in meaning-centered (District $\dot{I}$ ) classrooms would have benefited by being encouraged to attend to spelling patterns of words in order to develop the orthographic knowledge, phonemic awareness and meanings of an unknown word.

Adams (1990) discussed the benefit of knowing spellingsound relations:

Although the ultimate goal of instruction on word recognition is to develop direct pathways from print to meaning, the growth of young readers' visual vocabularies depends integrally on knowledge of spelling-sound relations. As its most obvious benefit, such knowledge enables independent word learning: Without such phonological support, 
acquisition of an adequate visual vocabulary would be

difficult, if not impossible. (pp. 411-412)

Students in all code-centered classrooms participated in cooperative learning, systematic skill program, daily writing activities, frequent writing assessments and independent activities more often than did students in the meaningcentered classrooms. Sixth grade students in the codecentered classrooms read more recreational books, passed criterion referenced tests and writing competencies more often and performed better on standardized tests in mechanics and comprehension than did sixth grade students in meaningcentered classrooms.

Language arts instruction observed in this study seemed to be used successfully with the majority of the student population. The percentage of multi-ethnic, low socioeconomic, low achievement, and learning handicapped students in the first, third and sixth grade code-centered and meaning-centered classrooms did not appear to make a difference in student performances. The inference is that proposed language arts programs that focus on differences in students and the use of varied and different curriculum materials may not affect student performance as much as the curriculum programs teachers were observed using in these two districts in their classroom instruction.

Sample students in first grade meaning-centered classrooms who participated in a systematic skill program and inventive spelling appeared to show improvement from the 
first grade students in 1989 in spelling on standardized test scores. Student sample mean 1990 NCE scores were compared to 1989 school NCE mean scores (Tables 52 and 54). Low performing students' writing performance progressed to the same point in both districts. High performing students' writing performance progressed to a higher stage in codecentered classrooms than did students in meaning-centered classrooms (estimated by teachers). Writing performance appears to be linked with reading performance in first grade, and students in meaning-centered classrooms reflected a marked performance in reading on standardized test scores. Spelling instruction that is balanced with specific instruction in spelling and inventive spelling may affect students' writing performance more than only encouraging inventive spelling in first grade. Organizational Processes

The high degree of openness and bonding (Table 40) among teachers seemed to agree slightly with students' notable performances in meaning-centered (District I) classrooms. The social bonding observed in District I among first and third grade teachers did agree with their students' marked performances. Therefore, it appears that openness and bonding in social situations and in day-to-day operations casually affect the instructional behaviors of the teachers or the academic performance of the students. The implication is that changes take place when openness and bonding behaviors are components of a collaborative and cooperative 
organization that continuously engages in the process of teaching and learning.

Recommendations Aimed at Strengthening the Implementation Prccess of the English-Language Arts Framework in Code-Centered and Meaning-Centered Classrooms

The California English-Ianguage Arts Framework has the potential to considerably influence student performance and classroom instruction. However, because of the limited number of guidelines addressing curriculum materials, teacher behaviors and organizational change processes, the implementation process of the language arts curriculum has the potential to take many directions. Some of the directions may not necessarily affect student performances.

Listed below are recommendations that are directed at increasing the potential for implementing a language arts program that will provide students with the greatest opporturities to affect their language arts performance. The following suggestions offer ways to bring greater movement in student achievement in a direction that will reduce the crisis in language arts education. curriculum Materials

Gersten et al., (1986) notes that specificly written plans offered for the teacher to follow is the power behind significant student outcomes. Teachers must be provided with the opportunities to practice, reinforce and relearn what 
they learned and continue to learn from their years of education. The recommendation is that curriculum materials should have more specific plans and explanations for the teacher: (a) that follow documented research outcomes and classroom successes, (b) that remind teachers to practice specific behaviors related to effective instructional management factors and effective instructional techniques, (c) that are somewhat teacher scripted, (d) that provide a complete discussion of the background knowledge, and (e) that contain literature selections which address minority languages and other cultures.

One link between the philosophy of the California English-Ianguage Arts Framework and the implementation process is the prescribed curriculum materials selected by the district. The recommendation for the implementation of a successful reform movement in education is to include a stage in the process that allows practicing and knowledgeable educators to review curriculum materials in reference to research, teacher practices, conflicting philosophies, perceptions and values, and what teachers and students cannot do rather than what they can do so that special interest groups represented by publishers, designers of curriculum, authors and positional educators will not be the sole influence on the development of curriculum materials to be selected by the district. 


\section{Teacher Behaviors}

Reading, writing, listening and speaking are in reciprocal relationships with cognitive, behavioral, motivational, linguistic, phonemic and decoding awarenesses. Teacher comments indicated that they perceived the language arts program to develop only motivational and behavioral awarenesses and not the other awarenesses. Teachers apparently were not able to explain or to discuss how language arts instruction develops all six of these relationships. If they are able to articulate these relationships, they will be more prepared to determine weaknesses and strengths in their language arts instruction. Teachers' should receive opportunities to discuss their values and perceptions about the language arts curriculum and the influences of reading, writing, listening and speaking on student performances.

Classrooms which were observed using both a systematic skill program and inventive spelling appeared to reflect the greatest improvement in the subject of spelling on the standardized tests. The suggestion is that opportunities should be provided for students to participate in inventive spelling and in specific spelling instruction.

Low performing first grade students who participated in both a systematic phonic instructional program and the literature curriculum seemed to perform at a higher level than students who did not participate in both a systematic phonic program and the literature curriculum. The proposal 
is that the performance of low performing students would make rapid growth in reading and writing if they were offered opportunities to participate in a balanced instructional program which would include the following three factors: hearing more literature read to them, (b) a systematic skill program which includes materials they can read, and (c) more writing opportunities.

Organizational processes

The extent to which opportunities were offered to facilitate the development of the cognitive-conceptual transformation was minimal in both districts. Without this cognitive-conceptual development teacher behaviors were rarely guided by their values and perceptions concerning the philosophy of the English-Language Arts Framework. All teachers in this study cared about the success of their students' progress in language arts. Some teachers are enthusiastically able to make any curriculum program successful just as some students are able to succeed regardless of the classroom instruction and curriculum. The responsibility of the organizational system is to provide teachers with the opportunities to develop their instructional delivery system just as teachers provide the opportunities for students to develop their skills.

Staff development practices in District I and District II did not appear to encourage and/or support the change process. Perhaps teacher training should be presented in the same manner as the California English-Language Arts Framework 
suggests that teachers teach students--demonstration, model, practice, correction, teach, feedback, sharing in a collegial fashion and coaching one another.

Principals seemed to be aware of essential parts necessary to support the change process: however, the power to energize the change process appeared to be missing. This missing power that should be present to challenge an educational crisis prompted several implications: (a) principals may not understand how the practice of collaborative relationships to facilitate the complexities of growth between staff members are related to restructuring and to dynamic change; (b) principals may spend their leadership time managing their school rather than practicing transformational leadership which effects change; (c) principals may not be sufficiently trained to participate in a transformational leadership process; and (d) educational organizations have not supported a principal's role as a transformational leader in restructuring education to address the educational crisis.

The practice of collaborative relationships and collegial teaching teams were observed to be missing in organizations in both districts. Research indicates that growth and development among staff members are related to restructuring and dynamic change (Argyris, 1985; Joyce, et al., 1990). A dynamic change process requires the restructuring of staff meetings and staff development practices. The implementation of a new language arts 
curriculum that is designed to effect student performances requires participation in collaborative relationships and collegial study teams.

Bonding for the purposes of classroom instruction should be created in a collaborating and cooperative organization that continuously engages in the process of teaching and learning. Creating and building a collaborative organization would be a difficult engineering issue. However, this collective action among organizational members may be the key to address more effectively the educational crisis that initiated the California English-Language Arts Framework. There is enough exploratory work based on theory, research and practice to develop strategies that would have a reasonable probability of success (Joyce, et al., 1990; Argyris, 1985). Furthermore, the California English-Language Arts Framework philosophy asks teachers to use cooperative learning practices with students in their classroom instruction. Organizations should use cooperative learning practices with their organizational members.

Suggestions for Further Research

\begin{abstract}
There were many concerns that surfaced from this research study, and more issues were raised than this study answered. Research in the following areas of study may assist in developing a greater understanding about how to implement a reform movement to address an educational crisis.
\end{abstract}


1. The subjects represented in this study were from two school districts in Southern California. A researcher could investigate what other districts, principals, teachers and communities have done to implement the California EnglishLanguage Arts Framework, and the effectiveness of its implementation on student performance.

2. This study represented only the first year of implementation. Further research could investigate the longitudinal effects of the implementation on student performance.

3. A researcher could explore the differences in student performance with students using inventive spelling practices and/or specific spelling instruction. The researcher would determine whether children participating in inventive spelling and specific spelling instruction would be able to write with more sophisticated vocabulary, reflect differences in knowledge, and be able to reach the writing stage of expression of concepts about human values at an earlier age.

4. The extent to which opportunities were offered to facilitate the development of the cognitive-conceptual transformation was minimal for both teachers and administrators in both districts. Teacher and administrative behaviors were rarely guided by their values and perceptions concerning the philosophy of the English-Ianguage Arts Framework. Future investigations could study the effect of opportunities that facilitate the development of cognitive- 
conceptual transformation on the organization and on student performances.

5. Low performing students enter first grade with less literacy preparation than do high performing students. Teachers estimated that low performing students made slow progress through reading and writing stages. Further investigation could be conducted as to how to structure the environment so as to give less prepared students more time for skill instruction, connected reading, and independent writing during a school day whether it be with teachers, adults or parents after school.

6. Classroom assessments--number of recreational books read, homework completed as expected, success on criterion tests and writing proficiency success--are contingent upon the classroom teacher's perceptions, awareness and value judgements of student performances. Achievement assessments, normed in 1984 and 1985, may be considered too dated to make effective curriculum decisions. However, both classroom and achievement assessments seemed to reflect similar strengths and weaknesses in student performances in both districts in this study. A researcher could explore and investigate a balanced assessment model of student performances that would match the achievement assessments, criterion assessments and informal classroom assessments available.

7. Further research could explore how to change the organizational collaboration context within a school year and the effects of this team collaboration model on commitment, 
perceptions, values, culture, motivation, and accountability of teachers, parents and students. There appears to be plenty of research evidence available from leadership studies, organizational change studies, organizational culture studies, business organizations and school organizations to apply to a design and to develop a model for organizational members of school districts.

8. There has been research supporting a fourth grade slump in student's reading and writing performances (Chall, 1990). One suggestion offered to prevent these slumps is to adjust the reading and language arts programs to the needs of different children as they approach fourth grade. In view of the findings from this limited research study, a researcher could explore the following explanation of a fourth grade slump. Low performing students are able to read familiar stories without the orthographic processor (Adams, 1990). Their curiosity and interest in new literature discoveries motivate them to memorize, examine familiar texts over and over again, and study the exquisite illustrations displayed in the literature books as early as first grade. The excitement of new literature discoveries continues to motivate and interest low performing students until some time between third and fourth grade when new curriculum materials introduce more specialized vocabulary and become more conceptually difficult. At this time, low performing students are now unable to hide their lack of skill development and conceptual development with natural 
enthusiasm, interest and motivation: therefore, a fourth grade slump seemingly appears and is noted. This slump phenomenon may have occurred in this study in third grade in District II. Further research could explore and investigate the differences in perceived reading and writing performances of low performing students' noted by their motivation and enthusiasm that is generated by the new language arts curriculum program, and their actual reading and writing performance rate of progress in reading less familiar books with understanding and their performance on informal and formal performance assessments and achievement assessments. 9. Finally, this limited study found that an emergent literature approach combined with a directed skill approach to language arts instruction affected student performance considerably. Additional research could be conducted to determine the affect of systematic skill instruction, teacher directed, combined with a balanced literature program, student centered, on student performances.

Concluding Remarks

The three interrelated dimensions of organizational change, the curriculum materials, teacher behaviors and organizational change processes, which are linked to student performance in code-centered (District II) and meaningcentered (District I) classrooms, suggest that these dimensions cannot be addressed separately or designated as 
the sole responsibility of the teacher or the principal. The present view. suggests that organizational change is the task of a shared cooperative relationship between and among organizational members. Research has provided a knowledge base for organizational change, effective teaching strategies and effective curriculum. The task of a successful implementation of a new reform movement in the language arts curriculum is the promotion, engineering and operationalization of cooperative team learning among members, principals, teachers, district administrators, students and community.

The three interrelated dimensions of organizational change appeared to be independent of one another in this study. Outstanding teachers were observed teaching students independent of reinforcement and feedback, an understanding of the language arts philosophy, and a limited working knowledge of effective teaching strategies. The potential effects that these teachers could have on student performance is an awakening revelation. The competent and impressive administrators, given the power, could revitalize and lead collaborative teams to a new academic language arts program for all students. This potential transformation of student performances is possible through members of the organization who participate themselves in being transformed to higher levels of performances through means of collaborative relationships. 
Collaborative transformation is a complex phenomenon that will require commitment and time to become part of the culture. It is the opinion of this researcher, that it is time to stop imposing various learning models on the educational system. On the basis of the special characteristics of our environment never before encountered, educators could benefit students and parents by working together through ccllaborative models that lead to changes. This research only serves as a small benchmark to point in a direction of change that will challenge the educational crisis to a shared responsibility. The crisis in education that initiated the California English-Language Arts Framework may also initiate a new model for shared instruction and greater student achievements. 
REFERENCES

Reproduced with permission of the copyright owner. Further reproduction prohibited without permission. 


\section{REFERENCES}

Adams, M. (1990). Beginning to read: Thinking and learning about print. Cambridge, MA: The MIT Press.

Anderson, C., Hiebert, E. H., Scott, J. A., \& Wilkinson, I. A. (1985). Becoming a nation of readers: The report of the commission on Reading. Washington, DC : The National Institute of Education.

Argyris, C. (1971). Organization and innovation. Homewood, IL: Irwin \& Dorsey

Argyris, C. (1982). How learning and reasoning processes affect organizational change. In P. S. Goodman, \& Associates (Eds.), Change in erganizations. San Francisco, CA: Jossey-Bass.

Argyris, C. (1985). Evaluating theories of action. In W. G. Bennis, K. D. Benne, \& R. Chin (Eds.), The planning of change. New York: Holt, Rinehart and Winston.

Argyris, C. (1987). People in organizations. In D. S. Pugh, D. J. Hickson, \& C. R. Hinings (Eds.), Writers on organizations. Beverly Hills, CA: Sage.

Argyris, C. , \& Schon, D. (1978). Organizational learning: A theory of action perspective. Reading, MA: AddisonWesley.

Armstrong, W. L. (1989, September). Illiteracy: An incurable disease or education malpractice? (Report contact: Sweet, Jr. 224-2946). Washington, DC: U.S. Senate Republican Policy Committee.

Aune, B. (1970). Rationalism, emoiricism, and pragmatism: An introduction New York: McGraw-Hill.

Baker, D. , \& Gottlieb, J. (1982). Attitude of teachers toward mainstreaming retarded children. In $\mathrm{J}$. Ysseldyke, \& B. Algozzine (Eds.), Critical issues in special and remedial education. Boston: Houghton Mifflin.

Baxter, C. (1988). The battle of the day-A critical analysis of the seven strategies used in the whole language approach as they are contrasted with some principles of direct instruction. The ADI News, $7,1-3$. 
Benne, K. D. (1985). The current state of planned changing in persons, groups, communities, and societies. In $W$.

G. Bennis, K. D. Benne, \& R. Chin (Eds.), The planning of change. New York: Holt, Rinehart and Winston.

Bennis, W. (1989). Why leaders can't lead: The unconscious conspiracy continues. San Francisco, CA: Jossey-Bass.

Berman, P. \& Mclaughlin, M. (1976). Implementation of educational innovations. Educational Forum, 40 (3), 345-370.

Bird, T., \& Little, J. (1986). How schools organize the teaching occupation. The Elementary Journal, 86 (4), 493-51.

Bloom, B. S. (1976). Human characteristics and scheol learning. New York: McGraw-Hill.

Bloom, B. S. (1971). Mastery learning. In J. H. Block (Ed.), Mastery learning: Theory and practice. New York: Holt, Rinehart, \& Winston.

Bloom, B.S. (1956). Taxonomy of educational objectives. Handbook I: Cognitive domain. New York: David McKay.

Bond, G.I. , \& Dykstra, R. (1967). The cooperative research program in first-grade reading instruction. Reading Research Quarterly, 2, 5-142.

Brandt, R. (1989). On learning research: A conversation with Lauren Resnick. Educational Ieadership, 46, 12-16.

Britton, J. (1972). Language and learning. Upper Montclair, NJ: Boynton Cook.

Brophy, J., \& Good, T. I. (1986). Teacher behavior and student achievement. In $M$. Wittrock (Ed.), The third handbook of research on teaching, (pp. 328-375). New York: McMillan.

Burns, J. M. (1978). Leadership. New York: Harper \& Row.

California State Board of Education (1987). Englishianguage arts framework for california public scheols kindergarten through grade twelve. Sacramento, California: Office of State Printing.

California State Board of Education. (1987). Handbook for planning an effective literature program. Sacramento, California: Office of State Printing. 
Carbo, M. (1987, November). Deprogramming reading failure: Giving unequal learners an equal chance. Phi Delta Kappan, 69, 197-202.

Carbo, M. (1988, November). "Debunking the great phonics myth." Rhi Delta Kappan, pp. 226-240.

Carbo, M. (1989, October). "An evaluation of Chall's response to 'debunking the great phonics myth." Phi Delta Kappan, p. 153.

Carnine, D. W. \& Gersten, R. (1985). The logistics of educational change. In J. Osborn, P.T. Wilson, \& R.C. Anderson (Eds.), Research base for literacy. Boston: D. c. Heath.

Carnine, D. W. , Silbert, J. , \& Kameenui, E. J. (1990). Direct instruction reading (2nd ed.). Toronto: Merrill.

Carroll, J. B. (1971). Problems of measurement related to the concept of learning for mastery. In J. H. Block (Ed.), Mastery learning: Theory and practice. New York: Holt, Rinehart, \& Winston.

Chall, J. S. (1983). Stages of reading development. New York: McGraw-Hill.

Chall, J. S. (1989, March). Learning to read: The great debate 20 years later. Phi Delta Kappan, pp. 521-538.

Chall, J. S. (1989, October). The uses of educational research: Comments on carbo. Phi Delta Kappan, pp. 158-160.

Chall, J.S., Jacobs, V.A. , \& Baldwin, L.E. (1990). The reading crisis: Why poor children fall behind. Cambridge, MA: Harvard United Press.

Charter, P.F. (1989, April). Special education/bilingual education: A collaborative model. Thrust, pp. 44-46.

Cohen, E. (1987). Designing groupwork. New York: Teacher's College, Columbia University.

Costa, A.I. (Ed.). (1985). Developing minds: A resource book for teaching thinking. Alexandria, Va: Association for Supervision and Curriculum Development.

Costa, A.I., \& Garmston, R.J. (1987, July). The art of cognitive coaching: Supervision for intelligent teaching (A workshop syllabus). Sacramento, CA: Institute For Intelligent Behavior. 
Downing, J. (1979). Reading and reasoning. New York: Springer-Verlag.

Duckworth, K. , \& Fielding, G. (1982). Identifying valid measures of reading. Exceptional Children, 49 (1), 3645 .

Dewey, J. (1956). The child and the curriculum and The school and soc: ety (combined ed.) . Chicago, Il: Univerisity of Chicago Press.

Duffy, G. , \& Roehler, I. (April, 1982). A study of teacher explanation behavior. Paper presented at the annual meeting of the International Reading Association, Chicago, Il.

Durr, W. K., Pikulski, J. J., Bean, R. M. , Cooper, J. D. , Glaser, N. A. , Greenlaw, M. J. , Schoephoerster, H. , Alsin, M. L., Au, K. H. , Barrera, R. B., Brzeinski, J. ', Bunyan, R. P. , Comas, J. C., Estrada, F. X. , Hillerich, R. L. , Johnson, T. G. , Mason, P. A. ' \& Renzulli, J.S. (1989). Houghten Miffiln Iiterary Readers. Geneva, Ill: Houghton Mifflin.

Edelsky, C. (1983). Hookin' 'em in at the start of school in a "whole language" classroom. Anthropology and Education Ouarterly, 14, 257-281.

Edmonds, R. (1979). Effective schools for the urban poor. Educational Leadership, 37, 15-24.

Edwards, V. (1983). Language in multicultural classrooms. London: Batsford Academic and Educational Ltd.

Engelmann, S., \& Carnine, D. (1982). Theory of instruction: Principles and applications. New York: Irvington.

Engelmann, S. , Bruner, E., Hanner, S., Osborn, J., \& Zoref, I. (1988). Reading mastery. Chicago, IL: Science Research Associates.

Estes, T. H. , Gutman, C. J., \& Harrison, E. K. (1989). Cultural literacy: What every educator needs to know. Educational Leadership, 46, 14-17.

Etzioni, A. (1987). The functioning of organizatiors. In D. S. Pugh, D. J. Hickson, \& C. R. Hinings (Eds.), Writers on organizations. Beverly Hills, CA: Sage'. 
Ferguson, I.C. (1989). Target teach: Instructional management software (Computer program). Scottsdale, AZ: Evans Newton.

Flesch, R. (1955). Why Johnny Can't Read. New York: NY. Harper and Row.

Foster, W. (1986). Paradigms and promises: New approaches to educational administration. New York: Prometheus Books.

Fuller, I. M. (1989). The relative effectiveness of a meaning emphasis approach and a phonics emphasis approach to teaching beginning reading in english to second or third grade bilingual spanish readers (secondgrade) (Doctoral dissertation, Boston University, 1989). Dissertation Abstracts International, 50, 2848A.

Fuchs, I. , \& Fuchs, D. (1986). Effects of Systematic Formative Evaluation: a Meta-analysis. Excentional Children, 53 (3), 199-208.

Fullan, M. (1982). The meaning of educational change. New York: Teachers College Press. Columbia University.

Garmston, R. , \& Pahre, B. (1988). Empowering teachers: Some practical steps. Thrust, 18 (2), 21-24.

Gerber, M. (1988). Tolerance and technology of instruction: Implications for special education reform. Exceptional children, 54 (4), 309-314.

Gersten, R. , \& Woodward, J. (1988). Integrating minority handicapped students into regular education: A staff development emphasis (Report no. OR 831223-035-2). Eugene, Oregon: University of Oregon Follow Through Project.

Gersten, R. , Woodward, J. \& Darch, C. (1986). Direct instruction: A research-based approach to curriculum design and teaching. Exceptional Children, 53 (1), 1731 .

Gersten, R. , Davis, G., Miller, B. , \& Green, W. (1986, April). The fragile role of the instructional supervisor in scheol improvement. Paper presented at AERA, San Francisco, California.

Gersten, R. (1990, April). In response to Connie Weaver [ Letter to the editor]. Education Week, p. 36. 
Glatthorn, A. A. (1987). Cooperative professional development: Peer-centered options for teacher growth. Educational Leadershig, 45 (3), 31-35.

Goldsberry, I.F. (1986, April). colleague consultation: another case of fools rush in. Paper presented at the annual meeting of the American Educational Research Association, San Francisco, CA.

Goodlad, J. I. (1984). A place called school: Prospects for the future. New York: McGraw Hill.

Goodman, K. S. (1986). What's whole in whele language? Portsmouth, NH: Heinemann Educational Books.

Graves, D. (1984). A researcher learns to write. Portsmouth, NH: Heinemann Educational Books.

Graves, D. (1982). Writing: Teachers and children at work. Portsmouth, NH: Heinemann Educational Books.

Groff, P. (1987). Preventing reading failure: An examination of the myths of reading instruction. Portland, OR: National Book Company.

Guba, E., \& Lincoln, Y. (1987). Effective Evaluation. San Francisco: Jossey-Bass.

Guskey, T. R. (1984). The influence of change in instructional effectiveness upon the affective characteristics of teachers. American Educational Research Journal, 21 (2), 245-259.

Hinkle, D. , Wiersma, W. , \& Jurs, S. (1979). Apolied statistics for the behavorial sciences. Dallas, Texas: Houghton Mifflin.

Hirsch, E. D. (1989). Hirsch responds: The best answer to a caricature is a practical program. Educational Leadership, 46, 18-19.

Huberman, A. M. , \& Miles, M.B. (1984). Innovation up clese: How scheel improvement works. New York: Plenum Press.

Hunt, D. E. (1971). Matching models in education. Toronto: Ontario Institute for Studies in Education.

Hunt, D. E. , \& Sullivan, E. V. (1974). Between osychology and education. Hinsdale, IL: Dryden. 
Hunter, M. (1967). Reinforcement theory for teachers. EI Segundo, CA: TIP. Hunter, M. (1967). Retention theory for teachers. El
Segundo, CA: TIP.

Hunter, M. (1969). Teach more-faster! EI Segundo, CA: TIP.

Hunter, M. (1971). Teach for transfer. El Segundo, CA: TIP.

Hunter, M. (1976). Prescriptions for improved instruction. El Segundo, CA: TIP.

Johnson, D. \& Johnson, R. (1987). Research show the benefits of adult cooperation. Educational Ieadership, 45 (3), 27-30.

Johnson, D. , Johnson, R. , \& Holubec, E. (1986). Circles of learning: Cooperation in the classroom (rev. ed.). Edina, MN: Interaction Book.

Johnson, D. , \& Johnson, F. (1987). Joining together: Group theory and group skills (3rd ed.). Englewood Cliffs, NJ: Prentice-Hall.

Jones, F. H. (1987). Positive classroom management. San Francisco: McGraw-Hill.

Joyce, B. ' \& Showers, B. (1980, February). Improving inservice training: The messages of research. Educational Leadership, pp. 379-382.

Joyce, B. , \& Weil, M. (1986). Models of teaching (3rd ed.). Englewood Cliffs, New Jersey: Prentice-Hall.

Joyce, B. 'Bennett, B. \& \& Rolheiser-Bennett, C. (1990). The self-educating teacher: Empowering teachers through research. In B. Joyce (Ed.), Changing school culture through staff development (pp. 26-39). Alexandria, Virginia: Association for Supervision and Curriculum Development.

Kahn, R. I. (1984). Conclusion: Critical themes in the study of change. In P.S. , Goodman, \& Associates (Eds.) ' Change in organizations. San Francisco, CA: Jossey-

Katz, D. , \& Kahn, R. I. (1978). The social esychology of erganization. New York: Wiley. 
Kauffman, J. M. , Gerber, M.M. , \& Semmel, M.I. (1988). Arguable assumptions underlying the regular education initiative. Journal of learning Disabilities, 21 (1), 6-12.

Knight, M. F. 'Meyers, H. M., Paolucci-Whitcomb, P. , Hasazi, S.E.' \& Nevin, A. (1981). A four year 'study of consulting teacher service. Behavorial Disorders, 6, 92-100.

Library of Congress (1983). Educators' guide: Special education dictionary. Westbury, New York: Heliodor Publications.

Loucks, S.F. , \& Zacchei, D. A. (1983). Applying our findings to todays innovations. Educational Leadership, $41(3), 28-31$.

Madigan, K. , \& Youngmayr, I. (1986, August). An overview: Supervision and monitoring direct instruction programs. Paper presented at the ADI Oregon Conference, Eugene,
OR.

Market Data Retrieval. (1990). CIC'S school directory: California. Shelton, CT: Author.

Manning, M. (1988, November). Early phonics instruction: Its effect on literacy development. Young Children, 44, $4-8$.

McGoldrick, M. , Pearce, J., \& Giordano, J. (Eds.) . (1982). Ethnicity and family theraoy, New York: The Guilford Press.

Ovando, C. J. (1983, April). Bilingual/bicultural education: Its legacy and its future. Phi Delta Kappan, pp. 564-568.

Paterson, G. R. (1989). Looking for Mr. Goodbooks: Reflections on whole language and direct instruction. Perspectives (Vol. 1, pp. 1-4). Chicago, IL: Science Research Associates.

Putnam, I. R. (1981). A descriptive study of two philosophically different approaches to reading readiness, as they were used in six inner city kindergartens (Doctoral dissertation, University of Pennsylvania, 1981). Dissertation Abstracts

International, 42, 4291A. 
Resnick, L. B. (1987). Education and learning to think. Washington, D.C.: Academy Press.

Resnick, I. B.., \& Weaver, P. (1978). Theory and practice of early reading. New York: John Wiley. Rogers, C. R. (1969). Ereedom to learn. Columbus, OH:
Merrill.

Rokeach, M. (1968). Beliefs, attitudes, and values: A theory of organization and change. San Francisco, CA: Jossey-Bass.

Rokeach, M. (1976). Observing teacher differences. In L. Cohen (Ed.), Educational research in classrooms and scheols. London, England: Harper \& Row.

Rothman, R. (1989, November). Judge finds California textbook guidelines illegal. Education Week, p.14.

Salvin, B. , Block, J. , Guskey, T. , Bloom, B. S. , Walberg, H. J., \& Hunter, M. (1988). 'On research and school organization: A conversation with Bob Salvin. Educational Leadership, 46 (2), 22-29.

San Diego City Schools (1987, June). Special education audit. San Diego, CA: Author.

Schein, E. H. (1986). Organizational culture and leadership. San Francisco, CA: Jossey-Bass.

SERN, (1985). Chinese culture. The Psychoeducational Model. California.

Showers, B. (1987, April). Teachers coaching teachers. Educational Leadership, pp. 43-47.

Showers, B. , Joyce, B., \& Bennett, B. (1987). Synthesis of research on staff development: A framework for future study and state-of-the-art analysis. Educational Leadership, 45 (3), 77-87.

Shulman, I. S. (1988). A union of insufficiencies: Strategies for teacher assessment in a period of educational reform. Educational Leadershio, 46 (3), 3641 .

Slavin, R. E. (1978). Using student team learning, the Johns Hopkins team learning project. Baltimore: Center for Social Organization in Schools, The Johns Hopkins 
Slavin, R. E. (1980). Cooperative learning. Review of Educational Research, 50 (2), 315-342.

Sprick, R. (1981). The solution book: A guide to classroom discipline, Chicago, II: Science Research Associates

Springer, S., \& Deutsch, G. (1985). Left brain, right brain. New York: W. H. Freeman.

Stahl, S., Osborn, J., \& Lehr, F. (1990). A summary. is summary of Beginning to read: Thinking and learning about print. Urbana-Champaign, IL: University of Illinois, Center for the Study of Reading and The Reading Research and Education Center.

Staw, B. M. (1984). Counterforces to change. In P. S. Goodman (Eds.), Change in organizations. San Francisco, California: Jossey-Bass.

Tikunoff, W. J. (1985). Applying significant bilingual instructional features in the classreom, Rosslyn, Virginia: InterAmerica Research Associates.

Timar, T. ' \& Kirp, D. (1989, March). Education reform in the 1980s: Lessons from the states. Phi Delta Kappan,
pp. 504-511.

Weaver, C. (1980). Reading process and practice: From socio-psycholinguistics to whole language, Portsmouth, $\mathrm{NH}$ : Heinemann Educational Books.

Weaver, C. '(1990, May). In response co Gersten [ Letter to the editor]. Education Week, p. 41.

Weaver, C. (1990, March). Weighing claims of 'phonics first' advocates. Education Week, p. 5.

Wells, G. (1981). Learning through interaction: The study of language development, New York: Cambridge University

Whimbey, A. ' \& Lockhead, J. (1985). Problem solving and comprehension. Philadelphia: Franklin Press. Wray, D. (1989, April). Reading: The new debate. Reading,
23, 2-8. 
Appendixes

Reproduced with permission of the copyright owner. Further reproduction prohibited without permission. 
Appendix A

Observation Instrument of Teacher Meetings

Reproduced with permission of the copyright owner. Further reproduction prohibited without permission. 
TEACHER MEETING OBSERVATION

\begin{tabular}{|l|l|l|}
\hline SCHOOL & DATE \\
\hline NUMBER IN ATIENDANCE & NUMBEER OF ADMINTSTRATORS \\
\hline PURPOSE OF MEETING & & LENGTH OF TMME OF MEETING
\end{tabular}

1. RELATIONSHIP BUILDNG

1. Value jodrements meds

2. Threens and concerns dirpelled

3. perphrien end cl ifyin?

4. Silence

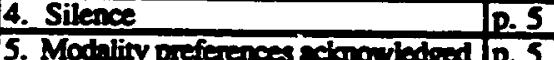

6. Belief symem relnowled ad p. S-6

7. Level of concen selonouled ad /0.5

$\begin{array}{ll}\text { 8. Undestading formined } & \text { p. } 6\end{array}$

9. Guided dincurvion

time, ploce rendadienecion leader

10. Members enlyze exterinl

bnowledre

11. Personvl bonowled ediscused

12. Open reflection of remech ind beliefs which leads to diecuscion of fume chinges.

13. Leds of participation in grow discossion

14. Not prepered for meeting

or diverevion.

\section{SHARNG, OPENNESS} and BONDnic

14. Tall sbout firuention

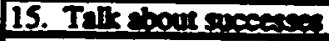

16. Talk about techin?

17. Talk about ides:

Ginem

\begin{tabular}{|l|c|}
\hline Not & Norved Oberved \\
\hline
\end{tabular}

D. 31

p.S

D. 5

D. 5

p. 32

1. 32

p. 32

19. Trll about common res?

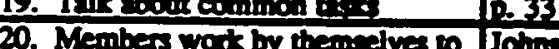

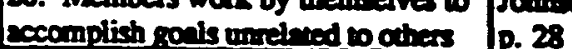

21. Socivl support alees plece outside of contrected time.

II. ORGANIZATIONAL SUPPORT

21. Consistent meeting phace and time

22. Access to time for

peer obervetions

23. Adminimpive reinforcement

and foentict. 
Appendix B

Principal Interview

Reproduced with permission of the copyright owner. Further reproduction prohibited without permission. 
PRINCIPAL INTERVIEW

\begin{tabular}{l}
\hline School Name \\
Principal \\
$\begin{array}{l}\text { Number of years of principalship at the } \\
\text { named school. }\end{array}$ \\
\hline
\end{tabular}

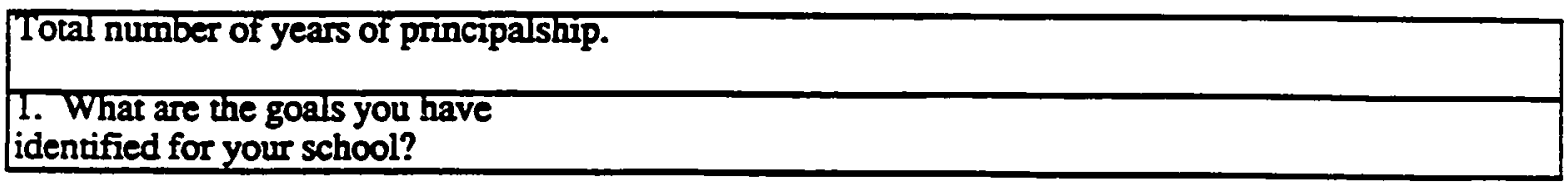

2. How co you create change in your school?

\begin{tabular}{|c|c|c|c|c|c|}
\hline $\begin{array}{l}\text { 3. How do you describe the type of } \\
\text { power you use when you expect change } \\
\text { to take place in the curriculum? }\end{array}$ & authonty & expertise & reward & cooperative & personal \\
\hline
\end{tabular}

\begin{tabular}{|}
\begin{tabular}{|l|l|l|l|l|}
\hline 4. How do you describe your type of \\
control with your teaching staff? \\
with your parent groups? \\
with your board members? \\
with your community members?
\end{tabular} & intluencing bargaining negotating & $\begin{array}{c}\text { game } \\
\text { playing }\end{array}$ & positional \\
\hline
\end{tabular}

\begin{tabular}{|c|c|c|c|c|}
\hline $\begin{array}{l}\text { 5. On a scale of one to ten, how do you } \\
\text { describe the group relationships and the } \\
\text { interpersonal relationships among your } \\
\text { teaching staff at this time? }\end{array}$ & \begin{tabular}{|l} 
Close \\
empathic \\
collaborative \\
supportative \\
$(10-9)$ \\
\end{tabular} & $(8-7)$ & $(6-5)$ & $\begin{array}{c}\text { distant } \\
\text { dogmatic } \\
\text { individualistic } \\
\text { independen } \\
(4-3) \quad(2-1) \\
\end{array}$ \\
\hline
\end{tabular}

\begin{tabular}{|c|c|c|c|c|}
\hline $\begin{array}{l}\text { 6. On a scale of one to ten, how well } \\
\text { do you feel that you could personally } \\
\text { train your staff on how to implement } \\
\text { the English-Language Arts Framework } \\
\text { in their classroom instruction? }\end{array}$ & $\begin{array}{l}\text { saifully } \\
\text { knowledgeably }\end{array}$ & $(6-5)$ & $(4-3)$ & $\begin{array}{l}\text { inability } \\
\text { competent } \\
(2-1)\end{array}$ \\
\hline
\end{tabular}

\begin{tabular}{|c|c|c|c|c|c|}
\hline $\begin{array}{l}\text { 7. On a scale of one to ten, how efrectivg } \\
\text { do you believe the philosophy of the } \\
\begin{array}{l}\text { Language Arts Framework will } \\
\text { be on student performance this year? } \\
\text {... three years from now? }\end{array}\end{array}$ & $\begin{array}{c}\text { very } \\
\text { effective } \\
(10-9)\end{array}$ & $\begin{array}{c}\text { effective } \\
(8-7)\end{array}$ & $\begin{array}{c}\text { somewhat } \\
\text { effective } \\
(6-5)\end{array}$ & $\begin{array}{c}\text { ineffective } \\
(4-3)\end{array}$ & $\begin{array}{c}\text { unknown } \\
(2-1)\end{array}$ \\
\cline { 2 - 7 } & & & & & \\
\hline
\end{tabular}

8. What person or author do you model your management and/or leadership style after? 
Appendix C

Teacher Interview

Reproduced with permission of the copyright owner. Further reproduction prohibited without permission. 


\section{Teacher Interview}

Clarification: Language Arts program includes reading program.

1. To what degree does the learning progress of $\bar{y}$ our students using the new English-Language Arts curriculum program meet or not meet your expectations?

very effectively effectively somewhat ineffectively not at
$(10-9)$
$(8-7)$
$(6-5)$
$(4-3)$
(2-1)

2. On a scale of 1-10, how closely do you follow the English-Ianguage Arts program presentation requirements in your class instruction? Explain.
high
$(10-9)$
$(8-7)$
$(6-5)$
$(4-3)$
low
(2-1)

3. To what degree do you maintain high expectations for all students in your classroom?

high

(10-9)

$(8-7)$

$(6-5)$

$(4-3)$

low

(2-1)

4. On a scale of 1-10, how much time during language Arts instruction do you spend responding to and using information from ethnicity and home
cultures?

high

(10-9)

$(8-7)$

$(6-5)$

$(4-3)$

low

(2-1)

5. How would you describe the different degrees of expected and not expected student behavior during your Ianguage Arts class instruction?

6. On a scale of 1-10, how much administrative support do you have for your English-Language Arts program? Support can be identified by more than adequate curriculum materials, school activities, publication resources, student academic acknowledgment, teacher reinforcement, parent involvement and coordination.

high

$(10-9)$

$(8-7)$

$(6-5)$

$(4-3)$

Iow

$(2-1)$ 
7. How would describe the differences in the strengths and weaknesses between an integrated English-Language Arts curriculum program and a integrated Language Arts literature program with a systematic skill program component?

8. How many hours would you estimate that you have you spent in Language Arts staff development workshops or conferences over the past two or three years? What kind of staff development in the EnglishLanguage Arts curriculum have you experienced? (school based management, publisher's materials presentation, San Diego Area Writing Project, CLP, California Iiterature Project)

9. At what stage of an integrated writing ability do you believe your advanced students have mastered and at what stage have your low students mastered? Integrated writing ability includes the components of the writing process, reflection of the understanding of literature, clarity of ideas, independent responses, and error free.

simple sentences simple paragraphs

$\begin{array}{ll}\text { descriptive } & \text { expression } \\ \text { paragraphs } & \text { of concepts }\end{array}$

expression

concepts about the human

condition or values
$(1-2)$
$(3-4)$
$(5-6)$
$(7-8)$
$(9-10)$

10. At what stage in the reading performance do you believe your advanced students have mastered and what stage have your low students mastered?

alphabet knowledge phonic skills decoding skills basic word fluent
recognition reading
(1)

reads less-familiar texts reading task is more conceptual and cognitive

reads less-familiar texts reading task is more abstract and technical specialized word recognition 
Appendix D

Teacher Questionnaires

Reproduced with permission of the copyright owner. Further reproduction prohibited without permission. 
QUESTIONNAIRE \#1

Name

Date

School

How would you describe the following teaching techniques

and management approaches that you use in your classroom?

\section{1. \\ Key Elements of Teaching \\ Bloom \\ Elements of Effective Teaching Clinical Supervision \\ Hunter}

\section{Language Experience Approach \\ Goodman von Allen}

2.

Teaching Thinking

Costa De Bono

Classroom Wriuing Instruction

San Diego Writing Project

Graves Moffett

\section{Problem Solving}

Whimbey

3.

Collaborative Teaching

Showers \& Joyce

Assertive Discipline
Cantor Sprick

\section{Classroom Management}

Jones

Cooperative Leaming

Slavin

\begin{tabular}{ccccc}
$\begin{array}{c}\text { very } \\
\text { effective }\end{array}$ & effective & $\begin{array}{c}\text { somewhat } \\
\text { effective }\end{array}$ & ineffective & $\begin{array}{c}\text { not } \\
\text { used }\end{array}$ \\
\hline 1 & 2 & 3 & 4 & 5 \\
1 & 2 & 3 & 4 & 5 \\
1 & 2 & 3 & 4 & 5
\end{tabular}

1

2

3

4

5

1

2

3

4

5

1

2

3

45

\section{1}

2

3

4

5

1

2

3

4

5

1

2

3

4

5

1

2

3

4

5 
QUESTIONNARE \#I

4.

Mastery Leaming

Bloom \& Carroll

Direct Instruction

Englemann

5.

Multimodal Approeches

Different Learning Styles

Hunt

Culural Differences

Ovando

Intellectual Differences

Left-Brain/Right-Brain

Springer \& Deutsch

Non-Directive Teaching

Rogers

\begin{tabular}{ccc}
$\begin{array}{c}\text { very } \\
\text { effective effective }\end{array}$ & $\begin{array}{l}\text { somewhat } \\
\text { effective ineffective }\end{array}$ & $\begin{array}{c}\text { not } \\
\text { used }\end{array}$ \\
\hline
\end{tabular}

1

2

3

4

5

1

2

3

4

5

1

2

3

4

5

1

2

3

4

5

1

2

3

4

5

1

2

3

4

5

The following question relates to the management of your classrooms

6. How many times during a week do you give cach student in your Language Arts class feedbeck through the following methods?

$\begin{array}{lllll}\text { individual consultations } & (0-1) & (2-3) & (4-5) & (>5) \\ \text { written essay lests } & (0-1) & (2-3) & (4-5) & (>5) \\ \text { scoring on writing samples } & (0-1) & (2-3) & (4-5) & (>5) \\ \text { oral presentations } & (0-1) & (2-3) & (4-5) & (>5) \\ \text { criterion referenced less } & (0-1) & (2-3) & (4-5) & (>5) \\ \text { academic progress on stills } & (0-1) & (2-3) & (4-5) & (>5) \\ \text { letrer grades on corrected papers } & (0-1) & (2-3) & (4-5) & (>5) \\ \text { portfolio consultation } & (0-1) & (2-3) & (4-5) & (>5) \\ \text { other methods } & (0-1) & (2-3) & (4-5) & (>5)\end{array}$


TEACHER QUESTIONNARE $: 2$

Name

\section{School}

1. How many years of teching experience? Gindeleved

2. How many years of reaching Language Arts an the elewentary level?

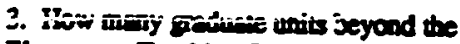
Elementery Texhing Crodemill do you brve?

4. Chect the teaching credeatints that you hold?

5. How many minutes each day do you bove schoduled for Laporage Ars insorvetion which includes reading?

\section{How may minutes each day do you

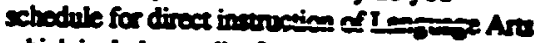 which inclodes reading?}

7. How mony minures each dy do you schedule for tecthing bagmege stills which includes reading tilly?

\section{How many miantes each day do you schedule for independen Lappos Ars activitios which inclodes reading}

9. How may avenge minues por dy do yoor

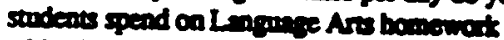
which inchedes reading?

10. Wha pecentere of the sudens in you Lengure Arte clane would you idenify who foll beiow the moional norm in Lengures Arsend reading?

11. What pecenenge of anders in your Language Ars clase woold you identify who fall below ponde level stility in Lrapere Are and readin?
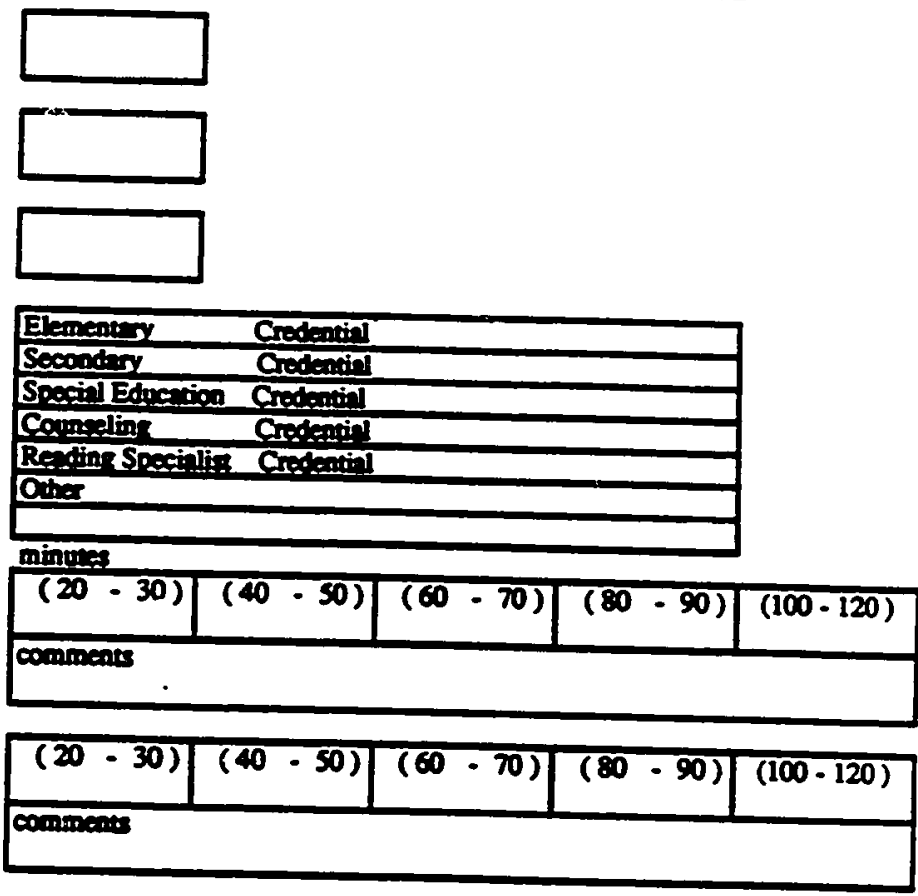

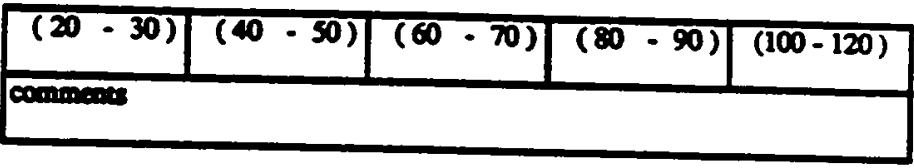

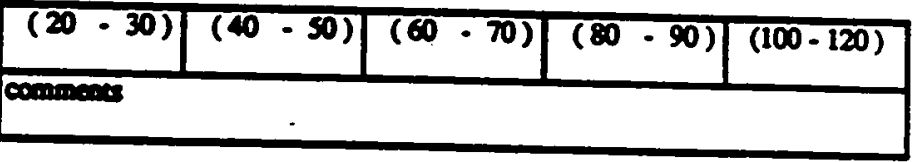

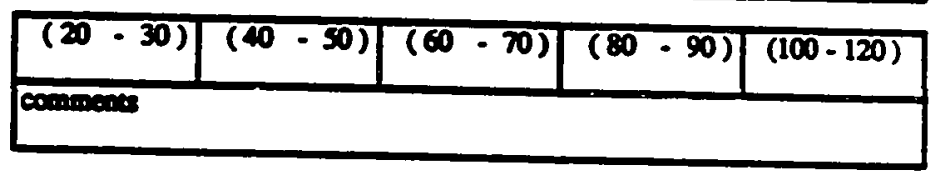

\begin{tabular}{|l|l|l|l|l|}
\hline$(100-85)$ & $(80-70)$ & $(65-55)$ & $(50-35)$ & $(30-15)$ \\
\hline comments
\end{tabular}

\begin{tabular}{|l|l|l|l|l|}
\hline$(100-85)$ & $(80-70)$ & $(65-55)$ & $(50-35)$ & $(30-15)$ \\
\hline comandis & & $(30.5$ & \\
\hline
\end{tabular}


12. What percenuge of your perents do you perceive model effective listering, spenting. reading and writing for your stodents in Englisb?

13. Whe percentage of sudeots echieve aversece or beter performuce on their criterion testing effors the first time?

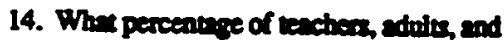
adminietentes in your school model effective lisening, speching, reading, and writing for studente?

15. What perceatere of tencters in your sctrool tech reading, writing, spectling and listening throughom sll subjects?

16. How may mimues during a week do you preticiple with your pees in ullines sbout inservecionel pretices oned in Lapgune Arts cheses which inclodes rendinge?

17. How many mimmes dering a weel do you pericipen in en oberverion of intrection is Lempure Ars ad reading followed by 2

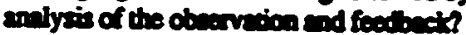

18. How many mineses duriogs weck do you paricipate in finding solutions of tenche identifed problems emone your peesen

19. How may minew drieg a wath do you

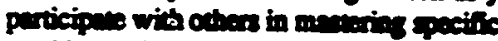
tenching atille bed ca models of tenetin and apposted with stref developinead

20. Eximine the averipe nomber of andent sebeced bools ench of your soderis bes read since the bejining of the sectod yee.

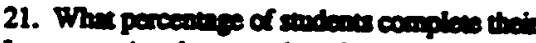

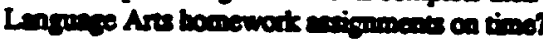

22. Eximine the pecceatape of modens in

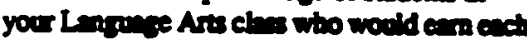
$\operatorname{scose}(1$ is low and 6 is biph) on tho dieriet writing poficioncy extan.

\begin{tabular}{|l|l|l|l|l|}
\hline$(100-85)$ & $(80-70)$ & $(65-55)$ & $(50-35)$ & $(30-15)$ \\
\hline comments & & $(30.5$ \\
\hline
\end{tabular}

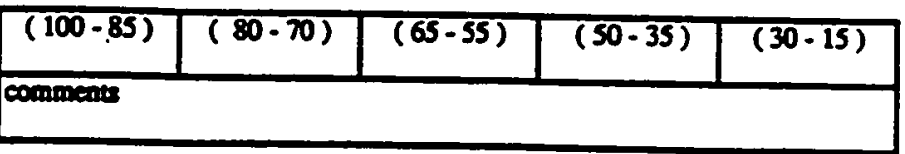

\begin{tabular}{|l|l|l|l|l|}
\hline$(0-20)$ & $(25 \cdot 40)$ & $(45-60)$ & $(65-80)$ & $(85-100)$ \\
\hline comments & & $(45)$ \\
\hline
\end{tabular}

\begin{tabular}{|l|l|l|l|l|}
\hline$(0.20)$ & $(25-40)$ & $(45-60)$ & $(65-80)$ & $(85-100)$ \\
\hline comments & & & \\
\hline
\end{tabular}

\begin{tabular}{|l|l|l|l|l|}
\hline$(0-20)$ & $(25-40)$ & $(45-60)$ & $(65-80)$ & $(85-120)$ \\
\hline commenss & & $(65)$ \\
\hline
\end{tabular}

\begin{tabular}{|l|l|l|l|l|}
\hline$(0-20)$ & $(25-40)$ & $(45-60)$ & $(65-80)$ & $(85-120)$ \\
\hline conmente & & \\
\hline
\end{tabular}

\begin{tabular}{|l|l|l|l|l|}
\hline$(0-20)$ & $(25-40)$ & $(45-60)$ & $(65-80)$ & $(85-120)$ \\
\hline coninews
\end{tabular}

\begin{tabular}{|l|l|l|l|l|}
\hline$(0-20)$ & $(25-40)$ & $(45-60)$ & $(65-80)$ & $(85-120)$ \\
\hline$\infty \operatorname{lom}$ & & & \\
\hline
\end{tabular}

\begin{tabular}{|l|l|l|l|l|}
\hline$(0-5)$ & $(6-10)$ & $(11-15)$ & $(16-21)$ & $(22-27)$ \\
\hline commencos & & & \\
\hline
\end{tabular}

\begin{tabular}{|l|l|l|l|l|}
\hline$(0-20)$ & $(25-40)$ & $(45 \cdot 60)$ & $(65-80)$ & $(85-100)$ \\
\hline conine.000
\end{tabular}

\begin{tabular}{|c|c|c|c|c|}
\hline 1 & 2 & 3 & 4 & $\begin{array}{c}506^{6} \\
\text { bish }\end{array}$ \\
\hline 5 & 5 & 5 & $\%$ & $\%$ \\
\hline conmens & & 5 & 5 \\
\hline
\end{tabular}


Appendix E

Teacher observation

Reproduced with permission of the copyright owner. Further reproduction prohibited without permission. 


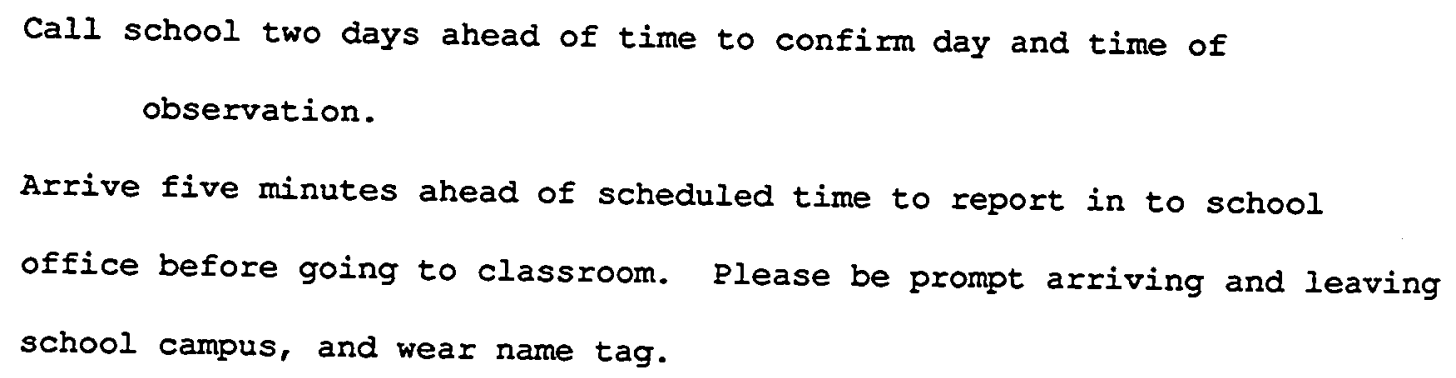

School

1. Record instructional management observations 15 minutes

Page 1, Control, numbers 1-4

Page 3, Curriculum, numbers 9-16

2. Record teacher positive feedback 5 minutes

Page 2, Number I

3. Observe seven identified students 15 minutes

Page 1, Time on Task Behavior, numbers 5-7

4. Record teacher positive feedback 5 minutes

Page 2, Number II

5. Conciide Instructional Management observations 5 minutes

Page 3, Numbers 9-16

6. Leave Thank You Note to Teacher and the next date of observation. 


\section{OBSERVATION EXPLANATION}

1. Classroom furniture is arranged in a distinct patern to enhance instruction, and to insure chalkboard and teacher visibility.

The best possible arrangement is one in which the teacher can move quickly and easily among students and from one student and to another. There is little distance between the teacher and any student in the classroom. Only four or five feet between the chalkboard and the nearest student is necessary. The teacher's desk is not between the teacher and the students and not between the students and the chalkboard (Jones, 1987, pp. 57-58). See attached picture of sample room arrangements.

2. Classroom goals and objectives are posted and specific procedures, rules and standards, are posted.

Goals are defined as the behaviors teachers' desire their students to exhibit in a positive learning enviornment. Rules reflect specific behaviors for the classroom that help students function in a complicated society. Three to five rules should be stated as positive expectations, and assertive guidelines. Positive and negative consequences should be posted somewhere around eye level.

3. Student work is displayed and classroom reflects a variety of activities promoting daily student success.

Student work is defined as actual written papers and art work promoting daily success identified by student names. 
4. Teacher is prepared to begin lesson on time. Materials for lesson are available.

Teacher begins actual instructional lesson without taking class time to gather, find, organize, and/or prepare materials while students wait for their materials or waits for the teacher to begin instruction.

5. Student's engaged time actually on task during allocated time set aside for given subject.

Engaged time is the amount of allocated time that the students are actually on task (Jones, p. 30). This does not mean scheduled time. It means directed teaching and involvement by the teacher and students or students in specific basic skills areas (Peterson, 1983, p. 214). An academic "down to business" atmosphere sets the tone. Students are held accountable (Peterson, p. 215). On-task behavior is rewarded in various ways (Peterson, p. 214).

6. Student's success rate in learning while working.

Multiple response activities that allow teacher to give feedback to a number of students on each question. Small groups with a monitor receiving feedback. Self-correction of independent seat work. Papers or seat work are spot checked by an adult (Peterson, p. 216). Classroom discussion of a literary work. Individual consultations between students and teacher. Student's abilities to read aloud unfamiliar but grade appropriate materials to explain plots and motivations of characters (California State Department of Education, p. 34).

7. Disruptions occur less than five minutes of allocated time.

Disruptions are defined as student behavior displaying out of seat, talking to neighbor, pencil tapping, note passing, playing with objects, or taking a break from assignment more than five minutes of time allocated for independent or group activities. 
8. Positive Feedback.

Tabulate the positive and negative attention given to student or students. Listen for remarks that praises or encourages students and/or body language that praises or encourages students, make a mark in the Positive column. When the student or students receive attention for an error, misbehavior, or reminder, make a mark in the Negative column.

9. Literature is read aloud

Students in kindergarten through grade three should hear good literature daily (p. 27). Students in grades three through six benefit from hearing literature read aloud daily (California state Department of Education, 1987, p. 29).

10. Ideas are shared with each other

Students in the early grades need many opportunities to express themselves, to speak and be heard. A variety of activities such as telling stories about pictures or experiences expand their speaking repertoire (p. 28). Students in grades three through six need many opportunities to formulate and share ideas with each other in smallgroup work and discussion (California State Department of Education, 1987, p. 29).

11. Writing is practiced, collected and reviewed

"Students who read and listen to written work begin to emulate in writing the language they have read and heard. Early writing programs must introduce instruction in prewriting, drafting, revising, and editing. The conventions of spelling, handwriting, grammar, and punctuation should be taught as subskills to meet individual student's needs as aides to the written communication process" (p. 28). Students in grades three through six should write daily and be encouraged to rethink, rearrange, and polish words. Direct teaching of the strategies for good writing and conventions of usage, spelling and punctuation 
should be taught in meaningful contexts (California state Department of Education, 1987, p. 29).

12. Cooperative learning groups are working

Students benefit from structured time for talking, listening, sharing and discussing what they think about a work of literature or a piece of writing. Students who learn to work with each other in cooperative learning groups based on mutual interests and criteria other than ability develop their capacity to use language creatively and critically." Students who participate in cooperative learning groups demonstrate positive attitudes, greater academic performance, and better ethnic and cultural understandings and relations (California state Department of Education, 1987, pp. 23, 26).

13. Minority languages and cultures are recognized

Activities and assignments that recognize the importance of minority languages and cultures are essential. A curriculum based on the following components: (1) a strong literacy program, (2) strategies to expand English fluency, (3) predictable story structures and language patterns, (4) the frequent use of visuals, recordings, pictures, films, objects, videotapes, (5) a variety of questioning techniques, (6) structural vocabulary building strategies, and (7) cooperative learning among themselves and English speakers (p. 23). The teacher and students demonstrate a positive climate for learning by respecting language and dialects that are linguistically different from standard English (California State Department of Education, 1987, p. 21).

14. Systematic skill program is taught

Students should be provided with concept development in all subject areas (p. 23). Reading instruction includes a systematic phonic program taught in the early grades (p. 43). Phonic instruction during the early grades should help students understand the letter-sound relationship (p. 28). Conventions of spelling, handwriting, grammar and 
punctuation should be taught (pp. 28-29). Supporting skills and subskills should not be fragmented or taught in isolation (p. 41). The use of semantic and structural analogy strategies should be emphasized in grades three through six (California State Department of Education, 1987, p. 45).

\section{Multimodal application is included in lesson}

The dramatization of a literary passage through photographs, magazine pictures, art objects, collages, student-produced art, elaborately designed journals, costumes or art presentations is promoting more meaningful learning for the visual learner. Auditory learners develop meaningful learning when they hear stories told or read aloud, when they participate in role-playing and the reader's theater. Kinesthetic learners make language growth possible when they use models, illustrations, time-flow charts, food testing, flip books, and costumes to understand the lessons (California State Department of Education, 1987, p. 201.

16. Structured lesson is observed (Jones, pp. 122-124).

A. Setting the stage Motivation

The teacher raises the level of concern or interest about the subject through various media: pictures, stories, drawings, drama or music. Students become interested and curious in learning more about the lesson.

Review

The teacher reviews the background or past learning that leads up to the subject or lesson about to be taught. Teacher incorporates the verbal modality of input and creates visual imagery.

Goals and Objectives

The teacher states the goais and objectives of the lesson to the students. The students will know what knowledge they will gain from the outcome of the lesson. 
B. Modeling

Explanation

The performance sequence begins. The teacher will explain the procedures and give directions as to how to complete the lesson or concept. The teacher will explain the lesson or concept through one step at a time.

Modeling

The teacher will model the concept through visual modality and linguistic mental imagery. The teacher may find it necessary to model the concept several times for the students. Structured Practice

The first performance that is modeled through seeing the concept is solidified with additional structured practice that the students perform and do in the classroom. Structured practice incorporates physical prompting when necessary to create correct performance of the skill along with kinesthetic memory. Structured practice usually takes place in the classroom immediately following the explanation and modeling of the concept. The first performance may be repeated with additional structured practice to ensure mastery of the skill or concept. The skill is repeated so the it becomes routine and comfortable.

c. Consolidation

Guided Practice

Initial mastery is further repeated during guided practice. Guided practice may be a repetition of the concept or skill through another form of practice with the teacher giving feedhack as the student works. This stage of the lesson directly deals with issues of retention.

Generalization

The initial mastery will be broadened and further solidified through generalization and discrimination so that the skill or concept can be used correctly in a variety of contexts. This phase of the lesson may take the form of various examples of comparisons and contrasts of concepts. 
Independent Practice

Independent practice extends the process of learning to the

transfer of learning. This phase of the lesson plan may be in the form of various related assignments to be completed at home or at another time in school: drawings, pictures, paper and pencil work, games, movies and etc. 
Classroom Furniture Arrangements

(Jones, 1987, pp. 57-64)

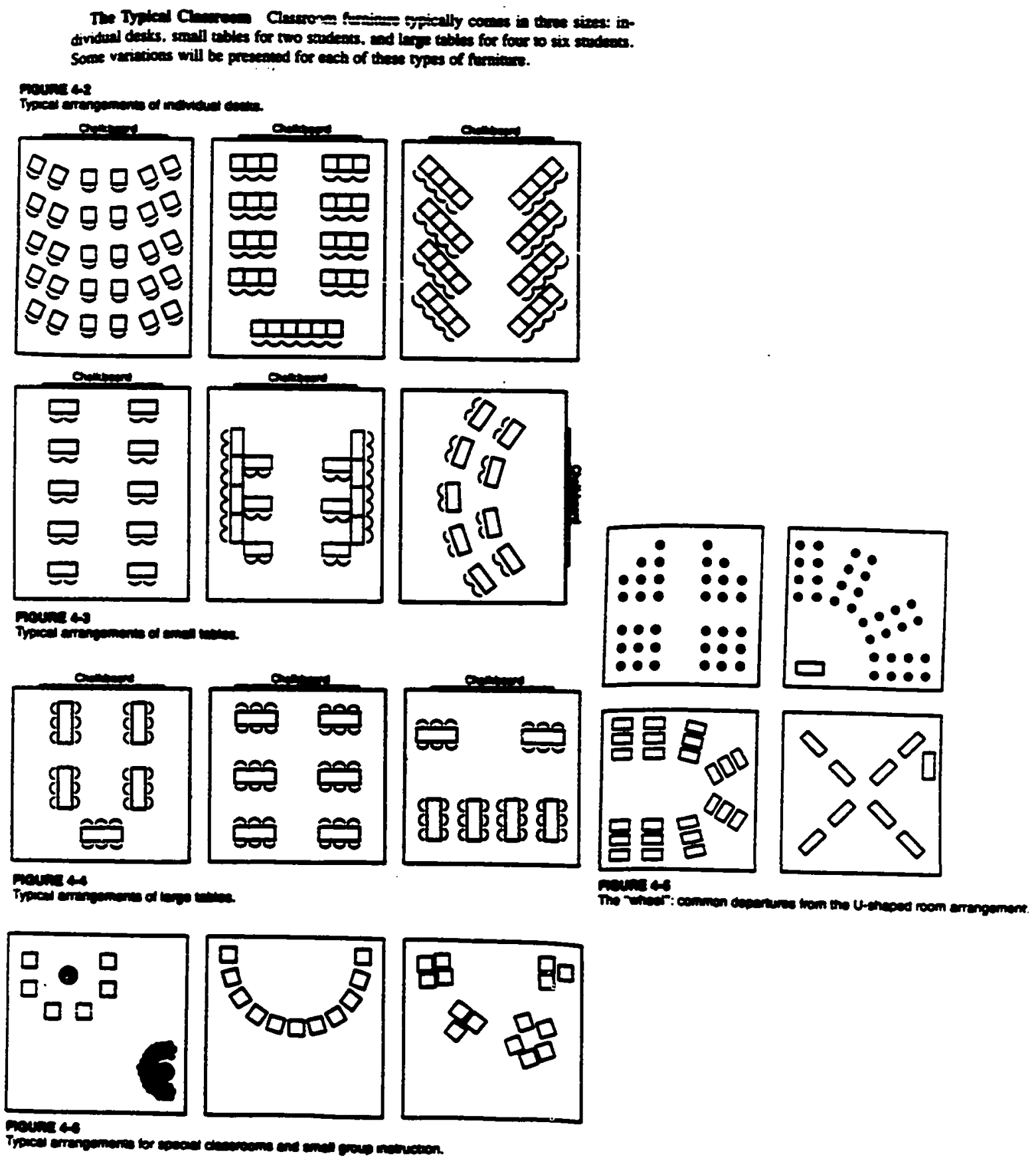




\section{TEACHER OBSERVATION}

Teacher

Grade

Date

\begin{tabular}{ll} 
Levels for Assessing Performance \\
Level I & Not yet performed \\
Level II & Performed at a satisfactory level \\
Level III & Performed at a inioh and exemplary level \\
\hline
\end{tabular}

4. Instructional Management CONIra

Discipline

Levels

1. Classroom furniture is arranged in a distinct pattern to enhance instruction, and to insure chalkboard and teacher visibility.

2. Classroom goals and objectives are posted and specific procedures, rules and standards are posted.

3. Student work is displayed and classroom reflects a variety of activities promoting daily student success.

4. Teacher is prepared to begin lesson

on time. Materials for lesson are available.

\section{Time On Task Behavior}

5. Siudent's engaged time actually on task during allocated time set aside for given subject.

6. Student's success rate in leaming while working.

7. Disruptions occur less than five minutes of allocated time. (Out of seat, taliking to neighbor, pencil tapping, note passing, playing with objects, taking a break from assignment). 


\section{CONTRO}

8. Positive Feedback

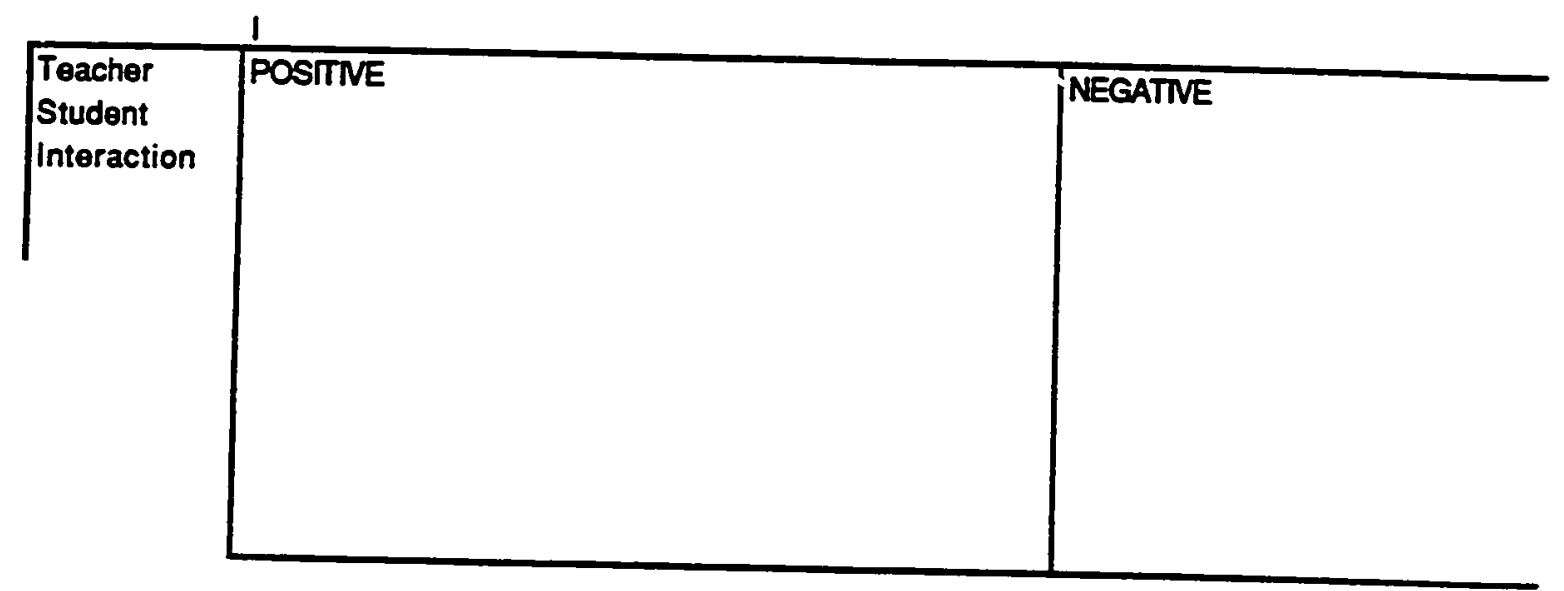

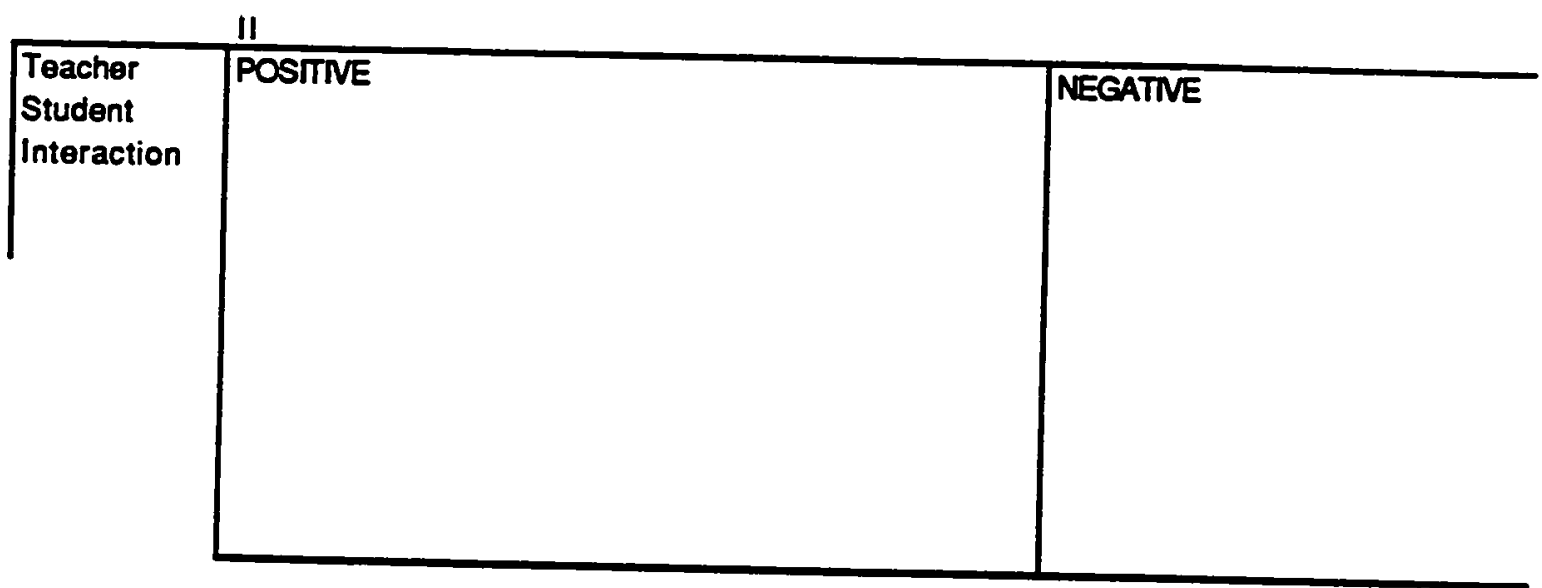

Negative interaction

When the student receives attention for an error or misbehavior even though the tone is positive.

Reminders are not to be considered positive attention.

Positive interaction

Praise should be given when only when students have put forth some effort.

Praise is valued when students see that it is the result of making an effort and doing a good job.

Praise should be varied. The best way to vary praise is to describe the behavior that is being praised.

Varied bohavior should be indicated by crossing the tally marks indicating a praise comment that is varied.

example: "This story is very creative. Fantastic use of your imagination." "Carol, thanks for waiting quietly."

Non-contingent praise should be indicated by circling the tally marks indicating a praise comment.

(Sprick, R. 1981, p. E. 5-6) 
Teacher

Grade

Date

\begin{tabular}{ll}
\hline Levels for Assessing Performance \\
Level I & Not yet performed \\
Leve! II & Performed at a satisfactory level \\
Level III & Performed at a high and exemplary level \\
\hline
\end{tabular}

2. Instructional Management

Curriculum

9. Literature is read aloud

10. Ideas are shared with each other

11. Writing is practiced, collected and reviewed

12. Cooperative leaming groups are working

13. Minority languages and cultures are recognized

14. Systematic skill program is taught

15. Multimodal application is included in lesson

16. Structured lesson is observed

\begin{tabular}{|l|}
\hline Motivation \\
\hline Review \\
\hline Goal and Objoctives \\
\hline Explanation \\
\hline Modeling \\
\hline Structured Practice \\
\hline Guided Practice \\
\hline Generalization \\
\hline Independent Practice \\
\hline
\end{tabular}


Appendix $\mathrm{F}$

Principal surveys

Reproduced with permission of the copyright owner. Further reproduction prohibited without permission. 
PRINCIPAL SURVEY \#I

Principal Dare

Classroom Teacher Grade Level

Total number of students in class

\begin{tabular}{|l|l|l|l|l|l|l|}
\hline & & & & & & \\
\hline $\begin{array}{l}\text { 1. How many students receive } \\
\text { free lunches? }\end{array}$ & January & Februar & March & April & May & June \\
\hline
\end{tabular}

2. How many students were absent from class?

3. How many students are identified for special education. and have active IEPs?

\begin{tabular}{|l|l|l|l|l|l|l|}
\hline 4. How many multi-ethnic & & & & & & \\
\hline students are in the classroom? & & & & & & \\
\hline & & & & & & \\
\hline Mexican American & & & & & & \\
\hline Other Hispanics & & & & & & \\
\hline American Indian & & & & & & \\
\hline Black American & & & & & & \\
\hline Inda-Chinese & & & & & & \\
\hline Other Asian & & & & & & \\
\hline Other & & & & & & \\
\hline
\end{tabular}


PRINCIPAL SURVEY *2

\section{9}

Principal $\ldots$

Teacher

\begin{tabular}{|l|l|l|l|l|}
\hline Test & CTBS & & MAT & \\
Form & & & & \\
\hline
\end{tabular}

A. Indicate the total number of students in Language Arts.

8. Indicate the total number of students who took the standardized test in each classroom.

1. Record the total class NCE (Normal Curve Equivalents) scores in the subject areas of Language Arts and Reading (if scores are reported separately).

I have provided NCE equivalents and percentile ranks

for your reference.

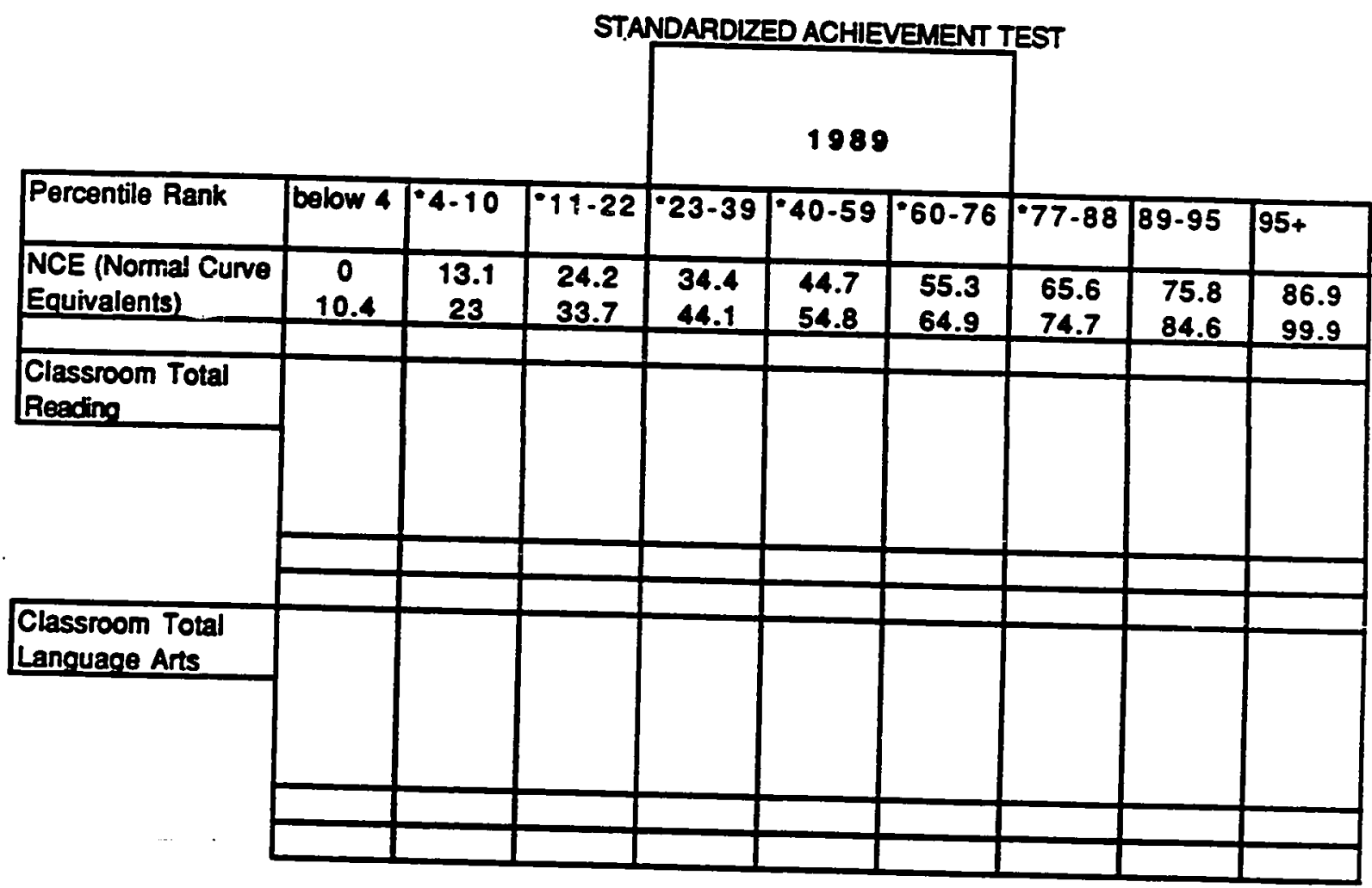


PRINCIPAL SURVEY \#2 1990

Principal Date

1990

Teacher

\begin{tabular}{|l|l|l|l|l|}
\hline Test & CTES & & MAT & \\
Form & & & & \\
\hline
\end{tabular}

A. Indicate the total number of students in Language Arts.

B. Indicate the total number of students who took the standardized test in each classroom.

1. Record the total class NCE (Normal Curve Equivalents) scores in the subject areas of Language Arts and Reading (if scores are reported separately). I have provided NCE equivalents and percentile ranks for your reference.

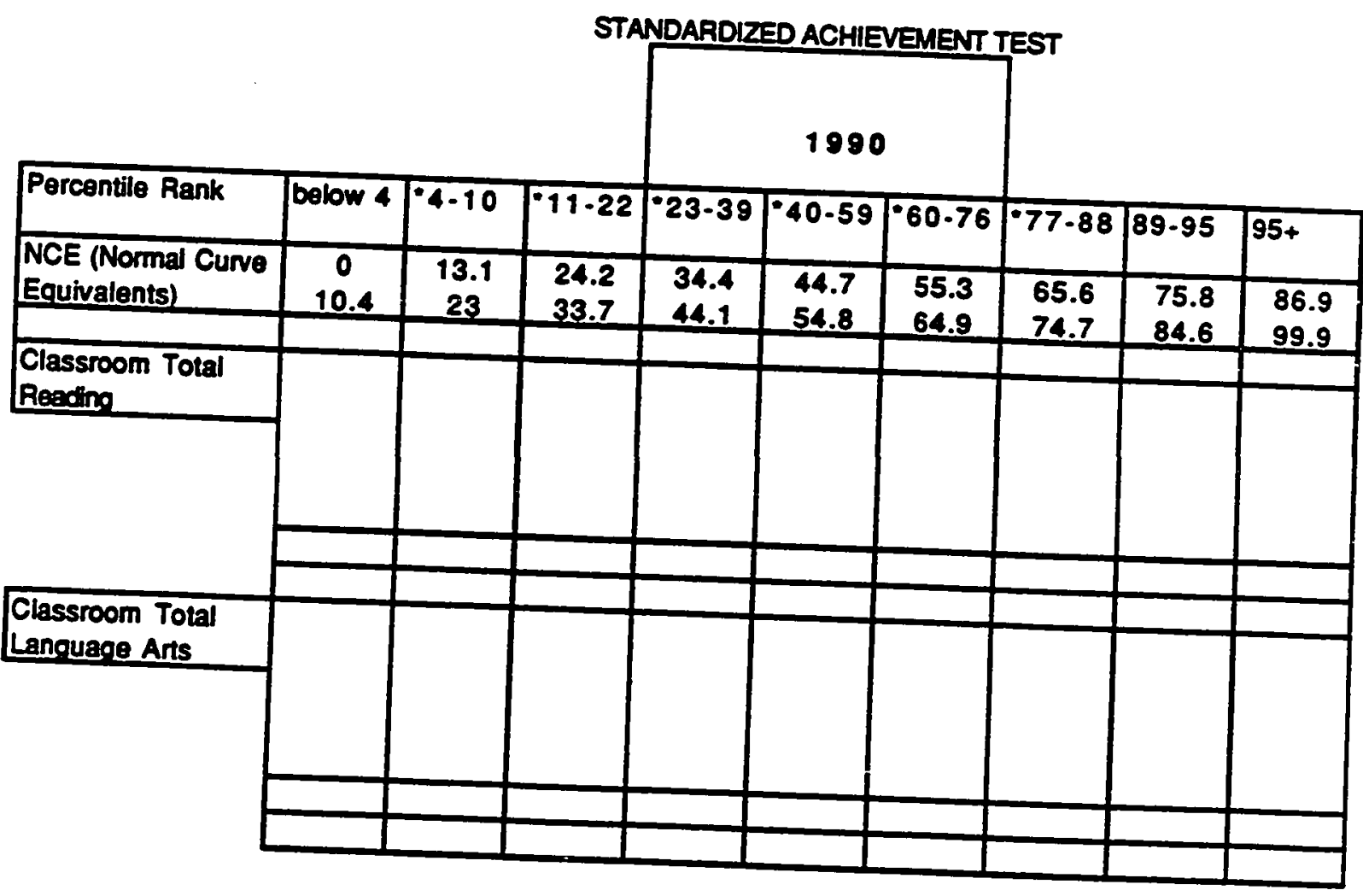


Principal

PRINCIPAL SURVEY \#3

\begin{tabular}{|l|ll|}
\hline Teacher & D. Student Name & \\
\hline & Sex & Ethmicity \\
\hline
\end{tabular}

A. Randomly select ten students in each third and sixth grade class.

Record the standardized test scores for each student from

first grade through fifth grade in the subjects of Language Arts and reading.

B. Record the total class NCE (Normal Curve Equivalents)

scores in the subject areas of Language Arts and reading (if scores are reported separately).

I have provided NCE equivalents and percentile ranks for your reference.

\begin{tabular}{|c|c|c|c|c|c|c|c|c|c|}
\hline Percentile Rank & below 4 & $4-10$ & $511-22$ & $-23-39$ & $-40-59$ & $1000-76$ & $77-88$ & $89-95$ & $95+$ \\
\hline $\begin{array}{l}\text { NCE (Normal Curve } \\
\text { Equivalents) } \\
\text { Reading Tocol }\end{array}$ & $\begin{array}{c}0 \\
10.4 \\
\end{array}$ & $\begin{array}{c}13.1 \\
23 \\
\end{array}$ & $\begin{array}{l}24.2 \\
33.7\end{array}$ & $\begin{array}{l}34.4 \\
44.1 \\
\end{array}$ & $\begin{array}{l}44.7 \\
54.8\end{array}$ & $\begin{array}{l}35.3 \\
64.9 \\
\end{array}$ & $\begin{array}{l}65.6 \\
74.7\end{array}$ & $\begin{array}{l}75.8 \\
84.6\end{array}$ & $\begin{array}{l}86.9 \\
99.9\end{array}$ \\
\hline grade 1 & & & & & & & & & \\
\hline grade 2 & & & & & & & & & \\
\hline grade 3 & & & & & & & & & \\
\hline grade 4 & & & & & & & & & \\
\hline grade 5 & & & & & & & & & \\
\hline grade 6 & & & & & & & & & \\
\hline Langareartson & & & & & & & & & \\
\hline grade 1 & & & & & & & & & \\
\hline grade 2 & & & & & & & & & \\
\hline grade 3 & & & & & & & & & \\
\hline grade 4 & & & & & & & & & \\
\hline grade 5 & & & & & & & & & \\
\hline grade 6 & & & & & & & & & \\
\hline & & & & & & & & & \\
\hline
\end{tabular}


Appendix G

confidentiality Agreements

Reproduced with permission of the copyright owner. Further reproduction prohibited without permission. 
Dear Language Arts Program Interviewee:

Thank you for volunteering to participate in the EnglishLanguage Arts study. This letter represents a writien assurance that you are guaranteed protection of personal and school anonymity in your questionnaire, survey, interview, student information and audio taped responses.

All data will be reported in a manner so that your personal and school confidentiality will be protected in all reoorting will be disguised. All quotations will be presented anonymously.

In consideration for your assistance in this study, you may request data collection information to be sent to you in a 23 page synopsis of the findings. This information will be mailed to the address you indicate below. Please return one copy of this form and keep the other copy
for your records.

Interviewee

Interviewer

Address to mail the synopsis: Name :

Address : zip 
Dear Clèssroom Teacher:

My name is Carolyn Salerno. I am conducting a study of the EnglishLanguage Arts instructional programs in grades one, three and six. This letter represents an invitation to you to participate in my study.

The purpose of my study is to determine how a meaning-centered approach versus a code-centered approach to the teaching of language arts affects student performance in a regular education classroom. Your voluntary participation would allow my assistants and me to observe your Language Arts class about once a month, ketween January and May, 1990. We will ask you to complete questionnaires concerning your teaching experience and education and surveys concerning your feelings and attitudes about your language Arts program. We will ask you to allow us to observe and audio tape your coaching sessions, group meetings and/or team meetings. We realize how complete your school day is with your students, therefore for will limit our contact with you until after the students have left for the day and at your convenience.

If you accept the invitation to participate in my study, you will be provided with a statement of confidentiality which will guarantee protection of personal and school anonymity in all of our data collection procedures. There is no agreement, written or verbal, beyond that expressed in this consent form and the statement of confidentiality form. It is the purpose of this study not to interfere with your classroom instruction. Therefore, we plan to have no interaction with
your students or their parents.

If you choose to volunteer for the study, information collected in your classroom will be available to you. You will find several of our data collection tools useful to your classroom instruction.

If you would like to volunteer to be a participant in the study or discuss the study with me before you volunteer, please sign this invitation, and keep a copy.

Please leave with the school secretary, your name, school, grade level, telephone number and a convenient time that I may contact you.

sincerely,

Carolyn Salerno

, the undersigned, understand the above explanations and, on that basis, I give consent to my voluntary participation in this research.

Signature of Classroom Teacher_Date

Location Date

Date

Signature of Carolyn Salerno 
Dear School Principal for the Language Arts Program Study:

Tharik you for volunteering to participate in the EnglishLanguage Arts study. This letter represents a written assurance that you are guaranteed protection of personal and school anonymity in the questionnaire, survey, interview, student information and audio taped responses.

All data will be reported in a manner so that your personal and school confidentiality will be protected in all reporting procedures. School names, student names and teacher names will be disguised. All quotations will be presented anonymously.

In consideration for your assistance in this study, you may request data collection information to be sent to you in a 23 page synopsis of the findings. This information will be mailed to the address you indicate below. Please return one copy of this form and keep the other copy for your records.

Principal

Interviewer 
Dear Principal:

My name is Carolyn Salerno. I am conducting a study of the EnglishLanguage Arts instructional programs in grades one, three and six. This letter represents an invitation to your school to participate in my study. If you would like to volunteer your school, please hand out the attached letters of invitation to classroom teachers in grades one, three and six.

The purpose of my study is to determine how a meaning-centered approach versus a code-centered approach to the teaching of language arts affects student performance in a regular education classroom. Your voluntary participation would allow my assistants and me to observe your language Arts classrooms five times, between January and May, 1990. Teachers will asked to complete questionnaires concerning their teaching experience and educational backgrounds and surveys concerning their feelings and attitudes about their Language Arts program. We will ask the teachers to allow us to observe and audio tape their coaching sessions, informal group discussions and/or team meetings. We will ask you to provide us with information concerning student placement, attendance, lunch counts, standardized test scores and ethnicity. We realize how complete a school day is with students, therefore we will limit our contact with teachers and you until after the students have left for the day and at your convenience.

If you accept the invitation to participate in my study, you will be provided with a statement of confidentiality which will guarantee protection of personal and school anonymity in all of our data collection procedures. There is no agreement, written or verbal, beyond that expressed in this consent form and the starement of confidentiality form. It is the purpose of this study not to interfere with your school organizational processes or classroom instruction. Therefore, we plan to have no interaction with your students or their parents.

If you choose to volunteer for the study, information collected in the classroom will be available to the classroom teachers.. Your teachers will find several of our data collection tools useful to their classroom
instruction.

If you would like to volunteer your school to be a participant in the study or discuss the study with me before you volunteer, please sign this invitation, and keep a copy. Please contact me at your convenience.

Sincerely,

Carolyn Salerno

I, the undersigned, understand the above explanations and, on that basis, I give consent to my voluntary participation in this research. Signature of Principal Date

\begin{tabular}{ll}
\hline Location & Date
\end{tabular}


Appendix H

Research Question Overview

Reproduced with permission of the copyright owner. Further reproduction prohibited without permission. 


\section{RESEARCH QUESTION OVERVIEW}

Dimension I--Curriculum Materials

1. To what degree are the published code-centered and meaning-centered Language Arts curriculum materials presentation recommendations followed by the classroom teacher?

$$
\text { Interview Teacher Appendix C *2 }
$$

Tables 4, 5

Dimension II-Teacher Behaviors

2. What teacher behaviors related to the instructional management factors are preformed in a code-centered and meaniag-centered English-Language Arts classroom?

$\begin{array}{llll}\text { Interview } & \text { Teacher } & \text { Appendix C } & \sharp 3 \\ \text { Questionnaire \#1 } & \text { Teacher } & \text { Appendix D } & \sharp 3,6 \\ \text { Observacion } & \text { Teacher } & \begin{array}{c}\text { Appendix E } \\ \text { Appendix E }\end{array} & \begin{array}{l}\# 1,2,3,4,5,6,7 \\ \end{array} \\ & & & \text { Tables 6-13 }\end{array}$

3. What are the differences between instructional techniques used in a code-centered classroom and a meaning-centured chaswoom?

$\begin{array}{llll}\text { Interview } & \text { Teacher } & \text { Appendix C } & \# 5 \\ \text { Questionnaire } \# 1 & \text { Teacher } & \text { Appendix D } & \# 1,2,3,4,5 \\ \text { Observation } & \text { Teacher } & \text { Appendix E } & \# 9,11,14,16 \\ & & & \text { Tables 14,15 }\end{array}$

4. To what extent are students able to exhibit leaming strategies acquired from being taught by teacher instructional behavioss specific to code-centered and meaning-centered strategies?

Interview Teacher Appendix C $\$ 9,10$

Tables16-21

5. To what extent do teacher values and perceptions gride teacher behavior in a code-centered classroom and/or a meaning-centered classroom?

$\begin{array}{llll}\text { Interview } & \text { Teacher } & \text { Appendix C } & \# 6,7,8 \\ \text { Questionnaire \#2 } & \text { Teacher } & \text { Appendix D } & \# 3,5,6,7,8 \\ & & & \# 11,12,14,15,17 \\ & & \text { Tables 22-31 }\end{array}$


Dimension II--Teacher Behaviors

6. To what degree is the classroom teacher committed to implementing and using a code-centered approach or a meaning-centered approach to teach the English-Language Arts curriculum?

$\begin{array}{llll}\text { Interview } & \text { Teacher } & \text { Appendix C } & \# 7 \\ \text { Questionnaire *2 } & \text { Teacher } & \text { Appendix D } & \# 16,18,19 \\ & & & \text { Table 32-34 }\end{array}$

Dimension III--Organizational Support

7. To what degree does the organization support the changes introduced by the English-Language Arts Framework?

$\begin{array}{llll}\text { Interview } & \text { Teacher } & \text { Appendix C } & \# \\ \text { Interview } & \text { Principal } & \text { Appendix B } & \# 1,2,3,4,5,6,7,8 \\ \text { Observation } & \text { Meetings } & \text { Appendix A } & \# 1-23 \\ & & & \text { Tables 35-40 }\end{array}$

8. How do the differences in materials, teacher behaviors and organizational processes between classrooms using a meaning-centered approach and a code-centered approach in Language Arts affect student performance?

$\begin{array}{llll}\text { Interview } & \text { Teacher } & \text { Appendix C } & \# 1 \\ \text { Principal Survey } \# 2 \text { 1990 } & \text { Appendix F } & \# 1 \\ \text { Principal Survey } \# 2 \text { 2 } 1989 & \text { Appendix F } & \# 1 \\ \text { Principal Survey \#3 } & \text { Appendix F } & \text { A,B } \\ \text { Questionnaire \#2 } & \text { Teacher } & \text { Appendix D } & \text { \#20, 22,21,13 } \\ & & & \text { Tables 41-53 }\end{array}$

Student Population

$\begin{array}{llll}\text { Questionnaire } \# 2 & \text { Teacher } & \text { Appendix D } & \# 10 \\ \text { Principal Survey \#1 } & \text { Appendix F } & \# 1,3,4 \\ & & \text { Tables 1-3 }\end{array}$

